INSTITUTO DE PESQUISAS ENERGÉTICAS E NUCLEARES Autarquia associada à Universidade de São Paulo

\title{
INVESTIGAÇÃO DO PROCESSO DE OBTENÇÃO DE ALUMINATOS DE BÁRIO E CÁlCIO PARA CONSTRUÇÃO E CARACTERIZAÇÃO DE CATODOS TERMIÔNICOS IMPREGNADOS PARA APLICAÇÃO EM DISPOSITIVOS DE MICROONDAS DE POTÊNCIA
}

\section{CRISTIANE HIGASHI}

Dissertação apresentada como parte dos requisitos para obtenção do Grau de Mestre em Ciências na Área de Tecnologia Nuclear - Materiais.

Orientador:

Dr. Cláudio Costa Motta

\section{SÃO PAULO}


INSTITUTO DE PESQUISAS ENERGÉTICAS E NUCLEARES Autarquia associada à Universidade de São Paulo

\section{INVESTIGAÇÃO DO PROCESSO DE OBTENÇÃO DE ALUMINATOS DE BÁRIO E CÁlCIO PARA CONSTRUÇÃO E CARACTERIZAÇÃO DE CATODOS TERMIÔNICOS IMPREGNADOS PARA APLICAÇÃO EM DISPOSITIVOS DE MICROONDAS DE POTÊNCIA}

\section{CRISTIANE HIGASHI}

Dissertação apresentada como parte dos requisitos para obtenção do Grau de Mestre em Ciências na Área de Tecnologia Nuclear - Materiais.

Orientador:

Dr. Cláudio Costa Motta

\section{SÃO PAULO}


Dedico este trabalho aos meus pais, Toshinori e Maria, aos meus irmãos Edgar e Ricardo, aos meus sobrinhos Juninho e Bia, a minha melhor amiga Cristina e ao meu companheiro Élio. 


\section{AGRADECIMENTOS}

Este trabalho só pôde ser concluído devido ao auxílio, carinho e amizade de pessoas a quem eu devo os meus sinceros agradecimentos.

Ao Dr. Cláudio Costa Motta, Capitão-de-Fragata (EN) da Marinha do Brasil, pela dedicação, disposição e amizade na orientação deste projeto.

À Dra. Cláudia Giovedi, pela amizade, apoio, discussão durante o desenvolvimento deste trabalho.

Ao Conselho Nacional de Desenvolvimento Científico e Tecnológico (CNPq) pela concessão da bolsa de estudos por meio do processo n. ${ }^{\circ}$ 133215/2004-0.

Ao Centro Tecnológico da Marinha em São Paulo (CTMSP) e ao Instituto de Pesquisas Energéticas e Nucleares (IPEN) por suas instalações e toda a sua equipe.

Ao Dr. Jivaldo do Rosário Matos (IQUSP), pelo auxílio, colaboração e realização de experimentos de Análise Térmica.

Ao Dr. Nelson Batista de Lima pela realização das análises de Difração de Raios X.

Ao Dr. Luis Antônio Genova pela concessão de materiais.

À Dra. Vera L. R. Salvador pela realização das análises de Espectrometria de Fluorescência de Raios X.

À toda equipe do Laboratório de Materiais Magnéticos do IPEN, pela ajuda prestada nos momentos de necessidade.

Ao Sr. Valdir Raimundo Jacob, pelo inestimável auxílio na construção do aparato experimental empregado ao longo deste trabalho.

Ao SO Coutinho, SG Cosme, SG Paschoa, CB Leal, CB Julio, CB Fábio e ao CB Handerson pela ajuda prestada durante a realização deste projeto.

Aos meus amigos e colegas do CTMSP: Daniel, Nivaldo, Eik, Fábio, Sônia, João, SD-FN Marcelo, SD-FN Bezerra, SD-FN Barros, SD-FN Barreto, CB Lucena, Eduardo, Rubens, Bruno, Luiz, Christina, Ricardo, Alfredo, Álvaro, Sandra, Antônio e Marcelo pela convivência e amizade. 
Aos meus pais Toshinori e Maria, e meus irmãos Ricardo e Edgar, pelo apoio e carinho.

Ao Élio Alberto Périgo, por seu apoio e amizade nos momentos difíceis deste trabalho, bem como toda a sua família pelo incentivo.

$\mathrm{E}$, principalmente, a todos os meus amigos que me apoiaram nesta difícil fase de minha vida, por meio de afetuosas conversas e carinho. 
"Impossível é apenas uma grande palavra usada por gente fraca que prefere viver no mundo como está, ao invés de usar o poder que tem para mudá-lo. Impossível não é um ato, é uma opinião. Impossível não é uma declaração. É um desafio. É hipotético. É temporário. Nada é impossível!” 


\title{
INVESTIGAÇÃO DO PROCESSO DE OBTENÇÃO DE ALUMINATOS DE BÁRIO E CÁlCIO PARA CONSTRUÇÃO E CARACTERIZAÇÃO DE CATODOS TERMIÔNICOS IMPREGNADOS PARA APLICAÇÃO EM DISPOSITIVOS DE MICROONDAS DE POTÊNCIA
}

\author{
CRISTIANE HIGASHI
}

\section{RESUMO}

O presente trabalho descreve os processos de preparação do aluminato de bário e cálcio, material emissor de elétrons, empregados nos catodos do tipo impregnado para utilização em uma válvula de microondas do tipo TWT.

Os catodos investigados constituem-se de uma pastilha de tungstênio porosa impregnada com aluminato de bário e cálcio com proporção molar 5:3:2. Para a síntese do aluminato, utilizaram-se três diferentes métodos: reação em estado sólido, precipitação e cristalização. A termogravimetria auxiliou na consolidação dos procedimentos de preparação dos aluminatos de modo a definir os parâmetros de pirólise/calcinação. Verificou-se que a técnica que apresentou melhores características de síntese foi o método da cristalização, pois esta apresentou uma menor temperatura de formação do aluminato $\left(800^{\circ} \mathrm{C}\right)$ em atmosfera oxidante $\left(O_{2}\right)$, quando comparada às técnicas de reação em estado sólido e de precipitação (temperatura de $1000^{\circ} \mathrm{C}$ em atmosfera redutora $-H_{2}$ ).

Utilizou-se o conceito da distribuição da função trabalho prática (PWFD) de Miram para a caracterização termiônica dos catodos impregnados. Empregando-se este método, foi possível traçar o perfil termiônico do catodo com aluminato de bário e cálcio. As curvas PWFD apresentaram a função trabalho média do catodo aluminato de, aproximadamente, $2,00 \mathrm{eV}$. 


\title{
INVESTIGATION OF BARIUM-CALCIUM ALUMINATE PROCESS TO MANUFACTURE AND CHARACTERIZE IMPREGNATED THERMIONIC CATHODE FOR POWER MICROWAVE DEVICES
}

\section{CRISTIANE HIGASHI}

\begin{abstract}
In the present work it is described the barium calcium aluminate manufacture processes employed to produce impregnated cathodes to be used in a traveling-wave tube (TWT).

The cathodes were developed using a tungsten body impregnated with barium and calcium aluminate with a 5:3:2 proportion (molar). Three different processes were investigated to obtain this material: solid-state reaction, precipitation and crystallization. Thermal analysis, thermogravimetry specifically, supported to determine an adequate preparation procedure (taking into account temperature, time and pirolisys atmosphere). It was verified that the crystallization showed a better result when compared to those investigated (solid-state reaction and precipitation techniques - formation temperature is about $1000^{\circ} \mathrm{C}$ in hydrogen atmosphere), whereas it presented the lower formation temperature $\left(800^{\circ} \mathrm{C}\right)$ in oxidizing atmosphere $\left(\mathrm{O}_{2}\right)$.

It was used the practical work function distribution theory (PWFD) of Miram to characterize thermionic impregnated cathode. The PWFD curves were used to characterize the barium-calcium aluminate cathode. PWFD curves shown that the aluminate cathode work function is about $2,00 \mathrm{eV}$.
\end{abstract}




\section{SUMÁRIO}

Página

Lista de Figuras

i

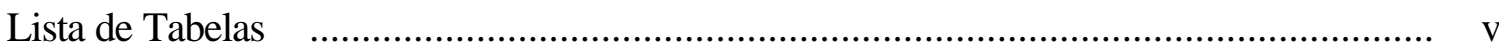

Lista de Símbolos .............................................................................................. vii

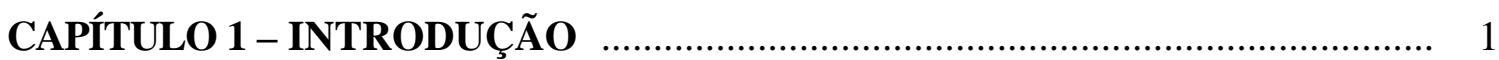

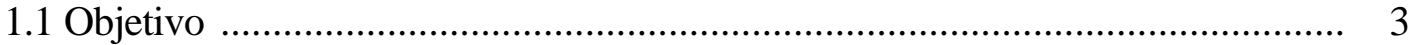

1.2 Organização do trabalho .............................................................................. 3

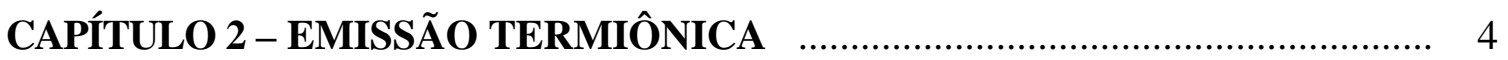

2.1 Introdução do Capítulo $\quad$................................................................................. 4

2.2 Formalismo da mecânica estatística $\quad$............................................................ 5

2.3 Especificação do estado microscópico de um sistema quântico $\quad$...................... 5

2.4 Formulação do problema estatístico e conexão com a termodinâmica $\quad$............ 7

2.5 Emissão termiônica - Equação de Richardson e o Efeito Schottky $\quad$............... 12

2.6 Conclusões do Capítulo $\quad$............................................................................ 15

\section{CAPÍTULO 3 - SOLUÇÃO DE LANGMUIR-BLODGETT PARA O} PROBLEMA DO DIODO ESFÉRICO - DETERMINAÇÃO DA PERVEÂNCIA …....................................................... 16

3.1 Introdução do Capítulo $\quad$............................................................................... 16

3.2 Formulação do problema do diodo esférico ............................................... 17

3.2.1 Determinação dos coeficientes $\mathrm{G}^{(n)}(0) \quad$ _.......................................... 19

3.3 Aplicação do resultado de Langmuir e Blodgett do diodo esférico para o problema do canhão de elétrons com fluxo convergente $\quad$.................................. 23

3.4 Síntese do canhão eletrônico de Pierce com fluxo convergente $\quad$.................... 24

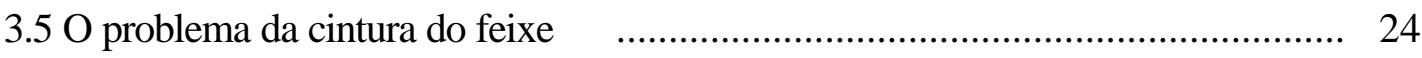

3.6 Fluxograma para síntese do canhão eletrônico de Pierce com fluxo

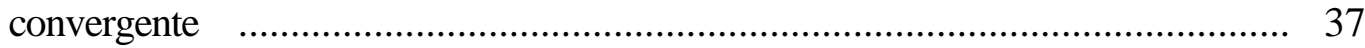

3.7 Aplicação da metodologia de síntese do canhão eletrônico para determinação da pervêancia do sistema

3.8 Caracterização termiônica - efeito da carga espacial no potencial do canhão eletrônico 
4.1 Introdução do Capítulo

4.2 Evolução dos materiais emissores de elétrons

4.3 Técnicas de fabricação dos catodos impregnados e seus efeitos na emissão

termiônica

4.3.1 Matéria-prima da matriz do catodo

4.3.2 Material impregnante 55

4.4 Aluminatos de bário e cálcio - Diagrama de equilíbrio 56

4.4.1 Sistema binário - $\mathrm{BaO}-\mathrm{Al}_{2} \mathrm{O}_{3}$ 56

4.2.2 Sistema ternário - $\mathrm{BaO}-\mathrm{CaO}-\mathrm{Al}_{2} \mathrm{O}_{3}$ 57

4.5 Hidratação dos materiais fontes de bário 59

4.6 Reações entre compostos de bário e tungstênio 60

4.7 Conclusões do Capítulo 62

\section{CAPÍTULO 5 - MATERIAIS: SÍNTESE, PROCESSAMENTO E}

CARACTERIZAÇÃO 64

5.1 Introdução do Capítulo 64

5.2 Síntese de pós 64

5.2.1 Técnica de reação em estado sólido 65

5.2.2 Técnica de solução 65

5.2.3 Técnicas de fase vapor 65

5.3 Etapas de processamento de pós 66

5.3.1 Secagem 66

5.3.2 Calcinação 66

5.3.3 Conformação 66

5.3.4 Sinterização 67

5.4 Técnicas de caracterização 68

5.4.1 Análise da distribuição do tamanho de partículas 68

5.4.2 Difração de raios $X$ 69

5.4.3 Espectroscopia no infravermelho _................................................ 69

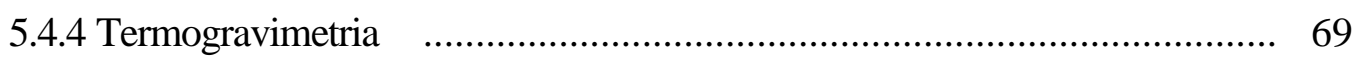

5.4.5 Microscopia eletrônica de varredura ................................................ 70

5.4.6 Fluorescência de raios X por dispersão de comprimento de onda $\quad$......... 70 5.5 Conclusões do Capítulo $\quad$.............................................................................. 70 
6.1 Introdução do Capítulo

6.2 Materiais precursores 73

6.3 Processo de preparação do aluminato via reação em estado sólido 74

6.4 Processo de preparação do aluminato via método de cristalização 75

6.5 Processo de preparação do aluminato via método de precipitação 76

6.6 Processo de fabricação da base do catodo impregnado 77

6.7 Desenvolvimento dos aparatos utilizados na preparação do catodo impregnado 79

6.8 Dimensionamento do canhão eletrônico 81

6.9 Metodologia empregada nas medidas termiônicas 83

6.9.1 Curvas PWFD - distribuição da função trabalho prática 83

6.9.1.1 Construção das curvas PWFD 83

6.9.1.2 Construção da curva PWFD para alta tensão de aceleração $\quad$... 94

6.10 Determinação da temperatura na superfície do catodo 102

6.11 Técnicas de análise dos aluminatos de bário e cálcio 103

6.11.1 Distribuição do tamanho de partículas 103

6.11.2 Difração de raios $X$ 103

6.11.3 Microscopia eletrônica de varredura (MEV) 103

6.11.4 Espectrômetro de fluorescência de raios X por dispersão de comprimento de onda 103

6.12 Conclusões do Capítulo 103

\section{CAPÍTULO 7 - RESULTADOS E DISCUSSÕES}

7.1 Introdução do Capítulo 105

7.2 Termogravimetria 106

7.3 Difração de raios $\mathrm{X}$ 114

7.4 Fluorescência de raios $\mathrm{X}$

7.5 Tamanho médio de partícula 117

7.6 Microscopia eletrônica de varredura

7.7 Espectroscopia no infravermelho 127

7.8 Caracterização termiônica 128

7.9 Fusão do aluminato de bário e cálcio 131

7.10 Conclusões do Capítulo 131 
CAPÍTULO 8 - CONCLUSÕES

133

8.1 Sugestões para trabalhos futuros 136

REFERÊNCIAS BIBLIOGRÁFICAS 


\section{LISTA DE FIGURAS}

Página

Figura 2.1 Diagrama dos níveis de energia de um metal (os pontos representam Íons positivos da rede sendo $L$ o seu período) $\quad$........................................ 4

Figura 2.2 Função degrau de energia $\quad$................................................................... 11

Figura 3.1 Ilustração do modelo catodo esférico. Os vetores ilustram a densidade de corrente de convecção $\vec{J}=e n_{e} \vec{v}$ radial em direção ao anodo $\quad \ldots \ldots \ldots \ldots . . . . .17$

Figura 3.2 Canhão eletrônico esférico. Área de emissão definida pelo cone cujo

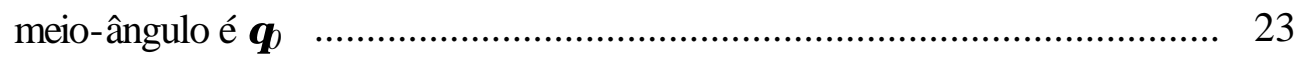

Figura 3.3 Geometria do canhão de Pierce com fluxo convergente $\quad$......................... 25

Figura 3.4 Diagrama dos meio-ângulos de cone .................................................. 29

Figura 3.5 Erro relativo à convergência da série $\quad$..................................................... 36

Figura 3.6 Metodologia de síntese do canhão eletrônico $\quad$....................................... 37

Figura 3.7 Efeito da geometria do canhão nas características do feixe eletrônico $\quad \ldots \quad 41$

Figura 3.8 Curva de variação do potencial/campo elétrico na região entre o catodo/ anodo (sem o efeito de carga espacial) ................................................. 44

Figura 3.9 Curva de variação do potencial/campo elétrico na região entre o catodo/ anodo (com o efeito de carga espacial) $\quad$.............................................. 45

Figura 4.1 Diagrama de equilíbrio do sistema $\mathrm{BaO}-\mathrm{Al}_{2} \mathrm{O}_{3} \quad$..................................... 56

Figura 4.2 Porção de alta bária do sistema $\mathrm{BaO}-\mathrm{Al}_{2} \mathrm{O}_{3}$ (Appendino), $\mathrm{B}=$ composto $\mathrm{BaO}$ e $\mathrm{B}_{\mathrm{x}} \mathrm{A}=$ composto da forma $\mathrm{x} \mathrm{BaO} \cdot \mathrm{Al}_{2} \mathrm{O}_{3}$

Figura 4.3 Seção isotérmica do diagrama de equilíbrio do $\mathrm{BaO}-\mathrm{CaO}-\mathrm{Al}_{2} \mathrm{O}_{3}$ a $1250^{\circ} \mathrm{C}$ 59

Figura 4.4 Diagrama de equilíbrio do sistema $\mathrm{BaO}-\mathrm{WO}_{3}$ 61

Figura 4.5 Diagrama de fases ternário do sistema $\mathrm{BaO}-\mathrm{CaO}-\mathrm{WO}_{3} \quad \ldots \ldots \ldots \ldots \ldots \ldots \ldots \ldots . . . . . . . . . . . . . . . . .62$

Figura 5.1 Estágios do processo de sinterização ................................................ 67

Figura 6.1 Processo de preparação e caracterização do aluminato via reação em estado sólido 74

Figura 6.2 Processo de preparação e caracterização do aluminato via reação de cristalização 76

Figura 6.3 Processo de preparação e caracterização do aluminato via reação de precipitação 
Figura 6.4 Processo de fabricação e de caracterização do catodo impregnado 78

Figura 6.5 Representação do processo de impregnação $\quad$....................................... 78

Figura 6.6 Forno de pirólise do aluminato de bário e cálcio 79

Figura 6.7 (a) Dispositivo de caracterização do catodo termiônico.

(b) Desenho esquemático de um sistema para medição de temperatura do catodo termiônico utilizando um pirômetro óptico 80

Figura 6.8 Forno para o processo de impregnação 81

Figura 6.9 Geometria do canhão eletrônico de Pierce (Perveância = 0,77 $\mu$ Perv) 82

Figura 6.10 Curva de emissão termiônica para um catodo reservatório do tipo MMM 84

Figura 6.11 Fluxograma para a extração dos parâmetros da curva $I$ x $V$ necessários para a construção da curva de desempenho 85

Figura 6.12 Curva de desempenho (Miram) para o catodo tipo MMM 88

Figura 6.13 Esquema para a construção da família de curvas de densidade de corrente de emissão versus a temperatura 90

Figura 6.14 Gráfico PWFD para $J_{F S C L}=8 \mathrm{Acm}^{-2}$ 91

Figura 6.15 Gráfico PWFD para $J_{F S C L}=4 \mathrm{Acm}^{-2}$ 92

Figura 6.16 Gráfico PWFD para $J_{F S C L}=2 \mathrm{Acm}^{-2}$ 92

Figura 6.17 Gráfico PWFD para $J_{F S C L}=1 \mathrm{Acm}^{-2}$ 93

Figura 6.18 Determinação da faixa de temperatura do catodo para alta tensão de aceleração 94

Figura 6.19 Curvas de Miram para $J_{F S C L}=8 \mathrm{Acm}^{-2}$ e para $J_{F S C L}=16 \mathrm{Acm}^{-2} \ldots \ldots \ldots \ldots . . . . .95$

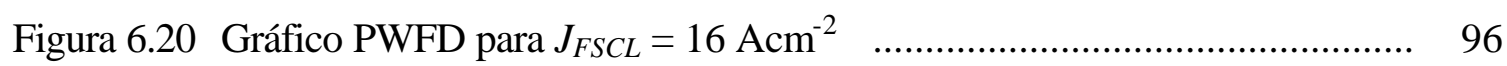

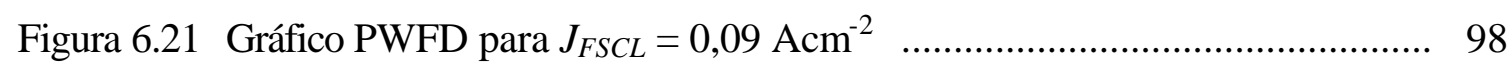

Figura 6.22 Curvas de Miram para $J_{F S C}=0,09 \mathrm{Acm}^{-2}$ e para $J_{F S C}=3 \mathrm{Acm}^{-2} \ldots \ldots \ldots \ldots . . .99$

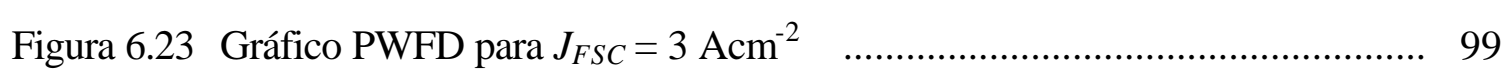

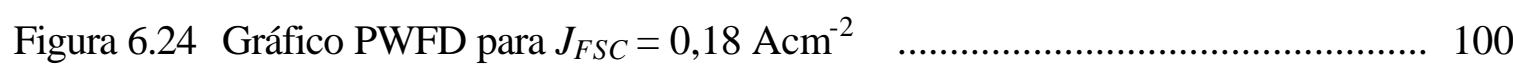

Figura 6.25 Curvas de Miram para $J_{F S C}=0,18 \mathrm{Acm}^{-2}$ e para $J_{F S C}=6 \mathrm{Acm}^{-2} \ldots \ldots \ldots \ldots . . .101$

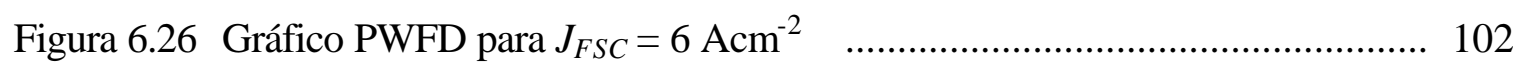

Figura 7.1 Curvas TG dos carbonatos de bário e de cálcio, do óxido de alumínio e da mistura componentes (cadinho de platina) em atmosfera oxidante .

Figura 7.2 Curvas TG dos carbonatos de bário e de cálcio, do óxido de alumínio e da mistura componentes (cadinho de platina)em atmosfera inerte 107 
Figura 7.3 Curvas TG/DTG do carbonato de bário em atmosfera inerte $\left(N_{2}\right)$

Figura 7.4 Curvas TG dos carbonatos de bário e de cálcio, do óxido de alumínio e da mistura componentes (cadinho de alumina) em atmosfera redutora

Figura 7.5 (a) Aluminato de bário e cálcio obtido pelo método de reação em estado sólido (forno - atmosfera redutora $T=1000^{\circ} \mathrm{C}$ ). (b) Aluminato de bário e cálcio obtido por meio da $\mathrm{TG}\left(T=1300^{\circ} \mathrm{C}\right)$

Figura 7.6 Curvas TG/DTG para amostra de aluminato de bário e cálcio com presença de carbono elementar em atmosfera oxidante $\left(\mathrm{O}_{2}\right)$

Figura 7.7 Curvas TG dos nitratos de bário, de cálcio, de alumínio e do produto da cristalização em atmosfera oxidante

Figura 7.8 Curvas TG do produto da precipitação em diferentes atmosferas (redutora e oxidante)

Figura 7.9 Curvas TG dos aluminatos de bário e cálcio obtidos pelos diferentes métodos de síntese estudados 113

Figura 7.10 Difratograma da mistura dos carbonatos de bário e de cálcio, e alumina

Figura 7.11 Difratograma do aluminato de bário e cálcio obtido por meio do método de reação em estado sólido (convencional)

Figura 7.12 Difratograma da mistura do produto da cristalização

Figura 7.13 Difratograma do aluminato de bário e cálcio obtido por meio do método de cristalização

Figura 7.14 Difratograma do aluminato de bário e cálcio obtido por meio da técnica de precipitação

Figura 7.15 Distribuição do tamanho de partícula para o aluminato obtido por meio da reação em estado sólido (a) Histograma. (b) Frequiência acumulada .

Figura 7.16 Distribuição do tamanho de partícula para o aluminato obtido por meio da reação em estado sólido (48h moagem) (a) Histograma.

(b) Freqüiência acumulada 119

Figura 7.17 Distribuição do tamanho de partícula para o aluminato obtido por meio da técnica de cristalização (a) Histograma. (b) Frequiência acumulada

Figura 7.18 Distribuição do tamanho de partícula para o aluminato obtido pela técnica de precipitação (a) Histograma. (b) Freqüência acumulada 121

Figura 7.19 Forma das partículas do aluminato de bário e cálcio formado pela reação em estado sólido 
Figura 7.20 Forma das partículas do aluminato de bário e cálcio formado pela técnica de cristalização

Figura 7.21 Forma das partículas do aluminato de bário e cálcio formado pela técnica de precipitação

Figura 7.22 Análises químicas do aluminato obtido por meio da técnica de reação De estado sólido em diferentes regiões

Figura 7.23 Análises químicas do aluminato obtido por meio da técnica de cristalização em diferentes regiões

Figura 7.24 Análises químicas do aluminato obtido por meio da técnica de precipitação em diferentes regiões 126

Figura 7.25 Curvas FTIR dos aluminatos obtidos pelos diferentes métodos 127

Figura 7.26 Curva de emissão termiônica para um catodo aluminato obtido pela técnica de reação em estado sólido 128

Figura 7.27 Curva de densidade de corrente x potência para o catodo aluminato ... 129

Figura 7.28 Gráfico PWFD para $J_{F S C}=400 \mathrm{mAcm}^{-2}$ 130

Figura 7.29 Gráfico PWFD para $J_{F S C}=800 \mathrm{mAcm}^{-2}$ 130

Figura 7.30 Cadinho de molibdênio com aluminato de bário e cálcio 131 


\section{LISTA DE TABELAS}

Página

Tabela 3.1 Parâmetros de entrada de diferentes canhões eletrônicos 39

Tabela 3.2 Parâmetros intermediários e de saída dos diferentes canhões

eletrônicos 40

Tabela 3.3 Parâmetros de entrada do canhão projetado 42

Tabela 3.4 Parâmetros intermediário e de saída do canhão investigado 42

Tabela 4.1 Evolução do catodo termiônico relativo ao desenvolvimento dos materiais que o compõem 50

Tabela 4.2 Características do pó de tungstênio 55

Tabela 4.3 Pastilha de tungstênio sinterizada em hidrogênio: características típicas 55

Tabela 4.4 Composição dos aluminatos de bário e cálcio 56

Tabela 4.5 Nomenclatura das fases do sistema $\mathrm{BaO}-\mathrm{CaO}-\mathrm{Al}_{2} \mathrm{O}_{3}$ 58

Tabela 6.1 Parâmetros utilizados na fabricação da base do catodo impregnado ...... 78

Tabela 6.2 Dados do experimento para o catodo reservatório do tipo MMM 84

Tabela 6.3 Corrente normalizada utilizada na construção da curva de Miram para

$$
I_{F S C L}=100 \mathrm{~mA}
$$

Tabela 6.4 Corrente normalizada utilizada na construção da curva de Miram para

$$
I_{F S C L}=200 \mathrm{~mA}
$$

Tabela 6.5 Corrente normalizada utilizada na construção da curva de Miram para

$$
I_{F S C L}=400 \mathrm{~mA}
$$

Tabela 6.6 Corrente normalizada utilizada na construção da curva de Miram para

$$
I_{F S C}=800 \mathrm{~mA}
$$

Tabela 6.7 Valores da densidade de corrente de emissão normalizada (sendo $\phi_{\max }$ a maior função trabalho, $\phi(\sim 50 \%)$ a função trabalho quando

$J_{\text {Miram }}=50 \%$ e $\phi_{\text {min }}$ a menor função

trabalho)

Tabela 6.8 Função trabalho média do catodo para diferentes densidades de corrente limitada pela carga espacial 93

Tabela 6.9 Densidade de corrente normalizada utilizada na construção da curva de Miram para $J_{F S C L}=0,09 \mathrm{Acm}^{-2}$ 
Tabela 6.10 Densidade de corrente normalizada utilizada na construção da curva de Miram para $J_{F S C L}=0,18 \mathrm{Acm}^{-2}$

Tabela 7.1 Dados de fluorescência de raios X para a amostra obtida pelos

diferentes métodos 


\section{LISTA DE SÍMBOLOS}

$A_{0} \quad$ Constante universal de Richardson $\left(120 \mathrm{~A} \mathrm{~cm}^{-2} \mathrm{~K}^{-2}\right)$

d Espaçamento interplanar

$e \quad$ Carga elétrica elementar $\left(1,60 \times 10^{-19} \mathrm{C}\right)$

E Energia total

$E_{c} \quad$ Autoenergias (autovalores)

$E_{c e} \quad$ Campo elétrico advindo da carga espacial

$E_{n} \quad$ Energia do estado quântico $n$

$E_{j} \quad$ Energia do estado quântico $j$

$f \quad$ Distancia focal

$G(u)$ Função

$H \quad$ Operador hamiltoniano

h Constante de Planck

$I_{0} \quad$ Corrente total (corrente do feixe eletrônico)

$I_{F S C L} \quad$ Corrente limitada pela carga espacial

j $\quad$ Estado quântico

$J \quad$ Densidade de corrente

$\vec{J} \quad$ Densidade de corrente de convecção

$J(r) \quad$ Densidade de corrente de convecção

$J_{F S C L}$ Densidade de corrente limitada pela carga espacial

$J_{o p} \quad$ Densidade de corrente de operação

$J_{T} \quad$ Densidade de corrente total

$J_{T L} \quad$ Densidade de corrente limitada pela temperatura

$k \quad$ Vetor de número de onda

K Constante

k' Constante

$k_{B} \quad$ Constante de Boltzmann $\left(1,381 \times 10^{-23} \mathrm{~J} / \mathrm{K}\right.$ ou $\left.8,615 \times 10^{-5} \mathrm{eV} / \mathrm{K}\right)$

$k_{F} \quad$ Vetor de onda de Fermi

$L \quad$ Período da rede do diagrama de níveis de energia

$m \quad$ Massa

$m_{e} \quad$ Massa de repouso do elétron $\left(9,11 \times 10^{-31} \mathrm{~kg}\right)$

n Número quântico 


\begin{tabular}{|c|c|}
\hline$n$ & Número inteiro de comprimentos de onda \\
\hline$n_{e}$ & Densidade volumétrica de corrente \\
\hline$n_{j}$ & Número de partícula no estado quântico $j$ \\
\hline$\left\langle n_{j}\right\rangle$ & Número de ocupação do estado $j$ \\
\hline$N$ & Número total de partículas \\
\hline$p$ & Coordenada polar \\
\hline Perv & Pervêancia \\
\hline$q_{j}$ & Coordenadas da partícula $j$ \\
\hline$r$ & Coordenada radial \\
\hline$r$ & Raio da órbita do elétron \\
\hline$r_{a}$ & Raio do orifício do anodo \\
\hline$R_{a}$ & Raio de curvatura do anodo \\
\hline$R_{c}$ & Raio de curvatura do catodo \\
\hline$r_{c}$ & Raio do disco do catodo \\
\hline$r_{w}$ & Raio da cintura do feixe \\
\hline$s$ & Momento angular intrínseco (spin) \\
\hline$T$ & Temperatura \\
\hline$T_{\text {catodo }}$ & Temperatura do catodo \\
\hline$T_{F}$ & Temperatura de Fermi \\
\hline$t$ & Tempo \\
\hline$u$ & Velocidade \\
\hline$U$ & Energia interna do sistema \\
\hline$v$ & Velocidade de convecção dos elétrons \\
\hline$V$ & Potencial \\
\hline$V$ & Volume \\
\hline$V(r)$ & Potencial eletrostático \\
\hline$v(r)$ & Velocidade de convecção dos elétrons \\
\hline$V_{a}$ & Potencial do anodo \\
\hline$Z$ & Número atômico do átomo \\
\hline$Z$ & Função de partição \\
\hline$z_{c a}$ & Distância entre o anodo-catodo \\
\hline$z_{w}$ & Alcance do feixe \\
\hline$W$ & Barreira de potencial do metal \\
\hline
\end{tabular}


$\alpha \quad$ Parâmetro do sistema (número total de partículas do sistema)

$\alpha \quad$ Coeficiente de temperatura

$\beta \quad$ Razão de aquecimento

a $\quad$ Multiplicidade do spin

$\tilde{a} D(\stackrel{\circ}{a})$ Densidade de estado de partícula única

$\delta \quad$ Desvio padrão

$\nabla \quad$ Operador Laplaciano

$\varepsilon_{0} \quad$ Permissividade elétrica do vácuo $\left(8,85 \times 10^{-12} \mathrm{C}^{2} / \mathrm{Nm}\right)$

$\stackrel{\circ}{a}_{F} \quad$ Energia de Fermi

$\phi_{n} \quad$ Autofunção de um operador (autoestado)

$\phi \quad$ Função trabalho

$\phi_{E} \quad$ Função trabalho efetiva

$\phi_{R} \quad$ Função trabalho de Richardson

$\hbar \quad$ Razão $h / 2 \pi$

$\lambda$ Comprimento de onda da radiação incidente

i Potencial químico

$\eta \quad$ Razão carga/massa

$\grave{e} \quad$ Ângulo de incidência da radiação

$\theta_{0}$ Meio-ângulo do cone de convergência do canhão

ó Número quântico de spin

$\ddot{o} \quad$ Função trabalho do material metálico

$\psi \quad$ Função de onda da partícula

$\Omega \quad$ Volume

$\Xi \quad$ Função de partição 


\section{CAPÍLULO 1 - INTRODUÇÃO}

A partir de 1999, iniciou-se, nas instalações do Centro Tecnológico da Marinha em São Paulo (CTMSP), um projeto de pesquisa e desenvolvimento tecnológico, destinado ao projeto e à construção de dispositivos de microondas de potência do tipo válvula de onda progressiva (TWT). Estes dispositivos são comumente empregados nos radares das fragatas da Marinha do Brasil.

Este projeto vem logrando êxito sendo que, a partir agosto de 2001, alguns protótipos para operação pulsada na banda- $\mathrm{x}$, com potência média de $320 \mathrm{~W}$, taxa de repetição de pulso de $10 \mathrm{kHz}$ e duração de pulso de, aproximadamente, $2 \mu \mathrm{s}$, começaram a entrar em operação. Alguns destes protótipos encontram-se instalados a bordo de fragatas da classe Greenhalgh. Entretanto, outros protótipos apresentaram tempo de vida reduzido em virtude da degradação do catodo, isto é, houve uma antecipada redução da densidade de corrente de emissão ao longo do período de operação da TWT, cessando a amplificação do sinal de microondas. Este fenômeno sugeriu o estabelecimento de uma investigação mais detalhada do processo de obtenção do material emissor de elétrons que compõe o catodo.

Para a adequada amplificação do sinal de microondas que se propaga ao longo da TWT, necessita-se de um feixe eletrônico com elevada densidade de corrente (superior a $2 \mathrm{Acm}^{-2}$ ). Para se obter um feixe eletrônico com tal característica, é necessário o controle das propriedades físico-químicas dos materiais utilizados como fontes de elétrons. Desta forma, a escolha da matéria-prima e a especificação da melhor metodologia de processamento desses materiais devem ser investigadas a fim de se obter o domínio da tecnologia de fabricação dos catodos termiônicos.

O catodo, das válvulas do tipo TWT, objeto de investigação no presente trabalho, apresenta basicamente a seguinte estrutura: um corpo de molibdênio, material emissor fonte de elétrons, constituído por uma pastilha de tungstênio porosa impregnada com aluminato de bário e cálcio e um filamento de tungstênio, que fornece energia térmica ao catodo. A composição química do material eletroemissor influencia diretamente as características de emissão termiônica, pois esta define a função trabalho do catodo. Entende-se, desta forma, que o processo de síntese do material emissor (processo no qual define as fases presentes no material final) é um dos fatores que determina as propriedades 
do catodo impregnado. Há diferentes processos que podem ser utilizados na obtenção do material emissor, dentre eles: a reação em estado sólido, o processo de cristalização e a técnica de precipitação. As diferenças existentes entre estas técnicas de síntese de materiais residem nas etapas constituintes de cada processo que definirão as propriedades do produto final obtido (pureza, tamanho de partícula, homogeneidade e estequiometria).

Outros fatores que influenciam a emissão termiônica nos catodos impregnados são as propriedades físico-químicas da pastilha do catodo, além da técnica empregada no processo de sua impregnação. A fabricação da pastilha do catodo (tungstênio metálico sinterizado com porosidade controlada) requer o controle de alguns parâmetros: tamanho de partícula do pó, distribuição do tamanho e forma da partícula, pureza do pó, pressão de compactação, temperatura de sinterização e, por fim, a distribuição da porosidade da pastilha de tungstênio sinterizada, pois esses parâmetros também contribuem para o tempo de vida do catodo termiônico [1].

Neste trabalho investigaram-se, também, os parâmetros de conformação e sinterização, além das técnicas de impregnação com o intuito de se traçar a melhor metodologia de fabricação dos catodos impregnados e, ainda, de se construir os equipamentos para síntese e caracterização dos materiais do catodo.

Com o objetivo de caracterizar os experimentos de síntese e análise dos materiais, utilizaram-se das seguintes técnicas: termogravimetria (TG), difração de raios $\mathrm{X}$ (DRX), espectroscopia de infravermelho por transformada de Fourier (FTIR), microscopia eletrônica de varredura (MEV) e análises relacionadas ao comportamento termiônico, em virtude da complexidade da padronização dos processos físico-químicos responsáveis pelo mecanismo de emissão.

Para a caracterização termiônica dos catodos investigados, realizou-se um estudo da metodologia de síntese do canhão eletrônico de Pierce de modo a determinar à geometria do canhão eletrônico adequada para a caracterização de emissão termiônica do catodo (tensão de aceleração e densidade de corrente de emissão, por exemplo). Realizouse, também, um estudo das características termiônicas segundo a teoria de Miram [2], por meio da distribuição da função trabalho do catodo, para se definir os parâmetros de emissão em condições de alta densidade de corrente de emissão, a partir de resultados obtidos, por experimentos realizados com baixa densidade de corrente de emissão. 


\subsection{Objetivo}

O objetivo deste trabalho é estabelecer de uma metodologia de síntese dos materiais emissores, compostos por aluminatos de bário e cálcio, a fim de que estes possam ser utilizados na fabricação de catodos impregnados para válvulas TWT. Tendo em vista que a medida da emissão termiônica é uma importante etapa de caracterização destes materiais emissores, desenvolveu-se um procedimento específico para estes testes, ou seja, a construção de um veículo que gerasse resultados confiáveis.

Este projeto foi desenvolvido nas instalações do Laboratório de Microondas de Potência da Divisão de Engenharia Eletrônica do CTMSP.

\subsection{Organização do trabalho}

O Capítulo 2 apresenta os conceitos básicos de emissão termiônica fundamentado na teoria quântica para a construção da equação de Richardson-Dushman, que relaciona a densidade de corrente de emissão com a função trabalho do material emissor e temperatura do catodo termiônico, além de parâmetros, como a diferença de potencial de aceleração do feixe eletrônico.

O Capítulo 3 quantifica o efeito das cargas espaciais em feixes eletrônicos, apresentando o modelo utilizado para a determinação da perveância do canhão eletrônico do tipo Pierce.

O Capítulo 4 descreve, brevemente, os diversos tipos de catodos existentes e a teoria do comportamento térmico dos aluminatos de bário e cálcio.

O Capítulo 5 relaciona as técnicas de síntese e os métodos de caracterização dos materiais empregados na construção do catodo impregnado.

O Capítulo 6 descreve os materiais e métodos empregados na obtenção dos materiais emissores de elétrons, as metodologias de obtenção dos aluminatos de bário e cálcio, os meios de caracterização dos materiais emissores e a construção dos aparatos de medição das características termiônicas do catodo impregnado.

O Capítulo 7 apresenta os resultados da caracterização dos aluminatos de bário e cálcio obtidos pelos diferentes métodos de síntese.

Por fim, no Capítulo 8 apresentam-se as conclusões do desenvolvimento deste projeto, bem como, algumas sugestões para trabalhos futuros. 


\section{CAPÍTULO 2 - EMISSÃO TERMIÔNICA}

\subsection{Introdução do Capítulo}

Neste Capítulo será discutido o fenômeno de emissão termiônica sob o ponto de vista da mecânica estatístico-quântica, com o objetivo de quantificá-lo, por meio de uma expressão para a densidade de corrente de emissão em função da temperatura, denominada Equação de Richardson-Dushman [3]-[6]. Muito embora esta abordagem possa ser encontrada em muitos livros textos, entende-se que sua apresentação é de relevância, não somente por um aspecto didático, mas, principalmente, por seguir todo o maquinário da mecânica estatístico-quântica.

A abordagem quântica é empregada tendo em vista que a razão entre a temperatura do catodo em condições típicas, $T_{\text {catodo }}$, e a temperatura de Fermi, $T_{F}$, é muito menor que a unidade $\left(T_{\text {catodo }} / T_{F}<<1\right)$. O problema dos elétrons de condução em um metal pode ser tratado utilizando o modelo de um gás férmions livres. Na Fig 2.1 ilustram-se os níveis de energia em um metal.

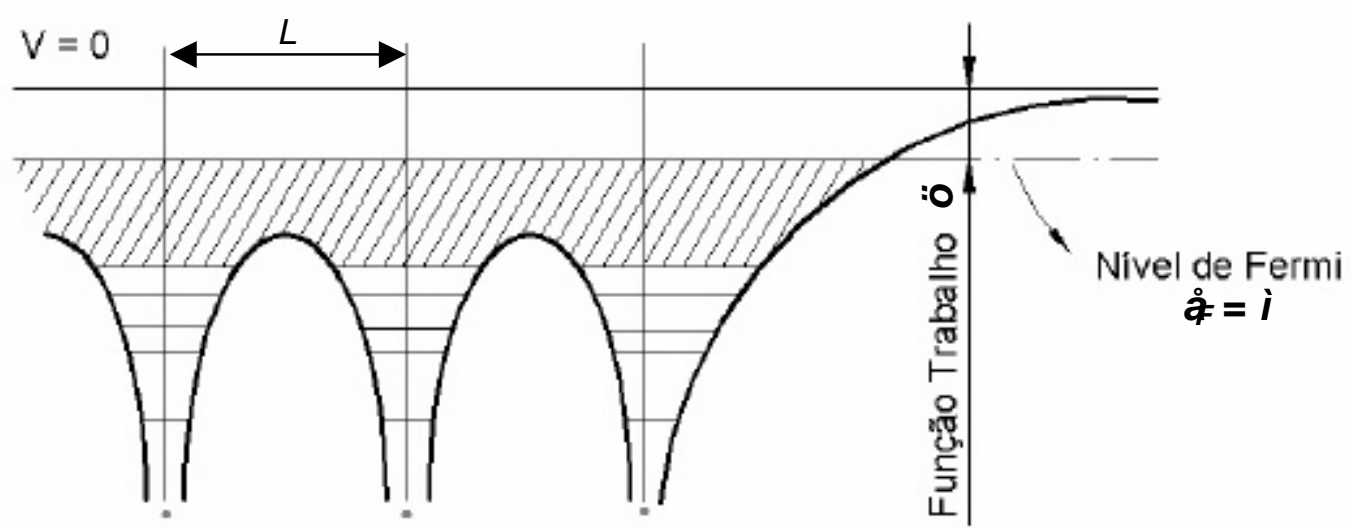

FIGURA 2.1 - Diagrama dos níveis de energia de um metal (os pontos representam íons positivos da rede sendo L o seu período).

Este Capítulo inicia-se com uma breve revisão do formalismo da mecânica estatística, apresentando os ingredientes de uma análise mecânico-estatístico de um sistema físico em equilíbrio. Posteriormente, descreve-se o estado microscópico do sistema quântico para que, em seguida, seja formulado o problema estatístico. Na Seção 2.4 é estabelecida uma conexão com a termodinâmica. Na Seção 2.5, apresenta-se a Equação de Richardson- 
Dushman. Ainda, nessa Seção, analisa-se o efeito da ação de campos elétricos moderadamente fortes $\left(<10^{6} \mathrm{~V} / \mathrm{cm}\right)$ sobre a emissão de um metal. Por fim, na Seção 2.6, são apresentadas as conclusões do Capítulo.

\subsection{Formalismo da mecânica estatística [6]}

Os ingredientes básicos de uma análise mecânico-estatística de um sistema físico, em equilíbrio, podem ser resumidos nas seguintes etapas:

1) especificação dos estados microscópicos do sistema, que formam um conjunto denominado de "ensemble" estatístico;

2) estabelecimento de um postulado estatístico básico e a utilização da teoria das probabilidades; e

3) estabelecimento de uma conexão com a termodinâmica, ou seja, com as variáveis visíveis do mundo macroscópico.

\subsection{Especificação do estado microscópico de um sistema quântico [4]-[6]}

Em mecânica quântica, o estado de um sistema estacionário é caracterizado pela função de onda $\Psi$, solução da equação de Schrödinger independente do tempo. Em geral, essa função de onda pode ser escrita em termos de uma combinação linear das funções pertencentes a um conjunto de ortogonal e completo, $\left\{\Phi_{n}\right\}$, denominado de autofunções de um operador, isto é,

$$
\Psi=\sum_{n} a_{n} \Phi_{n},
$$

onde as autofunções são soluções do seguinte problema de autovalor:

$$
H \Phi_{n}=E_{n} \Phi_{n}
$$

$H$ é o operador hamiltoniano e $E_{n}$ é a energia do estado quântico $n$. Os autoestados $\Phi_{n}$, caracterizados pelo conjunto de números quânticos $\{n\}$, fornecem uma maneira de contar os estados microscópicos do sistema.

Um sistema quântico formado por $N$ partículas idênticas pode ser representado pela função de onda:

$$
\Psi\left(q_{1}, \ldots, q_{i}, \ldots, q_{j}, \ldots q_{N}\right)
$$


onde $q_{j}$ designa todas as coordenadas da partícula $j$ (coordenadas e spin). No entanto, nem todas as funções de ondas desse tipo, que satisfazem à equação de Schrödinger independente do tempo, são representações aceitáveis de um sistema quântico. Deve-se exigir também que a função de onda satisfaça a propriedade de simetria,

$$
\Psi\left(q_{1}, \ldots, q_{i}, \ldots, q_{j}, \ldots q_{N}\right)= \pm \Psi\left(q_{1}, \ldots, q_{j}, \ldots, q_{i}, \ldots q_{N}\right),
$$

indicando que o estado quântico do sistema não se altera quando se trocam as coordenadas de duas partículas. As funções de onda anti-simétricas, sinal (-), estão associadas à partículas de spin semi-inteiro, como o caso dos elétrons onde $s=1 / 2$. Essas partículas são denominadas férmions e obedecem à estatística de Fermi-Dirac.

O problema dos elétrons livres em um metal pode ser descrito utilizando o modelo de uma partícula livre em uma caixa de potencial [3]. Neste caso a equação de Schrödinger independente do tempo se escreve:

$$
-\frac{\hbar^{2}}{2 m_{e}} \nabla^{2} \Phi=E \Phi
$$

onde o operador laplaciano em coordenadas retangulares tem a forma $\nabla^{2}=\partial^{2} / \partial x^{2}+\partial^{2} / \partial y^{2}+\partial^{2} / \partial z^{2}$. No problema da caixa de potencial, a condição para a função de onda é tal que: $\Phi=0$ em $x=0, L, y=0, L$ e $z=0, L$, que implica na seguinte solução da equação de onda:

$$
\Phi_{k_{1} k_{2} k_{3}}=\left(\frac{2}{L}\right)^{3 / 2} \operatorname{sen}\left(k_{1} x\right) \operatorname{sen}\left(k_{2} y\right) \operatorname{sen}\left(k_{3} z\right)
$$

onde, o conjunto de números inteiros $k_{i}$ é dado segundo:

$$
k_{i}=\frac{n_{i} \pi}{L}
$$

onde $n_{i}=1,2,3 \ldots$. O espectro de energia associado pode ser escrito como:

$$
E_{k}=\frac{\hbar^{2} k^{2}}{2 m_{e}}
$$

onde $k^{2}=k_{1}^{2}+k_{2}^{2}+k_{3}^{2}$ é o módulo ao quadrado do vetor número de onda. Isto em linguagem quântica significa dizer que a energia do elétron está quantizada. 
Generalizando para o caso de um sistema consistindo de $N$ partículas livres, a função de onda do sistema é obtida pelo produto das funções de onda para cada partícula, isto é,

$$
\Phi\left(x_{1}, x_{2}, \ldots x_{N}\right)=\Phi_{1}\left(x_{1}\right) \Phi_{2}\left(x_{2}\right) \ldots \Phi_{N}\left(x_{N}\right)
$$

O espectro de energia do sistema de $N$ partículas escrito como:

$$
E_{\text {Total }}=E_{1}+E_{2}+\ldots+E_{N}=\frac{\hbar^{2}}{2 m_{e}}\left[\left(k_{1}^{1}\right)^{2}+\left(k_{2}^{2}\right)^{2}+\ldots+\left(k_{N}^{N}\right)^{2}\right]
$$

No caso em que $L$ é muito grande, o intervalo entre os valores consecutivos de $k$ é muito pequeno e igual a $\pi / L$. Nesta situação pode-se substituir a soma em $k$ por uma integral:

$$
\sum_{k} f(\vec{k}) \rightarrow \frac{V}{(2 \pi)^{3}} \int_{V} d^{3} \vec{k} f(\vec{k})
$$

Para se considerar o spin, pode-se identificar um estado por meio do símbolo $j \equiv(\vec{k}, \sigma)$, que inclui o vetor de onda $k$ associado aos graus de liberdade de translação e o número quântico de spin $\sigma$.

\subsection{Formulação do problema estatístico e conexão com a termodinâmica [6]}

Devido às propriedades de simetria da função de onda de um estado quântico de um gás ideal fica completamente determinado pelo conjunto de números quânticos $\left\{n_{j}\right\}$, onde $j$ designa o estado quântico e $n_{j}$ o número de partículas naquele estado. No caso de férmions $n_{j}=0$ ou $n_{j}=1$ para qualquer $j$. A energia do sistema correspondente ao estado quântico $\left\{n_{j}\right\}$ é expressa segundo:

$$
E\left\{n_{j}\right\}=\sum_{j} \varepsilon_{j} n_{j}
$$

onde $\varepsilon_{j}$ é a energia do estado $j$. O número total de partículas é dado segundo:

$$
N=N\left\{n_{j}\right\}=\sum_{j} n_{j} .
$$

No ensemble canônico, pode-se escrever a função de partição $Z=Z(T, V, N)$ do gás ideal quântico na forma: 


$$
Z=Z(T, V, N)=\sum_{\left\{n_{j}\right\}} \exp \left(-\beta \sum_{j} \varepsilon_{j} n_{j}\right)
$$

com o vínculo de:

$$
\sum_{j} n_{j}=N
$$

onde o problema reside em calcular a soma sobre os números de ocupação com a restrição imposta pelo número fixo de partículas $N$.

No ensemble grande canônico, dados um volume $V$, uma temperatura $T$ e um potencial químico $\mu$, tem-se a grande função de partição $\Xi=\Xi(T, V, \mu)$, para férmions livre, a qual pode ser escrita como:

$$
\begin{gathered}
\Xi(T, V, \mu)=\sum_{N=0}^{\infty} \exp (\beta \mu N) Z(T, V, N), \\
\Xi(T, V, \mu)=\sum_{N=0}^{\infty} \exp (\beta \mu N) \sum_{\left\{n_{j}\right.} \exp \left(-\beta \varepsilon_{1} n_{1}-\beta \varepsilon_{2} n_{2}-\ldots\right)= \\
\sum_{N=0}^{\infty} \sum_{\left\{n_{j}\right\}} \exp \left[-\beta\left(\varepsilon_{1}-\mu\right) n_{1}-\beta\left(\varepsilon_{2}-\mu\right) n_{2}-\ldots\right]
\end{gathered}
$$

Tendo em vista que a soma é feita inicialmente sobre o conjunto de número de ocupação, $n_{j}$ com a restrição de $\sum_{j} n_{j}=N$, mas, como depois há outra soma sobre todos os valores possíveis de $N$, pode-se simplesmente fazer uma soma múltipla sobre todos os números de ocupação, sem qualquer restrição, o que corresponde a um rearranjo dos termos dessa soma. Desta forma,

$$
\Xi(T, V, \mu)=\sum_{n_{1}, n_{2}, \ldots} \exp \left[-\beta\left(\varepsilon_{1}-\mu\right) n_{1}-\beta\left(\varepsilon_{2}-\mu\right) n_{2}-\ldots\right]
$$

que pode ser fatorado, resultando:

$$
\Xi(T, V, \mu)=\prod_{j} \sum_{n} \exp \left[-\beta\left(\varepsilon_{j}-\mu\right) n\right]=\sum_{n_{1}} \exp \left[-\beta\left(\varepsilon_{1}-\mu\right) n_{1}\right] \sum_{n_{2}} \exp \left[-\beta\left(\varepsilon_{2}-\mu\right) n_{2}\right] \ldots
$$

A partir do conhecimento de $\Xi$ e utilizando o formalismo do ensemble grande canônico, podem-se obter as expressões para os valores esperados da energia e do número de partículas. $\mathrm{O}$ valor esperado $\left\langle n_{j}>\right.$ do número de ocupação do estado $j$ pode ser obtido segundo: 


$$
<n_{j}>=-\frac{1}{\beta} \frac{\partial}{\partial \varepsilon_{j}} \ln \Xi
$$

No caso da estatística de Fermi-Dirac $n=0$ ou $n=1$, tem-se:

$$
\Xi=\prod_{j} \sum_{n=0}^{1} \exp \left[-\beta\left(\varepsilon_{j}-\mu\right) n\right]=\prod_{j}\left\{1+\exp \left[-\beta\left(\varepsilon_{j}-\mu\right)\right]\right\}
$$

tomando-se o logaritmo natural,

$$
\ln \Xi=\sum_{j}\left\{1+\exp \left[-\beta\left(\varepsilon_{j}-\mu\right)\right]\right\}
$$

E, desta forma, o valor esperado no número de ocupação do estado $j$,

$$
<n_{j}>=-\frac{1}{\beta} \frac{\partial}{\partial \varepsilon_{j}} \ln \Xi=\frac{1}{\exp \left[\beta\left(\varepsilon_{j}-\mu\right)\right]+1},
$$

que é denominada de distribuição de Fermi-Dirac. Pode-se observar que $0 \leq<n_{j}>\leq 1$ de acordo com o princípio de exclusão de Pauli.

A partir do conhecimento de $\Xi$, o valor esperado da energia, $U$, (que é identificado no limite termodinâmico, com energia interna do sistema) e o valor esperado do número total de partículas, $N$, (identificado como o número termodinâmico de partículas), podem ser dados por:

$$
U=\sum_{j} \varepsilon_{j}<n_{j}>=\sum_{j} \frac{\varepsilon_{j}}{\exp \left[\beta\left(\varepsilon_{j}-\mu\right)\right]+1},
$$

e,

$$
N=\sum_{j}<n_{j}>=\sum_{j} \frac{1}{\exp \left[\beta\left(\varepsilon_{j}-\mu\right)\right]+1}
$$

Para férmions livres, na ausência de campos eletromagnéticos externos, o espectro de energia é dado por:

$$
\varepsilon_{j}=\varepsilon_{\vec{k}, \sigma}=\frac{\hbar^{2} k^{2}}{2 m_{e}} .
$$

No limite termodinâmico, a grande função de partição pode ser escrita em vista de (2.11), (2.19) e (2.23) como: 


$$
\ln \Xi(T, V, \mu)=\gamma \frac{V}{(2 \pi)^{3}} \int d^{3} \vec{k} \ln \left\{1+\exp \left[-\beta\left(\frac{\hbar^{2} k^{2}}{2 m_{e}}-\mu\right)\right]\right\},
$$

onde $\gamma=2 s+1$ é a multiplicidade do spin (para elétrons $s=1 / 2$ fornece $\gamma=2$ ). Nestas condições, os valores para o número termodinâmico de partícula e para a energia interna do Gás de Fermi podem ser escritos, respectivamente,

$$
\begin{gathered}
N=\gamma \frac{V}{(2 \pi)^{3}} \int d^{3} \vec{k} \frac{1}{\exp \left[\beta\left(\frac{\hbar^{2} k^{2}}{2 m_{e}}-\mu\right)\right]+1}, \\
U=\gamma \frac{V}{(2 \pi)^{3}} \int d^{3} \vec{k} \frac{\hbar^{2} k^{2}}{2 m_{e}} \frac{1}{\exp \left[\beta\left(\frac{\hbar^{2} k^{2}}{2 m_{e}}-\mu\right)\right]+1} .
\end{gathered}
$$

Devido a simetria esférica do espectro de energia dos férmions livres, pode-se reescrever essas expressões utilizando a energia $\varepsilon$ como variável de integração,

$$
\begin{gathered}
\ln \Xi(T, V, \mu)=\gamma V \int_{0}^{\infty} D(\varepsilon) \ln \{1+\exp [-\beta(\varepsilon-\mu)]\} d \varepsilon, \\
N=\gamma V \int_{0}^{\infty} D(\varepsilon) f(\varepsilon) d \varepsilon \\
U=\gamma V \int_{0}^{\infty} \varepsilon D(\varepsilon) f(\varepsilon) d \varepsilon
\end{gathered}
$$

onde,

$$
f(\varepsilon)=\frac{1}{\exp [\beta(\varepsilon-\mu)]+1},
$$

é a estatística de Fermi-Dirac, e

$$
D(\varepsilon)=\frac{1}{4 \pi^{2}}\left(\frac{2 m_{e}}{\hbar^{2}}\right)^{\frac{3}{2}} \varepsilon^{\frac{1}{2}}=C \varepsilon^{\frac{1}{2}}
$$

onde a constante $C$ depende da massa do férmion. $\gamma D(\varepsilon)$ é uma densidade (por energia e por volume) de estado de partícula única disponíveis para as partículas livres. 
Seja agora o problema do gás de Gás de Fermi completamente degenerado. Costuma-se dizer que um gás quântico no estado fundamental, à temperatura nula, está completamente degenerado. No caso dos férmions a temperatura nula $\beta \rightarrow \infty$, o número de ocupação mais provável dos estados é dado por uma função degrau de energia, conforme ilustrado na FIG. 2.2.

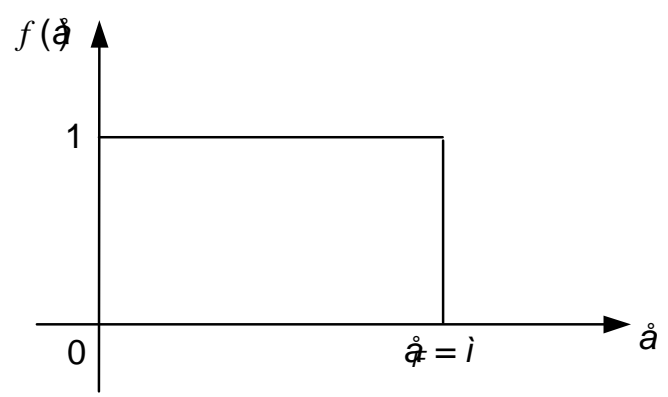

FIGURA 2.2 - Função degrau de energia.

O potencial químico, a temperatura nula, designado por $\varepsilon_{F}$, é denominado de energia de Fermi. Neste caso todos os estados estão ocupados até a energia de Fermi $\varepsilon_{F}$, mas permanecem vazios para $\varepsilon>\varepsilon_{F}$. É possível calcular a energia de Fermi em termos do número total de partículas $N$ e do volume $V$. No limite $\beta \rightarrow \infty$,

$$
N=\gamma V \int_{0}^{\varepsilon_{F}} D(\varepsilon) d \varepsilon
$$

que resulta em,

$$
N=\frac{2}{3} \gamma V \varepsilon_{F} D\left(\varepsilon_{F}\right)
$$

de onde vem que,

$$
\varepsilon_{F}=\frac{\hbar^{2}}{2 m_{e}}\left(\frac{6 \pi^{2}}{\gamma}\right)^{\frac{2}{3}}\left(\frac{N}{V}\right)^{\frac{2}{3}}
$$

A partir da energia de Fermi, pode-se definir a temperatura de Fermi,

$$
T_{F}=\frac{\varepsilon_{F}}{k_{B}}=\frac{\hbar^{2}}{2 m_{e} k_{B}}\left(\frac{6 \pi^{2}}{\gamma}\right)^{\frac{2}{3}}\left(\frac{N}{V}\right)^{\frac{2}{3}} .
$$


A temperatura de Fermi de um metal alcalino é tipicamente da ordem de $T_{F} \approx 10^{4} \mathrm{~K}$. No limite $T \ll T_{F}$ (gás ideal de Fermi degenerado) a função de distribuição de Fermi-Dirac $f(\varepsilon)$ tem a forma de um degrau arredondado. Tendo em vista de o potencial químico $\mu$ ser função de $T, V$ e $N$, ele deve ser ligeiramente menor do que seu valor $\varepsilon_{F}$, à temperatura ambiente, sendo expresso segundo,

$$
\mu=\varepsilon_{F}\left[1-\frac{\pi^{2}}{12}\left(\frac{T}{T_{F}}\right)^{2}+\ldots\right] .
$$

\subsection{Emissão termiônica - equação de Richardson e o efeito Schottky [3]-[6]}

O número de elétrons deixando uma superfície metálica, por unidade de área e por unidade de tempo, pode ser escrito como, considerando (2.25) e que os elétrons emitidos tenham velocidade $u_{z}$ :

$$
\begin{gathered}
J=e<n u_{z}> \\
n=\frac{N}{V}=\gamma \frac{1}{(2 \pi)^{3}} \int d^{3} \vec{k} u_{z} \frac{1}{\exp \left[\beta\left(\frac{\hbar^{2} k^{2}}{2 m_{e}}-\mu\right)\right]+1} \\
J(T)=2 e \frac{1}{(2 \pi)^{3}} \int d^{3} \vec{k} u_{z} \frac{1}{\exp \left[\beta\left(\frac{\hbar^{2} k^{2}}{2 m_{e}}-\mu\right)\right]+1} .
\end{gathered}
$$

Realizando uma mudança de variáveis $k=\frac{p}{\hbar}$, tem-se:

$$
d k_{x} d k_{y} d k_{z}=\frac{d p_{x} d p_{y} d p_{z}}{\hbar^{3}} \text { e } u_{z}=\frac{p_{z}}{m_{e}}
$$

desta forma:

$$
J(T)=2 e \frac{1}{(2 \pi)^{3}} \int_{p_{x}=-\infty}^{\infty} \int_{p_{y}=-\infty}^{\infty} \int_{p_{z}=\sqrt{2 m W}}^{\infty} \frac{d p_{x} d p_{y} d p_{z}}{\hbar^{3}} \frac{p_{z}}{m_{e}} \frac{1}{\exp \left[\beta\left(\frac{p^{2}}{2 m_{e}}-\mu\right)\right]+1}
$$


onde $p_{z}$ representa a energia mínima que o elétron deve possuir a fim de vencer a barreira de potencial. A integral dupla pode ser resolvida empregando as coordenadas polares $p_{x}=p_{r} \cos \theta$ e $p_{y}=p_{r} \operatorname{sen} \theta$ :

$$
J(T)=\frac{2 e}{h^{3}} \int_{p_{z}=\sqrt{2 m W}}^{\infty} \frac{p_{z}}{m_{e}} d p_{z} \int_{p_{r}=0}^{\infty} \frac{2 \pi p_{r} d p_{r}}{\exp \left[\beta\left(\frac{p_{r}^{2}}{2 m_{e}}+\frac{p_{z}^{2}}{2 m_{e}}-\mu\right)\right]+1} .
$$

Integrando-se em $p_{r}$, obtém-se:

$$
J(T)=\frac{4 \pi m_{e} e k_{B} T}{h^{3}} \int_{p_{z}=\sqrt{2 m W}}^{\infty} p_{z} d p_{z} \ln \left\{1+\exp \left[\beta\left(\mu-\frac{p_{z}^{2}}{2 m_{e}}\right)\right]\right\} .
$$

Realizando nova mudança de variáveis, $\varepsilon_{z}=\frac{p_{z}^{2}}{2 m_{e}}$,

$$
J(T)=\frac{4 \pi m_{e} e k_{B} T}{h^{3}} \int_{\varepsilon_{z}=W}^{\infty} d \varepsilon_{z} \ln \left\{1+\exp \left[\beta\left(\mu-\varepsilon_{z}\right)\right]\right\} .
$$

Observando que $\ln \left\{1+\exp \left[\beta\left(\mu-\varepsilon_{z}\right)\right]\right\} \cong \exp \left[\beta\left(\mu-\varepsilon_{z}\right)\right]$, quando $\exp \left[\beta\left(\mu-\varepsilon_{z}\right)\right]<<1$, a densidade de corrente de emissão pode ser escrita,

$$
J(T)=\frac{4 \pi m_{e} e k_{B} T}{h^{3}} \int_{\varepsilon_{z}=W}^{\infty} d \varepsilon_{z} \exp \left[\beta\left(\mu-\varepsilon_{z}\right)\right]
$$

e, finalmente,

$$
J(T)=\frac{4 \pi m_{e} e\left(k_{B} T\right)^{2}}{h^{3}} \exp \left[\frac{-(\mu-W)}{k_{B} T}\right]
$$

ou,

$$
J(T)=A_{0} T^{2} \exp \left(-\frac{\varphi}{k_{B} T}\right)
$$

onde $A_{0}=\frac{4 \pi m_{e} e k_{B}^{2}}{h^{3}}=120,4 \mathrm{~A} / \mathrm{cm}^{2} \mathrm{~K}^{2}$ é uma constante universal e $\varphi=\mu-W$ é a função trabalho do material metálico (FIG.2.1). Observando que $\mu \cong \varepsilon_{F}$, a função trabalho representa a altura da barreira de potencial acima do nível de Fermi. 
O efeito da ação de campo elétricos moderadamente fortes $\left(<10^{6} \mathrm{~V} / \mathrm{cm}\right)$ sobre a emissão de um metal é denominado de efeito Schottky. Considerando a intensidade do campo elétrico $E$ (admitindo o campo elétrico ser uniforme na superfície e com a direção perpendicular), a diferença $\Delta$ entre a energia potencial de um elétron em uma distância $z$ da superfície e uma distância $2 z$ de sua carga imagem no interior do metal, pode-se escrever:

$$
\Delta(z)=W-e E z-\frac{1}{4 \pi \varepsilon_{0}} \frac{e^{2}}{4 z} \operatorname{com} z>0
$$

onde $W$ é a barreira de potencial do metal, o segundo termo é atrativo devido ao campo elétrico externo e o terceiro termo, também atrativo da força imagem entre o elétron que parte e sua imagem induzida no metal. O máximo valor da função $\Delta(z)$ ocorre para,

$$
\frac{d}{d z} \Delta(z)=-e E+\frac{1}{4 \pi \varepsilon_{0}} \frac{e^{2}}{4 z^{2}}=0
$$

que produz $z=\sqrt{e / 16 \pi \varepsilon_{0} E}$. Desse modo,

$$
\Delta_{\max }(z)=W-\frac{e^{3 / 2}}{4 \pi \varepsilon_{0}} \sqrt{E}
$$

pode ser observado que o campo elétrico externo efetivamente reduz a altura da barreira $W$ de potencial por uma quantidade $e^{3 / 2} \sqrt{E} / 4 \pi \varepsilon_{0}$. Consequentemente, a densidade de corrente termiônica na presença do campo será maior que aquela na ausência de campo para uma mesma temperatura. A expressão para a densidade de corrente de emissão termiônica pode ser escrita segundo:

$$
J(T, E)=A_{0} T^{2} \exp \left(\frac{-\varphi}{k_{B} T}\right) \exp \left(\frac{e^{3 / 2} \sqrt{E}}{4 \pi k_{B} T}\right)
$$

Substituindo os valores numéricos,

$$
J(T, E)=120 T^{2} \exp \left(-\frac{11606}{T} \varphi\right) \exp \left(\frac{4,4}{T} \sqrt{E}\right)\left(A / \mathrm{cm}^{2}\right)
$$

sendo a função trabalho expressa em elétron-volt, a temperatura em kelvin e o campo elétrico em volt $/ \mathrm{cm}$. 


\subsection{Conclusões do Capítulo}

Descreveu-se o fenômeno de emissão termiônica sob o ponto de vista da mecânica estatístico-quântico. Abordados os ingredientes básicos da análise mecânicoestatística de um sistema em equilíbrio, formulou-se o problema estatístico aplicando-se conceitos fundamentais da termodinâmica. Em vista dos conceitos quânticos e empregando a relação entre a carga, densidade e velocidade do elétron, $J=e\langle n u\rangle$, obteve-se a expressão da densidade de corrente de emissão de Richardson-Dushman. Por fim, quantifica-se o efeito de campos elétricos sobre o metal: efeito Schottky. Este efeito reduz a altura da barreira de potencial em um material metálico e, conseqüentemente, aumenta a densidade de corrente de emissão para uma mesma temperatura. 


\section{CAPÍTULO 3 - SOLUÇÃO DE LANGMUIR-BLODGETT PARA O PROBLEMA DO DIODO ESFÉRICO - DETERMINAÇÃO DA PERVEÂNCIA}

\subsection{Introdução do Capítulo}

Neste Capítulo, discute-se o problema do fluxo de corrente elétrica limitado pela carga espacial, em um diodo esférico, com o objetivo de obter o valor para a máxima corrente elétrica que poderá ser extraída deste diodo. Na solução do problema do diodo esférico, Langmuir e Blodgett [7] obtiveram uma expressão que permite calcular a máxima corrente que pode ser extraída de um diodo esférico a uma dada voltagem do anodo. Empregando-se o resultado de Langmuir e Blodgett, Pierce [8] desenvolveu um procedimento para se determinar a densidade de corrente limitada pela carga espacial em um setor cônico do diodo esférico e, assim, desenvolveu um procedimento para o projeto básico de um canhão eletrônico de fluxo convergente. Como resultado, obteve-se uma expressão para a determinação da perveância do canhão que depende somente de suas características geométricas.

Descreve-se um procedimento analítico não-iterativo para a síntese do canhão eletrônico do tipo Pierce com fluxo convergente anteriormente desenvolvido por Tiwary e Basu [9]. Para se obter este procedimento, alguns fatores foram considerados: a divergência do feixe eletrônico (passagem do feixe eletrônico através do orifício do anodo) e efeito da lente eletrostática devido à abertura do anodo, resultando em uma expressão que relaciona os raios do catodo e do anodo com a cintura do feixe eletrônico.

$\mathrm{Na}$ Seção 3.2, apresenta-se a solução do problema proposto por LangmuirBlodgett [7]. Posteriormente, a expressão obtida para a densidade de corrente limitada pela carga espacial é modificada de acordo com a proposta de Pierce [8]. Na Seção 3.5, apresenta-se a influência do orifício do anodo. Na Seção 3.6, descreve-se um fluxograma para a síntese do canhão eletrônico baseado na teoria apresentada por Basu [9]. Finalmente, na Seção 3.7, são apresentados alguns exemplos da aplicação da metodologia de síntese do canhão eletrônico discutida durante este Capítulo. Na Seção 3.8, apresenta-se o efeito da carga espacial no campo elétrico da superfície do catodo. Por fim, na Seção 3.9, é apresentada a conclusão do Capítulo. 


\subsection{Formulação do problema do diodo esférico}

O problema do canhão eletrônico pode ser formulado como segue. Seja o diodo esférico, conforme ilustrado na FIG. 3.1, que consiste de duas cascas esféricas metálicas concêntricas. A externa de raio $R_{c}$ é o catodo e a interna de $R_{a}$ é o anodo. O catodo está polarizado com $V\left(r=R_{c}\right)=0$ e o anodo $V\left(r=R_{a}\right)=V_{a}$. Admite-se que a superfície $r=R_{c}$ emite elétrons que são acelerados em direção ao anodo $\left(r=R_{a}\right)$ de maneira que a corrente total é denotada por $I_{0}$. A região entre $R_{a} \leq r \leq R_{c}$ está sob vácuo de maneira a não existir nenhum fenômeno colisional que possa gerar o fenômeno da avalanche eletrônica.

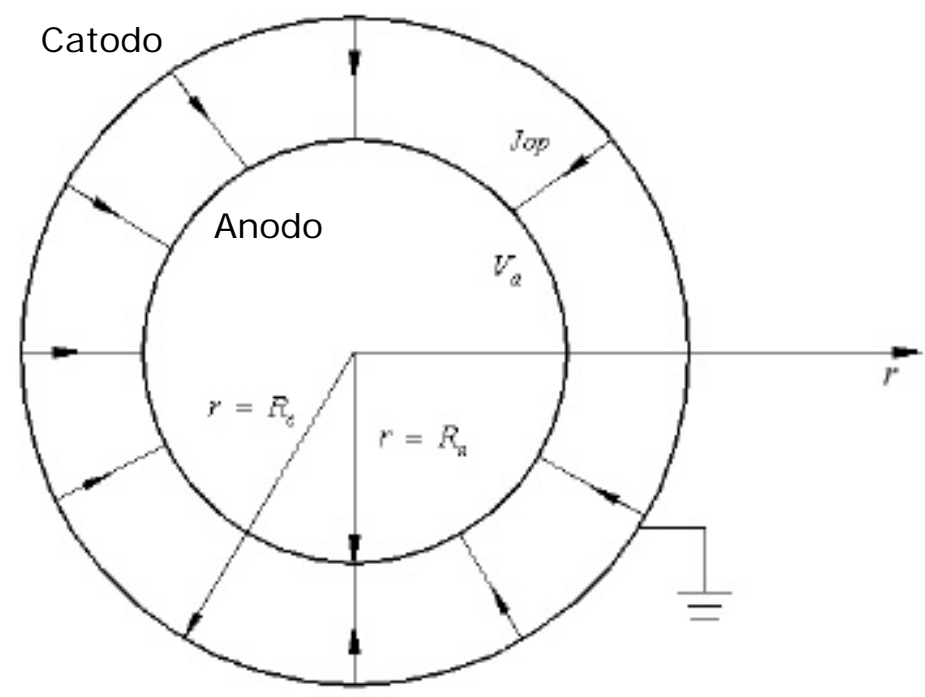

FIGURA 3.1- Ilustração do modelo catodo esférico. Os vetores ilustram a densidade de corrente de convecção $\vec{J}=e n_{e} \vec{v}$ radial em direção ao anodo.

O primeiro passo para a solução do problema é obter uma expressão que relacione a distribuição radial de potencial eletrostático $V(r)$ do canhão eletrônico com a corrente total $I_{0}$ do feixe. Para isto, são consideradas as seguintes equações:

1) Equação de Poisson para o potencial eletrostático. Para uma distribuição de potencial que depende somente da coordenada radial $r$, isto é, $V(\vec{r})=V(r)$, a equação de Poisson pode ser escrita como:

$$
\frac{d^{2} V}{d r^{2}}+\frac{2}{r} \frac{d V}{d r}=\frac{e n_{e}(r)}{\varepsilon_{0}}
$$

onde $n_{e}(r)$ é a densidade volumétrica de corrente (em número), $e$ é a carga do elétron e $\varepsilon_{0}$ é a permissividade elétrica do vácuo. 
2) Densidade de corrente de convecção $J(r)=J_{o p}$, que poderá ser escrita como:

$$
J_{o p}=e n_{e}(r) v(r)
$$

onde $J_{o p}(r)=\frac{I_{0}}{4 \pi r^{2}}$ e $v=v(r)$ é a velocidade de convecção dos elétrons que fluem do catodo em direção ao anodo.

3) Conservação de energia,

$$
\frac{1}{2} m v^{2}=e V(r)
$$

que traduz o fenômeno do trabalho realizado pelo campo elétrico sobre os elétrons corresponder à variação da energia cinética dos mesmos. Resolvendo (3.3) para v, substituindo $v$ em (3.2), resolvendo a expressão obtida para $e n_{e}(r)$ e, então, substituindo em (3.1), resulta:

$$
\frac{d^{2} V}{d r^{2}}+\frac{2}{r} \frac{d V}{d r}-k^{\prime} \frac{V^{-1 / 2}}{r^{2}}=0
$$

onde a constante $k$ 'é dada por:

$$
k^{\prime}=\frac{I_{0}}{4 \pi(2 \eta)^{1 / 2} \varepsilon_{0}}
$$

e $\eta=\frac{e}{m_{e}}$ é a razão carga/massa para o elétron. Langmuir e Blodgett propuseram a seguinte solução para a equação diferencial (3.4):

$$
V(r)=\left(\frac{9}{4} k^{\prime}\right)^{2 / 3} G^{4 / 3}(u) \text { para } u=\ln \frac{r}{R_{c}} .
$$

A função $G(u)$ deve satisfazer as seguintes condições de contorno:

a) $G(u=0)=0$, isto é, para $r=R_{c}$, o potencial deverá ser nulo (potencial do catodo).

b) $G\left(u=\ln \frac{R_{a}}{R_{c}}\right)$, deve ser tal que $\left(\frac{9}{4} k^{\prime}\right)^{2 / 3} G^{4 / 3}\left(\ln \frac{R_{a}}{R_{c}}\right)=V_{a}$, onde $V_{a}$ é o potencial do anodo.

c) A solução proposta por Langmuir e Blodgett é uma solução por série infinita construída tomando-se por base a expansão da função $G(u)$ na série de Taylor, em torno do ponto $u=0$; 


$$
G(u)=G(0)+\frac{u}{1 !} G^{\prime}(0)+\frac{u^{2}}{2 !} G^{\prime \prime}(0)+\frac{u^{3}}{3 !} G^{\prime \prime \prime}(0)+\frac{u^{4}}{4 !} G^{i v}(0)+\ldots
$$

onde os coeficientes da expansão $G^{(n)}(0)$ são coeficientes a serem determinados de maneira que as condições de contorno sejam satisfeitas.

\subsubsection{Determinação dos coeficientes $G^{(n)}(0)$}

Nesta Subseção descrevem-se as etapas de determinação dos coeficientes da solução da série proposta por Langmuir e Blodgett. De tal forma a obter a função:

$$
G=G\left[\ln \left(\frac{r}{R_{c}}\right)\right]
$$

Dividindo-se (3.4) por $\frac{k^{\prime}}{r^{2}} V^{-1 / 2}$ obtém-se:

$$
\frac{r^{2} V^{1 / 2}}{k^{\prime}} \frac{d^{2} V}{d r^{2}}+\frac{2 r V^{1 / 2}}{k^{\prime}} \frac{d V}{d r}-1=0
$$

Calculando-se as derivadas de (3.6), tem-se que a derivada primeira é dada por:

$$
\frac{d V}{d r}=\left(\frac{9}{4} k^{\prime}\right)^{2 / 3} \frac{4}{3} G(u)^{1 / 3} \frac{d G}{d r},
$$

e a derivada segunda:

$$
\frac{d^{2} V}{d r^{2}}=\left(\frac{9}{4} k^{\prime}\right)^{2 / 3} \frac{4}{3}\left[\frac{1}{3} G(u)^{-2 / 3}\left(\frac{d G}{d r}\right)^{2}+G(u)^{1 / 3} \frac{d^{2} G}{d r^{2}}\right],
$$

substituindo em (3.8) torna-se:

$$
3 r^{2} G(u) \frac{d^{2} G}{d r^{2}}+r^{2}\left(\frac{d G}{d r}\right)^{2}+6 r G(u) \frac{d G}{d r}-1=0 .
$$

Efetuando a mudança de variável:

$$
u=\ln \frac{r}{R_{c}},
$$

(3.10) pode ser escrita como:

$$
3 G(u) \frac{d^{2} G}{d u^{2}}+3 G(u) \frac{d G}{d u}+\left(\frac{d G}{d u}\right)^{2}-1=0
$$


A equação diferencial, não-linear, de segunda ordem (3.12) pode ser utilizada para a determinação dos coeficientes da expansão (3.6). Para isto, considera-se: $r=R_{c}, u=\ln 1=0$ e, portanto, $G(0)=0$ e (3.12) fornece:

$$
\left.\left(\frac{d G}{d u}\right)^{2}\right|_{u=0}=1 \text { ou }\left.\frac{d G}{d u}\right|_{u=0}= \pm 1
$$

A solução $G^{\prime}(0)=-1$ indica um feixe com fluxo convergente e a solução $G^{\prime}(0)=+1$ um feixe com fluxo divergente. Os demais coeficientes são determinados de maneira similar.

Determinação dos coeficientes da equação proposta por Langmuir e Blodgett por meio das derivadas de (3.12):

Para a determinação de $G^{\prime \prime}(0)$ utiliza-se um procedimento semelhante à aquele utilizado para a determinação de $G^{\prime}(0)$. Deriva-se (3.12) e calcula-se o valor da expressão para $u=0$. Segundo estes passos, obtém-se:

$$
3 \frac{d G}{d u} \frac{d^{2} G}{d u^{2}}+3 G(u) \frac{d^{3} G}{d u^{3}}+3\left(\frac{d G}{d u}\right)^{2}+3 G(u) \frac{d^{2} G}{d u^{2}}+2 \frac{d G}{d u} \frac{d^{2} G}{d u^{2}}=0
$$

Calculando para $G(0)=0$ :

$$
\left.\frac{d^{2} G}{d u^{2}}\right|_{u=0}=\frac{3}{5} \text { onde utilizou-se }\left.\frac{d G}{d u}\right|_{u}=-1
$$

Derivando (3.14) e calculando o valor da expressão obtida no ponto $u=0$ :

$$
5\left(\frac{d^{2} G}{d u^{2}}\right)^{2}+8 \frac{d G}{d u} \frac{d^{3} G}{d u^{3}}+3 G(u) \frac{d^{4} G}{d u^{4}}+9 \frac{d G}{d u} \frac{d^{2} G}{d u^{2}}+3 G(u) \frac{d^{3} G}{d u^{3}}=0 .
$$

Calculando para $G(0)=0$ :

$$
\left.\frac{d^{3} G}{d u^{3}}\right|_{u=0}=-\frac{9}{20}
$$

De maneira similar:

$$
18 \frac{d^{2} G}{d u^{2}} \frac{d^{3} G}{d u^{3}}+11 \frac{d G}{d u} \frac{d^{4} G}{d u^{4}}+3 G(u) \frac{d^{5} G}{d u^{5}}+9\left(\frac{d^{2} G}{d u^{2}}\right)^{2}+12 \frac{d G}{d u} \frac{d^{3} G}{d u^{3}}+3 G(u) \frac{d^{4} G}{d u^{4}}=0
$$

Calculando para $G(0)=0$ : 


$$
\left.\frac{d^{4} G}{d u^{4}}\right|_{u=0}=\frac{189}{550}
$$

Idem para $G^{v}(0)$ :

$$
\begin{gathered}
18\left(\frac{d^{3} G}{d u^{3}}\right)^{2}+29 \frac{d^{2} G}{d u^{2}} \frac{d^{4} G}{d u^{4}}+14 \frac{d G}{d u} \frac{d^{5} G}{d u^{5}}+3 G(u) \frac{d^{6} G}{d u^{6}}+30 \frac{d^{2} G}{d u^{2}} \frac{d^{3} G}{d u^{3}}+ \\
15 \frac{d G}{d u} \frac{d^{4} G}{d u^{4}}+3 G(u) \frac{d^{5} G}{d u^{5}}=0
\end{gathered}
$$

Calculando para $G(0)=0$ :

$$
\left.\frac{d^{5} G}{d u^{5}}\right|_{u=0}=-\frac{39933}{154000}
$$

Finalmente para $G^{v i}(0)$ :

$$
\begin{gathered}
65 \frac{d^{3} G}{d u^{3}} \frac{d^{4} G}{d u^{4}}+43 \frac{d^{2} G}{d u^{2}} \frac{d^{5} G}{d u^{5}}+17 \frac{d G}{d u} \frac{d^{6} G}{d u^{6}}+3 G(u) \frac{d^{7} G}{d u^{7}}+30\left(\frac{d^{3} G}{d u^{3}}\right)^{2}+ \\
45 \frac{d^{2} G}{d u^{2}} \frac{d^{4} G}{d u^{4}}+18 \frac{d G}{d u} \frac{d^{5} G}{d u^{5}}+3 G(u) \frac{d^{6} G}{d u^{6}}=0
\end{gathered}
$$

Calculando para $G(0)=0$ :

$$
\left.\frac{d^{6} G}{d u^{6}}\right|_{u=0}=\frac{2525013}{13090000}
$$

Substituindo as soluções obtidas nas derivadas de (3.12) em (3.6), os seis termos da série podem ser escritos como:

$$
G(u)=-u+\frac{3}{10} u^{2}-\frac{3}{40} u^{3}+\frac{63}{4400} u^{4}-\frac{13311}{6160000} u^{5}+\frac{280557}{1047200000} u^{6}+\ldots
$$

então a função $G=G\left[\ln \left(\frac{R_{c}}{r}\right)\right]$ é dada pela série infinita:

$$
\begin{gathered}
G\left[\ln \left(\frac{R_{c}}{r}\right)\right]=\ln \left(\frac{R_{c}}{r}\right)+\frac{3}{10} \ln ^{2}\left(\frac{R_{c}}{r}\right)+\frac{3}{40} \ln ^{3}\left(\frac{R_{c}}{r}\right)+\frac{63}{4400} \ln ^{4}\left(\frac{R_{c}}{r}\right)+ \\
\frac{13311}{6160000} \ln ^{5}\left(\frac{R_{c}}{r}\right)+\frac{280557}{1047200000} \ln ^{6}\left(\frac{R_{c}}{r}\right)+\ldots
\end{gathered}
$$


Esta série pode ser truncada no sexto termo, pois este termo representa um erro máximo de 0,4\% para uma razão de $R_{c} / r$ entre 1,1 e 10 (faixa de valores empregados nos cálculos posteriores).

Para o cálculo da perveância do sistema ou ainda da corrente máxima de um diodo esférico, considera-se que $V(r)$ é dado por:

$$
V(r)=\left[\frac{9 I_{0}}{16 \pi(2 \eta)^{1 / 2} \varepsilon_{0}}\right]^{2 / 3} G^{4 / 3}\left[\ln \left(\frac{R_{c}}{r}\right)\right] .
$$

Observe que para $r=R_{c}, G(\ln 1)=0$ e, portanto $V\left(r=R_{c}\right)$, satisfaz a condição de contorno para $r=R_{c}$ (potencial do catodo). Por outro lado, para $r=R_{a}$, tem-se que $V\left(r=R_{a}\right)=V_{a}$ e então (3.26) se escreve:

$$
V_{a}=\left[\frac{9 I_{0}}{16 \pi(2 \eta)^{1 / 2} \varepsilon_{0}}\right]^{2 / 3} G_{a}^{4 / 3},
$$

onde

$$
\begin{gathered}
G_{a}=G\left(r=R_{a}\right)=\ln \left(\frac{R_{c}}{R_{a}}\right)+\frac{3}{10} \ln ^{2}\left(\frac{R_{c}}{R_{a}}\right)+\frac{3}{40} \ln ^{3}\left(\frac{R_{c}}{R_{a}}\right)+\frac{63}{4400} \ln ^{4}\left(\frac{R_{c}}{R_{a}}\right)+ \\
\frac{13311}{6160000} \ln ^{5}\left(\frac{R_{c}}{R_{a}}\right)+\frac{280557}{1047200000} \ln ^{6}\left(\frac{R_{c}}{R_{a}}\right)+\ldots
\end{gathered}
$$

A expressão (3.27) traduz um fenômeno físico de muita relevância, que pode ser formulado como segue: dados $R_{c}, R_{a}$ e $V_{a}$ haverá uma corrente máxima (ou limite) que poderá ser drenada pelo diodo esférico de Langmuir (independente da superfície emissora ter a capacidade de emitir mais elétrons), cujo valor é dado, resolvendo-se (3.27) para $I_{0}$ :

$$
I_{0}=\left[\frac{4}{9} \frac{4 \pi \varepsilon_{0}(2 \eta)^{1 / 2}}{G_{a}^{2}}\right] V_{a}^{3 / 2} .
$$

A constante entre colchetes é denominada de perveância do diodo esférico:

$$
\text { Perv }=\frac{4}{9} \frac{4 \pi \varepsilon_{0}(2 \eta)^{1 / 2}}{G_{a}^{2}}
$$

e que depende somente da razão logarítmica entre os raios do catodo e anodo:

$$
\text { Perv }=\operatorname{Perv}\left[\ln \left(\frac{R_{c}}{R_{a}}\right)\right] .
$$


A equação (3.28) pode ser escrita como,

$$
I_{0}=\operatorname{Perv} V_{a}^{3 / 2}
$$

que permite calcular a máxima corrente $I_{0}$ que pode ser extraída do diodo esférico para uma dada voltagem do anodo.

\subsection{Aplicação do resultado de Langmuir e Blodgett do diodo esférico para o problema do canhão de elétrons com fluxo convergente}

J. R. Pierce [8] interpretou de maneira notável o resultado de Langmuir e Blodgett para o problema do fluxo de elétrons limitado pela carga espacial e foi capaz de utilizá-lo no projeto de canhão eletrônico de fluxo convergente. O problema pode ser ilustrado conforme FIG. 3.2.

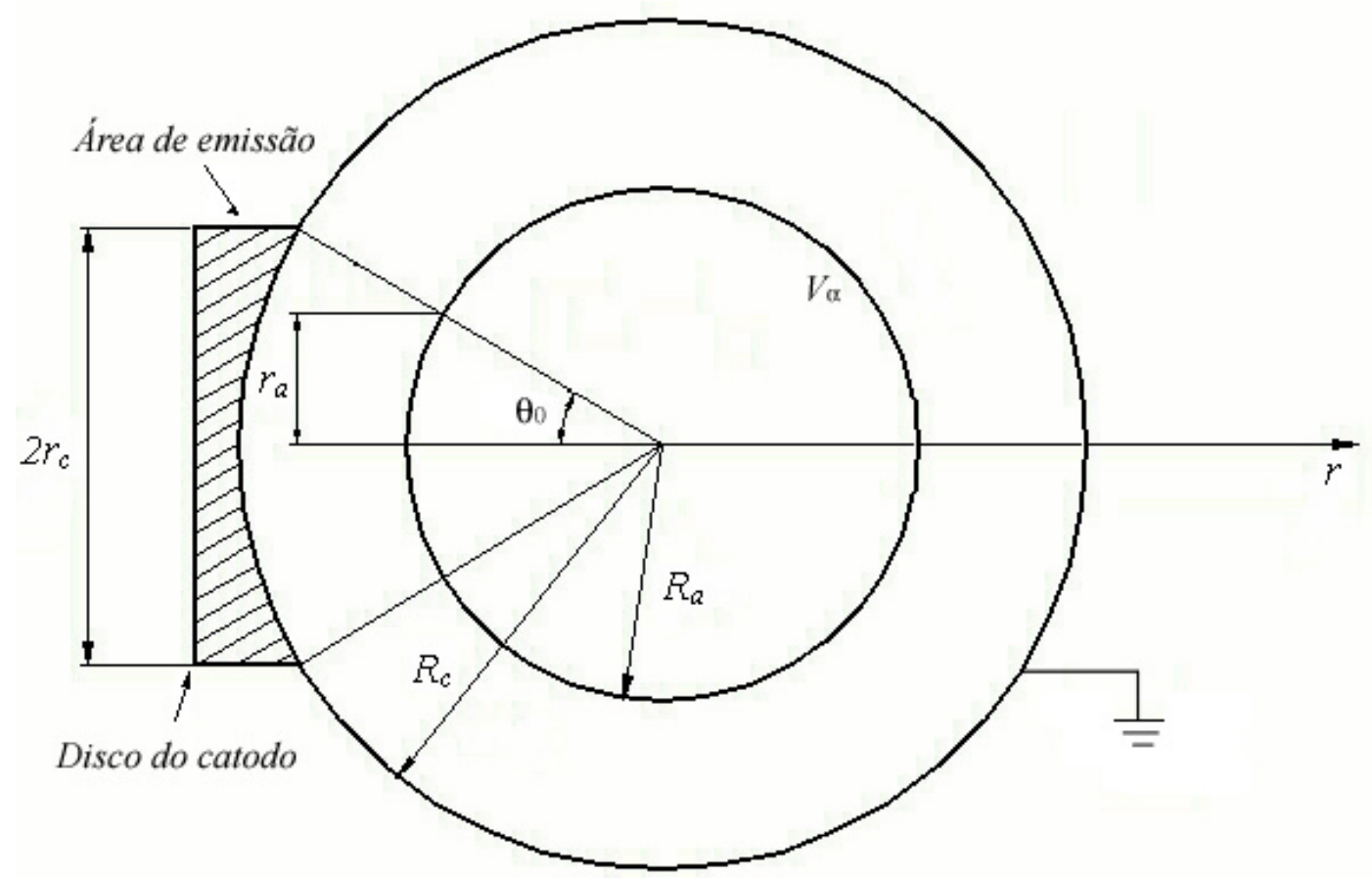

FIGURA 3.2 - Canhão eletrônico esférico. Área de emissão definida pelo cone cujo meio-ângulo é $\theta_{0}$.

O diâmetro do disco do catodo é denotado por $2 r_{c}$ e o orifício do anodo por $2 r_{a}$. $\theta_{0}$ é denominado de meio-ângulo do cone de convergência do canhão. Para se obter a expressão para a perveância em um setor cônico pode-se utilizar o seguinte argumento: se a área emissora de elétrons for da forma de uma calota esférica de raio $R_{c}$, então, a máxima corrente que poderá ser drenada pelo anodo será: 


$$
I_{0}=\left[\frac{4}{9} \frac{4 \pi \varepsilon_{0}(2 \eta)^{1 / 2}}{G_{a}^{2}}\left(\frac{1-\cos \theta_{0}}{2}\right)\right] V_{a}^{3 / 2}
$$

Esta expressão implica que a máxima densidade de corrente que poderá ser extraída da superfície emissora, para uma dada voltagem do anodo $V_{a}$, será:

$$
J=\frac{I_{0}}{\pi r_{c}^{2}},
$$

mesmo que o catodo, para uma dada temperatura de trabalho, seja capaz de fornecer uma densidade de emissão superior. A perveância do canhão eletrônico de Pierce pode ser assim expressa:

$$
\operatorname{Perv}=\frac{4}{9} \frac{4 \pi \varepsilon_{0}(2 \eta)^{1 / 2}}{G_{a}^{2}}\left(\frac{1-\cos \theta_{0}}{2}\right)
$$

\subsection{Síntese do canhão eletrônico de Pierce com fluxo convergente}

Há alguns procedimentos analíticos para a síntese do canhão eletrônico de Pierce com fluxo convergente. Nesta Seção discutir-se-á um deles, no qual consiste em um procedimento não-iterativo desenvolvidos por Tiwary e Basu [9]. A discussão inicia-se com o desenvolvimento teórico do problema. Posteriormente discutem-se os resultados gerados pela metodologia de Tiwary e Basu. Esta metodologia foi empregada como ponto de partida para o projeto do aparato experimental desenvolvido para as medidas termiônicas dos catodos do tipo aluminato em estudo.

O problema central do projeto do canhão eletrônico de Pierce com fluxo convergente é o seguinte: especificados o potencial do anodo $V_{a}$, a corrente de feixe $I_{0}$, a densidade de corrente de operação $J_{o p}$ e a cintura do feixe $r_{w}$ (a ser definida), deseja-se obter os raios de curvatura do catodo e do anodo, $R_{c}$ e $R_{a}$, respectivamente. E, também, deste modo calcular o meio-ângulo do cone $\theta_{0}$, o raio do disco do catodo $r_{c}$, o raio do orifício do anodo $r_{a}$, a distância entre catodo-anodo, $z_{c a}=R_{c}-R_{a}$ e o alcance do feixe $z_{w}$.

\subsection{O problema da cintura do feixe}

Para que o feixe eletrônico produzido no canhão eletrônico de Pierce possa ser utilizado, é necessário que o anodo possua um orifício. Desta forma, os elétrons que forem acelerados em direção ao anodo, passarão por esta abertura e continuarão seus movimentos. Como resultado das forças de carga espacial o feixe eletrônico, que é 
convergente na região entre o catodo e o anodo, começará a divergir na região além do anodo, tendo em vista que a região além do anodo pode ser considerada, por hipótese, livre da ação de campo elétrico externo. Deste modo, o raio da seção transversal do feixe atingirá um valor mínimo a uma certa distância do anodo. Nestas condições, define-se a cintura do feixe $r_{w}$ como sendo este valor mínimo de área da seção transversal. A cintura do feixe $r_{w}$ está localizada a uma distância $z_{w}$, denominada alcance do feixe. A FIG. 3.3 ilustra este problema.

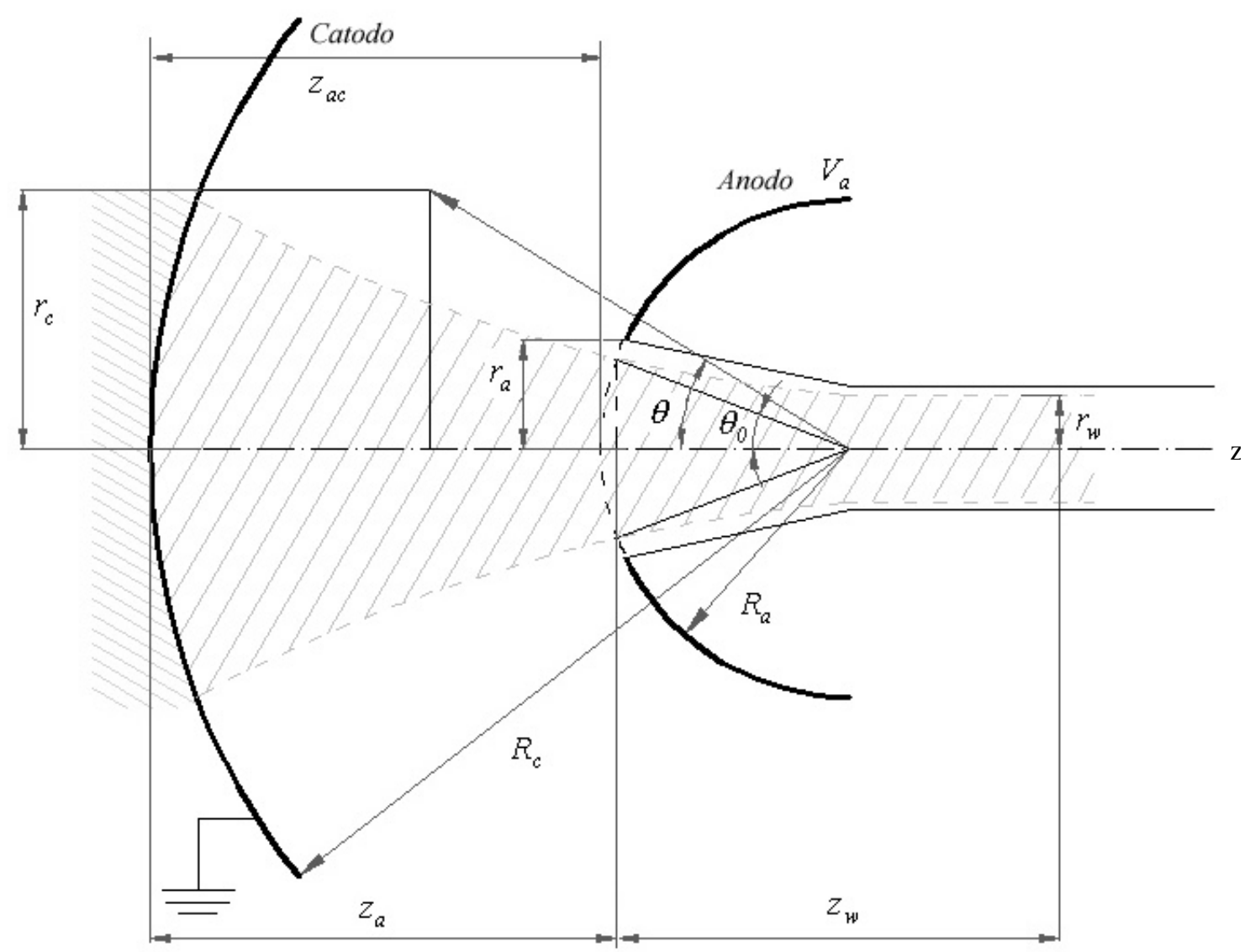

FIGURA 3.3 - Geometria do canhão de Pierce com fluxo convergente.

$\mathrm{O}$ tratamento desenvolvido a seguir para determinar $r_{w}$ e $z_{w}$ baseia-se em um modelo simples unidimensional, o qual considera que a resultante das forças atuantes nos elétrons na extremidade do feixe seja, exclusivamente, devido àcarga espacial do feixe. A equação da trajetória pode ser obtida empregando-se a segunda lei de Newton que, em coordenadas cilíndricas $(\rho, z)$, é escrita como: 


$$
\frac{d^{2} \rho}{d t^{2}}=\eta E_{c e}
$$

onde $E_{c e}$ é o campo devido àcarga espacial, que segundo a lei de Gauss para a eletrostática pode ser escrito como:

$$
E_{c e}=\frac{e n_{e}}{2 \varepsilon_{0}} \rho
$$

Lembrando que $v_{z}=\frac{d z}{d t}$, o lado esquerdo de (3.35) se escreve como:

$$
\frac{d^{2} \rho}{d t^{2}}=v_{z}^{2} \frac{d^{2} \rho}{d z^{2}}
$$

e, portanto, a equação da trajetória torna-se:

$$
v_{z}^{2} \frac{d^{2} \rho}{d z^{2}}=\left(\frac{e n_{e} \eta}{2 \varepsilon_{0}}\right) \rho(z) .
$$

A densidade de corrente de convecção $J_{o p}=e n_{e} v_{z}$, pode ser utilizada para escrever a (3.38) como:

$$
\frac{d^{2} \rho}{d z^{2}}=\left(\frac{\eta J_{o p}}{2 v_{z}^{3} \varepsilon_{0}}\right) \rho(z) .
$$

A velocidade axial do feixe $v_{z}$ se relaciona com o potencial do anodo $V_{a}$ e a densidade de corrente com a corrente $I_{0}$ do feixe segundo as expressões:

$$
\begin{gathered}
v_{z}=\sqrt{2 \eta V_{a}} \\
J_{o p}=\frac{I_{0}}{\pi \rho^{2}}
\end{gathered}
$$

Desta forma (3.38) passa a ser escrita segundo:

$$
\frac{d^{2} \rho}{d z^{2}}=\frac{K^{2}}{2} \frac{1}{\rho},
$$

onde,

$$
K^{2}=\left[\frac{\text { Perv }}{2 \pi \varepsilon_{0}(2 \eta)^{1 / 2}}\right] .
$$


A equação (3.39) pode ser integrada diretamente, multiplicando-se ambos os lados por $2 \frac{d \rho}{d z}$, resultando em:

$$
2 \frac{d \rho}{d z}\left(\frac{d^{2} \rho}{d z^{2}}\right)=K^{2} \frac{1}{\rho} \frac{d \rho}{d z}
$$

ou

$$
\frac{d}{d z}\left(\frac{d \rho}{d z}\right)^{2}=K^{2} \frac{1}{\rho} \frac{d \rho}{d z},
$$

que reduz a:

$$
d\left(\frac{d \rho}{d z}\right)^{2}=K^{2} \frac{d \rho}{\rho} .
$$

Integrando ambos os lados da equação acima se obtêm:

$$
\left(\frac{d \rho}{d z}\right)^{2}=K^{2} \ln \rho-K^{2} \ln A=K^{2} \ln \frac{\rho}{A},
$$

onde $A$ é uma constante de integração, que pode ser determinada sob a hipótese:

$$
\frac{d \rho}{d z}=0 \text { para } \rho=\rho_{0} .
$$

Portanto,

$$
\left(\frac{d \rho}{d z}\right)^{2}=K^{2} \ln \frac{\rho}{\rho_{0}},
$$

$\mathrm{ou}$

$$
\frac{d \rho}{d z}= \pm K \ln ^{1 / 2} \frac{\rho}{\rho_{0}}
$$

Com a determinação da equação da trajetória do feixe eletrônico, pode agora descrever o efeito do orifício do anodo. Se o anodo não apresentasse a abertura $\left(r_{a}\right)$, poderse-ia esperar que o feixe eletrônico radial mantivesse sua natureza convergente na direção do ângulo de meio cone $\theta_{0}$, atingindo o ponto $z=R_{c}$. Contudo, para que se possa utilizar o feixe é necessário que o anodo tenha um orifício. Desse modo, após o feixe passar pelo orifício do anodo, este estará em uma região livre de campo e divergirá em virtude da 
carga espacial conforme discutido. Se $r_{w}$ for denominado de cintura do feixe sob a condição $\frac{d \rho}{d z}=0$, então $\rho_{0}=r_{w}$. Para determinar $z$ para $\rho=r_{w}$, ou seja, o alcance do feixe, pode-se integrar (3.41) com sinal negativo, obtendo-se:

$$
\int_{0}^{-z_{W}} d z=-\frac{1}{K} \int_{r_{w}}^{r_{a}} \frac{d \rho}{\ln \frac{\rho}{r_{w}}}=-\frac{r_{w}}{K} \int_{1}^{r_{a} / r_{w}} \frac{d x}{\ln ^{1 / 2} x}
$$

portanto:

$$
z_{w}=\frac{r_{w}}{K} \int_{1}^{r_{a} / r_{w}} \frac{d x}{\ln ^{1 / 2} x}
$$

A integral pode ser resolvida em série [7], resultando em:

$$
\int_{1}^{r_{a} / r_{w}} \frac{d x}{\ln ^{1 / 2} x}=2\left[\ln ^{1 / 2}\left(\frac{r_{a}}{r_{w}}\right)+\frac{1}{3 \cdot(1 !)} \ln ^{3 / 2}\left(\frac{r_{a}}{r_{w}}\right)+\frac{1}{5 \cdot(2 !)} \ln ^{5 / 2}\left(\frac{r_{a}}{r_{w}}\right)+\frac{1}{7 \cdot(3 !)} \ln ^{7 / 2}\left(\frac{r_{a}}{r_{w}}\right)+\ldots\right],
$$

e, portanto, $z_{w}$ é determinado segundo:

$$
\begin{gathered}
z_{w}=2 \frac{r_{w}}{K}\left[\ln ^{1 / 2}\left(\frac{r_{a}}{r_{w}}\right)+\frac{1}{3 \cdot(1 !)} \ln ^{3 / 2}\left(\frac{r_{a}}{r_{w}}\right)+\frac{1}{5 \cdot(2 !)} \ln ^{5 / 2}\left(\frac{r_{a}}{r_{w}}\right)\right. \\
\left.+\frac{1}{7 \cdot(3 !)} \ln ^{7 / 2}\left(\frac{r_{a}}{r_{w}}\right)+\ldots\right] .
\end{gathered}
$$

Outras relações de relevância são aquelas da razão da abertura do anodo $r_{a}$ e da cintura do feixe $r_{w}$. A inclinação da trajetória $\frac{d \rho}{d z}$ pode ser escrita, com ajuda da FIG. 3.3, como:

$$
\left.\frac{d \rho}{d z}\right|_{z=z_{a}}=-\tan \theta_{0}
$$

onde o sinal negativo indica a natureza convergente do fluxo entre o catodo e o anodo. Utilizando (3.41) pode-se escrever:

$$
\frac{d \rho}{d z}=-K \ln ^{1 / 2} \frac{\rho}{r_{w}} \text { ou }\left.\frac{d \rho}{d z}\right|_{\rho=r_{a}}=-K \ln ^{1 / 2} \frac{r_{a}}{r_{w}}
$$

portanto, 


$$
K \ln ^{1 / 2} \frac{r_{a}}{r_{w}}=\tan \theta_{0}
$$

$\mathrm{ou}$

$$
\frac{r_{a}}{r_{w}}=\exp \left[\frac{\tan ^{2} \theta_{0}}{K^{2}}\right] .
$$

A expressão (3.43) relaciona a abertura do anodo com o raio da cintura do feixe eletrônico, ou seja, tanto o raio da cintura do feixe como o meio-ângulo do cone depende do orifício presente no anodo. Contudo, esta expressão não considerou o efeito da lente produzida pela abertura do anodo. É possível, então, considerar este efeito, utilizando o modelo ilustrado na FIG. 3.4.

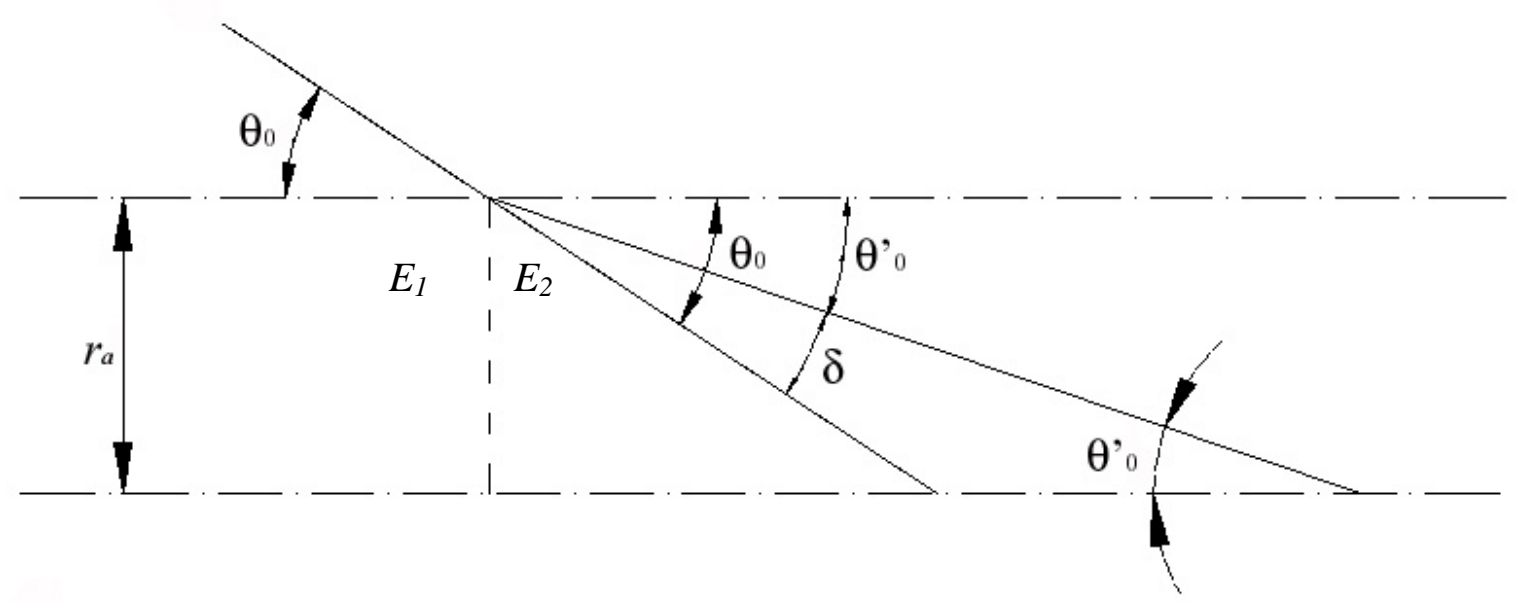

FIGURA 3.4 - Diagrama dos meio-ângulos de cone.

$\operatorname{Seja} \theta_{0}{ }^{\prime}$ o novo meio-ângulo de cone, com ajuda da FIG. 3.4 tem-se $\theta_{0}^{\prime}=\theta_{0}-\delta$. Novamente pode-se escrever:

$$
\frac{r_{a}}{r_{w}}=\exp \left[\frac{\tan ^{2} \theta_{0}^{\prime}}{K^{2}}\right] .
$$

No desenvolvimento que segue, tem-se o objetivo de obter a relação entre $\theta_{0}$ e $\theta_{0}^{\prime}$. O efeito do orifício do anodo pode ser descrito considerando o problema de uma lente eletrostática. Uma segunda distância focal $f_{\mathrm{z}}$ seria produzida sendo esta dada por: 


$$
f_{z}=\frac{4 V_{a}}{E_{1}-E_{2}}
$$

onde $E_{1}$ e $E_{2}$ são as intensidades do campo elétrico ao longo do eixo do canhão nas vizinhanças da abertura do canhão nas regiões à esquerda e à direita do anodo, respectivamente. Observe que $E_{l}$ é negativo em virtude do potencial positivo do anodo em relação ao catodo e $E_{2}=0$, tendo em vista que o feixe emerge em uma região livre de campo (localizado no interior do anodo). Desse modo, a lente eletrostática de distância focal $f_{2}$ terá uma ação divergente, cujo ângulo de refração será denotado por $\theta_{0}^{\prime}$, conforme FIG. 3.4:

$$
\theta=\theta_{0}^{\prime}+\delta
$$

Considerando que o desvio $\delta$ seja pequeno, ele pode ser escrito como:

$$
\delta=\frac{r_{a}}{\left|f_{2}\right|}
$$

Mas segundo (3.45) na condição de $E_{2}=0$ tem-se:

$$
f_{2}=\frac{4 V_{a}}{E_{1}} \text {. }
$$

Por outro lado sabe-se que:

$$
E_{1}=-\frac{d V_{z}(z)}{d z}
$$

Observe que nas regiões entre catodo-anodo, devido à simetria do problema, foram utilizadas coordenadas esféricas, mas após o orifício do anodo o feixe apresenta simetria cilíndrica. Então se pode escrever que:

$$
\left.\frac{d V_{z}(z)}{d z}\right|_{z=z_{a}}=\left.\frac{d V(r)}{d r}\right|_{z=z_{a}} .
$$

Desta forma, pode-se obter uma expressão para $E_{l}$, utilizando a expressão (3.27). Para tal escreve-se:

$$
V(r)=\frac{G(r)^{4 / 3}}{G_{a}^{4 / 3}} V_{a},
$$

e, derivando-se, obtém-se: 


$$
\frac{d V}{d r}=\frac{4}{3} \frac{V_{a}}{G_{a}^{4 / 3}} G^{1 / 3}(r) \frac{d G(r)}{d r} .
$$

Mas:

$$
\frac{d G^{2}}{d r}=2 G \frac{d G}{d r},
$$

então,

$$
\frac{d G^{2}}{d r}=\frac{d G^{2}}{d\left(\frac{R_{c}}{r}\right)} \frac{d\left(\frac{R_{c}}{r}\right)}{d r}=-\frac{d G^{2}}{d\left(\frac{R_{c}}{r}\right)} \frac{R_{c}}{r^{2}} .
$$

Portanto, para $r=R_{a}$, tem-se:

$$
\left.\frac{d V}{d r}\right|_{r=r_{a}}=-\left.\frac{2}{3} \frac{V_{0}}{G_{a}^{2}} \frac{R_{c}}{R_{a}^{2}}\left[\frac{d G^{2}}{d\left(\frac{R_{c}}{r}\right)}\right]\right|_{r=R_{a}} .
$$

Substituindo este resultado em (3.48), obtém-se:

$$
f_{2}=-\frac{6 G_{a}^{2}}{\frac{R_{c}}{R_{a}^{2}}\left[\frac{d G^{2}}{\left.d\left(\frac{R_{c}}{r}\right)\right] \mid}\right.} .
$$

Substituindo (3.47) em (3.46):

$$
\theta_{0}^{\prime}=\theta_{0}-\delta=\theta_{0}-\frac{r_{a}}{\left|f_{2}\right|}=\theta_{0}\left[1-\frac{r_{a}}{\left|f_{2}\right| \theta_{0}}\right],
$$

chega-se finalmente a:

$$
\theta_{0}^{\prime}=\theta_{0}\left\{1-\frac{1}{6}\left(\frac{R_{c}}{R_{a}}\right) \frac{1}{G_{a}^{2}}\left[\frac{d G^{2}\left(\frac{R_{c}}{r}\right)}{d\left(\frac{R_{c}}{r}\right)}||_{r=R_{a}}\right\},\right.
$$


onde a expressão para $G\left[\ln \left(\frac{R_{c}}{r}\right)\right]$ é obtida de (3.25).

Considerando o catodo como uma casca esférica com setor cônico com ângulo $2 \theta_{0}$, obtém-se:

$$
K^{2}=\frac{4}{9} \frac{1-\cos \theta}{G_{a}^{2}}
$$

Para se obter uma expressão para a relação $\frac{r_{c}}{r_{w}}$, pode-se proceder como segue. Por semelhança de triângulo:

$$
\frac{r_{c}}{R_{c}}=\frac{r_{a}}{R_{a}}
$$

Desta forma:

$$
\frac{r_{c}}{r_{w}}=\frac{R_{c}}{R_{a}} \frac{r_{a}}{r_{w}}
$$

Sob a hipótese de $\theta_{0}$ e $\theta_{0}^{\prime}$ próximos a zeros:

$$
\begin{gathered}
\tan \theta_{0}^{\prime} \approx \theta_{0}^{\prime}, \\
\cos \theta \approx 1-\frac{\theta_{0}^{2}}{2} .
\end{gathered}
$$

A expressão (3.53), sob esta mesma condição pode ser escrita como:

$$
\frac{r_{c}}{r_{w}}=\frac{R_{c}}{R_{a}} \exp \left(\frac{\tan ^{2} \theta_{0}^{\prime}}{K^{2}}\right) \approx \frac{R_{c}}{R_{a}} \exp \left(\frac{\theta_{0}^{\prime 2}}{K^{2}}\right) .
$$

Substituindo (3.51) obtém-se:

$$
\frac{r_{c}}{r_{w}}=\frac{R_{c}}{R_{a}} \exp \left\{\frac{\theta_{0}^{2}}{K^{2}}\left[1-\left.\frac{1}{6}\left(\frac{R_{c}}{R_{a}}\right) \frac{1}{G_{a}^{2}} \frac{d G^{2}\left(\frac{R_{c}}{r}\right)}{d\left(\frac{R_{c}}{r}\right)}\right|_{r=R_{a}}\right]^{2}\right\} .
$$

Esta expressão relaciona os raios do catodo e do anodo com o raio do disco do catodo $r_{c}$ e a cintura do feixe $r_{w}$. A expressão (3.52) sob a condição dos ângulos próximos de zeros:

$$
\frac{\theta_{0}^{2}}{K^{2}}=\frac{9}{2} G_{a}^{2}
$$


Considerando a (3.54), desenvolve-se primeiramente a expressão interna que está elevada ao quadrado. A sua derivada segunda,

$$
\left.\frac{d G^{2}\left(\frac{R_{c}}{r}\right)}{d\left(\frac{R_{c}}{r}\right)}\right|_{r=R_{a}}=\left.2 G_{a} \frac{d G}{d\left(\frac{R_{c}}{r}\right)}\right|_{r=R_{a}} .
$$

Considerando-se (3.25), o cálculo da derivada pode ser realizado como segue:

$$
\begin{aligned}
& G\left(\frac{R_{c}}{r}\right)=\ln \left(\frac{R_{c}}{r}\right)+\frac{3}{10} \ln ^{2}\left(\frac{R_{c}}{r}\right)+\frac{3}{40} \ln ^{3}\left(\frac{R_{c}}{r}\right)+\frac{63}{4400} \ln ^{4}\left(\frac{R_{c}}{r}\right)+\frac{13311}{6160000} \ln ^{5}\left(\frac{R_{c}}{r}\right)+ \\
& +\frac{280557}{1047200000} \ln ^{6}\left(\frac{R_{c}}{r}\right)+\ldots \\
& \left.\frac{d G}{d\left(\frac{R_{c}}{r}\right)}\right|_{r=R_{a}}=\left[1+\frac{3}{5} \ln \left(\frac{R_{c}}{R_{a}}\right)+\frac{9}{40} \ln ^{2}\left(\frac{R_{c}}{R_{a}}\right)+\frac{63}{1100} \ln ^{3}\left(\frac{R_{c}}{R_{a}}\right)+\frac{13311}{1232000} \ln ^{4}\left(\frac{R_{c}}{R_{a}}\right)+\right. \\
& \left.\frac{841671}{523600000} \ln ^{5}\left(\frac{R_{c}}{R_{a}}\right)+\ldots\right] \frac{R_{a}}{R_{c}}
\end{aligned}
$$

Por outro lado, resumindo (3.54), tem-se:

$$
\frac{r_{c}}{r_{w}}=\frac{R_{c}}{R_{a}} \exp \left\{\frac{9}{2} G_{a}^{2}\left[1-\frac{1}{6}\left(\frac{R_{c}}{R_{a}}\right) \frac{2}{G_{a}} C\left(\frac{R_{a}}{R_{c}}\right)\right]^{2}\right\},
$$

onde, a constante $C$ é dada por:

$$
\begin{aligned}
C=\left[1+\frac{3}{5} \ln \left(\frac{R_{c}}{R_{a}}\right)+\right. & \frac{9}{40} \ln ^{2}\left(\frac{R_{c}}{R_{a}}\right)+\frac{63}{1100} \ln ^{3}\left(\frac{R_{c}}{R_{a}}\right)+\frac{13311}{1232000} \ln ^{4}\left(\frac{R_{c}}{R_{a}}\right), \\
& \left.+\frac{841671}{523600000} \ln ^{5}\left(\frac{R_{c}}{R_{a}}\right)+\ldots\right]
\end{aligned}
$$

simplificando:

$$
\frac{r_{c}}{r_{w}}=\frac{R_{c}}{R_{a}} \exp \left[\frac{1}{2}\left(3 G_{a}-C\right)^{2}\right],
$$

sabe-se que: 


$$
G_{a}=\ln \left(\frac{R_{c}}{R_{a}}\right)+\frac{3}{10} \ln ^{2}\left(\frac{R_{c}}{R_{a}}\right)+\frac{3}{40} \ln ^{3}\left(\frac{R_{c}}{R_{a}}\right)+\frac{63}{4400} \ln ^{4}\left(\frac{R_{c}}{R_{a}}\right)+\frac{13311}{6160000} \ln ^{5}\left(\frac{R_{c}}{r}\right)+\ldots
$$

então:

$$
3 G_{a}=3 \ln \left(\frac{R_{c}}{R_{a}}\right)+\frac{9}{10} \ln ^{2}\left(\frac{R_{c}}{R_{a}}\right)+\frac{9}{40} \ln ^{3}\left(\frac{R_{c}}{R_{a}}\right)+\frac{189}{4400} \ln ^{4}\left(\frac{R_{c}}{R_{a}}\right)+\frac{39933}{6160000} \ln ^{5}\left(\frac{R_{c}}{r}\right)+\ldots
$$

A subtração das duas séries resulta em:

$$
\begin{aligned}
& 3 G_{a}-C= {\left[3 \ln \left(\frac{R_{c}}{R_{a}}\right)+\frac{9}{10} \ln ^{2}\left(\frac{R_{c}}{R_{a}}\right)+\frac{9}{40} \ln ^{3}\left(\frac{R_{c}}{R_{a}}\right)+\frac{189}{4400} \ln ^{4}\left(\frac{R_{c}}{R_{a}}\right)+\frac{39933}{6160000} \ln ^{5}\left(\frac{R_{c}}{r}\right)+\ldots\right]-} \\
& {\left[1+\frac{3}{5} \ln \left(\frac{R_{c}}{R_{a}}\right)+\frac{9}{40} \ln ^{2}\left(\frac{R_{c}}{R_{a}}\right)+\frac{63}{1100} \ln ^{3}\left(\frac{R_{c}}{R_{a}}\right)+\frac{13311}{1232000} \ln ^{4}\left(\frac{R_{c}}{R_{a}}\right)+\frac{841671}{523600000} \ln ^{5}\left(\frac{R_{c}}{R_{a}}\right)+\ldots\right] } \\
&=-1+\frac{12}{5} \ln \left(\frac{R_{c}}{R_{a}}\right)+\frac{27}{40} \ln ^{2}\left(\frac{R_{c}}{R_{a}}\right)+\frac{369}{2200} \ln ^{3}\left(\frac{R_{c}}{R_{a}}\right)+\frac{39609}{1232000} \ln ^{4}\left(\frac{R_{c}}{R_{a}}\right) . \\
&+\frac{2552634}{523600000} \ln ^{5}\left(\frac{R_{c}}{R_{a}}\right)+\ldots
\end{aligned}
$$

Substituindo em $\frac{r_{c}}{r_{w}}$, tem-se:

$$
\begin{gathered}
\frac{r_{c}}{r_{w}}=\frac{R_{c}}{R_{a}} \exp \left\{\frac { 1 } { 2 } \left[-1+\frac{12}{5} \ln \left(\frac{R_{c}}{R_{a}}\right)+\frac{27}{40} \ln ^{2}\left(\frac{R_{c}}{R_{a}}\right)+\frac{369}{2200} \ln ^{3}\left(\frac{R_{c}}{R_{a}}\right)+\frac{39609}{1232000} \ln ^{4}\left(\frac{R_{c}}{R_{a}}\right)+\right.\right. \\
\left.\left.+\frac{2552634}{523600000} \ln ^{5}\left(\frac{R_{c}}{R_{a}}\right)+\ldots\right]^{2}\right\}
\end{gathered}
$$

ainda, efetuando o quadrado da série, obtém-se:

$$
\begin{gathered}
\frac{r_{c}}{r_{w}}=\frac{R_{c}}{R_{a}} \exp \left\{\frac { 1 } { 2 } \left[1-\frac{24}{5} \ln \left(\frac{R_{c}}{R_{a}}\right)+\frac{441}{100} \ln ^{2}\left(\frac{R_{c}}{R_{a}}\right)+\frac{639}{220} \ln ^{3}\left(\frac{R_{c}}{R_{a}}\right)+\frac{23031}{19250} \ln ^{4}\left(\frac{R_{c}}{R_{a}}\right)+\right.\right. \\
\left.\left.+\frac{97128396}{261800000} \ln ^{5}\left(\frac{R_{c}}{R_{a}}\right)+\ldots\right]\right\}
\end{gathered}
$$

Simplificando, obtém-se finalmente uma expressão para $\frac{r_{c}}{r_{w}}$ : 


$$
\begin{gathered}
\frac{r_{c}}{r_{w}}=\frac{R_{c}}{R_{a}} \exp \left[\frac{1}{2}-\frac{12}{5} \ln \left(\frac{R_{c}}{R_{a}}\right)+\frac{441}{200} \ln ^{2}\left(\frac{R_{c}}{R_{a}}\right)+\frac{639}{440} \ln ^{3}\left(\frac{R_{c}}{R_{a}}\right)+\frac{23031}{38500} \ln ^{4}\left(\frac{R_{c}}{R_{a}}\right)+\right. \\
\left.+\frac{48564198}{261800000} \ln ^{5}\left(\frac{R_{c}}{R_{a}}\right)+\ldots\right]
\end{gathered}
$$

A série infinita (3.56) pode ser invertida para determinar uma expressão para $\frac{R_{c}}{R_{a}}$ em função de $\frac{r_{c}}{r_{w}}$, chegando-se a:

$$
\begin{aligned}
& \ln \left(\frac{r_{c}}{r_{w}}\right)=\ln \left(\frac{R_{c}}{R_{a}}\right)+\frac{1}{2}-\frac{12}{5} \ln \left(\frac{R_{c}}{R_{a}}\right)+\frac{441}{200} \ln ^{2}\left(\frac{R_{c}}{R_{a}}\right)+\frac{639}{440} \ln ^{3}\left(\frac{R_{c}}{R_{a}}\right)+\frac{23031}{38500} \ln ^{4}\left(\frac{R_{c}}{R_{a}}\right)+ \\
&+\frac{48564198}{261800000} \ln ^{5}\left(\frac{R_{c}}{R_{a}}\right)+\ldots \\
& \ln \left(\frac{r_{c}}{r_{w}}\right)=\frac{1}{2}-\frac{7}{5} \ln \left(\frac{R_{c}}{R_{a}}\right)+ \frac{441}{200} \ln ^{2}\left(\frac{R_{c}}{R_{a}}\right)+\frac{639}{440} \ln ^{3}\left(\frac{R_{c}}{R_{a}}\right)+\frac{23031}{38500} \ln ^{4}\left(\frac{R_{c}}{R_{a}}\right)+ \\
&+\frac{48564198}{261800000} \ln ^{5}\left(\frac{R_{c}}{R_{a}}\right)+\ldots
\end{aligned}
$$

que pode expressa da seguinte forma:

$$
y=a_{0}+a_{1} \gamma+a_{2} \gamma^{2}+a_{3} \gamma^{3}+a_{4} \gamma^{4}+\ldots
$$

sendo $y=\ln \left(\frac{r_{c}}{r_{w}}\right), \gamma=\ln \left(\frac{R_{c}}{R_{a}}\right)$ e $a_{n}$ : os coeficientes da série. Então:

$$
y=\frac{1}{2}-\frac{7}{5} \gamma+\frac{441}{200} \gamma^{2}+\frac{639}{440} \gamma^{3}+\frac{23031}{38500} \gamma^{4}+\frac{24282099}{130900000} \gamma^{5}+\ldots
$$

A inversão desta série pode ser realizada da seguinte forma:

$$
\gamma=b_{0}+b_{1} y+b_{2} y^{2}+b_{3} y^{3}+b_{4} y^{4}+\ldots
$$

Considerando os seguintes valores de $\frac{R_{c}}{R_{a}}$ [7]: 1,41; 1,76; 1,91; 2,10;2,41 e 2,60, resolvese o sistema linear determinado os coeficientes $b_{0}, b_{1}, b_{2}, b_{3}, b_{4}$ e $b_{5}$. Para $\gamma_{0}=-\gamma=\ln \left(\frac{R_{a}}{R_{c}}\right)$ 


$$
\begin{aligned}
\gamma_{0}=0,099493 & -1,820707 \ln \left(\frac{r_{c}}{r_{w}}\right)+1,925535 \ln ^{2}\left(\frac{r_{c}}{r_{w}}\right)-1,133440 \ln ^{3}\left(\frac{r_{c}}{r_{w}}\right) \\
& +0,326941 \ln ^{4}\left(\frac{r_{c}}{r_{w}}\right)-0,036137 \ln ^{5}\left(\frac{r_{c}}{r_{w}}\right)
\end{aligned}
$$

A convergência da expressão acima é satisfatória, menor que $7 \%$, para a razão de convergência entre $2<\frac{r_{c}}{r_{w}}<10$, como pode ser observado na FIG. 3.5 .

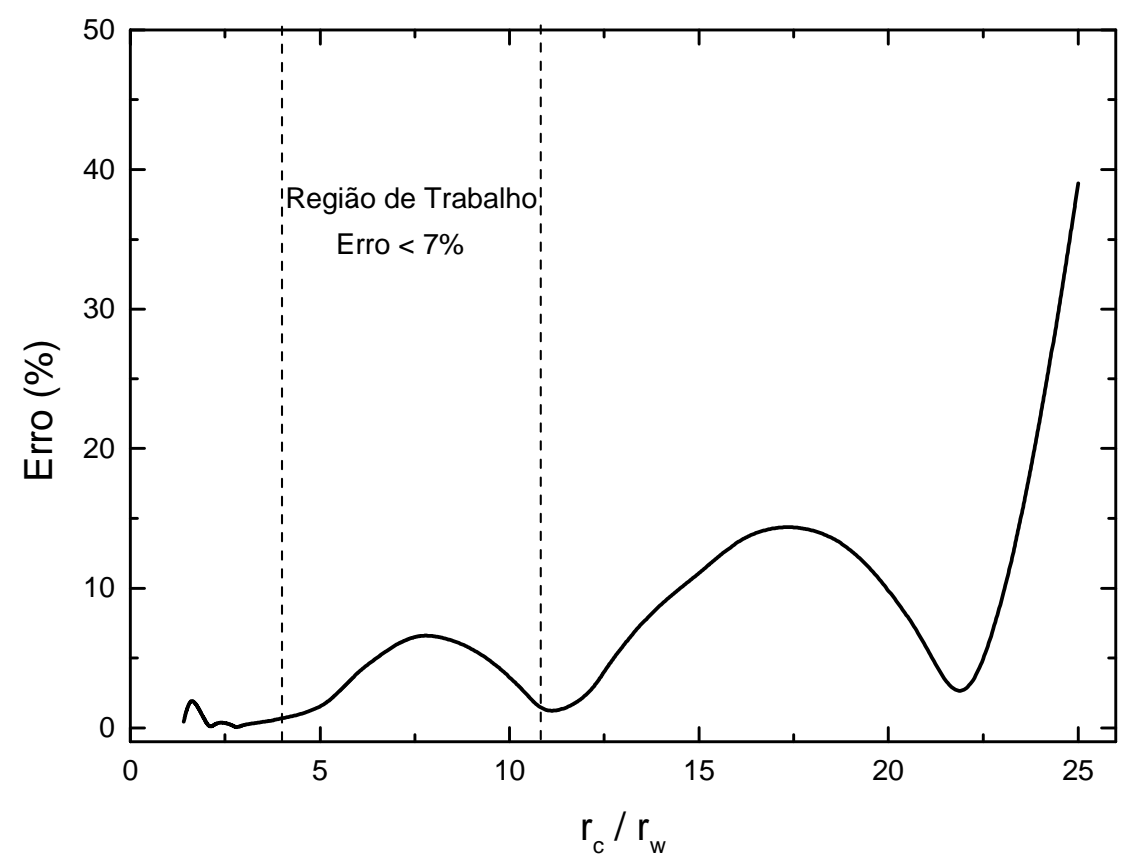

FIGURA 3.5 - Erro relativo à convergência da série.

Por meio da FIG. 3.5, verifica-se que quando a razão $\frac{r_{c}}{r_{w}}$ está entre 2 e 10 (valores empregados na prática como pode ser verificado posteriormente, Seção 3.6), o desvio é pouco significativo quando se consideram os erros decorrentes das medidas termiônicas. 


\subsection{Fluxograma para síntese do canhão eletrônico de Pierce com fluxo convergente}

Na FIG. 3.6 é apresentado um procedimento para a síntese do canhão eletrônico de Pierce fundamentado na teoria de Langmuir-Blodgett (limitação da corrente pela carga espacial) e nas metodologias analíticas adotadas por Basu.

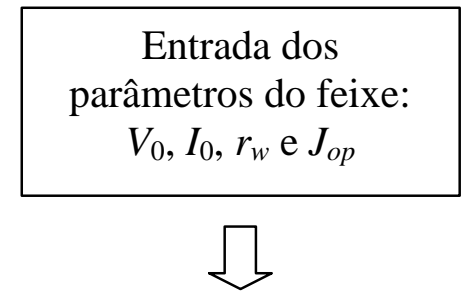

Determinação dos parâmetros geométricos do canhão de Pierce

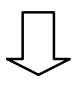

1. Raio do disco do catodo, $r_{c}$

$$
r_{c}=\left(\frac{I_{0}}{\pi J_{o p}}\right)^{1 / 2}
$$

2. Razão de convergência, $\frac{r_{c}}{r_{w}}$

3. Razão entre o raio do catodo e do anodo, $\ln \frac{R_{c}}{R_{a}}$ $\ln \frac{R_{c}}{R_{a}}=-0,099493+1,820707 \ln \left(\frac{r_{c}}{r_{w}}\right)-1,925535 \ln ^{2}\left(\frac{r_{c}}{r_{w}}\right)+\ldots$

4. Seno do meio-ângulo do cone de convergência, $\operatorname{sen} \theta$

$$
\begin{gathered}
G_{a}=\ln \left(\frac{R_{c}}{R_{a}}\right)+\frac{3}{10} \ln ^{2}\left(\frac{R_{c}}{R_{a}}\right)+\frac{3}{40} \ln ^{3}\left(\frac{R_{c}}{R_{a}}\right)+\frac{63}{4400} \ln ^{4}\left(\frac{R_{c}}{R_{a}}\right)+\ldots \\
\text { Perv }=\frac{I_{0}}{\left(V_{0}\right)^{3 / 2}} \\
K^{2}=\left[\frac{\text { Perv }}{2 \pi \varepsilon_{0}(2 \eta)^{1 / 2}}\right] \\
\cos \theta=1-\frac{9}{4}\left(K G_{a}\right)^{2}
\end{gathered}
$$

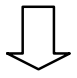




$$
\operatorname{sen} \theta=\sqrt{1-\cos ^{2} \theta}
$$

5. Raio do catodo, $R_{c}$

$$
R_{c}=\frac{r_{c}}{\operatorname{sen} \theta}
$$

6. Raio do anodo, $R_{a}$

$$
R_{a}=R_{c} \exp \left(\ln \frac{R_{c}}{R_{a}}\right)
$$

7. Raio do disco do anodo, $r_{a}$

$$
r_{a}=R_{a}(\operatorname{sen} \theta) \quad \text { (observar FIG. 3.2) }
$$

8. Espaçamento catodo-anodo, $z_{c a}$

$$
z_{c a}=R_{c}-R_{a}
$$

9. Alcance do feixe, $z_{w}$

$$
z_{w}=2 \frac{r_{w}}{K}\left[\ln ^{1 / 2}\left(\frac{r_{a}}{r_{w}}\right)+\frac{1}{3 \cdot(1 !)} \ln ^{3 / 2}\left(\frac{r_{a}}{r_{w}}\right)+\frac{1}{5 \cdot(2 !)} \ln ^{5 / 2}\left(\frac{r_{a}}{r_{w}}\right)+\ldots\right]
$$

10. Meio-ângulo do cone, $\theta$

$$
\theta=\operatorname{arcsen} \theta
$$

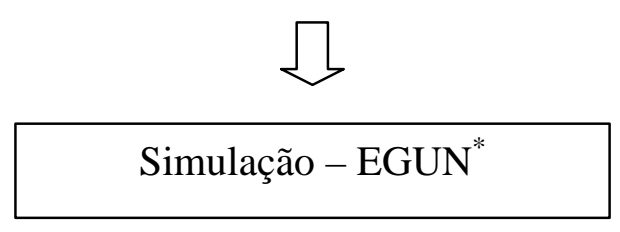

FIGURA 3.6 - Metodologia de síntese do canhão eletrônico.

Observa-se na FIG. 3.6 que o projeto de um canhão eletrônico do tipo Pierce é dividido em duas etapas: a) síntese da geometria do canhão eletrônico, considerando primeiramente os seguintes parâmetros de entrada: $V_{0}, I_{0}, r_{w}$ e $J_{o p}$, e a determinação dos parâmetros geométricos do catodo $\left(r_{c}, R_{c}, r_{a}, R_{a}, z_{w}\right.$, e aqueles que estão ilustrados na FIG.3.6) e b) simulação do canhão eletrônico.

\footnotetext{
${ }^{*}$ Herrmannsfeldt, W. B. EGUN - An electron optics and gun design program. Stanford, California: SLAC Pubs and Reports, 1988.
} 


\subsection{Aplicação da metodologia de síntese do canhão eletrônico para determinação da perveância do sistema}

Por meio de dados fornecidos pela literatura [9], aplicou-se a metodologia empregada por Basu na determinação da perveância do canhão eletrônico de Pierce. A TAB. 3.1 apresenta os parâmetros de entrada de diferentes canhões convergentes. Para os dados fornecidos utilizou-se a metodologia de síntese do canhão para a obtenção da geometria do canhão e de suas características (como perveância, meio-ângulo do cone e razão de convergência), as quais estão apresentadas na TAB. 3.2, para posterior comparação destes dados com aqueles provenientes do canhão projetado no presente trabalho, TAB. 3.3.

TABELA 3.1 - Parâmetros de entrada de diferentes canhões eletrônicos [9].

\begin{tabular}{cccc}
\hline & Litton L-2087 & $\begin{array}{c}\text { Varian VTC } \\
6364\end{array}$ & Fros and Purl \\
& & 9,5 & 1,0 \\
\hline$V_{0}(\mathrm{kV})$ & 10,0 & 0,373 & 0,038 \\
$I_{0}(\mathrm{~A})$ & 0,550 & 0,08382 & 0,0760 \\
$r_{w}(\mathrm{~cm})$ & 0,09398 & 1,593 & 0,0188 \\
$J_{o p}\left(\mathrm{~A} \mathrm{~cm}^{-2}\right)$ & 1,737 & & \\
\hline
\end{tabular}


TABELA 3.2 - Parâmetros intermediários e de saída dos diferentes canhões eletrônicos.

\begin{tabular}{|c|c|c|c|c|c|c|}
\hline & \multicolumn{2}{|c|}{ Litton L-2087 } & \multicolumn{2}{|c|}{ Varian VTC 6364} & \multicolumn{2}{|c|}{ Fros and Purl } \\
\hline & $\begin{array}{c}\text { Método } \\
\text { desenvolvido }\end{array}$ & $\begin{array}{l}\text { Método de } \\
\text { Basu }\end{array}$ & $\begin{array}{c}\text { Método } \\
\text { desenvolvido }\end{array}$ & $\begin{array}{l}\text { Método de } \\
\text { Basu }\end{array}$ & $\begin{array}{c}\text { Método } \\
\text { desenvolvido }\end{array}$ & $\begin{array}{c}\text { Método de } \\
\text { Basu }\end{array}$ \\
\hline Perveância ( $\mu$ Perv) & 0,55 & 0,55 & 0,4028 & 0,4028 & 1,2017 & 1,2017 \\
\hline Convergência do feixe $\left(\frac{r_{c}}{r_{w}}\right)$ & 3,378 & 3,378 & 3,257 & 3,257 & 10,554 & 10,554 \\
\hline Razão $\frac{R_{c}}{R_{a}}$ & 1,987 & 1,985 & 1,972 & 2,389 & 2,3977 & 2,3930 \\
\hline Raio do disco do catodo, $r_{c}(\mathrm{~mm})$ & 3,175 & 3,175 & 2,730 & 2,730 & 8,021 & 8,021 \\
\hline Raio do disco do anodo, $r_{a}(\mathrm{~mm})$ & 1,5975 & 1,6000 & 1,3844 & 1,143 & 3,345 & 3,352 \\
\hline Raio do anodo, $R_{a}(\mathrm{~mm})$ & 6,861 & 6,884 & 7,031 & 4,253 & 7,307 & 7,341 \\
\hline Raio do catodo, $R_{c}(\mathrm{~mm})$ & 13,635 & 13,665 & 13,865 & 10,158 & 17,521 & 17,567 \\
\hline Distância catodo-anodo, $z_{c a}(\mathrm{~mm})$ & 6,774 & 6,780 & 6,8341 & 5,906 & 10,214 & 10,226 \\
\hline Alcance do feixe, $z_{w}(\mathrm{~mm})$ & 12,820 & 12,846 & 12,85 & 9,407 & 17,586 & 17,612 \\
\hline Meio-ângulo do cone, $\theta\left(^{\circ}\right)$ & 13,46 & 13,44 & 11,36 & 15,59 & 27,25 & 27,17 \\
\hline
\end{tabular}

Por meio dos resultados apresentados na TAB. 3.2, verifica-se que os valores obtidos pelo método desenvolvido no presente trabalho (baseado nos fundamentos apresentados por Basu) estão próximos aos resultados apresentados na literatura [9]. Entretanto, para o canhão da Varian VTC 6364, houve uma variação significativa nos parâmetros dependentes do raio do catodo, como pode ser observado na TAB. 3.2. Mesmo com a variação apresentada nestes resultados, se valida o procedimento empregado para a obtenção dos parâmetros geométricos dos canhões eletrônicos do tipo Pierce. 
A TAB. 3.3 apresenta os parâmetros de entrada do procedimento de síntese do canhão eletrônico. Deseja-se verificar a variação dos parâmetros intermediários e de saída devido à corrente aplicada e/ou do raio da cintura do feixe, fixando-se o potencial $V_{0}$. A TAB. 3.4 mostra os resultados obtidos pelo procedimento de síntese do canhão eletrônico desenvolvido no presente trabalho. As discussões dos resultados da síntese dos canhões eletrônicos estão apresentadas na FIG. 3.7. Para este exemplo, considera-se duas situações, onde a diferença entre estas seja o raio da cintura do feixe, a primeira é igual a $0,09 \mathrm{~cm}$ e a segunda $0,18 \mathrm{~cm}$.

\section{Situação 1 e 2:}

1) Tensão de aceleração:

$V_{0}=$ constante

Variação da corrente do feixe, $I_{0}$ (aumento).

2) Não há variação no raio da cintura do feixe (manter a convergência do feixe eletrônico).
1) Resulta em um aumento da perveância do canhão eletrônico

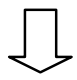

2) Variação na geometria do canhão eletrônico (redução do $R_{c}$ e do $R_{a}$ de forma que $R_{d} / R_{a}=$ constante).

Afirma-se:

- Há uma relação entre o raio da cintura do feixe eletrônico e a geometria do canhão (raio do catodo e raio do anodo). Esta relação mostra que para manter o valor de $r_{w}$ constante é necessário que a razão entre os raios do catodo e do anodo também seja a mesma (ou seja, deve se manter a convergência do feixe eletrônico).

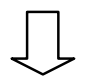

Resultando em:

- Uma redução da distância catodo-anodo $\left(z_{c a}\right)$ e do alcance do feixe eletrônico $\left(z_{w}\right)$; e

- Um aumento no meio-ângulo de cone.

\section{Comparação das duas situações:}

1) Aumento do raio da cintura do feixe.

2) Perveância constante para diferentes canhões.
1) Resulta em uma redução da convergência do feixe eletrônico

2) Alteração na geometria do canhão eletrônico - redução da razão $R_{\mathrm{c}} / R_{\mathrm{a}}$ (houve um aumento em seus raios).

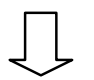

Resultando em:

- Um aumento na distância catodo-anodo $\left(z_{c a}\right)$ e no alcance do feixe eletrônico $\left(z_{w}\right)$; e

- Uma redução do meio-ângulo de cone.

FIGURA 3.7 - Efeito da geometria do canhão nas características do feixe eletrônico. 
TABELA 3.3 - Parâmetros de entrada do canhão projetado.

\begin{tabular}{|c|c|c|c|c|c|c|c|c|c|c|c|c|}
\hline & \multicolumn{6}{|c|}{ (a) } & \multicolumn{6}{|c|}{ (b) } \\
\hline & Canhão & Canhão & Canhão & Canhão & Canhão & Canhão & Canhão & Canhão & Canhão & Canhão & Canhão & Canhão \\
\hline & $\# 1$ & $\# 2$ & \#3 & \#4 & $\# 5$ & \#6 & $\# 7$ & \#8 & \#9 & \#10 & \#11 & $\# 12$ \\
\hline$V_{0}(\mathrm{kV})$ & 30 & 30 & 30 & 30 & 30 & 30 & 30 & 30 & 30 & 30 & 30 & 30 \\
\hline$I_{0}(\mathrm{~A})$ & 3,0 & 3,2 & 3,4 & 3,6 & 3,8 & 4,0 & 3,0 & 3,2 & 3,4 & 3,6 & 3,8 & 4,0 \\
\hline$r_{w}(\mathrm{~cm})$ & 0,09 & 0,09 & 0,09 & 0,09 & 0,09 & 0,09 & 0,18 & 0,18 & 0,18 & 0,18 & 0,18 & 0,18 \\
\hline$J_{o p}\left(\mathrm{~A} \mathrm{~cm}^{-2}\right)$ & 2,5289 & 2,6975 & 2,8661 & 3,0347 & 3,2032 & 3,3718 & 2,5289 & 2,6975 & 2,8661 & 3,0347 & 3,2032 & 3,3718 \\
\hline
\end{tabular}

TABELA 3.4 - Parâmetros intermediário e de saída do canhão investigado.

\begin{tabular}{|c|c|c|c|c|c|c|c|c|c|c|c|c|}
\hline & \multicolumn{6}{|c|}{ (a) } & \multicolumn{6}{|c|}{ (b) } \\
\hline & Canhão & Canhão & Canhão & Canhão & Canhão & Canhão & Canhão & Canhão & Canhão & Canhão & Canhão & Canhão \\
\hline & $\# 1$ & $\# 2$ & $\# 3$ & $\# 4$ & \#5 & \#6 & $\# 7$ & \#8 & \#9 & $\# 10$ & \#11 & $\# 12$ \\
\hline$\mu$ Perv & 0,5774 & 0,6158 & 0,6543 & 0,6928 & 0,7313 & 0,7698 & 0,5774 & 0,6158 & 0,6543 & 0,6928 & 0,7313 & 0,7698 \\
\hline$\left(r_{c} / r_{w}\right)$ & 6,8277 & 6,8277 & 6,8277 & 6,8277 & 6,8278 & 6,8278 & 3,4139 & 3,4139 & 3,4139 & 3,4139 & 3,4139 & 3,4139 \\
\hline$\frac{R_{c}}{R_{a}}$ & 2,2714 & 2,2714 & 2,2714 & 2,2714 & 2,2714 & 2,2714 & 1,9917 & 1,9917 & 1,9917 & 1,9917 & 1,9917 & 1,9917 \\
\hline$r_{c}(\mathrm{~mm})$ & 6,145 & 6,145 & 6,145 & 6,145 & 6,145 & 6,145 & 6,145 & 6,145 & 6,145 & 6,145 & 6,145 & 6,145 \\
\hline$r_{a}(\mathrm{~mm})$ & 2,705 & 2,705 & 2,705 & 2,705 & 2,705 & 2,705 & 3,085 & 3,085 & 3,085 & 3,085 & 3,085 & 3,085 \\
\hline$R_{a}(\mathrm{~mm})$ & 9,105 & 8,823 & 8,566 & 8,3313 & 8,1154 & 7,916 & 12,888 & 12,484 & 12,118 & 11,782 & 11,473 & 11,189 \\
\hline$R_{c}(\mathrm{~mm})$ & 20,682 & 20,041 & 19,457 & 18,924 & 18,433 & 17,981 & 25,668 & 24,865 & 24,135 & 23,466 & 22,851 & 22,284 \\
\hline$z_{c a}(\mathrm{~mm})$ & 11,577 & 11,218 & 10,891 & 10,592 & 10,318 & 10,065 & 12,780 & 12,381 & 12,017 & 11,684 & 11,378 & 11,096 \\
\hline$z_{w}(\mathrm{~mm})$ & 21,795 & 21,102 & 20,475 & 19,895 & 19,365 & 18,874 & 24,231 & 23,462 & 22,761 & 22,120 & 21,530 & 20,985 \\
\hline$\theta\left({ }^{\circ}\right)$ & 17,28 & 17,86 & 18,41 & 18,95 & 19,47 & 19,98 & 13,85 & 14,31 & 14,75 & 15,18 & 15,60 & 16,00 \\
\hline
\end{tabular}




\subsection{Caracterização termiônica - efeito da carga espacial no potencial do canhão eletrônico}

Nesta Seção investiga-se o efeito da carga espacial no potencial do canhão eletrônico. Considerando-se um diodo esférico, onde o catodo está polarizado a $0 \mathrm{~V}$ e o anodo está polarizado com $V_{a}$, tem-se dois casos, quando:

- Ausência de elétrons, neste caso a densidade de corrente de emissão nula, e o potencial existente entre os eletrodos satisfaz a equação de Laplace:

$$
\nabla^{2} \Phi=\frac{1}{r^{2}} \frac{d}{d r}\left(r^{2} \frac{d V}{d r}\right)=0 .
$$

Sendo a condição de contorno para a resolução de (3.58), $V\left(r=R_{c}\right)=0$ e $V\left(r=R_{a}\right)=V_{\mathrm{a}}$, tem-se a expressão do potencial como sendo:

$$
V(r)=\frac{V_{a}}{\frac{1}{R_{c}}-\frac{1}{R_{a}}}\left(\frac{1}{R_{c}}-\frac{1}{r}\right) .
$$

Sabe-se que o campo elétrico é dado por:

$$
E_{r}=-\nabla V=-\frac{d V(r)}{d r}
$$

então, a expressão para o campo elétrico entre os eletrodos é dada por:

$$
E_{r}=\frac{V_{a}}{\frac{1}{R_{c}}-\frac{1}{R_{a}}}\left(\frac{1}{r^{2}}\right) .
$$

- Presença de elétrons que formam um feixe eletrônico cuja corrente é $I_{0}$. A expressão que fornece o valor do potencial entre os eletrodos é dada pela expressão desenvolvida por Langmuir e Blodgett:

$$
V(r)=\left[\frac{9 I_{0}}{16 \pi(2 \eta)^{1 / 2} \varepsilon_{0}} \frac{2}{(1-\cos \theta)}\right]^{2 / 3} G^{4 / 3}\left(\frac{R_{c}}{r}\right)
$$

e a expressão para o campo elétrico:

$$
\begin{gathered}
E_{r}=\frac{4}{3 r}\left[\frac{9 I_{0}}{16 \pi(2 \eta)^{1 / 2} \varepsilon_{0}} \frac{2}{(1-\cos \theta)}\right]^{2 / 3} G_{0}^{1 / 3} \\
{\left[1+\frac{6}{10} \ln \left(\frac{R_{c}}{r}\right)+\frac{9}{40} \ln ^{2}\left(\frac{R_{c}}{r}\right)+\frac{252}{4400} \ln ^{3}\left(\frac{R_{c}}{r}\right)+\ldots\right]}
\end{gathered}
$$


Empregando-se as expressões para o potencial e para o campo elétrico na condição que não há carga espacial, as suas curvas características são apresentadas na FIG. 3.8 .

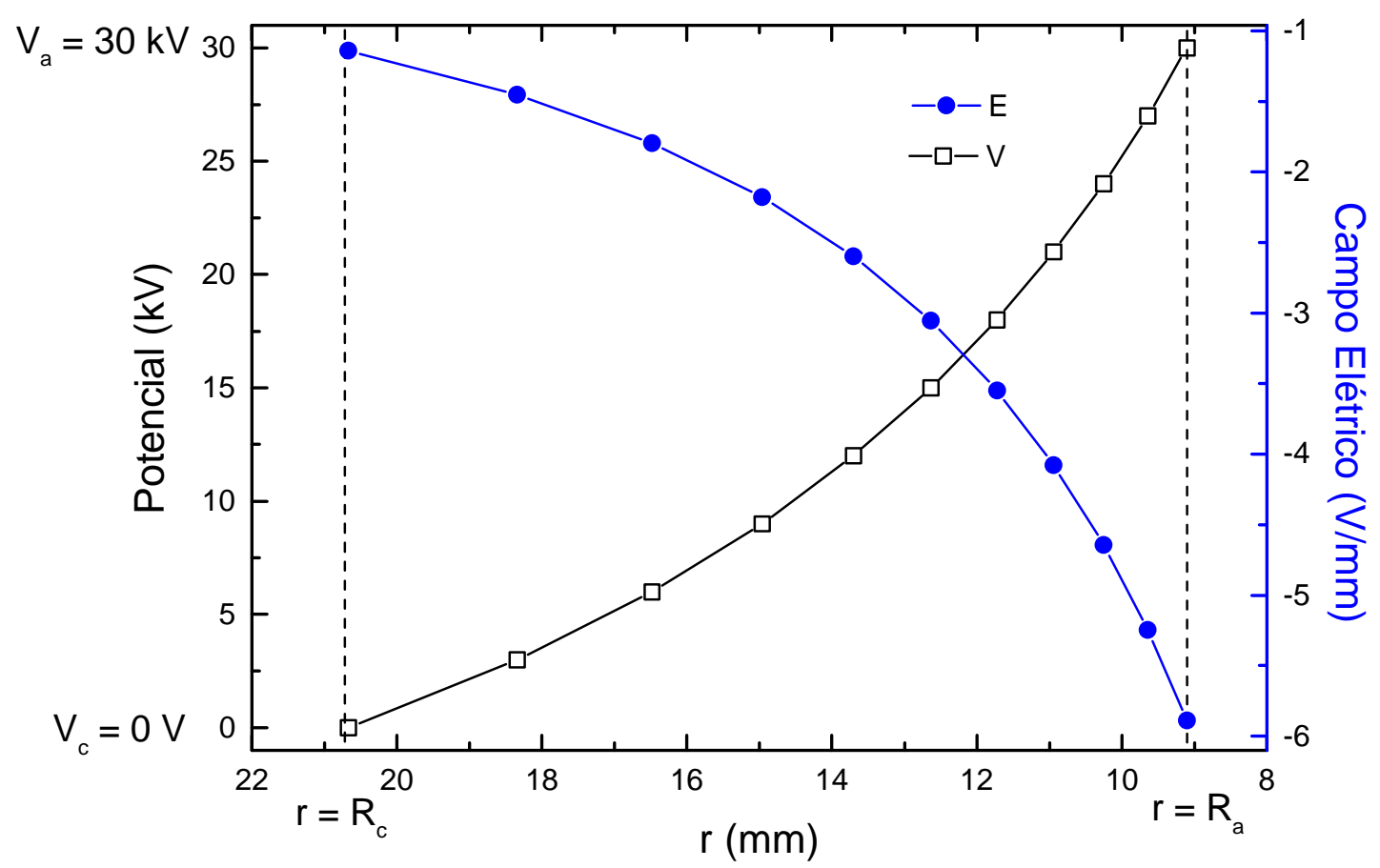

FIGURA 3.8 - Curva de variação do potencial/campo elétrico na região entre o catodo/anodo (sem o efeito de carga espacial).

Verifica-se por meio da FIG. 3.8 que na ausência de carga espacial o campo elétrico na superfície do catodo $\left(r=R_{c}\right)$ é diferente de zero.

Posteriormente, considerou-se o efeito da carga espacial, neste caso, as curvas características do potencial e do campo elétrico estão representadas na FIG. 3.9. 


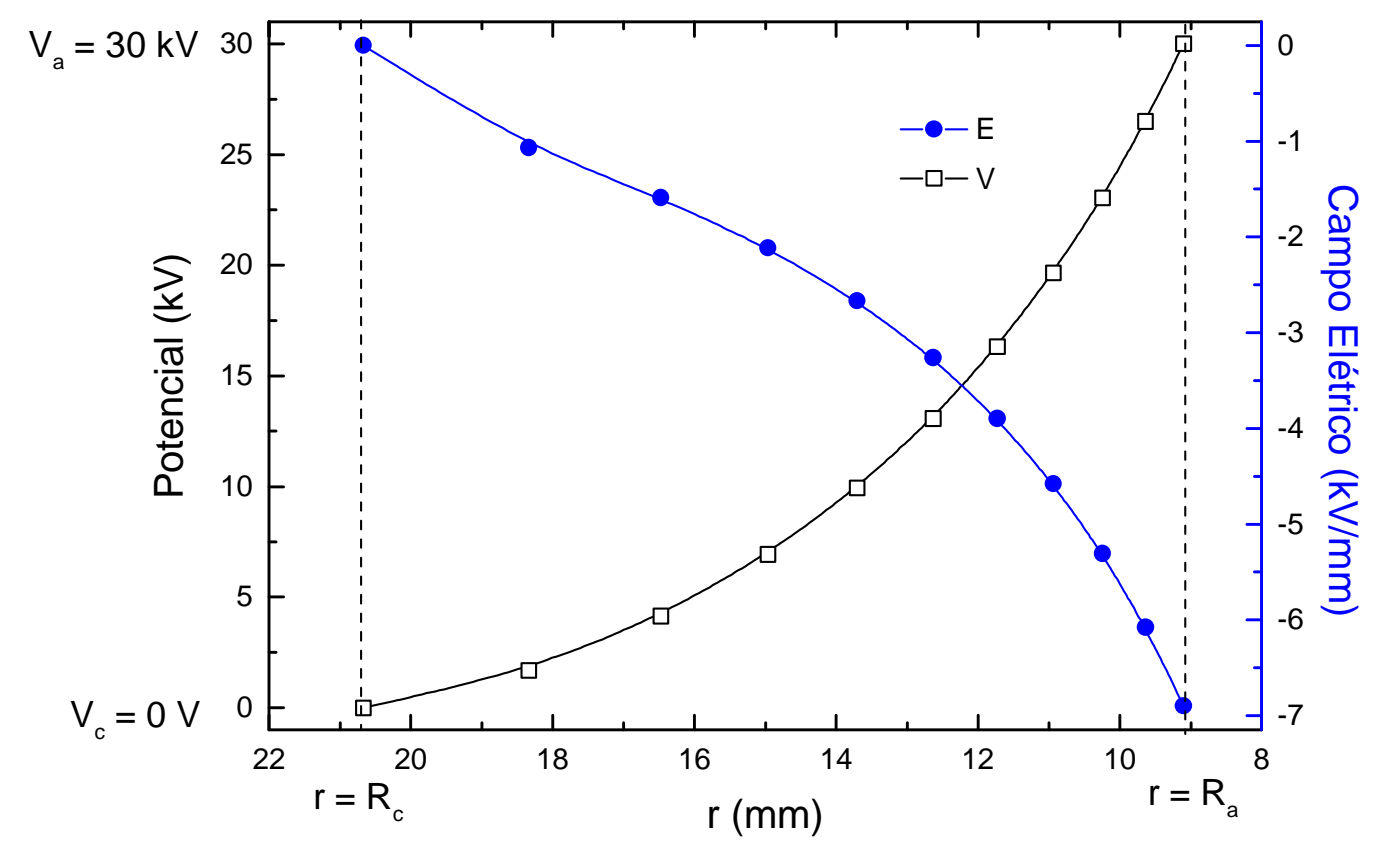

FIGURA 3.9 - Curva de variação do potencial/campo elétrico na região entre o catodolanodo (com o efeito de carga espacial).

Na FIG. 3.9, verifica-se que o campo elétrico na superfície do catodo é nulo, ou seja, na condição de carga espacial ou melhor fluxo limitado pela carga espacial o efeito Schottky é reduzido (igual a zero, pois $E=0$ ). Ao se trabalhar no regime de carga espacial não é necessário considerar o efeito Schottky na equação da densidade de corrente de emissão do catodo.

\subsection{Conclusões do Capítulo}

Neste Capítulo, apresentou-se a solução do problema do fluxo de corrente elétrica limitada pela carga espacial empregando-se o modelo do diodo esférico. Por meio desta foi possível observar um efeito extremamente relevante, analisando a equação do potencial (3.26), uma vez fixado o raio do anodo, o raio do catodo e uma dada diferença de potencial entre o catodo e o anodo, haverá uma corrente máxima que poderá ser drenada pelo diodo esférico de Langmuir. Verificou-se ainda que a razão entre a corrente máxima do feixe e o potencial de aceleração é igual a uma constante que depende apenas das características geométricas do diodo esférico, constante denominada perveância do canhão.

Determinou-se densidade de corrente de emissão limitada pela carga espacial em um setor cônico do diodo esférico por meio do procedimento de Pierce. Aplicando-se a 
expressão da perveância do sistema, dependente das características geométricas, definiramse os parâmetros de um canhão eletrônico de fluxo convergente. Por meio dos exemplos apresentados neste Capítulo, verifica-se a influencia da geometria do canhão eletrônico de Pierce nas características do feixe eletrônico (por exemplo: corrente de emissão e convergência do feixe).

Realizando-se os estudos apresentados neste Capítulo foi possível traçar um procedimento analítico que pode ser empregado na construção do aparato experimental de caracterização termiônica. E este procedimento garante que o fluxo eletrônico seja limitado pela carga espacial, o que reduz ou elimina o efeito Schottky.

Realizou-se um estudo do potencial e do campo elétrico na superfície do catodo. Por meio destes estudos, verificou-se que o efeito da carga espacial apresenta uma propriedade extremamente importante sobre a distribuição do potencial na região entre os eletrodos. Nesta condição, de carga espacial, observou-se que o campo elétrico na superfície do catodo é nulo, diferentemente do que ocorre quando não há o efeito da carga espacial, $\mathrm{E} \neq 0$. 


\section{CAPÍTULO 4 - CATODOS TERMIÔNICOS}

\subsection{Introdução do Capítulo}

Neste Capítulo descrevem-se os principais tipos de catodos termiônicos desenvolvidos na indústria e em centro de pesquisas de válvulas microondas, comparando os seus principais parâmetros termiônicos (relação entre os materiais utilizados na fabricação do catodo termiônico com a sua eficiência). Nesta descrição verifica-se que a diversificação dos materiais empregados nestes catodos está relacionada à necessidade ao avanço tecnológico das válvulas de microondas, no que concerne à suas condições de operação: densidade de corrente de emissão, tempo de vida do catodo e temperatura de operação [3], [10]-[13]. São dezenas de anos de pesquisa e investigação destes materiais, desde o primeiro catodo termiônico que se tratava de um filamento de tungstênio, até os catodos investigados atualmente, como os catodos impregnados, que são utilizados em elaborados dispositivos eletrônicos.

Os precursores dos catodos impregnados foram os denominados catodos óxidos, que se constituem de uma base metálica coberta com uma camada de óxidos de metais alcalinos terrosos. Posteriormente surgiu o catodo tipo L, que utiliza uma matriz porosa e impregnada. A principal característica desse catodo foi reduzir a taxa de evaporação do material fonte de bário. Conseguinte, foram investigados outros materiais emissores de elétrons, como o aluminato de bário e cálcio em conjunto com o tungstênio, os quais dispunham de baixa função trabalho, alta densidade de corrente e elevado tempo de vida (quando comparado ao catodo óxido, como observado na FIG. 4.1). E, assim, até o presente momento, são desenvolvidos novos materiais e novas técnicas de fabricação desses catodos para suprir à necessidade de melhores parâmetros de emissão termiônica. Em razão dessas pesquisas, surgiram outros tipos de catodos, tais como: catodo reservatório, catodo prensado, catodo tipo $\mathrm{M}$, catodo escandato, catodo tipo MMM e catodo do tipo CMM.

$\mathrm{Na}$ Seção 4.2 comparam-se os diversos tipos de catodos existentes, descrevendo as suas características de emissão termiônica. Na Seção 4.3, apresentam-se algumas técnicas para a fabricação dos catodos impregnados e as dependências do 
processamento dos materiais nas características termiônicas. Na Seção 4.4, descreve-se o diagrama de equilíbrio dos aluminatos de bário e cálcio com o intuito de relacionar a temperatura formação dos materiais emissores às fases dos aluminatos presentes. Posteriormente, apresenta-se uma breve teoria sobre a estabilidade dos aluminatos de bário e cálcio em condições ambientais. E, em seguida, na Seção 4.6 descrevem-se as reações do aluminato de bário e cálcio com o tungstênio que ocorrem no início do processo de emissão termiônica. Por fim, na Seção 4.7, apresenta-se a conclusão do Capítulo.

\subsection{Evolução dos materiais emissores de elétrons}

As pesquisas por novos materiais para a fabricação dos catodos termiônicos foram motivadas em meio à modernização das válvulas de microondas que requerem alta densidade de corrente de emissão $\left(>2 \mathrm{Acm}^{-2}\right)$, bom desempenho em relação ao tempo de vida (acima de 10.000 h), menor temperatura de operação (comparada aos catodos de metais refratários, temperatura de operação $2027^{\circ} \mathrm{C}$ ), maior resistência ao processo de envenenamento (reação do material com os gases presentes no interior dos dispositivos eletrônicos), menor taxa de evaporação do material emissor, por exemplo [10]-[11]. A TAB. 4.1 mostra a evolução dos materiais utilizados nos catodos termiônicos.

Na TAB 4.1 observa-se a variação dos principais parâmetros da emissão termiônica em razão dos diferentes materiais empregados na construção dos catodos. Verifica-se que os primeiros catodos utilizados na produção de corrente termiônica foram àqueles utilizados em válvulas de alta potência para radiodifusão. Estes catodos são constituídos somente de um filamento de tungstênio [12]. Em virtude de sua alta função trabalho $(\sim 4,6 \mathrm{eV})$, a temperatura de operação é, também elevada $\left(2200^{\circ} \mathrm{C}\right)$.

Observa-se, também, na TAB. 4.1, que com a descoberta do catodo óxido, houve um aumento significativo da densidade de corrente de emissão, de dezenas de $\mathrm{mA} / \mathrm{cm}^{2}$ para centenas de $\mathrm{mA} / \mathrm{cm}^{2}$. O catodo tipo L é provido de baixa função trabalho $(2,0 \mathrm{eV})$ e de longo tempo de vida $(8.000 \mathrm{~h})$.

Ainda na TAB. 4.1, verifica-se que o catodo impregnado opera a temperaturas de aproximadamente $1100^{\circ} \mathrm{C}$, e o seu tempo de vida é de alguns milhares de horas. $\mathrm{O}$ catodo tipo M possui uma matriz impregnada cuja superfície é recoberta com um filme fino, como pode ser observado na TAB. 4.1. O depósito do filme na superfície do catodo, gera uma redução da temperatura de operação de aproximadamente $90^{\circ} \mathrm{C}$, comparada à mesma densidade de emissão obtida no catodo impregnado. Em 1975 surgiu um catodo do tipo matriz metálica mista (MMM) para superar os problemas relacionados com a 
deterioração da superfície do catodo do tipo M. Nos catodos do tipo MMM, observam-se correntes de 4,0 $\mathrm{Acm}^{-2}$ em temperatura menor que $1000^{\circ} \mathrm{C}$.

Uma importante característica do catodo impregnado é a possibilidade de operar os catodos a temperaturas menores $\left(800-1000^{\circ} \mathrm{C}\right)$ quanto comparadas ao catodo de filamento de metais refratários $\left(2527^{\circ} \mathrm{C}\right)$, pois um catodo que trabalha em baixa temperatura de operação reflete em um menor aquecimento ou reduzida potência do filamento, ocasionando uma maior eficiência da válvula de microondas. Se menos calor é dissipado na válvula, menos calor é radiado e conduzido, havendo um menor aquecimento dos componentes adjacentes. Ademais, a alta temperatura provoca a expansão térmica do catodo o que ocasiona uma mudança no espaçamento dos eletrodos e, portanto, a variação das características elétricas da válvula. Este fenômeno também pode levar a evaporação dos materiais fontes de elétrons, reduzindo o tempo de vida do amplificador [1], [10]-[13].

Os catodos, com baixa função trabalho $(<2,0 \mathrm{eV})$, podem gerar semelhantes densidades de corrente de emissão a uma temperatura menor comparado a um catodo com alta função trabalho. Por isso inúmeras investigações são realizadas para se obter materiais com reduzida função trabalho. Nesta Seção, descrevem-se diversos tipos de catodos, enfatizando-se os impregnados que utilizam o aluminato de bário e cálcio como material fonte de bário (responsável pela redução da função trabalho da base do catodo). Estes catodos apresentam uma maior resistência ao envenenamento, garantindo bons resultados de densidade de corrente de emissão e tempo de vida, em particular, às válvulas TWT. 
TABELA 4.1 - Evolução do catodo termiônico relativo ao desenvolvimento dos materiais que o compõem [1], [10]-[38]. ${ }^{1}$

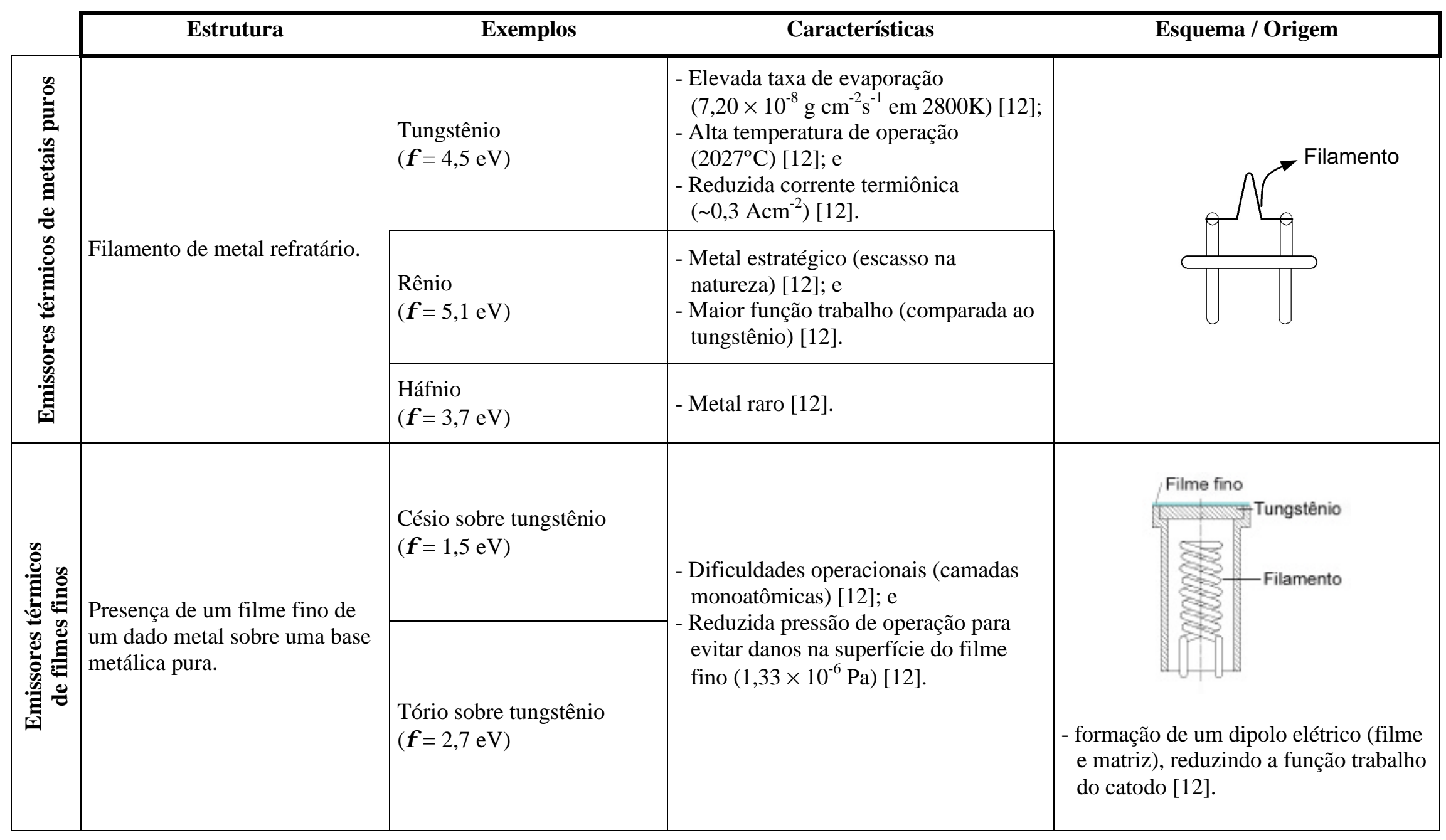

\footnotetext{
${ }^{1}$ Todos os dados fornecidos na tabela podem variar em função dos parâmetros utilizados (porosidade do metal da base, característica dos materiais e parâmetros de operação).
} 


\begin{tabular}{|c|c|c|c|c|}
\hline & Estrutura & Exemplos & Características & Esquema / Origem \\
\hline 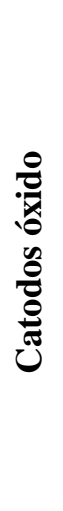 & $\begin{array}{l}\text { Base metálica coberta com uma } \\
\text { camada de óxido dos metais } \\
\text { alcalinos-terrosos. }\end{array}$ & $\begin{array}{l}\text { - Óxidos de bário, estrôncio } \\
\text { e cálcio. } \\
\text { ( } \phi=1-2 \mathrm{eV}) ; \text { e } \\
\text { - Base: } N i \text { ou liga de } N i \text {. }\end{array}$ & $\begin{array}{l}\text { - Reduzida função trabalho da } \\
\text { superfície emissora [12]; } \\
\text { - Densidade de corrente: } 500 \mathrm{~mA} \mathrm{~cm}^{-2} \\
\text { (contínua) e } 100 \mathrm{Acm}^{-2} \text { (pulsada) [15]; } \\
\text { - Alta taxa de evaporação da camada de } \\
\text { óxido [11]; } \\
\text { - Baixa temperatura de operação (800- } \\
\text { 925C) [13]; e } \\
\text { - Suscetibilidade ao envenenamento } \\
\text { [13], [15]. }\end{array}$ & $\begin{array}{l}\text { - Go4 Wehnelt [12]; } \\
\text { - Comportamento de um semicondutor } \\
\text { intrínseco tipo } n \text { [12]. }\end{array}$ \\
\hline Uి & $\begin{array}{l}\text { - Disco de tungstênio poroso; e } \\
\text { - Presença de cavidade } \\
\text { preenchida por carbonatos. }\end{array}$ & $\begin{array}{l}\text { - Carbonatos de bário, } \\
\text { estrôncio e cálcio. } \\
(\phi=2,0 \mathrm{eV})\end{array}$ & $\begin{array}{l}\text { - Dificuldade no controle da porosidade } \\
\text { do disco de } W[12],[10] ; \\
\text { - Elevada temperatura de operação } \\
\quad\left(\sim 1250^{\circ} \mathrm{C}\right)[12],[16] ; \\
\text { - Tempo de vida: } 8.000 \mathrm{~h}[12] ; \\
\text { - Dificuldade na uniformidade da } \\
\text { temperatura no catodo [10]; e } \\
\text { - Formação de compostos não emissores } \\
\quad\left(\mathrm{BaWO}_{6}\right)[10] .\end{array}$ & $\begin{array}{l}\text { Mstura de } \\
\text { carbonatcs } \\
\text { 1950 Lemmens, Jasen e Loosfer } \\
\text { (Philips Research Laboratories) [12]. }\end{array}$ \\
\hline \multirow{3}{*}{ 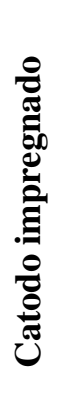 } & \multirow{3}{*}{$\begin{array}{l}\text { Disco de tungstênio poroso } \\
\text { impregnado com o material } \\
\text { emissor. } \\
\text { (a função trabalho deste catodo } \\
\text { varia tanto com a } \\
\text { estequiometria do material } \\
\text { emissor utilizado quanto com } \\
\text { as propriedades físicas da } \\
\text { matriz de } W \text { ) }\end{array}$} & $\begin{array}{l}\text { Aluminato de bário } \\
\text { (tipo A) }\end{array}$ & $\begin{array}{l}\text { - Melhora das propriedades térmicas; e } \\
-\phi=1,53 \mathrm{eV}[12] .\end{array}$ & \multirow{3}{*}{$\begin{array}{l}\text { Tungstênio } \\
\text { - 1953 R. Levi [12]; } \\
\text { - 1955 R. Levi (adição do } \mathrm{CaO} \text { ) [12]. }\end{array}$} \\
\hline & & $\begin{array}{l}\text { Aluminato de bário e cálcio } \\
\text { (tipo B / 5:3:2) }\end{array}$ & $\begin{array}{l}\text { - Redução na evaporação de Ba; e } \\
\text { - } \phi=1,67 \text { eV [12]. }\end{array}$ & \\
\hline & & $\begin{array}{l}\text { Aluminato de bário e cálcio } \\
\text { (tipo S / 4:1:1) }\end{array}$ & $\begin{array}{l}\text { - Excelente resistência ao } \\
\text { envenenamento; e } \\
\text { - } \phi=2,0 \mathrm{eV} \mathrm{[12].}\end{array}$ & \\
\hline
\end{tabular}




\begin{tabular}{|c|c|c|c|c|}
\hline & Estrutura & Exemplos & Características & Esquema / Origem \\
\hline 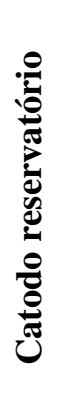 & $\begin{array}{l}\text { Existência de uma cavidade } \\
\text { para o armazenamento do } \\
\text { material emissor. } \\
\text { (variação da função trabalho } \\
\text { com as propriedades físicas da } \\
\text { pastilha de } W \text { ) }\end{array}$ & $\begin{array}{l}\text { - Disco de tungstênio } \\
\text { poroso; e } \\
\text { - Aluminato de bário e } \\
\text { cálcio (5:3:2). }\end{array}$ & $\begin{array}{l}\text { - Densidade de corrente: } 2,1-2,3 \mathrm{Acm}^{-2} \\
\left(800-850^{\circ} \mathrm{C} \text { - contínua) }\right. \\
\text { 25-35 } \mathrm{Acm}^{-2}\left(800-850^{\circ} \mathrm{C}-\text { pulsada }\right) \\
\text { [16]; } \\
\text { - Alto tempo de vida: } 35000 \mathrm{~h}\left(2 \mathrm{Acm}^{-2}\right. \\
\text { - 1000 } \mathrm{C})[17] ; \\
\text { - Função trabalho: } 2,1 \mathrm{eV}[18] ; \mathrm{e} \\
\text { - Temperatura de trabalho: } 800-1100 \mathrm{C}_{\mathrm{b}} \\
\text { [16]. }\end{array}$ & - Aplicações aeroespaciais [12]. \\
\hline 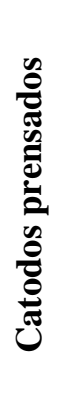 & $\begin{array}{l}\text { Misturas de pós-refratários e } \\
\text { pós do material emissor de } \\
\text { elétrons. }\end{array}$ & $\begin{array}{l}\text { - Tungstênio (25\%); } \\
\text { - Molibdênio (75\%); e } \\
\text { - Aluminato de bário e } \\
\text { cálcio (5-3-2). }\end{array}$ & $\begin{array}{l}\text { - Função trabalho: 1,70 eV [12]; } \\
\text { - Densidade de corrente de emissão: } \\
\text { 2,50 } \mathrm{Acm}^{-2}[12] ; \\
\text { - Tempo de vida: } \sim 5000 \mathrm{~h} \text { [12]; } \\
\text { - Baixa taxa de evaporação de Ba [12]; } \\
\text { - Boa resistência ao envenenamento } \\
\text { [12]; e } \\
\text { - Boa resistência ao bombardeamento } \\
\text { iônico [12]. }\end{array}$ & $\begin{array}{l}\text { - 1956 Coppola e Hughes [12]; } \\
\text { - Indústria eletrônica [12]. }\end{array}$ \\
\hline \multirow[b]{2}{*}{ 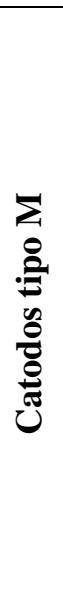 } & \multirow[b]{2}{*}{$\begin{array}{l}\text { Catodo do tipo impregnado } \\
\text { com filme metálico em sua } \\
\text { superfície (evaporação de } \\
\text { metais). }\end{array}$} & Filme de irídio (5000 Å) & \multirow[b]{2}{*}{$\begin{array}{l}\text { - Aumento na densidade de corrente de } \\
\text { emissão }\left(8-10 \mathrm{Acm}^{-2} \text {, temperatura de }\right. \\
1020 \pm 10^{\circ} \mathrm{C}_{\mathrm{b}} \text {, contínuo }[19] ; \\
\text { - Densidade de corrente: } 94 \mathrm{Acm}^{-2} \\
\left.\text { (pulsado, temperatura de } 1060^{\circ} \mathrm{C}_{\mathrm{b}}\right) \\
\text { [19]; } \\
\text { - Função trabalho } \sim 1,86 \mathrm{eV}[1] ; \\
\text { - Degradação do filme metálico [20]; e } \\
\text { - Porosidade } 18 \% \text { [20], [21]. }\end{array}$} & \multirow[b]{2}{*}{$\begin{array}{l}\text { - } 1966 \text { P. Zalm e A. J. A. Van } \\
\text { Stratum [1]; } \\
\text { - Fonte de elétrons utilizada nas } \\
\text { válvulas de microondas[1]. }\end{array}$} \\
\hline & & $\begin{array}{l}\text { Filme de rutênio } \\
(5000 \AA)\end{array}$ & & \\
\hline
\end{tabular}




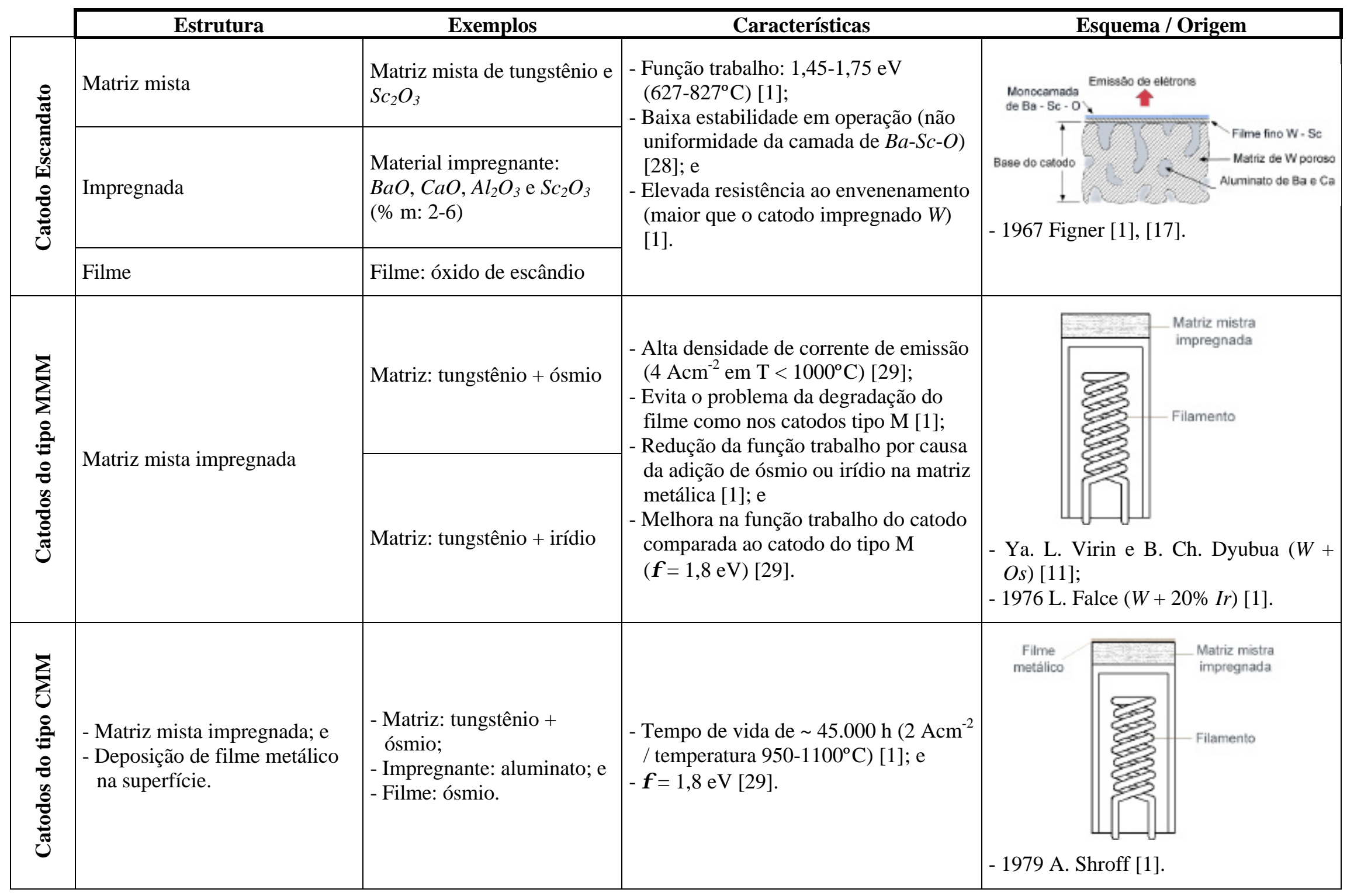




\subsection{Técnicas de fabricação dos catodos impregnados e seus efeitos na emissão termiônica}

A escolha dos materiais do catodo, para uma determinada válvula de microondas, é determinada pelos seguintes fatores: o ambiente no qual o catodo será operado, a densidade de corrente necessária, o tempo de vida desejado, a temperatura na qual o catodo deverá operar para gerar a densidade de emissão especificada e a potência a ser fornecida ao filamento do catodo [10]. Pode-se dividir os materiais que compõe o catodo em: matéria-prima para a matriz do catodo e material impregnante.

\subsubsection{Matéria-prima da matriz do catodo}

A matriz do catodo impregnado constitui-se de um metal refratário poroso. Em geral, utiliza-se o tungstênio devido a sua estabilidade em alta temperatura, reduzindo reações com o aluminato durante o processo de impregnação. Na fabricação das pastilhas de tungstênio poroso, há técnicas especialmente desenvolvidas para a sua obtenção com porosidade controlada. O controle da porosidade requer a avaliação das propriedades físico-químicas do pó de tungstênio e dos parâmetros de conformação da pastilha: tamanho e distribuição do tamanho de partículas, forma da partícula, grau de pureza do pó, pressão de compactação e temperatura de sinterização da pastilha. Na etapa de conformação da pastilha de tungstênio, por exemplo, uma variável importante é o controle do empacotamento inicial (grau de retração/densidade a verde) da pastilha. Pois um empacotamento pobre (alta fricção entre as partículas) pode levar àoxidação da superfície e protuberâncias das partículas, como cantos pontiagudos e, ainda, pode ocasionar a formação de poros interconectados e irregulares. Estas características influenciam na difusão dos aluminatos àsuperfície do catodo e, conseqüentemente, afeta as características de emissão termiônica, como o tempo de vida do catodo. A TAB. 4.2 mostra as principais características do pó de tungstênio utilizado na fabricação dos catodos impregnados e a TAB. 4.3 lista os parâmetros importantes das pastilhas de tungstênio poroso (como a técnica de sintetize do pó de tungstênio, o tamanho médio de partícula, a forma da partícula e, por fim, as impurezas presentes neste material) [10]. 
TABELA 4.2 - Características do pó de tungstênio [10].

\begin{tabular}{llcc}
\hline $\begin{array}{l}\text { Tipo } \\
\text { Tamanho de partícula } \\
\text { Forma }\end{array}$ & \multicolumn{3}{l}{$\begin{array}{l}\text { Tungstênio reduzido em atmosfera de hidrogênio } \\
\text { Analisador Fisher: média entre } 6,0 \mu \mathrm{m} \mathrm{e} 8,0 \mu \mathrm{m} \\
\text { Angular }\end{array}$} \\
\hline \multicolumn{4}{c}{ Impurezas Típicas } \\
\hline \multicolumn{1}{c}{ Elemento } & $\mathbf{p p m}$ & Elemento & ppm \\
$\mathrm{Al}$ & 10 & $\mathrm{Mn}$ & 10 \\
$\mathrm{C}$ & 10 & $\mathrm{Mo}$ & 200 \\
$\mathrm{Ca}$ & 10 & $\mathrm{Ni}$ & 40 \\
$\mathrm{Co}$ & 10 & $\mathrm{O}$ & 1000 \\
$\mathrm{Cr}$ & 30 & $\mathrm{~Pb}$ & 10 \\
$\mathrm{Cu}$ & 10 & $\mathrm{Si}$ & 10 \\
$\mathrm{Fe}$ & 50 & $\mathrm{Sn}$ & 10 \\
$\mathrm{Mg}$ & 10 & $\mathrm{Ti}$ & 20 \\
\hline
\end{tabular}

TABELA 4.3 - Pastilha de tungstênio sinterizada em hidrogênio: características típicas [10].

\begin{tabular}{ll}
\hline Densidade & $(15,44 \pm 0,4) \mathrm{g} \mathrm{cm}^{-3}$ (ou $80 \% \pm 2 \% \mathrm{da}$ \\
& densidade teórica do tungstênio) \\
Diâmetro médio do poro & $3 \mu \mathrm{m}$ \\
Faixa do diâmetro do poro & $1-7 \mu \mathrm{m}$ \\
Área média do poro & $(16 \pm 8) \mu \mathrm{m}^{2}$ \\
Densidade de poros & $8000-36000$ poros por $\mathrm{mm}^{2}$ \\
\hline
\end{tabular}

\subsubsection{Material impregnante}

Há diversos fatores que influenciam as características de emissão termiônica. Um destes fatores é a composição do material impregnante ou mistura emissora. Ao longo dos anos, diversas misturas emissoras foram investigadas para prover altas densidades de corrente de emissão (> 2,0 $\mathrm{A} \mathrm{cm}^{-2}$ ), baixa taxa de sublimação e longo tempo de vida (> 10.000 horas). Um dos compostos que é utilizado com maior freqüência como material emissor é o óxido de bário. Entretanto, este composto é higroscópico em condição ambiental normal, convertendo-se rapidamente em hidróxido de bário [10].

A estabilização do óxido de bário pode ser obtida por meio da adição de outros compostos como: silicatos de metais alcalinos terrosos, aluminatos, toriatos, berilatos, boratos, tungstatos e escandatos. Destes materiais, o aluminato de bário e cálcio (vide seção 4.1) é um dos mais utilizados, pois o processo de formação destes aluminatos é o mais conhecido, mas os escandatos e os tungstatos de bário têm sido amplamente investigados [10].

Para os aluminatos de bário e cálcio existem três composições mais freqüentemente utilizadas, conforme apresentado na TAB. 4.4. 
TABELA 4.4 - Composição dos aluminatos de bário e cálcio [10]-[11].

\begin{tabular}{ccccc}
\hline & $\mathrm{BaO}$ & $\mathbf{C a O}$ & $\mathrm{Al}_{2} \mathrm{O}_{3}$ & Tipo de catodo \\
\hline Proporção molar & 4 & 1 & 1 & $\mathrm{~S}$ \\
Peso molar (\%) & 79,5 & 7,3 & 13,2 & \\
Proporção molar & 3 & 1 & 1 & - \\
Peso molar (\%) & 74,4 & 9,1 & 16,5 & \\
Proporção molar & 5 & 3 & 2 & $\mathrm{~B}$ \\
Peso molar (\%) & 67,3 & 14,8 & 17,9 & \\
\hline
\end{tabular}

\subsection{Aluminatos de bário e cálcio - Diagrama de equilíbrio}

Com o intuito de conhecer os produtos das reações de formação do aluminato de bário e cálcio, é necessário descrever o equilíbrio das fases dos seguintes sistemas: $\mathrm{BaO}-\mathrm{Al}_{2} \mathrm{O}_{3}$ (sistema binário) e $\mathrm{BaO}-\mathrm{CaO}-\mathrm{Al}_{2} \mathrm{O}_{3}$ (sistema ternário) [39].

\subsubsection{Sistema binário - $\mathrm{BaO}-\mathrm{Al}_{2} \mathrm{O}_{3}$}

$\mathrm{O}$ primeiro composto do sistema binário $\mathrm{BaO}-\mathrm{Al}_{2} \mathrm{O}_{3}, \mathrm{o} \mathrm{BaAl}_{2} \mathrm{O}_{4}$, foi descoberto por Wartenberg \& Reusch. Toropov descobriu mais dois compostos adicionais: o $\mathrm{Ba}_{3} \mathrm{Al}_{2} \mathrm{O}_{6}$ e o $\mathrm{BaAl}_{12} \mathrm{O}_{19}$. Posteriormente, Toropov e Galakhov construíram o primeiro diagrama de equilíbrio para o sistema $\mathrm{BaO}-\mathrm{Al}_{2} \mathrm{O}_{3}$, como representado na FIG. 4.1, e ainda, determinaram os pontos de fusão do $\mathrm{BaAl}_{2} \mathrm{O}_{4}\left(1830^{\circ} \mathrm{C}\right)$, do $\mathrm{Ba}_{3} \mathrm{Al}_{2} \mathrm{O}_{6}\left(1750^{\circ} \mathrm{C}\right)$ e do $\mathrm{BaAl}_{12} \mathrm{O}_{19}\left(1900^{\circ} \mathrm{C}\right)$ [39], como ilustrado na FIG. 4.1.

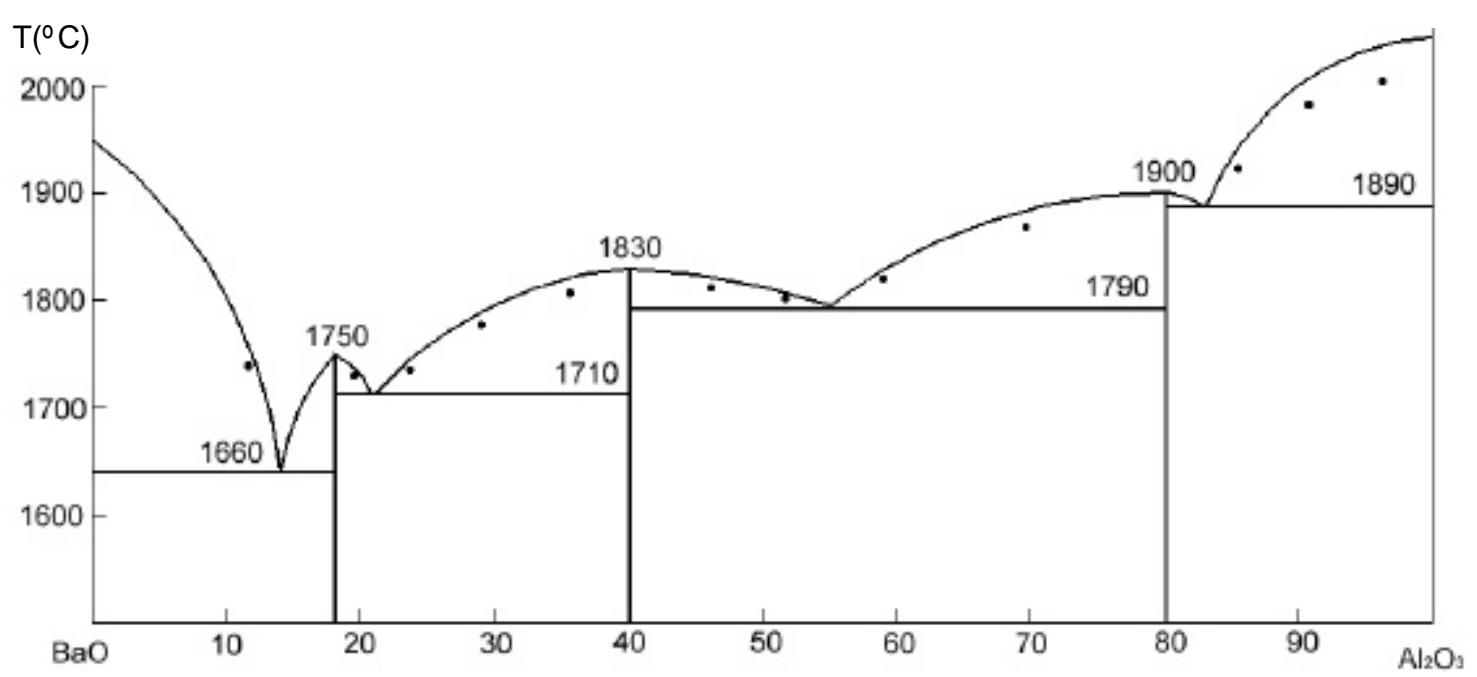

FIGURA 4.1 - Diagrama de equilíbrio do sistema $\mathrm{BaO}-\mathrm{Al}_{2} \mathrm{O}_{3}$ (Toropov e Galakhov). 
Appendino investigou a porção de alta bária do sistema binário entre $\mathrm{BaO}$ e $\mathrm{Ba}_{3} \mathrm{Al}_{2} \mathrm{O}_{6}$, identificando desta forma, cinco novas fases por meio da difração de raios $\mathrm{X}$ : $\mathrm{Ba}_{4} \mathrm{Al}_{2} \mathrm{O}_{7}$ (estável acima de $940^{\circ} \mathrm{C}$ ), $\mathrm{Ba}_{5} \mathrm{Al}_{2} \mathrm{O}_{8}$ (estável em $940^{\circ} \mathrm{C}$ ), $\mathrm{Ba}_{7} \mathrm{Al}_{2} \mathrm{O}_{10}$ (estável em $1050^{\circ} \mathrm{C}$ ), $\mathrm{Ba}_{8} \mathrm{Al}_{2} \mathrm{O}_{11}$ (estável acima de $1050^{\circ} \mathrm{C}$ ) e $\mathrm{Ba}_{10} \mathrm{Al} l_{2} \mathrm{O}_{13}$ (estável em $1130^{\circ} \mathrm{C}$ ). A FIG. 4.2 mostra o diagrama de equilíbrio desenvolvido por Appendino [39].

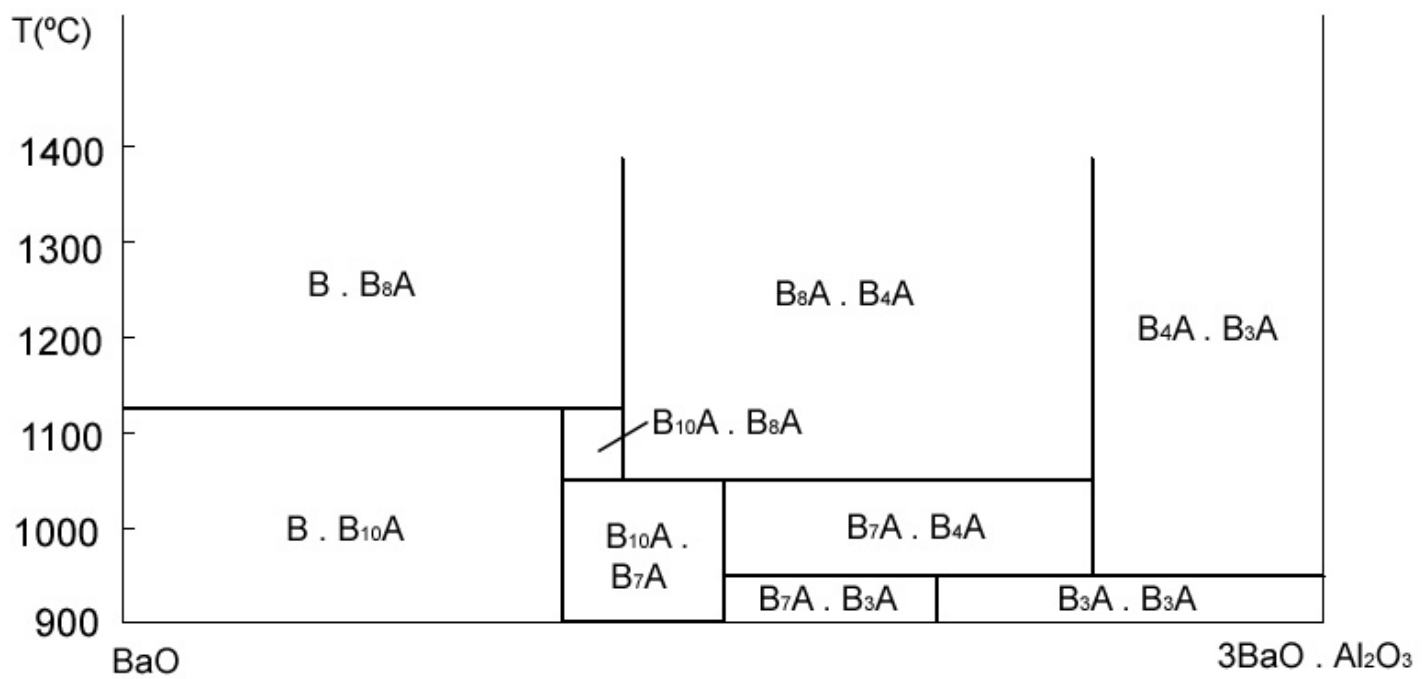

FIGURA 4.2 - Porção de alta bária do sistema $\mathrm{BaO}-\mathrm{Al}_{2} \mathrm{O}_{3}$ (Appendino), $\mathrm{B}=$ composto $\mathrm{BaO} e$ $B_{x} A=$ composto da forma $x \mathrm{BaO} \cdot \mathrm{Al}_{2} \mathrm{O}_{3}$.

No diagrama de equilíbrio, apresentado na FIG. 4.2, observa-se a estabilidade das fases do sistema $\mathrm{BaO}-\mathrm{Al}_{2} \mathrm{O}_{3}$ em determinadas faixas de temperatura.

\subsubsection{Sistema ternário $\mathrm{BaO}-\mathrm{CaO}-\mathrm{Al}_{2} \mathrm{O}_{3}$}

Durante as investigações do sistema $\mathrm{BaO}-\mathrm{CaO}-\mathrm{Al}_{2} \mathrm{O}_{3}$ na região de alta porção de bária, encontraram-se dificuldades no preparo das amostras, cuja porcentagem de $\mathrm{CaO}$ e $\mathrm{BaO}$ era superior a $75 \%$ mol, em virtude da alta suscetibilidade das amostras, isto é, estas reagem facilmente com os cadinhos de platina, a umidade do ar e o dióxido de carbono [39].

Appendino foi o primeiro a alcançar êxito na pesquisa do $\mathrm{BaO}-\mathrm{CaO}-\mathrm{Al}_{2} \mathrm{O}_{3}$ por meio da investigação da seção isotérmica deste sistema na temperatura de $1250^{\circ} \mathrm{C}$, como mostra a FIG. 4.3. Durante a investigação da solubilidade sólida do $\mathrm{CaO}$ no $\mathrm{Ba}_{4} \mathrm{Al}_{2} \mathrm{O}_{7}$, Appendino verificou a existência de uma nova fase ternária: $\mathrm{Ba}_{3} \mathrm{CaAl}_{2} \mathrm{O}_{7}$. Wolten sugeriu que este novo composto era uma solução sólida com uma composição que variava de $\mathrm{Ba}_{4} \mathrm{Al}_{2} \mathrm{O}_{7}-\mathrm{Ba}_{4-x} \mathrm{Ca}_{x} \mathrm{Al}_{2} \mathrm{O}_{7}$ [39]. A TAB. 4.5 apresenta a nomenclatura de algumas fases que compõe o diagrama ternário do sistema $\mathrm{BaO}-\mathrm{CaO}-\mathrm{Al}_{2} \mathrm{O}_{3}$. 
TABELA 4.5 - Nomenclatura das fases do sistema $\mathrm{BaO}-\mathrm{CaO}-\mathrm{Al}_{2} \mathrm{O}_{3}$.

\begin{tabular}{cc}
\hline & Nomenclatura \\
\hline 311 & $3 \mathrm{BaO} \cdot \mathrm{CaO} \cdot \mathrm{Al}_{2} \mathrm{O}_{3}$ ou $\mathrm{Ba}_{3} \mathrm{CaAl}_{2} \mathrm{O}_{7}$ \\
411 & $4 \mathrm{BaO} \cdot \mathrm{CaO} \cdot \mathrm{Al}_{2} \mathrm{O}_{3}$ ou $\mathrm{Ba}_{4} \mathrm{CaAl}_{2} \mathrm{O}_{8}$ \\
532 & $5 \mathrm{BaO} \cdot 3 \mathrm{CaO} \cdot 2 \mathrm{Al}_{2} \mathrm{O}_{3}$ ou $\mathrm{Ba}_{5} \mathrm{Ca}_{3} \mathrm{Al}_{4} \mathrm{O}_{14}$ \\
612 & $6 \mathrm{BaO} \cdot 1 \mathrm{CaO} \cdot 2 \mathrm{Al}_{2} \mathrm{O}_{3}$ ou $\mathrm{Ba}_{6} \mathrm{CaAl}_{4} \mathrm{O}_{13}$ \\
$\mathrm{BCA}$ & $\mathrm{BaO} \cdot \mathrm{CaO} \cdot \mathrm{Al}_{2} \mathrm{O}_{3}$ ou $\mathrm{BaCaAl}_{2} \mathrm{O}_{5}$ \\
$\mathrm{~B}_{2} \mathrm{CA}$ & $2 \mathrm{BaO} \cdot \mathrm{CaO} \cdot \mathrm{Al}_{2} \mathrm{O}_{3}$ ou $\mathrm{Ba}_{2} \mathrm{CaAl}_{2} \mathrm{O}_{6}$ \\
$\mathrm{~B}_{3} \mathrm{~A}$ & $3 \mathrm{BaO} \cdot \mathrm{Al}_{2} \mathrm{O}_{3}$ ou $\mathrm{Ba}_{3} \mathrm{Al}_{2} \mathrm{O}_{6}$ \\
$\mathrm{~B}_{4} \mathrm{~A}$ & $4 \mathrm{BaO} \cdot \mathrm{Al}_{2} \mathrm{O}_{3}$ ou $\mathrm{Ba}_{4} \mathrm{Al}_{2} \mathrm{O}_{7}$ \\
$\mathrm{~B}_{4} \mathrm{~A}_{\mathrm{SSL}}$ & Limite de solução sólida substitucional do $\mathrm{Ca}$ em $\mathrm{B}_{4} \mathrm{~A}$ \\
\hline
\end{tabular}

Asselanis investigou a possibilidade de obtenção das temperaturas das linhas solidus e liquidus das composições na porção de alta bária do sistema ternário, incluindo aqueles correspondentes aos impregnantes comerciais: $3 \mathrm{BaO} \cdot \mathrm{CaO} \cdot \mathrm{Al}_{2} \mathrm{O}_{3}$ (311), $5 \mathrm{BaO}$. $3 \mathrm{CaO} \cdot 2 \mathrm{Al}_{2} \mathrm{O}_{3}$ (532), e $4 \mathrm{BaO} \cdot \mathrm{CaO} \cdot \mathrm{Al}_{2} \mathrm{O}_{3}$ (411). Nesta região, ele encontrou que a temperatura solidus varia de $1650^{\circ} \mathrm{C}-1800^{\circ} \mathrm{C}$ e a liquidus de $1750^{\circ} \mathrm{C}-1900^{\circ} \mathrm{C}$ [39].

Tarter aprimorou as temperaturas solidus e liquidus do 311, 532 e 411, e ainda determinou as características dos cinco compostos comerciais adicionais: $6 \mathrm{BaO} \cdot \mathrm{CaO} \cdot 2 \mathrm{Al}_{2} \mathrm{O}_{3}$ (612), $11 \mathrm{BaO} \cdot 6 \mathrm{CaO} \cdot 4 \mathrm{Al}_{2} \mathrm{O}_{3}\left(\mathrm{~B}_{11} \mathrm{C}_{6} \mathrm{~A}_{4}\right), 2 \mathrm{BaO} \cdot \mathrm{CaO} \cdot \mathrm{Al}_{2} \mathrm{O}_{3}\left(\mathrm{~B}_{2} \mathrm{CA}\right)$, e $\mathrm{BaO} \cdot \mathrm{CaO} \cdot \mathrm{Al}_{2} \mathrm{O}_{3}$ (BCA) [36].

Hill, Hann e Suitch estudaram as características de fusão em quarenta compostos de alta porção de bária do sistema ternário. Eles determinaram o limite de solubilidade do cálcio no $\mathrm{Ba}_{3} \mathrm{Al}_{2} \mathrm{O}_{6}(18,8 \% \mathrm{~mol})$ e no $\mathrm{Ba}_{4} \mathrm{Al}_{2} \mathrm{O}_{7}(20,5 \% \mathrm{~mol})$ [39]. A FIG. 4.3 ilustra as fases do sistema $\mathrm{BaO}-\mathrm{CaO}-\mathrm{Al}_{2} \mathrm{O}_{3}$ a $1250^{\circ} \mathrm{C}$. 


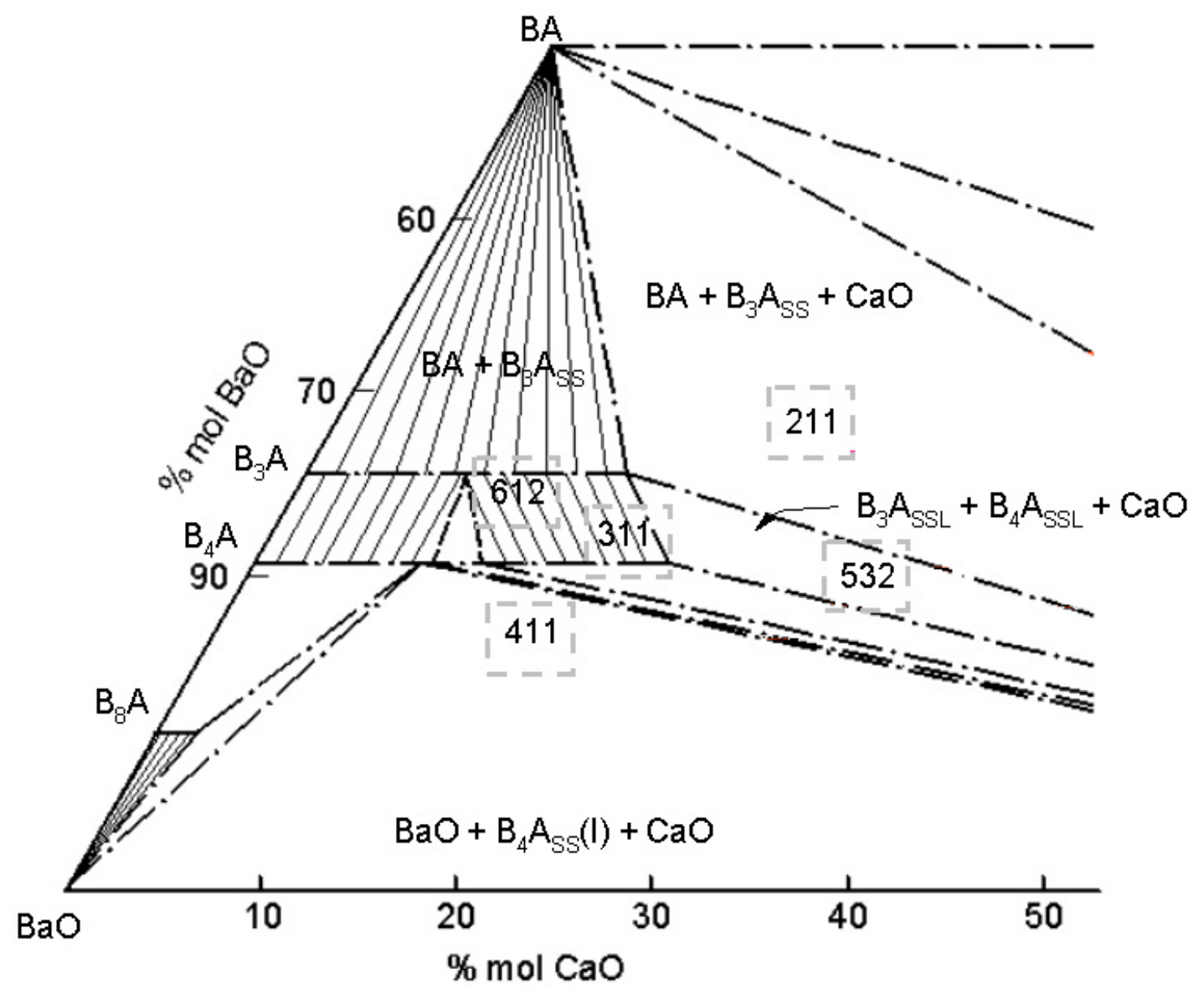

FIGURA 4.3 - Seção isotérmica do diagrama de equilíbrio do $\mathrm{BaO}-\mathrm{CaO}-\mathrm{Al}_{2} \mathrm{O}_{3}$ a $1250^{\circ} \mathrm{C}$ (Appendino).

\subsection{Hidratação dos materiais fontes de bário}

A hidratação dos materiais fontes de bário pode causar um sério impacto no desempenho dos catodos impregnados ou reservatórios. As reações entre alguns tipos de aluminatos de bário com os gases provenientes do ambiente podem resultar em diversos efeitos deletérios. Um desses efeitos é a alteração do volume do produto final do aluminato hidratado resultando em trincas na matriz de tungstênio nos catodos impregnados. Outro efeito da hidratação é a decomposição dos hidratos proveniente da reação do aluminato com a umidade, resultando em produtos gasosos que geram trincas na matriz de tungstênio. Além disso, esses produtos da decomposição gasosa podem oxidar a matriz de tungstênio e, ainda, podem causar a reação do material impregnante com a matriz formando um tungstato complexo. Por isso a importância na investigação da hidratação dos aluminatos [39].

Toropov mostrou que $\mathrm{Ba}_{3} \mathrm{Al}_{2} \mathrm{O}_{6}$ é solúvel em água (altamente higroscópio). No estudo do sistema $\mathrm{BaO}-\mathrm{Al}_{2} \mathrm{O}_{3}$, Wallmark e Westgren encontraram dificuldades na análise 
de difração de raios X (DRX) do $B a O$ e dos aluminatos, com composição > 50\% mol de $B a O$, pois estes materiais se mostram higroscópicos. Por isso, foram realizadas investigações da hidratação de alguns compostos de bário, como: $\mathrm{Ba}(\mathrm{OH})_{2} ; \mathrm{Ba}(\mathrm{OH})_{2} \cdot \mathrm{H}_{2} \mathrm{O}$, $\mathrm{Ba}(\mathrm{OH})_{2} \cdot 2 \mathrm{H}_{2} \mathrm{O}, \mathrm{Ba}(\mathrm{OH})_{2} \cdot 8 \mathrm{H}_{2} \mathrm{O}$ [39].

Ohlinger e Rebstock ao investigarem o composto 411 em ambientes ao nível do mar, observaram um ganho de massa de $40 \%$ relativo ao material anidro. As fases detectadas nas análises de DRX foram: $\mathrm{Ba}(\mathrm{OH})_{2} \cdot 8 \mathrm{H}_{2} \mathrm{O} ; \mathrm{Ca}(\mathrm{OH})_{2}$ e $\mathrm{BaCO}_{3}$. Ohlinger e Rebstock observaram a decomposição das amostras 411 por meio da termogravimetria. Nestes experimentos, verificou-se sete diferentes eventos de perdas de massa, dos quais cinco foram identificados: os três primeiros eventos correspondem respectivamente à decomposição do $\mathrm{Ba}(\mathrm{OH})_{2} \cdot 8 \mathrm{H}_{2} \mathrm{O}$ em $\mathrm{Ba}(\mathrm{OH})_{2} \cdot 2 \mathrm{H}_{2} \mathrm{O}$; e os dois últimos eventos, são decorrentes à decomposição $\mathrm{Ba}(\mathrm{OH})_{2} \cdot 2 \mathrm{H}_{2} \mathrm{O}$ em $\mathrm{Ba}(\mathrm{OH})_{2} \cdot \mathrm{H}_{2} \mathrm{O}$ e do $\mathrm{Ba}(\mathrm{OH})_{2} \cdot \mathrm{H}_{2} \mathrm{O}$ em $\mathrm{Ba}(\mathrm{OH})_{2}$ anidro. Em alta temperatura, foram observadas a decomposição do $\mathrm{Ba}(\mathrm{OH})_{2}$ anidro, do $\mathrm{Ca}(\mathrm{OH})_{2}$ anidro e do $\mathrm{BaCO}_{3}$, formando: $\mathrm{BaO} ; \mathrm{CaO} ; \mathrm{H}_{2} \mathrm{O}$ e $\mathrm{CO}_{2}$ [39].

\subsection{Reações entre compostos de bário e tungstênio}

A redução da função trabalho dos catodos do tipo reservatório ocorre em razão da formação da monocamada de bário sobre o emissor [10], [39], conforme a reação:

$$
W+\text { óxido impregnante contendo } \mathrm{Ba} \rightarrow \mathrm{Ba} \text { e/ou } \mathrm{BaO}
$$

A proposta de Brodie e Jenkins para os catodos impregnados era que a reação entre o tungstênio e o aluminato de bário e cálcio ocorresse em dois estágios. Inicialmente, o material fonte dissocia-se para produzir vapor de $\mathrm{BaO}$ nos interstícios entre o impregnante e o emissor de tungstênio, conforme a reação:

$$
3 \mathrm{BaO} \cdot \mathrm{Al}_{2} \mathrm{O}_{3} \rightarrow 2 \mathrm{BaO} \mathrm{O}_{(\mathrm{v})}+\mathrm{BaO} \cdot \mathrm{Al}_{2} \mathrm{O}_{3}
$$

Em seguida, o vapor do óxido de bário reage com o tungstênio para formar vapor de $B a$ e um tungstato de bário:

$$
2 \mathrm{BaO}+1 / 3 \mathrm{~W} \rightarrow \mathrm{Ba}+1 / 3 \mathrm{Ba}_{3} \mathrm{WO}_{6}
$$

Os tungstatos que podem ser gerados da reação acima estão presentes no diagrama de fases do sistema $\mathrm{BaO}-\mathrm{WO}_{3}$, [10],[39], como mostra a FIG. 4.4. Neste diagrama observa-se as menores temperaturas de fusão dos tungstatos, representados pelos pontos eutéticos do diagrama. 


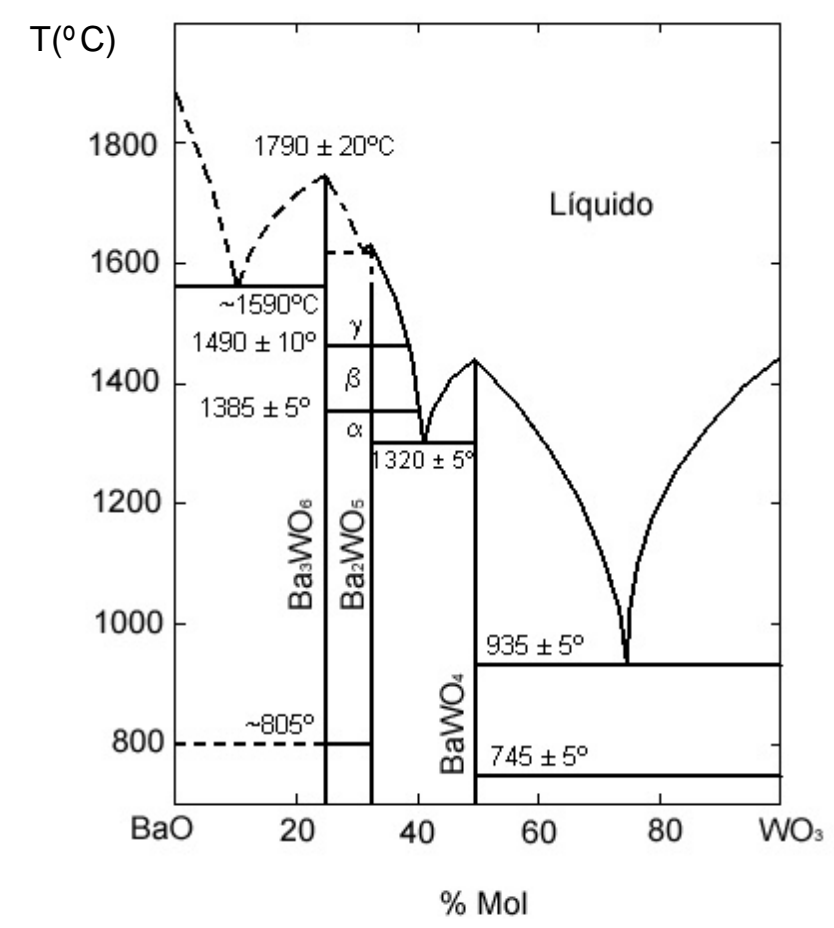

FIGURA 4.4 - Diagrama de equilíbrio do sistema $\mathrm{BaO}-\mathrm{WO}_{3}$.

Rittner, Rutledge e Ahlert escolheram a composição $5 \mathrm{BaO} \cdot 2 \mathrm{Al}_{2} \mathrm{O}_{3}$ como material impregnante, pois esta é a proporção estequiométrica que se possui a menor temperatura de fusão sem bário livre. Esta composição é uma mistura eutética de $\mathrm{Ba}_{3} \mathrm{Al}_{2} \mathrm{O}_{6}$ e $\mathrm{BaAl}_{2} \mathrm{O}_{4}$. Entretanto o último composto é quimicamente inerte, ou seja, não reage para a formação de vapor de bário [10], [39]. A reação de produção do vapor de bário é dada por:

$$
2 / 3 \mathrm{Ba}_{3} \mathrm{Al}_{2} \mathrm{O}_{6}+1 / 3 \mathrm{~W} \rightarrow 1 / 3 \mathrm{BaWO}_{4}+2 / 3 \mathrm{BaAl}_{2} \mathrm{O}_{4}+\mathrm{Ba}
$$

Por meio de análises químicas, Rittner, Rutledge e Ahlert identificaram os produtos que eram liberados do catodo, $B a$ e $B a O$. Eles propuseram que o óxido de bário identificado pela análise química era produzido por meio da oxidação do $B a$ quando este passava através da pastilha de $W$ poroso, ou ainda, pela decomposição do $\mathrm{Ba}_{3} \mathrm{Al}_{2} \mathrm{O}_{6}$ por meio da seguinte reação:

$$
1 / 2 \mathrm{Ba}_{3} \mathrm{Al}_{2} \mathrm{O}_{6} \rightarrow 1 / 2 \mathrm{BaAl}_{2} \mathrm{O}_{4}+\mathrm{BaO}
$$

Eles sugeriram a hipótese da obtenção do composto $\mathrm{Ca}_{2} \mathrm{BaWO}_{6}$ na reação do aluminato de bário e cálcio (5:3:2) com o tungstênio, diferentemente do composto obtido com o aluminato de bário, $\mathrm{BaWO}_{4}$ [10], [39]. O diagrama de equilíbrio do sistema ternário $\mathrm{BaO}-\mathrm{CaO}-\mathrm{WO}_{3}$, proposto por Kreidler, mostra que há um composto ternário $\mathrm{Ba}_{2} \mathrm{CaWO}_{6}$ ao invés de $\mathrm{Ca}_{2} \mathrm{BaWO}_{6}$ proposto por Rittner (definido pela região a,b,c e d, 
ilustrada na FIG. 4.5).

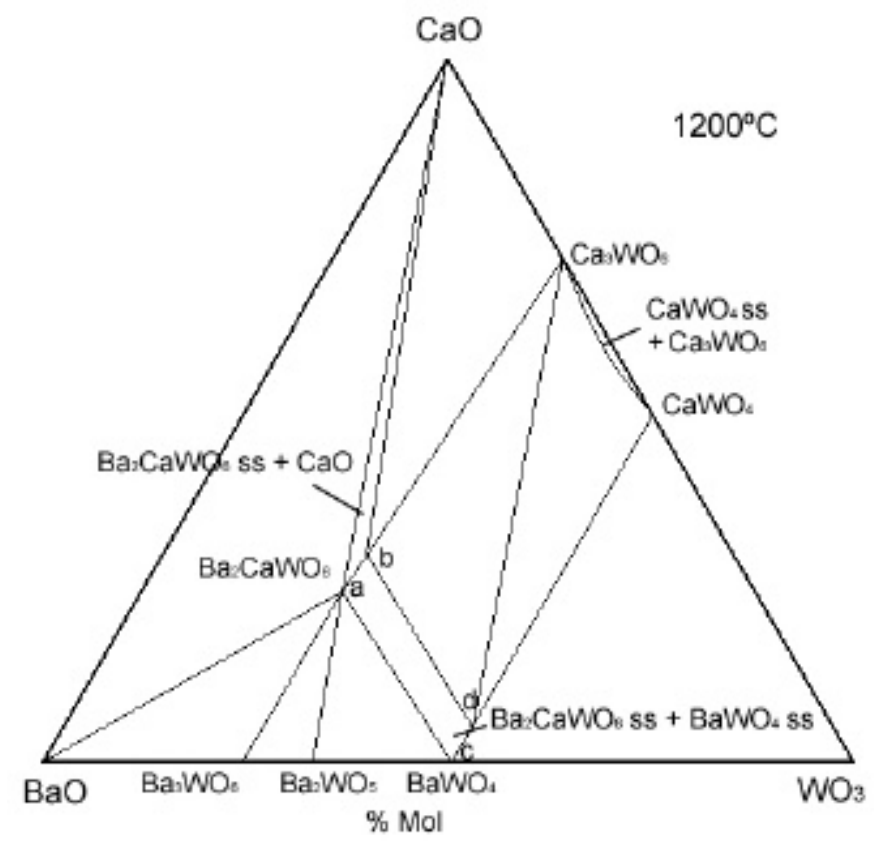

FIGURA 4.5 - Diagrama de equilíbrio ternário do sistema $\mathrm{BaO}-\mathrm{CaO}-\mathrm{WO}_{3}$.

Shroff, Paullel e Tonnerre submeteram filamentos de tungstênio coberto por aluminato de bário e cálcio a processos de ativação e testes de vida, com o propósito de identificar os produtos de reação dos catodos impregnados. Após os testes, foram realizadas análises de DRX e as fases observadas foram: $\mathrm{BaAl}_{2} \mathrm{O}_{4} ; \mathrm{BaWO}_{4}$ e $\mathrm{CaWO}_{4}$.[10], [39].

Sarver-Verhey, após realizar um teste de tempo de vida de 28.000 horas em um catodo impregnado (411) realizaram a análise de DRX e identificaram os dois principais compostos depositados na superfície do tungstênio poroso: $\mathrm{Ba}_{2} \mathrm{CaWO}_{6}$ e $\mathrm{BaWO}_{4}$ [39].

\subsection{Conclusões do Capítulo}

Neste Capítulo listaram-se os principais materiais empregados na fabricação dos catodos termiônicos utilizados na pesquisa de novos catodos para aumentar a eficiência nas condições de operações (emissão termiônica) das válvulas de microondas. Na primeira parte deste Capítulo apresentou-se o efeito das etapas de síntese da matriz do catodo (pastilha de tungstênio) no tempo de vida do catodo impregnado. Posteriormente, apresentaram-se as composições de alguns aluminatos de bário e cálcio. Esse material é o responsável pela redução do valor da função trabalho do catodo impregnado. 
Descreveu-se o digrama de equilíbrio dos aluminatos de bário e cálcio para traçar as reações responsáveis pela redução da função trabalho do catodo impregnado. E ainda, apresentaram-se os efeitos da hidratação dos aluminatos no desempenho do catodo termiônico (como a oxidação do tungstênio). 


\section{CAPÍTULO 5 - MATERIAIS: SÍNTESE, PROCESSAMENTO E CARACTERIZAÇÃO}

\subsection{Introdução do Capítulo}

Neste Capítulo descrevem-se as etapas de síntese de materiais e sua caracterização (física e química) a fim de traçar a melhor metodologia de fabricação dos catodos impregnados. Como apresentado no Capítulo 4, observa-se que a composição ou a fase presente no aluminato de bário e cálcio influencia as propriedades termiônicas do catodo. Desta forma a síntese do material emissor, que é responsável pela formação das fases presentes no aluminato, é uma etapa importante na fabricação dos catodos impregnados.

A rota de processamento dos materiais metálicos influencia as propriedades físicas do produto final. Portanto, para se traçar a metodologia de obtenção das pastilhas de tungstênio poroso é importante investigar os parâmetros de compactação e sinterização do tungstênio, pois estes definem a sua densidade (porosidade), característica fundamental no processo de impregnação do catodo. Os pós-precursores e os materiais processados são analisados para se adequar a metodologias de fabricação dos catodos. Algumas das técnicas empregadas são: distribuição do tamanho de partícula por meio do espalhamento laser, difração de raios X (análise das fases), espectroscopia no infravermelho (composição química), termogravimetria (transformação físico-química) e microscopia eletrônica de varredura (distribuição e forma das partículas) e fluorescência de raios X (composição química).

Na Seção 5.2, apresentam-se as técnicas de síntese de pós, suas vantagens e desvantagens. Na Seção 5.3, descrevem-se as etapas de processamento de pós e na Seção 5.4, são apresentados alguns métodos de caracterização dos pós. Posteriormente, são apresentadas as conclusões deste Capítulo.

\subsection{Síntese de pós}

Há diversas técnicas de síntese de pós, de tal forma que estas podem ser agrupadas em três grupos: técnica de estado sólido, técnica de solução e a técnica de fase 
vapor. Cada qual fornece características físico-químicas definidas pelo processamento (entre elas: composição e tamanho de partícula).

\subsubsection{Técnica de reação em estado sólido}

Esta técnica, caracterizada pelas reações em estado sólido de óxidos ou carbonatos, é denominada mistura de pós ou método cerâmico. Os pós-precursores são misturados e submetidos a tratamentos térmicos em diferentes temperaturas até a obtenção do material desejado. A técnica de reação em estado sólido apresenta as seguintes desvantagens: tratamentos térmicos a elevadas temperaturas, baixo grau de homogeneidade química, possível formação de fases cristalinas indesejáveis e contaminação durante a moagem do material. As suas principais vantagens são: simplicidade e baixo custo [40][43].

\subsubsection{Técnica de solução}

A técnica de solução, denominada técnica não-convencional, apresenta as seguintes vantagens: alta pureza, alta homogeneidade química e pequeno tamanho de partículas do material sintetizado. Nesta técnica utilizam-se soluções contendo os cátions desejados. Estas soluções são preparadas por meio da dissolução de um sal, geralmente nitratos, sulfatos e cloretos em um solvente, em geral a água. Na escolha dos sais precursores, consideram-se os seguintes fatores: pureza, solubilidade e custo. A etapa de eliminação dos solventes é importante, pois deve ser realizada de forma a evitar a segregação dos componentes. A eliminação do solvente pode ser feita por vaporização, precipitação/filtração e/ou secagem do líquido [40]-[44].

Dentro desta técnica há uma subdivisão que está relacionada ao produto da reação do solvente com o soluto, são elas: precipitação simultânea e coprecipitação dos hidróxidos, precursores poliméricos ou citratos e sol-gel.

\subsubsection{Técnicas de fase vapor}

A técnica de fase vapor, também denominada técnica não convencional, apresenta as mesmas vantagens da técnica de solução. Neste processo, utiliza-se um ou mais reagentes na forma de vapor em pequenas concentrações devido à baixa densidade destes gases. Como conseqüência, essas técnicas produzem partículas finas e não aglomeradas. Esta técnica não é recomendada para materiais de composições mais complexas, contendo três ou mais cátions, devido ànecessidade de altas temperaturas para 
a fase vapor e controle das reações entre eles. Dentro desta técnica há uma subdivisão que está relacionada com a natureza das reações do vapor: vaporização-condensação, decomposição de vapor, reações vapor-vapor, reações vapor-líquido, e reações vaporsólido [40]-[44].

\subsection{Etapas de processamento de pós}

O processamento de pós é constituído de diversas etapas, dentre elas estão presentes: secagem, calcinação, conformação e a sinterização.

\subsubsection{Secagem}

A secagem é uma etapa da sintetização em que o material é submetido a um aquecimento geralmente inferior a $250^{\circ} \mathrm{C}$. Os materiais precursores passam por esta etapa para a remoção de água, seja ela adsorvida, ocluída, sorvida ou essencial (água de hidratação ou constituição) [42]-[44].

\subsubsection{Calcinação}

$\mathrm{Na}$ calcinação ocorre a etapa de decomposição térmica que envolve a dissociação dos sais em seus componentes ácidos e básicos, como por exemplo, a decomposição dos carbonatos e a obtenção das fases desejadas. Alguns parâmetros da calcinação, como intervalo de tempo, temperatura e atmosfera, podem ser determinados pelas curvas termogravimétricas dos materiais precursores [42]-[44].

\subsubsection{Conformação}

Nesta etapa conferem-se ao pó um pré-formato e estabelecem-se os pontos de contato entre as partículas para a consolidação no processo de sinterização. Há diversas técnicas de conformação: compactação uniaxial, compactação isostática àfrio ou àq uente, colagem de barbotina, moldagem por injeção, entre outras [40]-[47]. Em geral, são utilizadas duas técnicas:

\section{a) Compactação uniaxial}

Fundamenta-se na aplicação de pressão sobre um molde, que contém o material na forma de pó, por meio um ou mais punções. 


\section{b) Compactação isostática a frio}

Consiste na aplicação de pressão sobre um molde flexível que contém o pó. Essa pressão é advinda da pressurização de um líquido onde o molde é imerso. Por meio desta compactação obtém-se um corpo com uma densificação mais homogênea comparada àprensagem uniaxial.

\subsubsection{Sinterização}

A sinterização é um processo termodinâmico, onde um sistema de partículas, pó ou compactado, forma uma estrutura coerente por meio da redução da área de uma determinada superfície. Este processo resulta na formação de contornos de grãos, crescimento de pescoços de união entre as partículas, decréscimo na porosidade e aumento do tamanho de grão, levando o sistema à densificação e à contração volumétrica. $\mathrm{O}$ processo de sinterização no estado sólido apresenta basicamente três estágios: inicial; intermediário e final, como mostra a FIG. 5.1 [40]-[47].

A sinterização é influenciada por vários fatores, como por exemplo: tamanho e distribuição de partículas, temperatura e tempo de tratamento, atmosfera de sinterização e coeficiente de difusão.

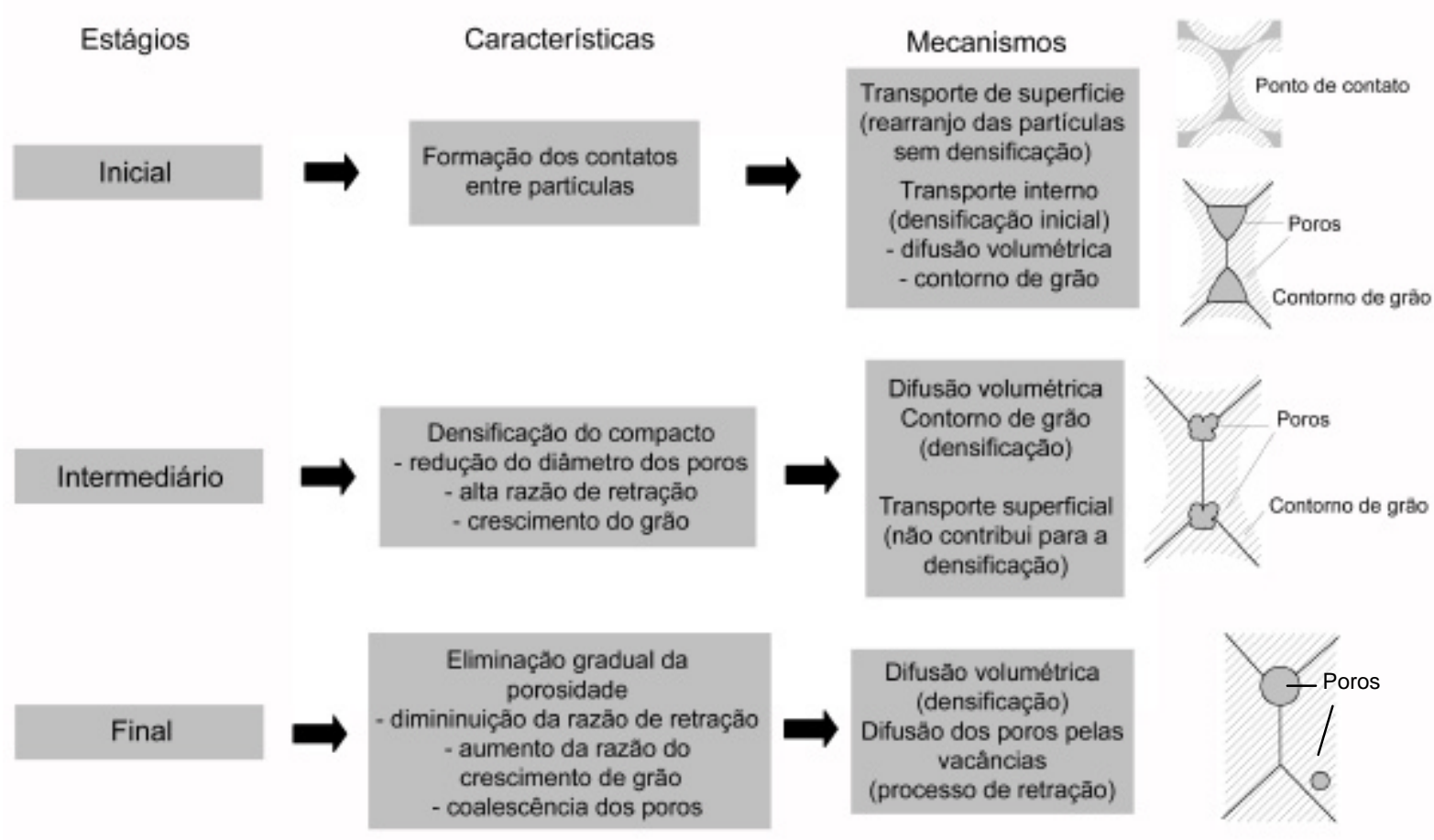

FIGURA 5.1 - Estágios do processo de sinterização. 


\subsection{Técnicas de caracterização}

Algumas das técnicas geralmente empregadas na caracterização do póssintetizados e do produto processado são apresentados nesta Seção. Trata-se das análises: do tamanho de partícula, das fases do produto sintetizado, da composição química do material e do comportamento térmico dos pós-precursores e do produto sintetizado.

\subsubsection{Análise da distribuição do tamanho de partícula}

Tendo em vista que a partícula não é, na maioria dos casos, uma esfera perfeita, o seu tamanho depende da técnica empregada na sua medição. As análises do tamanho de partícula podem ser realizadas por diversos tipos de equipamentos que, geralmente, não fornecem valores equivalentes devido aos diferentes parâmetros medidos. A maior parte dos analisadores de tamanho de partículas utiliza parâmetros geométricos (dimensão máxima, área de seção transversal mínima, área superficial, área projetada ou volume) e considera uma partícula esférica como padrão. Os métodos comumente empregados na medição do tamanho de partícula são: microscopia, peneiramento, sedimentação, espalhamento laser e raios X [40]-[47].

A técnica de espalhamento laser proporciona uma medição na faixa de 0,1 a $500 \mu \mathrm{m}$. Este método permite a determinação da distribuição dos diâmetros médios de partículas utilizando os fenômenos de difração e a de difusão de um feixe de laser ao atravessar o meio onde se encontram as partículas em suspensão. Esta técnica é aplicada para pós que se dispersam facilmente em água, álcool ou ar e, também, para suspensões e emulsões [40]-[47]. O princípio da técnica consiste na passagem das partículas em meio líquido através de um feixe de laser. O feixe de luz ao atingir uma partícula, pode sofrer os seguintes efeitos: transmissão, adsorção e espalhamento. Desta forma a luz pode ser difratada, refletida e refratada. A luz espalhada pode ser influenciada por diferentes fatores: índice de refração relativo ao meio de suspensão das partículas, comprimento de onda da luz, além do tamanho e forma das partículas. Os detectores na câmara de análise recebem informações relativas àintensidade e ao ângulo da luz espalhada e, os sinais dos detectores, são posteriormente convertidos em informações a respeito da distribuição de tamanho de partículas [40]-[47].

Dependendo do tamanho médio das partículas, pode-se aplicar duas teorias:

- Teoria de Fraunhöffer (difração): para menor tamanho de partícula e maior ângulo de difração de um feixe luminoso que atravessa uma população de partículas; e 
- Teoria de Mies (difração-difusão): que é válida para partículas maiores do que o comprimento de luz utilizado.

\subsubsection{Difração de raios $X$}

A difração de raios $\mathrm{X}$ é uma técnica que permite determinar a estrutura cristalina do material, quantificar as fases cristalinas presentes no material em análise, além de detectar a perfeição e a orientação dos cristais que compõe o material. Esta técnica consiste na interação entre a radiação eletromagnética e a matéria ordenada [40]-[47]. Quando os átomos estão regularmente espaçados em uma rede cristalina e a radiação incidente tem a mesma ordem de grandeza deste espaçamento, ocorrerá a difração desta radiação, sendo as interações construtivas descritas pela equação de Bragg:

$$
n \lambda=2 d \operatorname{sen} \theta
$$

onde $n$ é um número inteiro de comprimentos de onda, $\lambda$ é comprimento de onda da radiação incidente, $d$ é o espaçamento interplanar e $\theta$ é o ângulo de incidência da radiação. Os valores de $d$ para compostos padrões estão tabelados, disponíveis no banco de dados do sistema JCPDS (Joint Committee for Powder Diffraction Studies) da International Union of Cristallography.

\subsubsection{Espectroscopia no infravermelho}

É uma técnica de análise química de materiais. A frequiência da radiação de infravermelho é da mesma ordem de grandeza da vibração molecular, de modo que há possibilidade da interação entre a radiação e a vibração molecular (momento de dipolo elétrico) e, assim, torna-se possível a caracterização das possíveis moléculas existentes no material [40]-[47]. O espectro do infravermelho é o registro gráfico da radiação absorvida de um conjunto de moléculas iluminadas com radiação infravermelho de frequiência adequada. Neste caso, ter-se-á um espectro que relaciona absorbância e número de onda. O inverso da absorbância é a transmitância [40]-[47].

\subsubsection{Termogravimetria}

Termogravimetria é uma técnica de análise térmica em que a variação da massa da amostra (perda ou ganho) é determinada como uma função da temperatura e/ou tempo, enquanto a amostra é submetida a uma programação controlada de temperatura. 
A curva obtida neste tipo de análise pode ser influenciada por fatores instrumentais e por aqueles relacionados à características da amostra. Dentre os instrumentais podem ser citados: a razão de aquecimento, a atmosfera do forno e a sensibilidade do mecanismo de registro. Em relação à características da amostra, podem ser citados: a quantidade de amostra analisada, o tamanho de partícula e sua condutividade térmica [48].

\subsubsection{Microscopia eletrônica de varredura - MEV}

A observação em microscópio eletrônico de varredura geralmente é realizada quando se deseja obter informações topológicas ou químicas de um material, variando-se a energia do feixe de elétrons utilizado [40]-[47].

O princípio de funcionamento do microscópio eletrônico de varredura (MEV) consiste em interagir o feixe de elétrons produzido por um canhão eletrônico com a superfície de um material. Essa interação produz a emissão de elétrons secundários, retroespalhados e Auger, catodo luminescência, raios $\mathrm{X}$ característicos e fótons. Os elétrons secundários e os retroespalhados são os sinais utilizados na geração da imagem no MEV. O MEV é um equipamento capaz de reproduzir imagens de alta resolução da ordem de até 300.000 vezes, permitindo a obtenção de dados tanto estruturais quanto químicos [40]-[47].

\subsubsection{Fluorescência de raios $X$ por dispersão de comprimento de onda (WDXRF)}

Esta técnica é utilizada na determinação qualitativa e/ou quantitativa dos constituintes de um determinado material. As vantagens dessa técnica são: a realização de análises químicas multielementrares; alta sensibilidade e, não destrutiva.

A WDXRF consiste na incidência de um feixe de raios $\mathrm{X}$ em uma amostra, e desta forma, há a produção de radiações fluorescentes (transições eletrônicas dos elétrons das camadas mais internas dos átomos), que são características para cada elemento químico. As radiações difratadas são captadas por um detector e traduzida em dados que posteriormente podem ser analisados [49].

\subsection{Conclusões do Capítulo}

Neste Capítulo apresentou-se, primeiramente, uma breve descrição das técnicas de síntese e as etapas de processamentos de pós (metálicos e/ou cerâmicos). Relacionandose as vantagens/desvantagens de cada técnica de síntese que pode ser empregada no 
processo de obtenção dos aluminatos de bário e cálcio. O controle dos parâmetros de síntese e processamento dos pós define as características físico-químicas dos materiais, que por sua vez influencia diretamente as propriedades termiônicas do catodo impregnado. Por fim, descreveram-se as técnicas de caracterização dos pós que auxiliam na definição da metodologia de obtenção dos aluminatos de bário e cálcio. 


\section{CAPÍTULO 6 - MATERIAIS E MÉTODOS}

\subsection{Introdução do Capítulo}

Este Capítulo se dedica a apresentar tanto a metodologia de fabricação quanto a de caracterização dos catodos impregnados.

As etapas que constituem a fabricação do catodo impregnado são as seguintes: síntese do material impregnante, análise químico-física do aluminato de bário e cálcio, análise físico-química do pó de tungstênio, conformação e sinterização das pastilhas de tungstênio poroso e impregnação (preenchimento dos poros da matriz de tungstênio).

Para se determinar a eficiência dos catodos impregnados fabricados no presente trabalho foi necessário realizar um estudo de um método de caracterização do catodo (determinar a densidade de corrente de emissão e a sua função trabalho). Desta forma, apresentar-se-á, a seguir, um procedimento de caracterização termiônica que está fundamentado no conceito da distribuição da função trabalho prática (PWFD) desenvolvido por Miram. Por meio desta metodologia é possível mensurar o perfil termiônico dos catodos impregnados. O conceito da PWFD pode também ser empregado na síntese de um canhão eletrônico para alta tensão de aceleração, tendo como base as características de emissão de um experimento realizado em baixa tensão de aceleração. $\mathrm{O}$ fato da curva PWFD ser uma distribuição e a função trabalho o valor mais provável desta distribuição, torna esta técnica adequada para catodos que apresentam heterogeneidade tanto em temperatura superficial como em emissão. Tal situação é comumente observada na prática.

Na Seção 6.2, apresenta-se a seleção dos materiais de partida empregados nas técnicas de síntese do aluminato de bário e cálcio investigadas neste trabalho. Nas Seções seguintes são traçadas as rotas de síntese dos aluminatos que empregam as técnicas de reação em estado sólido e de solução. A Seção 6.6 descreve o processo de fabricação da base do catodo impregnado e a sua etapa de impregnação. Na Seção 6.7 são apresentados os aparatos utilizados na fabricação do catodo impregnado. Posteriormente, na Seção 6.8, é apresentada o dimensionamento do canhão eletrônico que são utilizados nos experimentos de caracterização termiônica. Nas Seções 6.9 e 6.10, apresenta-se o procedimento de 
caracterização termiônica do catodo (segundo a metodologia da PWFD). Em seguida, na Seção 6.11, descreve-se o procedimento de caracterização físico-química dos aluminatos de bário e cálcio. Por fim, na Seção 6.12, apresenta-se as conclusões do Capítulo.

\subsection{Materiais precursores}

Os materiais precursores empregados na preparação dos aluminatos de bário e cálcio utilizados neste trabalho estão apresentados conforme a técnica utilizada:

a) Reação em estado sólido

- Carbonato de bário, $\mathrm{BaCO}_{3}$ (VETEC pA);

- Carbonato de cálcio, $\mathrm{CaCO}_{3}$ (VETEC pA);

- Óxido de alumínio, $\mathrm{Al}_{2} \mathrm{O}_{3}$ (VETEC pA); e

- Álcool etílico anidro, $\mathrm{C}_{2} \mathrm{H}_{6} \mathrm{OH}$ (VETEC pA).

b) Técnica de precipitação

- Nitrato de bário, $\mathrm{Ba}\left(\mathrm{NO}_{3}\right)_{2}$ (CAAL pA);

- Nitrato de cálcio, $\mathrm{Ca}\left(\mathrm{NO}_{3}\right)_{2} \cdot 4 \mathrm{H}_{2} \mathrm{O}$ (CAAL pA);

- Nitrato de alumínio, $\mathrm{Al}_{2}\left(\mathrm{NO}_{3}\right)_{3} \cdot 9 \mathrm{H}_{2} \mathrm{O}$ (VETEC pA);

- Hidróxido de amônio, $\mathrm{NH}_{4} \mathrm{OH}$ (CAAL pA); e

- Carbonato de amônio, $\left(\mathrm{NH}_{4}\right)_{2} \mathrm{CO}_{3}$ (VETEC pA).

c) Técnica de cristalização

- Carbonato de bário, $\mathrm{BaCO}_{3}$ (VETEC pA);

- Carbonato de cálcio, $\mathrm{CaCO}_{3}$ (VETEC pA );

- Alumínio metálico, $A l$ (ANIDROL Pureza 99,5\%); e

- Ácido nítrico, $\mathrm{HNO}_{3}$ (LABSYNTH pA).

Para a conformação da base de tungstênio poroso do catodo empregou-se o seguinte material:

- Tungstênio metálico, W(JB QUÍMICA). 


\subsection{Processo de preparação do aluminato via reação em estado sólido [50]}

A síntese dos aluminatos emissores de elétrons utilizando a reação em estado sólido ocorre por meio de duas etapas principais: a moagem (homogeneização) e a pirólise. O aluminato de bário e cálcio poderia ser obtido por meio da reação dos seus respectivos óxidos, entretanto, devido à instabilidade destes óxidos (hidratação), a solução sólida ( $\mathrm{B} a \mathrm{O}$ $\left.+\mathrm{CaO}+\mathrm{Al}_{2} \mathrm{O}_{3}\right)$ é, geralmente, obtida a partir dos carbonatos de cálcio e bário e do óxido de alumínio.

Cada reagente deve ser previamente seco em estufa para que a umidade presente seja removida e, assim, possa ser mensurada a quantidade de massa correta de reagente, de forma que se obtenha o material emissor na proporção estequiométrica desejada, ou seja, após a reação de decomposição por efeito da temperatura (pirólise), tenham-se 5 moles de $\mathrm{BaO}: 3$ moles de $\mathrm{CaO}: 2$ moles de $\mathrm{Al}_{2} \mathrm{O}_{3}$. Para isso, é importante verificar o comportamento térmico de cada reagente (carbonatos e óxido de alumínio) utilizado. No presente trabalho realiza-se a análise de perda de massa por meio da termogravimetria (análise da perda de massa em função da temperatura/tempo). Um esquema do processo de preparação do aluminato via reação em estado sólido é apresentado na FIG. 6.1.

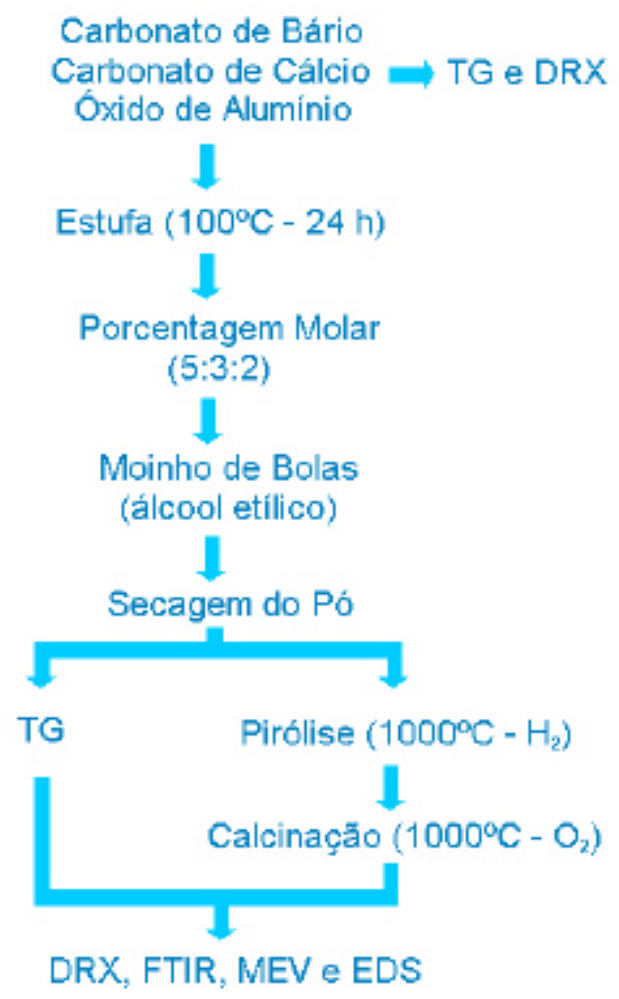

FIGURA 6.1- Processo de preparação e caracterização do aluminato via reação em estado sólido. 
Para que haja a formação dos aluminatos, os reagentes (carbonatos de metais alcalinos terrosos e alumina) são mantidos em forno de hidrogênio por, aproximadamente, 5 horas, a uma temperatura de $1000^{\circ} \mathrm{C}$. Após a reação de pirólise há a formação dos aluminatos, dentre os quais: $\mathrm{BaAl}_{12} \mathrm{O}_{4}, \mathrm{Ca}_{2} \mathrm{BaAl}_{2} \mathrm{O}_{6}$ e $\mathrm{Ba}_{3} \mathrm{Al}_{2} \mathrm{O}_{6}$.

\subsection{Processo de preparação do aluminato via método de cristalização [51]}

A síntese de materiais pelo método de cristalização apresenta as seguintes vantagens em relação aos processos em estado sólido: melhor homogeneização do sistema, maior controle da estequiometria da mistura, reduções na temperatura e no tempo da calcinação e utilização de atmosfera oxidante. As reações envolvidas neste processo de preparação dos aluminatos são:

$$
\begin{aligned}
& 5 \mathrm{BaCO}_{3}+10 \mathrm{HNO}_{3} \rightarrow 5 \mathrm{Ba}\left(\mathrm{NO}_{3}\right)_{2}+5 \mathrm{H}_{2} \mathrm{O}+5 \mathrm{CO}_{2}, \\
& 3 \mathrm{CaCO}_{3}+6 \mathrm{HNO}_{3} \rightarrow 3 \mathrm{Ca}\left(\mathrm{NO}_{3}\right)_{2}+3 \mathrm{H}_{2} \mathrm{O}+3 \mathrm{CO}_{2}, \\
& 4 \mathrm{Al}+\mathrm{gHNO}_{3} \rightarrow 4 \mathrm{Al}\left(\mathrm{NO}_{3}\right)_{3} \cdot y \mathrm{H}_{2} \mathrm{O}+x \mathrm{NO}_{z} .
\end{aligned}
$$

O produto de cristalização, após a calcinação, é;

$$
\begin{gathered}
5 \mathrm{Ba}\left(\mathrm{NO}_{3}\right)_{2}+3 \mathrm{Ca}\left(\mathrm{NO}_{3}\right)_{2}+4 \mathrm{Al}\left(\mathrm{NO}_{3}\right)_{3} \longrightarrow \Delta \\
5 \mathrm{BaO} \cdot 3 \mathrm{CaO} \cdot 2 \mathrm{Al}_{2} \mathrm{O}_{3}+\mathrm{iNO}_{x}
\end{gathered}
$$

O método de cristalização apresenta a vantagem de na etapa de calcinação, como pode ser observado em (6.4), os produtos de reação serem, o aluminato de bário e / ou cálcio e gases do tipo $N O_{x}$. Já na etapa de pirólise com a presença dos carbonatos (reação em estado sólido), a reação incompleta de formação do gás $C O_{x}$ pode gerar carbono elementar que influencia as características do aluminato de bário e cálcio obtido. Neste caso, outra etapa de calcinação em atmosfera oxidante se faz necessária para a remoção do carbono elementar. As etapas do método de cristalização estão apresentadas na FIG. 6.2. 


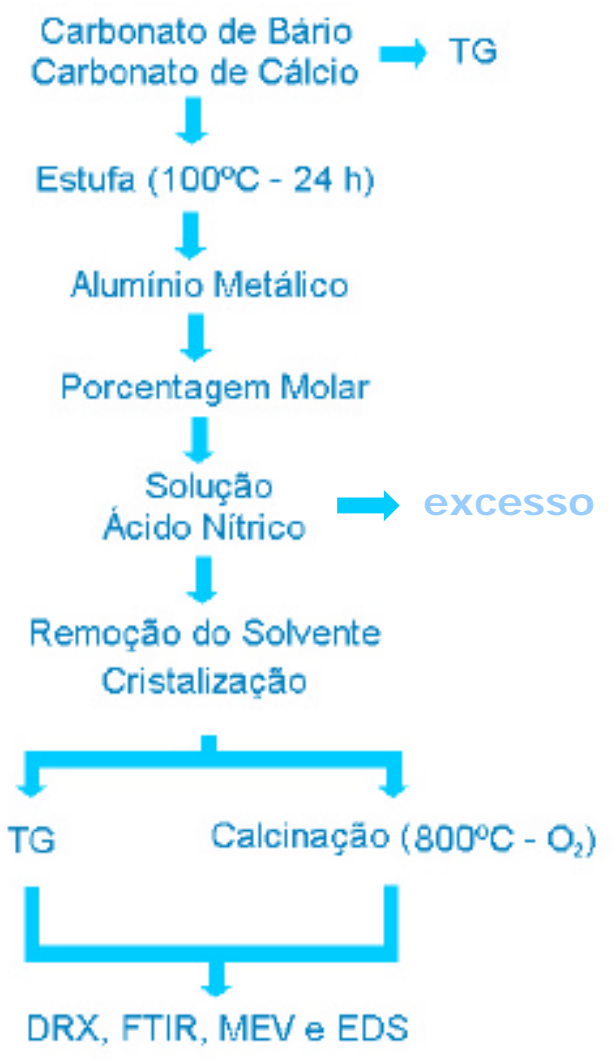

FIGURA 6.2 - Processo de preparação e caracterização do aluminato via reação de cristalização.

O produto final da cristalização é, antes da etapa de pirólise em atmosfera oxidante, analisado termicamente para se determinar as temperaturas de decomposição e formação do aluminato de bário e/ou cálcio.

\subsection{Processo de preparação do aluminato via método de precipitação}

Semelhante ao método de cristalização, o método de precipitação quando comparado à reação em estado sólido apresenta as mesmas vantagens de melhor homogeneização e maior pureza do produto final, pois ambas representam métodos químicos de síntese. A precipitação apresenta, também, vantagens significativas na etapa de pirólise (obtenção do aluminato de bário e cálcio), já que neste caso, segundo a literatura [52], o tempo de pirólise $\left(1000^{\circ} \mathrm{C}\right.$ e atmosfera redutora) é de, aproximadamente, 30 minutos. A metodologia de obtenção do aluminato pelo método de precipitação desenvolvida no presente trabalho está representada na FIG. 6.3. 


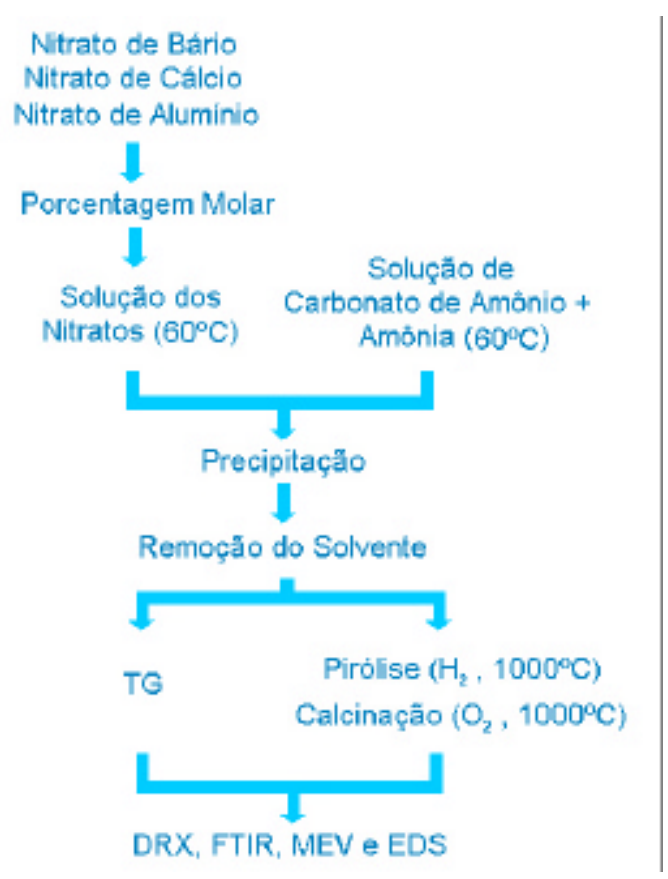

FIGURA 6.3 - Processo de preparação e caracterização do aluminato via reação de precipitação.

As reações envolvidas na rota de preparação do aluminato pelo método de precipitação são as seguintes:

$$
\begin{gathered}
{\left[5 \mathrm{Ba}\left(\mathrm{NO}_{3}\right)_{2}+3 \mathrm{Ca}\left(\mathrm{NO}_{3}\right)_{2}+4 \mathrm{Al}\left(\mathrm{NO}_{3}\right)_{3}\right]_{a q}+\left[x\left(\mathrm{NH}_{4}\right)_{2} \mathrm{CO}_{3}\right]_{a q}} \\
5 \mathrm{BaCO}_{3}+3 \mathrm{CaCO}_{3}+4 \mathrm{Al}(\mathrm{OH})_{3}+\text { gases } *
\end{gathered},
$$

* Gases advindos da decomposição do carbonato de amônio (ex.: $\mathrm{CO}_{2}, \mathrm{CO}_{\text {e }} \mathrm{NH}_{3}$ ).

$$
5 \mathrm{BaCO}_{3}+3 \mathrm{CaCO}_{3}+4 \mathrm{Al}(\mathrm{OH})_{3} \longrightarrow\left(5 \mathrm{BaO} \cdot 3 \mathrm{CaO} \cdot 2 \mathrm{Al}_{2} \mathrm{O}_{3}\right)+\text { gases *. }
$$

*Gases produzidos na etapa de pirólise (ex.: $\mathrm{CO}_{2}$ e $\mathrm{CO}$ )

\subsection{Processo de fabricação da base do catodo impregnado}

A base do catodo impregnado é composta de uma pastilha de tungstênio porosa impregnada com o material fonte de bário. Para tanto se utiliza pó de tungstênio de alta pureza com a distribuição de tamanho de partícula na faixa de 2 a $14 \mu \mathrm{m}$. A porosidade da pastilha de tungstênio varia com as seguintes características iniciais do pó: tamanho e distribuição do tamanho de partícula. Os parâmetros de conformação e de sinterização das pastilhas de tungstênio estão apresentados na TAB.6.1 [1],[10]. A FIG. 6.4 ilustra o processo de fabricação da base do catodo impregnado. 
TABELA 6.1 - Parâmetros utilizados na fabricação da base do catodo impregnado.

\begin{tabular}{cccc}
\hline \multicolumn{2}{c}{ Parâmetro de conformação } & \multicolumn{2}{c}{ Parâmetros de sinterização } \\
\hline $\begin{array}{c}\text { Pressão de pré- } \\
\text { compactação } \\
\text { (prensagem uniaxial) }\end{array}$ & 3 ton cm $^{-2}$ & Temperatura & $1900-2500^{\circ} \mathrm{C}$ \\
$\begin{array}{c}\text { Pressão de } \\
\text { compactação } \\
\text { (prensagem isostática) }\end{array}$ & $140-200 \mathrm{MPa}$ & Tempo & $10-300 \mathrm{~min}$ \\
& Densidade & $\begin{array}{c}\text { Hidrogênio } \\
\text { (redutora) }\end{array}$ \\
\hline
\end{tabular}

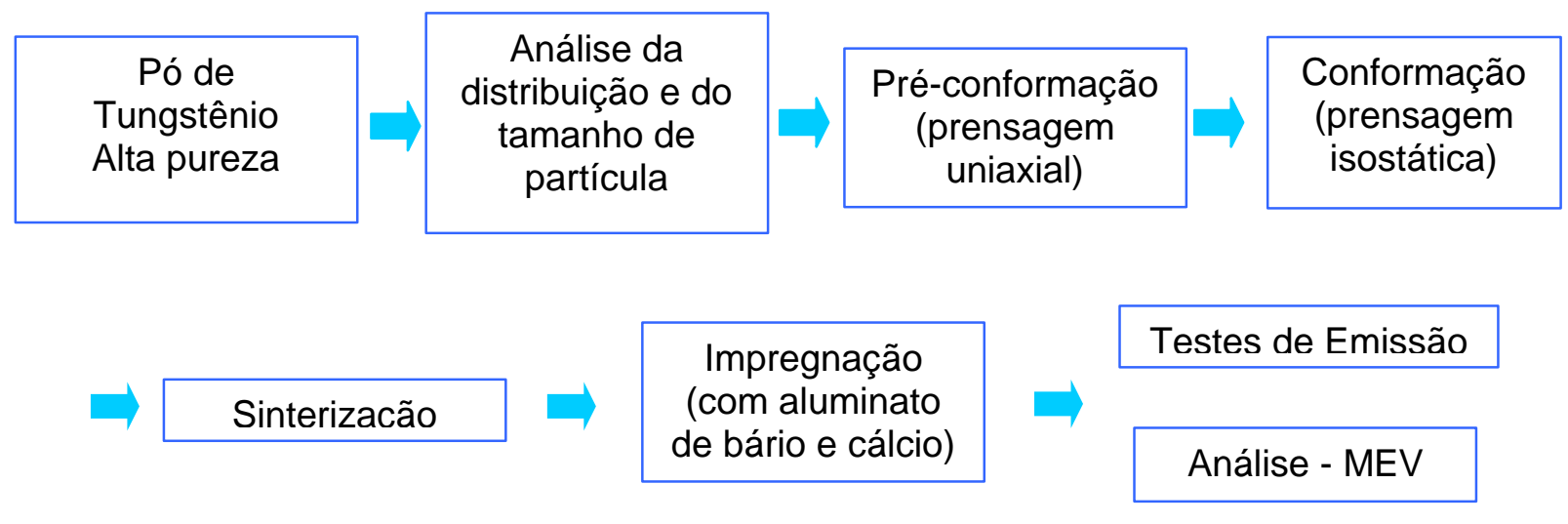

FIGURA 6.4 - Processo de fabricação e de caracterização do catodo impregnado.

A impregnação da matriz metálica de tungstênio poroso com o aluminato é obtida por meio do efeito de capilaridade onde os poros existentes na pastilha são preenchidos com o aluminato. A FIG. 6.5 ilustra o processo de impregnação e apresenta os parâmetros do processo [1],[10].

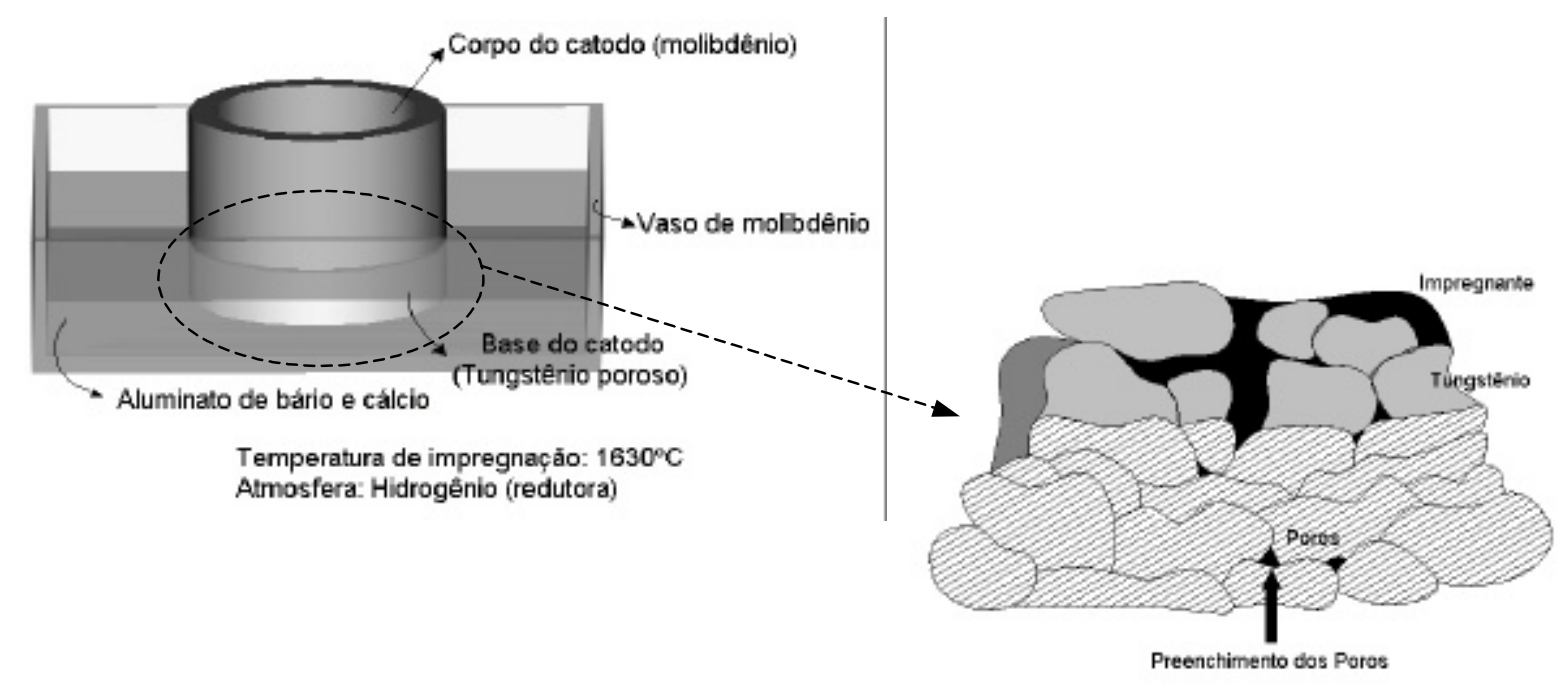

FIGURA 6.5 - Representação do processo de impregnação. 


\subsection{Desenvolvimento dos aparatos utilizados na preparação do catodo impregnado}

As FIG. 6.6 a 6.8 mostram alguns dos aparatos desenvolvidos para o processo de fabricação dos catodos impregnados. A FIG. 6.6 apresenta o forno utilizado na obtenção dos aluminatos de bário e cálcio, compostos de um sistema de vácuo (bomba mecânica e bomba difusora - pressão da ordem de $10^{-5}$ torr) e um sistema de aquecimento resistivo capaz de atingir temperaturas até $1200^{\circ} \mathrm{C}$.

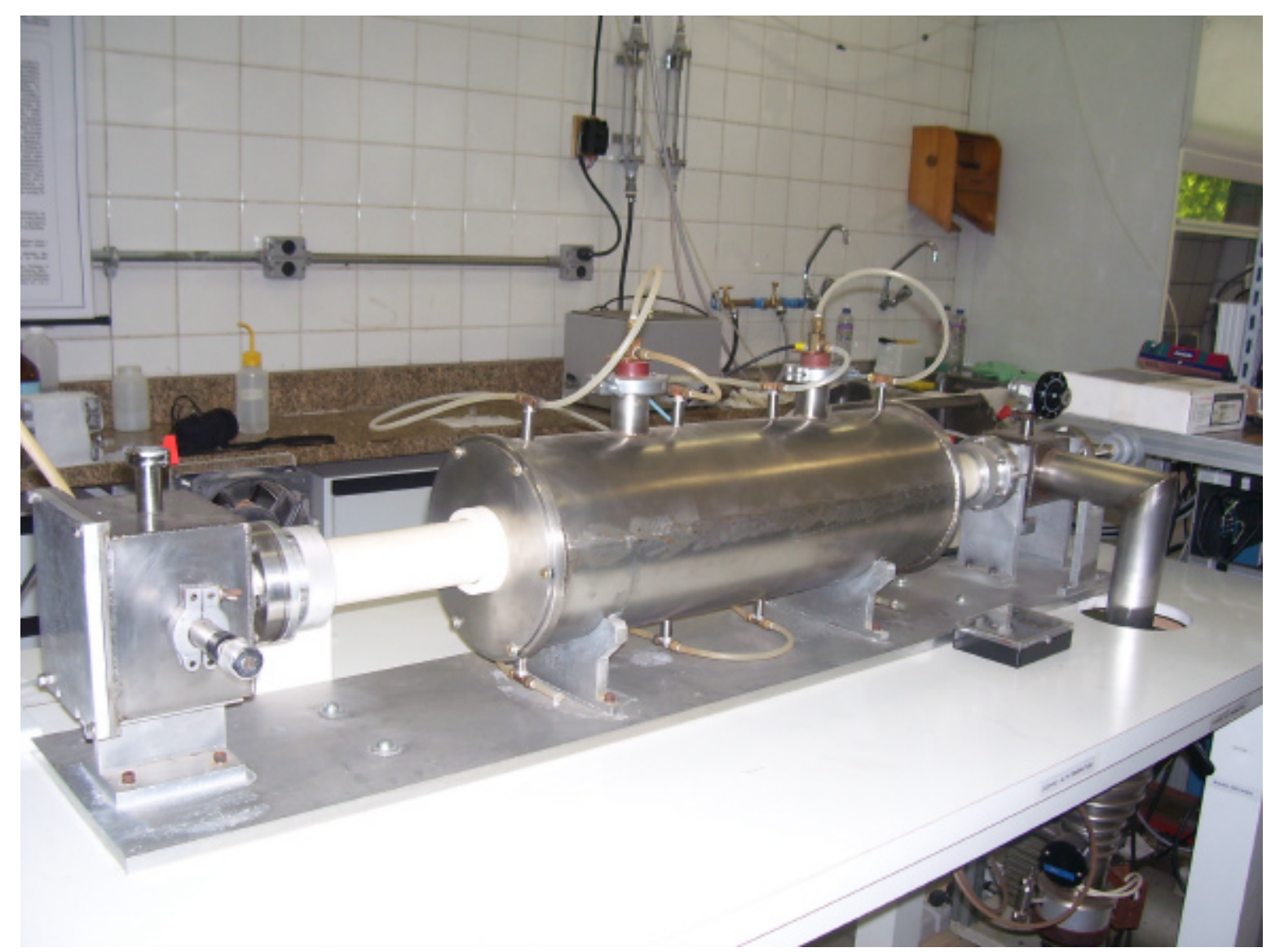

FIGURA 6.6 - Forno de pirólise do aluminato de bário e cálcio.

As FIG. 6.7 (a) e (b) apresentam o sistema de caracterização da emissão termiônica, que possui um sistema de ultra-alto vácuo capaz de atingir pressões da ordem de $10^{-9}$ torr. A leitura da temperatura do catodo é realizada por meio de um pirômetro óptico. 


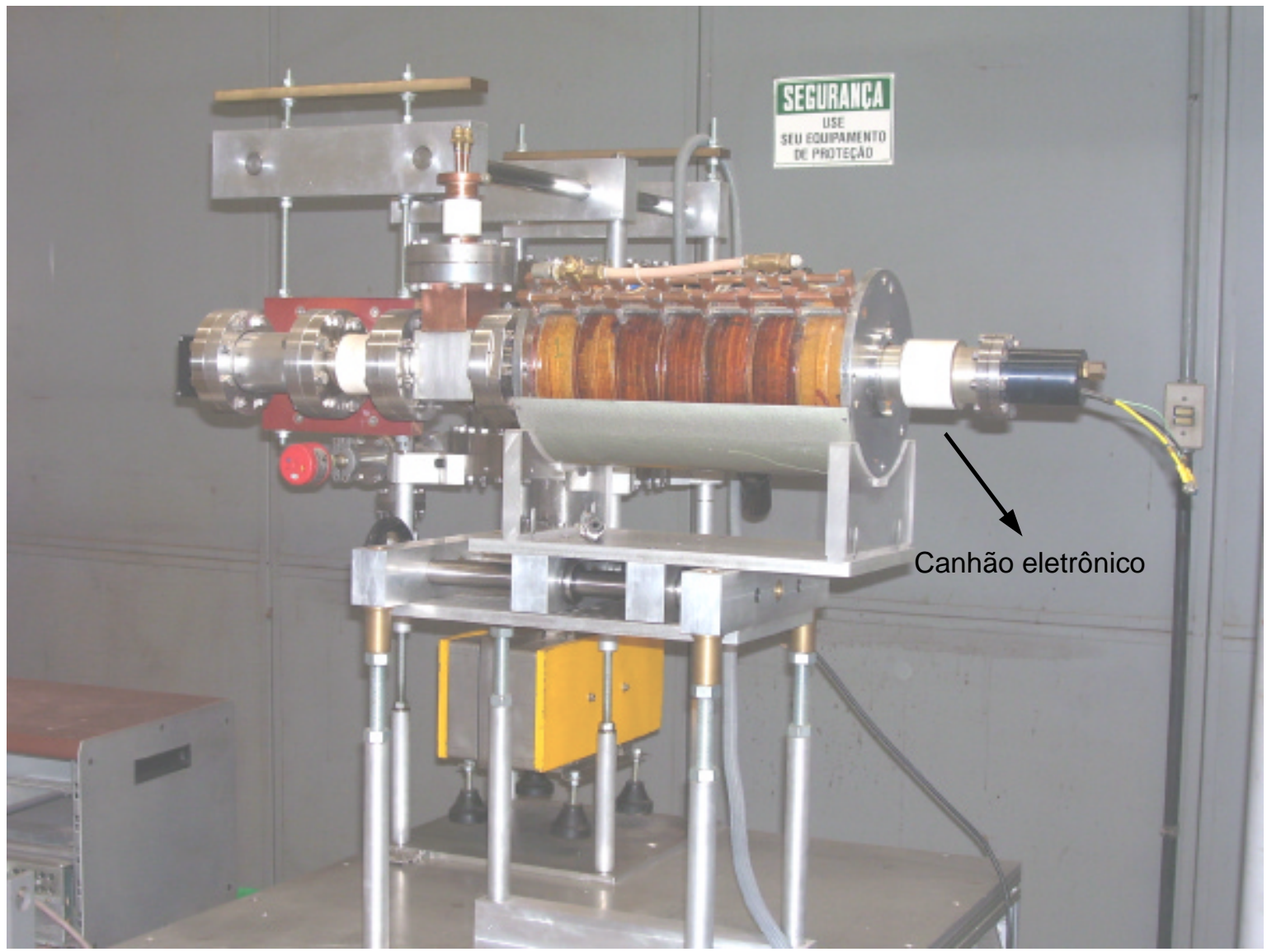

(a)

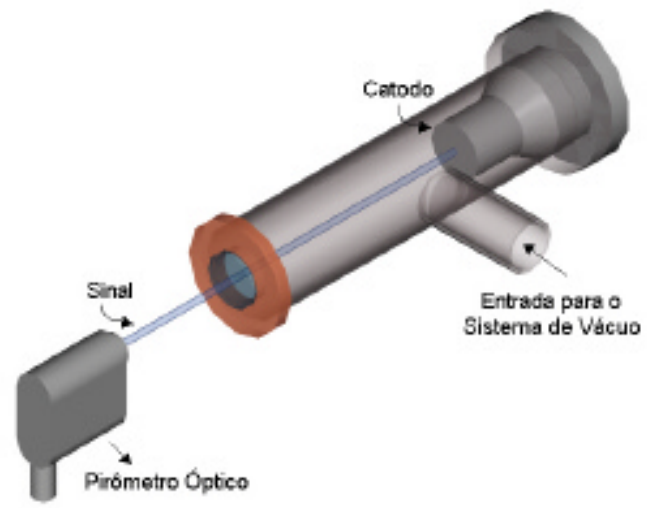

(b)

FIGURA 6.7 - (a) Dispositivo de caracterização do catodo termiônico. (b) Desenho esquemático de um sistema para medição de temperatura do catodo termiônico utilizando um pirômetro óptico.

A FIG. 6.8 ilustra o forno que é utilizado na etapa de impregnação, que também possui um sistema de vácuo (pressão da ordem de $10^{-5}$ torr) e entrada para gases (como hidrogênio, oxigênio e nitrogênio). 


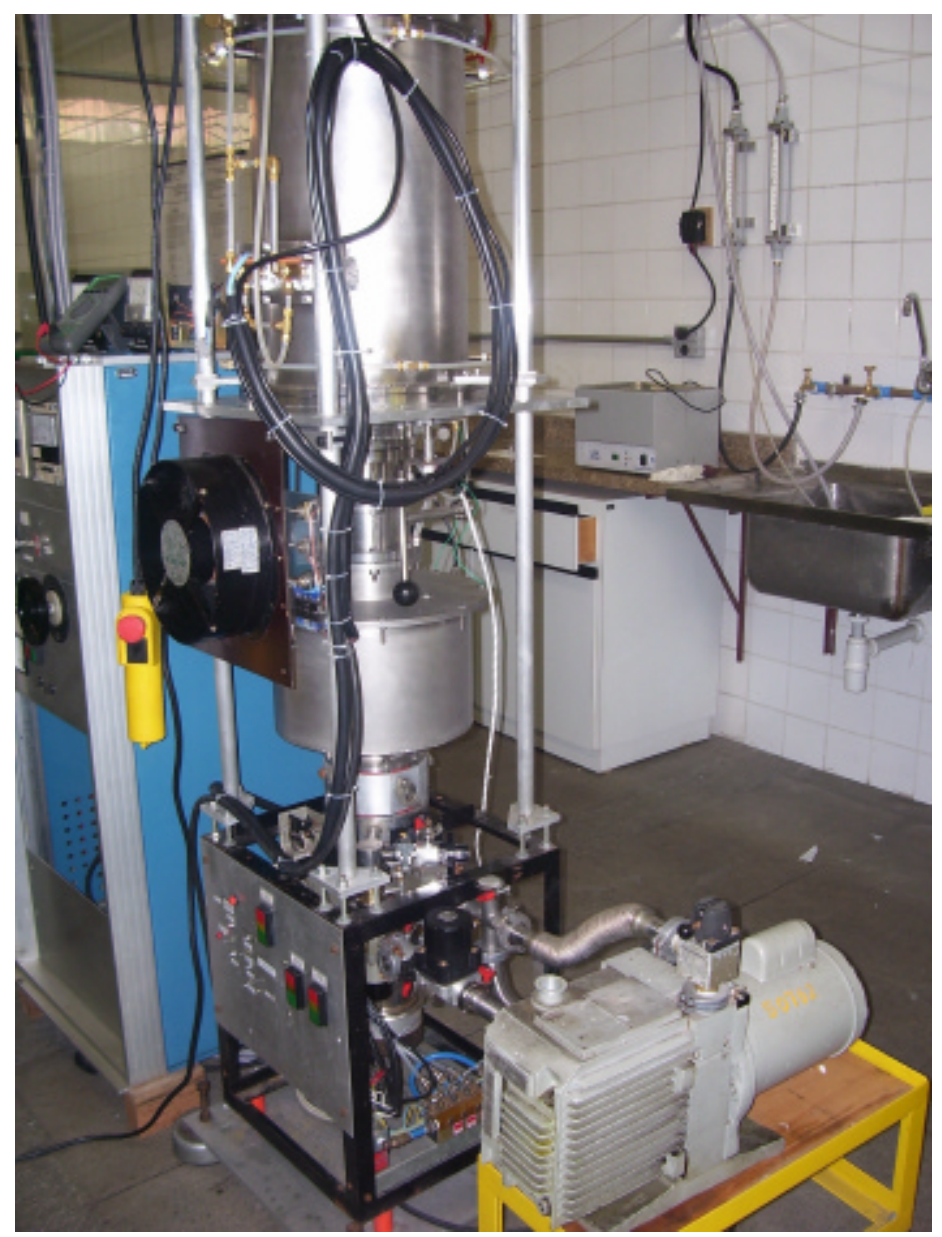

FIGURA 6.8 - Forno para o processo de impregnação.

\subsection{Dimensionamento do canhão eletrônico}

Como discutido no Capítulo 3, a geometria do canhão eletrônico (raio do catodo e do anodo) define as características do feixe eletrônico (densidade de corrente de emissão, tensão de aceleração e, conseqüentemente, a perveância do canhão). O objetivo do dimensionamento do canhão eletrônico foi a adequação das dimensões do canhão eletrônico em desenvolvimento, comparando-se as medidas de um canhão de referência, mantendo as condições de operação do canhão eletrônico em regime de carga espacial. Como o presente trabalho visa investigar as características do material emissor que compõe o catodo, todos os parâmetros existentes na válvula de microondas de potência foram adequados ao modelo de referência e à metodologia desenvolvida para a síntese do canhão eletrônico de Pierce. Por este motivo, manteve-se as características do canhão eletrônico de uma TWT de referência para que estas não comprometessem o presente trabalho. A FIG. 6.9 ilustra os parâmetros da geometria do canhão eletrônico de Pierce. 


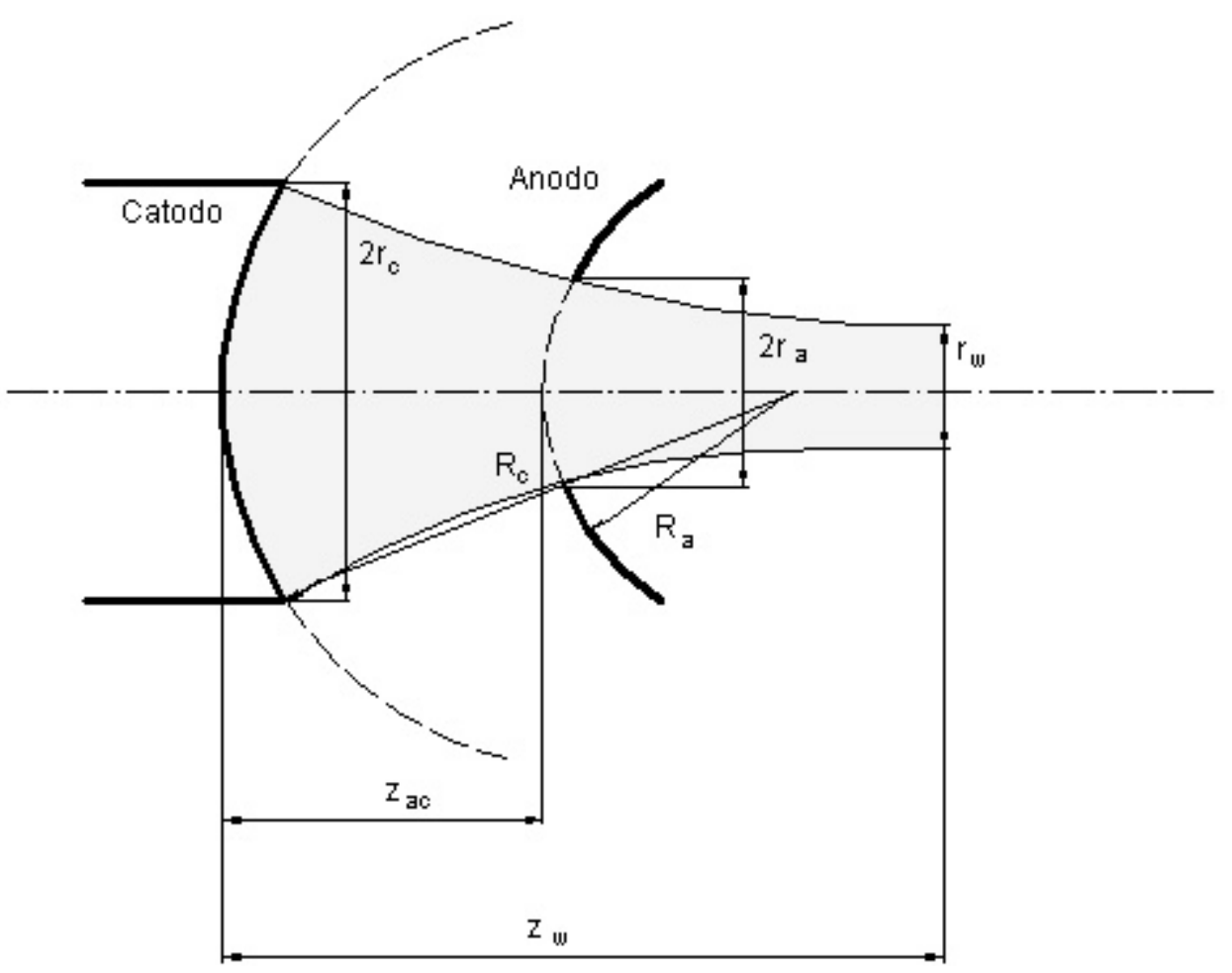

FIGURA 6.9 - Geometria do canhão eletrônico de Pierce (Perveância $=0,77 \mu$ Perv).

As peças utilizadas na fabricação do canhão eletrônico passaram por etapas de usinagem, limpeza e brasagem. Basicamente, os materiais utilizados na sua confecção foram: cobre livre de oxigênio, aço inoxidável, alumina, kovar, tungstênio e molibdênio. Vale ressaltar que os constituintes do canhão passaram por uma análise de detecção de vazamento. Esta etapa é fundamental, pois as válvulas de microondas operam em regime de ultra-alto vácuo. 


\subsection{Metodologia empregada nas medidas termiônicas}

Nesta Seção apresentar-se-á uma das técnicas de medidas emissão de elétrons dos catodos termiônicos. Avaliou-se nesta Seção, o desempenho de um catodo por meio da determinação da curva de distribuição da função trabalho prática (practical work function distribution - PWFD) e ainda, apresentou-se um procedimento de síntese de um canhão eletrônico para alta tensão.

\subsubsection{Curvas PWFD - distribuição da função trabalho prática}

As distribuições PWFD são utilizadas para qualificar o desempenho do catodo termiônico em toda a faixa de operação, por meio da determinação da função trabalho efetiva. Assim, pode-se avaliar o desempenho dos catodos em qualquer temperatura de operação. Para qualificar os catodos termiônicos, Miram propôs um gráfico padrão que relaciona a densidade de corrente no limite de carga espacial, normalizada, com a temperatura. A PWFD, neste caso, é obtida por meio da interseção da curva de Miram ou curva de desempenho com as curvas teóricas de Richardson-Dushman.

O método da PWFD descreve o perfil de operação de cada tipo de catodo termiônico, possibilitando a comparação dos perfis termiônicos de diferentes catodos. A PWFD também permite o projeto de canhões eletrônicos para alta tensão de operação empregando-se medidas experimentais realizadas em baixo potencial de aceleração. Em 6.9.1.1 descreve-se o procedimento de construção da PWFD.

\subsubsection{Construção das curvas PWFD}

Obtêm-se as curvas de Miram por meio do gráfico obtido a partir das medidas de corrente ou densidade de corrente versus o potencial de aceleração para diferentes temperaturas do catodo. A FIG. 6.10 mostra a curva corrente versus a tensão de aceleração para um catodo reservatório tipo MMM de um experimento realizado por Miram [2]. Realizou-se o experimento nas seguintes condições: faixa de temperatura de 820 a $1100^{\circ} \mathrm{C}$ com incremento de $20^{\circ} \mathrm{C}$ e intervalo do potencial de aceleração de 0 a $5500 \mathrm{~V}$, nesta situação a corrente termiônica medida variou de 0 a 800 mA.

A curva de emissão termiônica, $I$ x $V$, apresentada na FIG. 6.10, mostra que a uma temperatura acima de $1060^{\circ} \mathrm{C}$, a corrente é limitada pela carga espacial, ou seja, para que haja um acréscimo na corrente de emissão é necessário aumentar a tensão. 


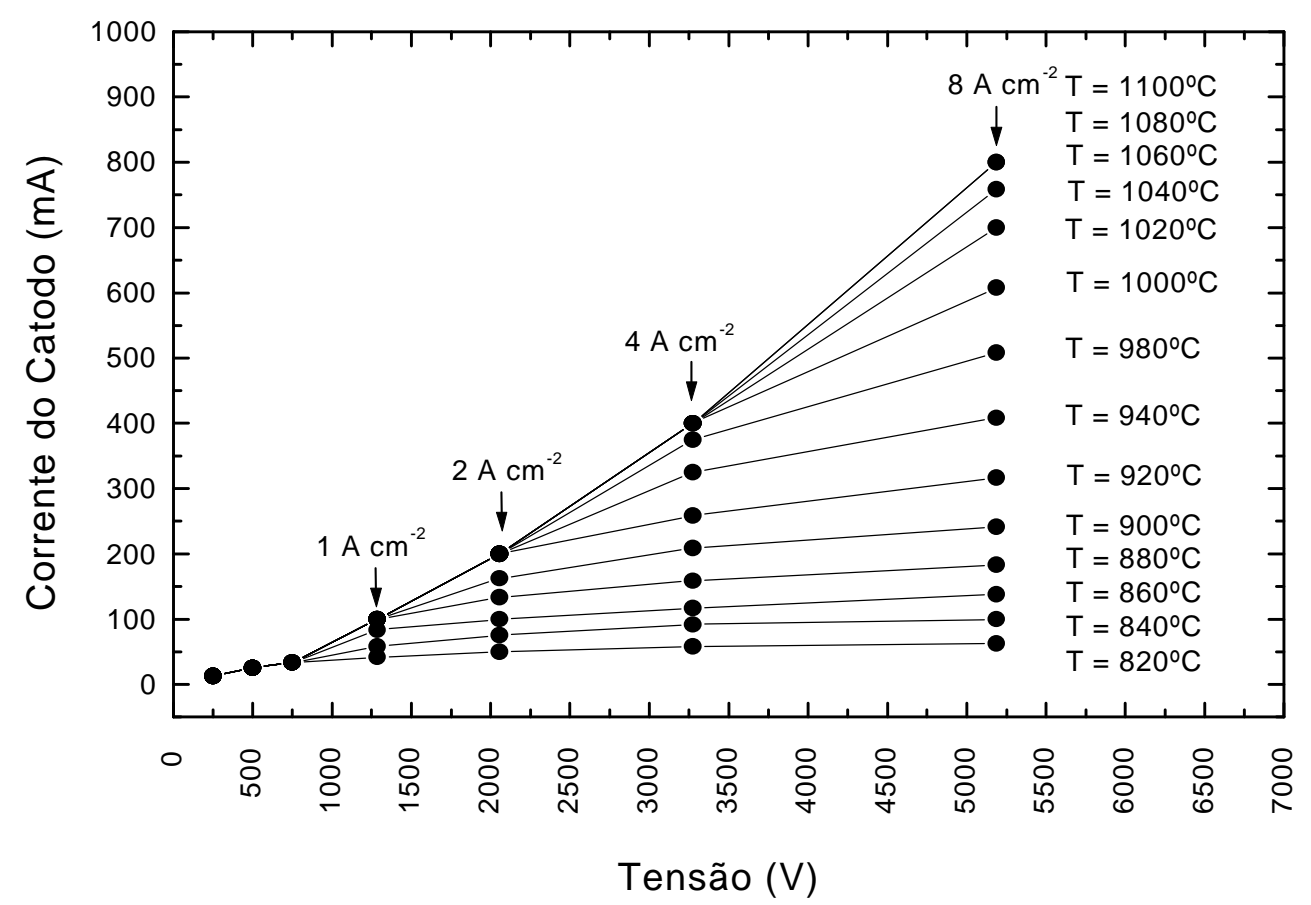

FIGURA 6.10 - Curva de emissão termiônica para um catodo reservatório do tipo MMM.

Para se construir a curva de Miram ou de desempenho considerou-se o fluxograma ilustrado na FIG. 6.11. Os dados do experimento de Miram para o catodo MMM estão apresentados na TAB. 6.2.

TABELA 6.2 - Dados do experimento para o catodo reservatório do tipo MMM.

\begin{tabular}{cccc}
\hline Corrente $(\mathrm{mA})$ & Densidade de Corrente $\left(\mathrm{Acm}^{-2}\right)$ & Tensão $(\mathrm{V})$ & Perveância $(\mu$ Perv $)$ \\
\hline 100 & 1,0 & 1288 & \\
200 & 2,0 & 2055 & 21,5 \\
400 & 4,0 & 3275 & \\
800 & 8,0 & 5186 & \\
\hline
\end{tabular}

Por meio da TAB. 6.2, verifica-se que a perveância do canhão, dada por Perv $=J / V^{3 / 2}$ é, aproximadamente, $21,5 \mu$ Perv, considerando a área do catodo igual a $0,1 \mathrm{~cm}^{-2}$. 
Selecionar $I_{0}$ ou $J_{0}$

(na temperatura que o

fluxo de elétrons é

limitada pela carga espacial)

Medir a tensão de aceleração, $V_{0}$, em $I_{0}$ ou

$J_{0}$

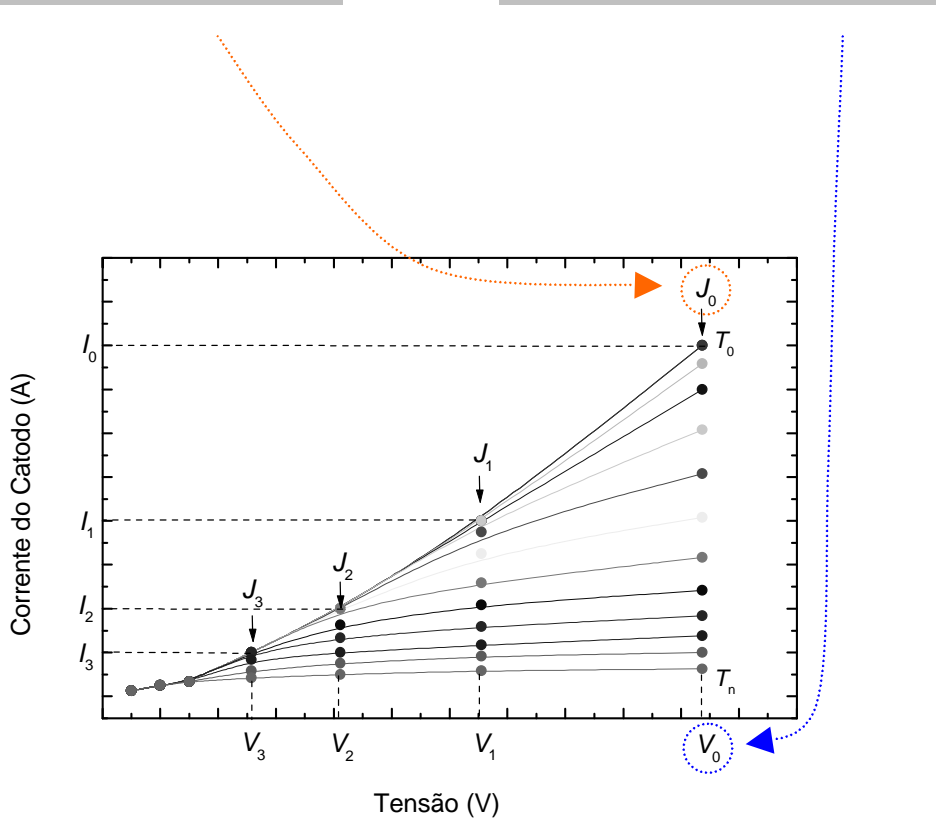

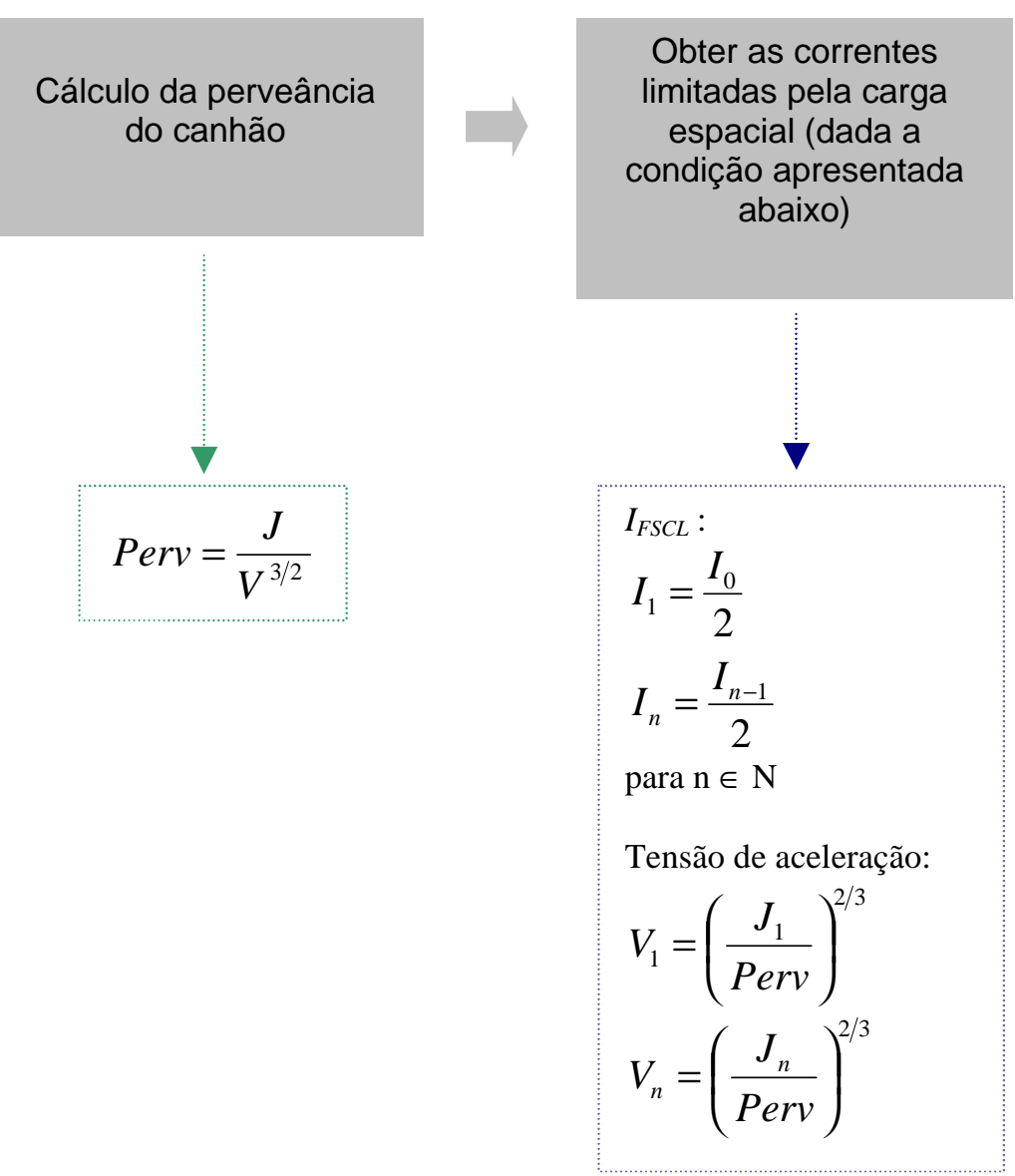

FIGURA 6.11 - Fluxograma para a extração dos parâmetros da curva I x V necessários para a construção da curva de desempenho. 
Para cada tensão aplicada traçaram-se as curvas de Miram, corrente de emissão normalizada versus temperatura. No processo de normalização das curvas consideraram-se as correntes limitadas pela carga espacial como parâmetro de normalização, cujos valores estão apresentados nas TAB.6.3 a 6.6.

TABELA 6.3 - Corrente normalizada utilizada na construção da curva de Miram para

\begin{tabular}{|c|c|c|}
\hline $\mathrm{T}\left({ }^{\circ} \mathrm{C}\right)$ & $\mathrm{I}(\mathrm{mA})$ & $\begin{array}{l}\text { Corrente normalizada } \\
\qquad I(\%)=\frac{I}{I_{F S C L}} \cdot 100\end{array}$ \\
\hline 1100 & 100 & 100 \\
\hline 1080 & 100 & 100 \\
\hline 1060 & 100 & 100 \\
\hline 1040 & 100 & 100 \\
\hline 1020 & 100 & 100 \\
\hline 1000 & 100 & 100 \\
\hline 980 & 100 & 100 \\
\hline 940 & 100 & 100 \\
\hline 920 & 100 & 100 \\
\hline 900 & 100 & 100 \\
\hline 880 & 100 & 100 \\
\hline 860 & 83,3 & 83,3 \\
\hline 840 & 66,6 & 66,6 \\
\hline 820 & 50,0 & 50 \\
\hline
\end{tabular}

TABELA 6.4 - Corrente normalizada utilizada na construção da curva de Miram para $I_{F S C L}=200 \mathrm{~mA}$.

\begin{tabular}{ccc}
\hline $\mathrm{T}\left({ }^{\circ} \mathrm{C}\right)$ & $\mathrm{I}(\mathrm{mA})$ & $\begin{array}{c}\text { Corrente normalizada } \\
I(\%)=\frac{I}{I_{F S C L}} \cdot 100\end{array}$ \\
& & 100 \\
\hline 1100 & 200 & 100 \\
1080 & 200 & 100 \\
1060 & 200 & 100 \\
1040 & 200 & 100 \\
1020 & 200 & 100 \\
1000 & 200 & 100 \\
980 & 200 & 100 \\
940 & 200 & 100 \\
920 & 200 & 83,5 \\
900 & 167 & 66,7 \\
880 & 133,4 & 50,0 \\
860 & 100 & 37,5 \\
840 & 75,0 & 29,2 \\
820 & 58,4 & \\
\hline
\end{tabular}


TABELA 6.5 - Corrente normalizada utilizada na construção da curva de Miram para

\begin{tabular}{|c|c|c|}
\hline $\mathrm{T}\left({ }^{\circ} \mathrm{C}\right)$ & $\mathrm{I}(\mathrm{mA})$ & $\begin{array}{l}\text { Corrente normalizada } \\
\qquad I(\%)=\frac{I}{I_{F S C L}} \cdot 100\end{array}$ \\
\hline 1100 & 400 & 100 \\
\hline 1080 & 400 & 100 \\
\hline 1060 & 400 & 100 \\
\hline 1040 & 400 & 100 \\
\hline 1020 & 400 & 100 \\
\hline 1000 & 400 & 100 \\
\hline 980 & 367 & 91,8 \\
\hline 940 & 325 & 81,3 \\
\hline 920 & 258,3 & 64,6 \\
\hline 900 & 208,3 & 52,1 \\
\hline 880 & 158,3 & 39,6 \\
\hline 860 & 116,6 & 29,2 \\
\hline 840 & 91,8 & 22,9 \\
\hline 820 & 65,5 & 16,4 \\
\hline
\end{tabular}

TABELA 6.6 - Corrente normalizada utilizada na construção da curva de Miram para $I_{F S C L}=800 \mathrm{~mA}$.

\begin{tabular}{ccc}
\hline $\mathrm{T}\left({ }^{\circ} \mathrm{C}\right)$ & $\mathrm{I}(\mathrm{mA})$ & $\begin{array}{c}\text { Corrente normalizada } \\
I(\%)\end{array}$ \\
& & $\frac{I}{I_{F S C L}} \cdot 100$ \\
\hline 1100 & 800 & 100 \\
1080 & 800 & 100 \\
1060 & 800 & 100 \\
1040 & 767 & 95,9 \\
1020 & 700 & 87,5 \\
1000 & 617 & 77,3 \\
980 & 517 & 64,6 \\
940 & 412,5 & 51,6 \\
920 & 325 & 40,6 \\
900 & 245,8 & 30,7 \\
880 & 191,6 & 24 \\
860 & 141,6 & 17,7 \\
840 & 100 & 12,5 \\
820 & 66,6 & 8,3 \\
\hline
\end{tabular}

A FIG. 6.12 mostra as curvas de desempenho para o experimento de Miram para o catodo tipo MMM. Nos ajustes das curvas de Miram empregou-se a técnica de 
mínimos quadrados. Obteve-se o melhor ajuste da curva de Miram utilizando a função sigmoidal Boltzmann.

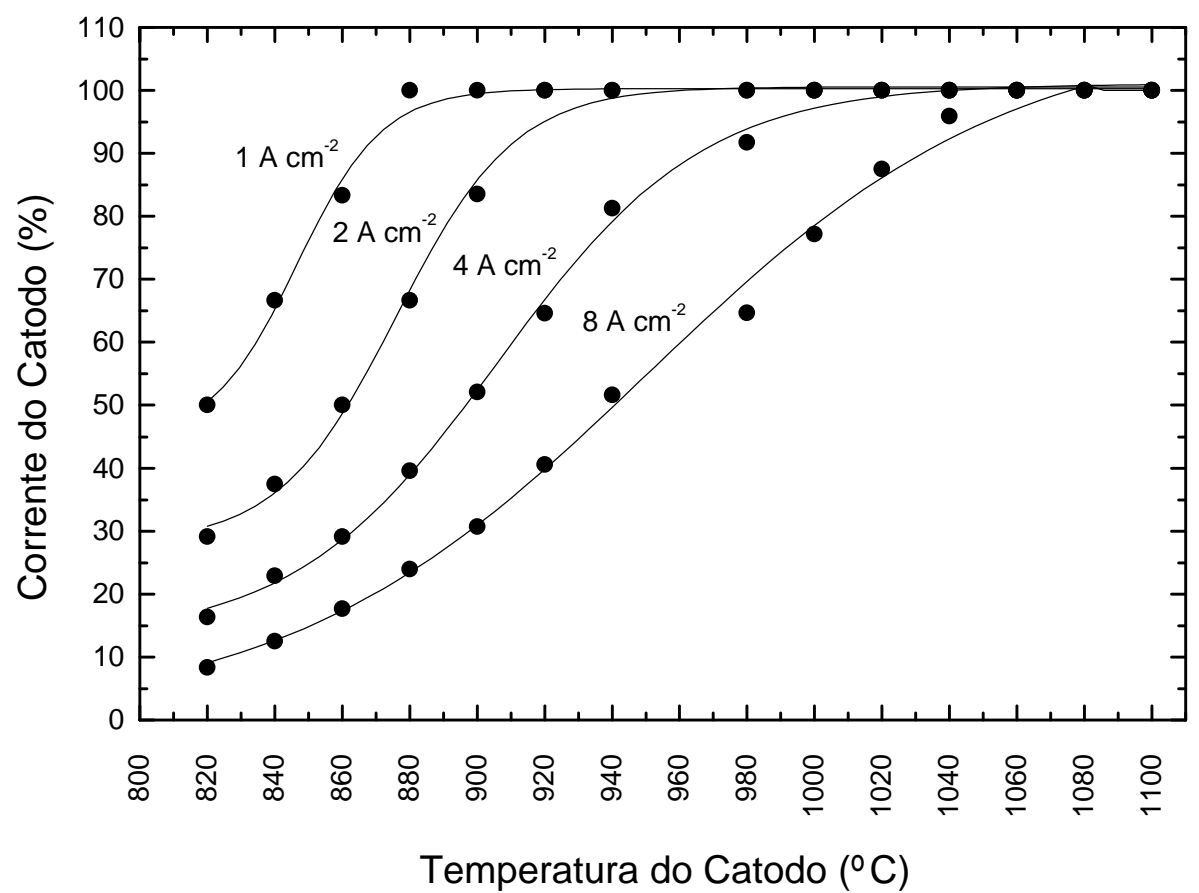

FIGURA 6.12 - Curvas de desempenho (Miram) para o catodo tipo MMM.

Verifica-se por meio da FIG. 6.12 que as curvas de Miram de diferentes $J_{F S C L}$ apresentam comportamentos aproximadamente semelhantes para as correntes normalizados maiores que $50 \%$, desta forma, há a possibilidade da construção da curva de desempenho para os experimentos que empregam alta tensão de aceleração.

$\mathrm{Na}$ etapa seguinte para a construção da curva PWFD, deve-se traçar uma família de curvas teóricas normalizadas da corrente de emissão limitada pela temperatura para cada curva de desempenho. Para isso, utilizou-se da equação de RichardsonDushman, para uma faixa de valores de funções trabalho, dada por:

$$
J(T)=120 \cdot T^{2} \cdot \exp \left(\frac{-\phi_{E}}{k_{B} T}\right)
$$

Considerando-se o experimento as curvas de Miram do catodo MMM, determinaram-se as curvas PWFD para os diferentes valores de $J_{F S C L}$. Para isso, utilizou-se o intervalo de temperatura do experimento de Miram, ou seja, de 820 a $1100^{\circ} \mathrm{C}(1093,15$ a $1373,15 \mathrm{~K})$. 
Os gráficos da corrente de emissão teórica versus a temperatura do catodo para diferentes funções trabalhos são apresentados a seguir.

a) Para $J_{F S C}=8 \mathrm{~A} \mathrm{~cm}^{-2}$

Para se traçar a família de curvas teóricas normalizadas da corrente de emissão limitada pela temperatura para $J_{F S C L}=8 \mathrm{Acm}^{-2}$, deve-se inicialmente delimitar o intervalo da função trabalho a ser empregando neste caso, por meio da obtenção do valor da maior função trabalho do catodo (dados os valores da densidade de corrente de emissão limitada pela carga espacial, $8 \mathrm{Acm}^{-2}$, e da máxima temperatura de operação, $\left.1373,15 \mathrm{~K}\left(1100^{\circ} \mathrm{C}\right)\right)$ empregando-se (6.7). As demais funções trabalho deste experimento devem ser menores que a função trabalho obtida na solução de (6.7), neste caso, $\phi<2,03 \mathrm{eV}$, conforme ilustrado na FIG. 6.13. Para cada função trabalho definida anteriormente traça-se a curva da corrente de emissão normalizada versus a temperatura. Alguns dos valores obtidos aplicando-se (6.7) estão apresentados na TAB. 6.7.

TABELA 6.7 - Valores da densidade de corrente de emissão normalizada (sendo $\phi_{\max }$ a maior função trabalho, $\phi(\sim 50 \%)$ a função trabalho quando $J_{\text {Miram }}=50 \%$ e $\phi_{\min }$ a menor função trabalho).

\begin{tabular}{ccccccccc}
\hline \multirow{2}{*}{$\mathrm{T}\left({ }^{\circ} \mathrm{C}\right)$} & $\mathrm{T}(\mathrm{K})$ & \multicolumn{2}{c}{$\phi_{\max }=2,03 \mathrm{eV}$} & \multicolumn{2}{c}{$\phi(\sim 50 \%)=1,84 \mathrm{eV}$} & \multicolumn{2}{c}{$\phi_{\min }=1,79 \mathrm{eV}$} \\
& \multicolumn{3}{c}{$J\left(\mathrm{Acm}^{-2}\right)$} & $J(\%)$ & $J\left(\mathrm{Acm}^{-2}\right)$ & $J(\%)$ & $J\left(\mathrm{Acm}^{-2}\right)$ & $J(\%)$ \\
\hline 1100 & 1373,15 & 0,800 & 100,00 & 3,851 & 481,42 & 5,877 & 734,65 \\
1080 & 1353,15 & 0,603 & 75,36 & 2,970 & 371,30 & 4,561 & 570,17 \\
1060 & 1333,15 & 0,451 & 56,33 & 2,274 & 284,28 & 3,515 & 439,35 \\
1040 & 1313,15 & 0,334 & 41,76 & 1,728 & 215,99 & 2,688 & 336,03 \\
1020 & 1293,15 & 0,245 & 30,68 & 1,302 & 162,79 & 2,040 & 255,00 \\
1000 & 1273,15 & 0,179 & 22,34 & 0,973 & 121,67 & 1,535 & 191,93 \\
986,85 & 1260 & 0,144 & 18,04 & 0,800 & 100,00 & 1,146 & 143,23 \\
980 & 1253,15 & 0,129 & 16,11 & 0,721 & 90,14 & 1,268 & 158,49 \\
956,24 & 1229,39 & 0,086 & 10,78 & 0,499 & 62,36 & 0,800 & 100,00 \\
940 & 1213,15 & 0,065 & 8,12 & 0,385 & 48,10 & 0,621 & 77,61 \\
920 & 1193,15 & 0,045 & 5,67 & 0,277 & 34,62 & 0,450 & 56,31 \\
900 & 1173,15 & 0,031 & 3,92 & 0,197 & 24,65 & 0,323 & 40,43 \\
880 & 1153,15 & 0,021 & 2,67 & 0,139 & 17,36 & 0,230 & 28,71 \\
860 & 1133,15 & 0,014 & 1,80 & 0,097 & 12,08 & 0,161 & 20,16 \\
840 & 1113,15 & 0,010 & 1,19 & 0,066 & 8,30 & 0,112 & 13,98 \\
820 & 1093,15 & 0,006 & 0,78 & 0,045 & 5,63 & 0,077 & 9,58 \\
\hline
\end{tabular}




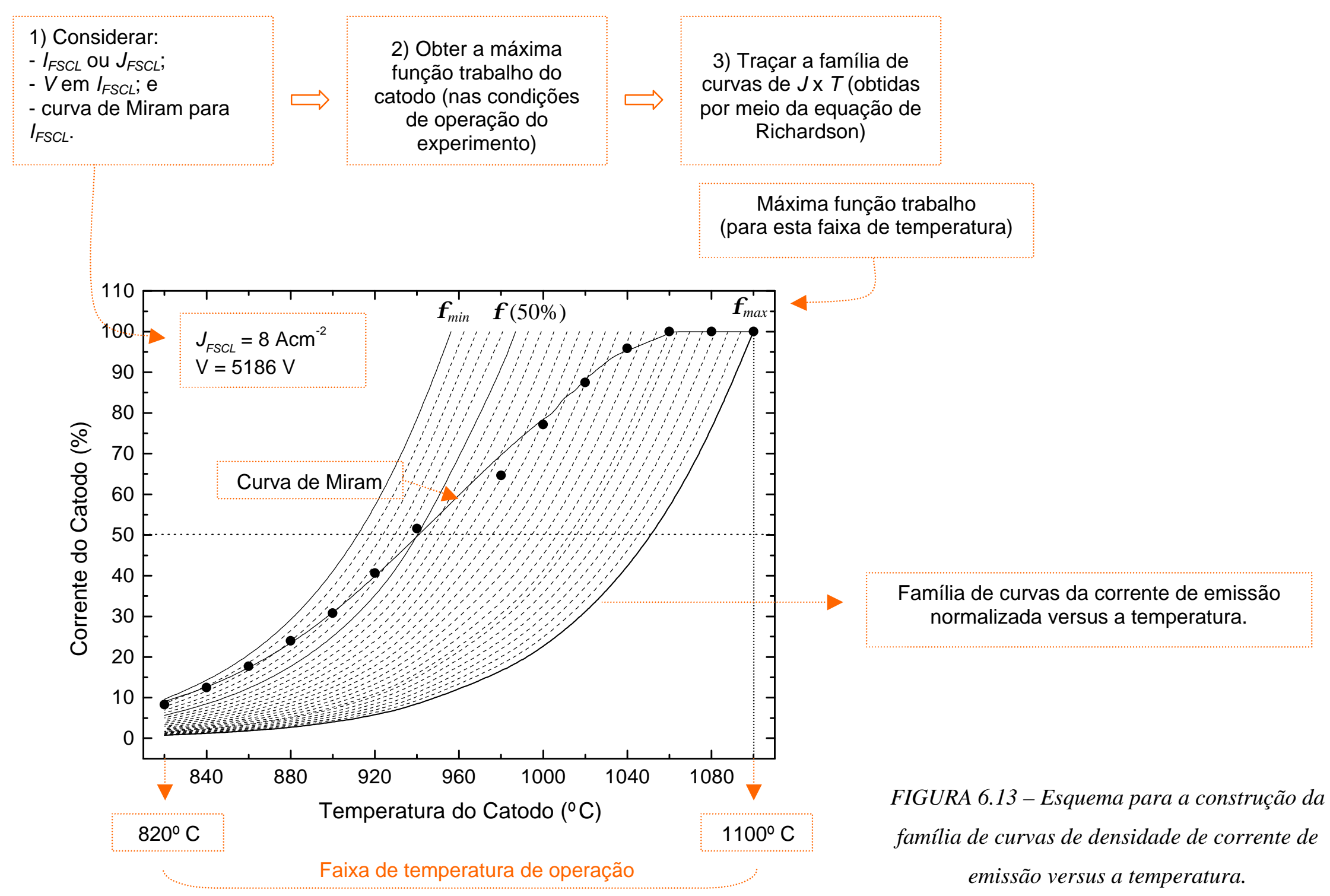


A obtenção da curva PWFD é uma técnica empírica. Define-se o intervalo do eixo das ordenadas de $f\left(\phi_{E}\right)$ a partir da curva de Miram (eixo da corrente de emissão normalizada) e, obtêm-se os pontos de intersecção das curvas de Miram e de Richardson. Para $J_{F S C L}=8 \mathrm{Acm}^{-2}$, a PWFD está ilustrada na FIG. 6.14.

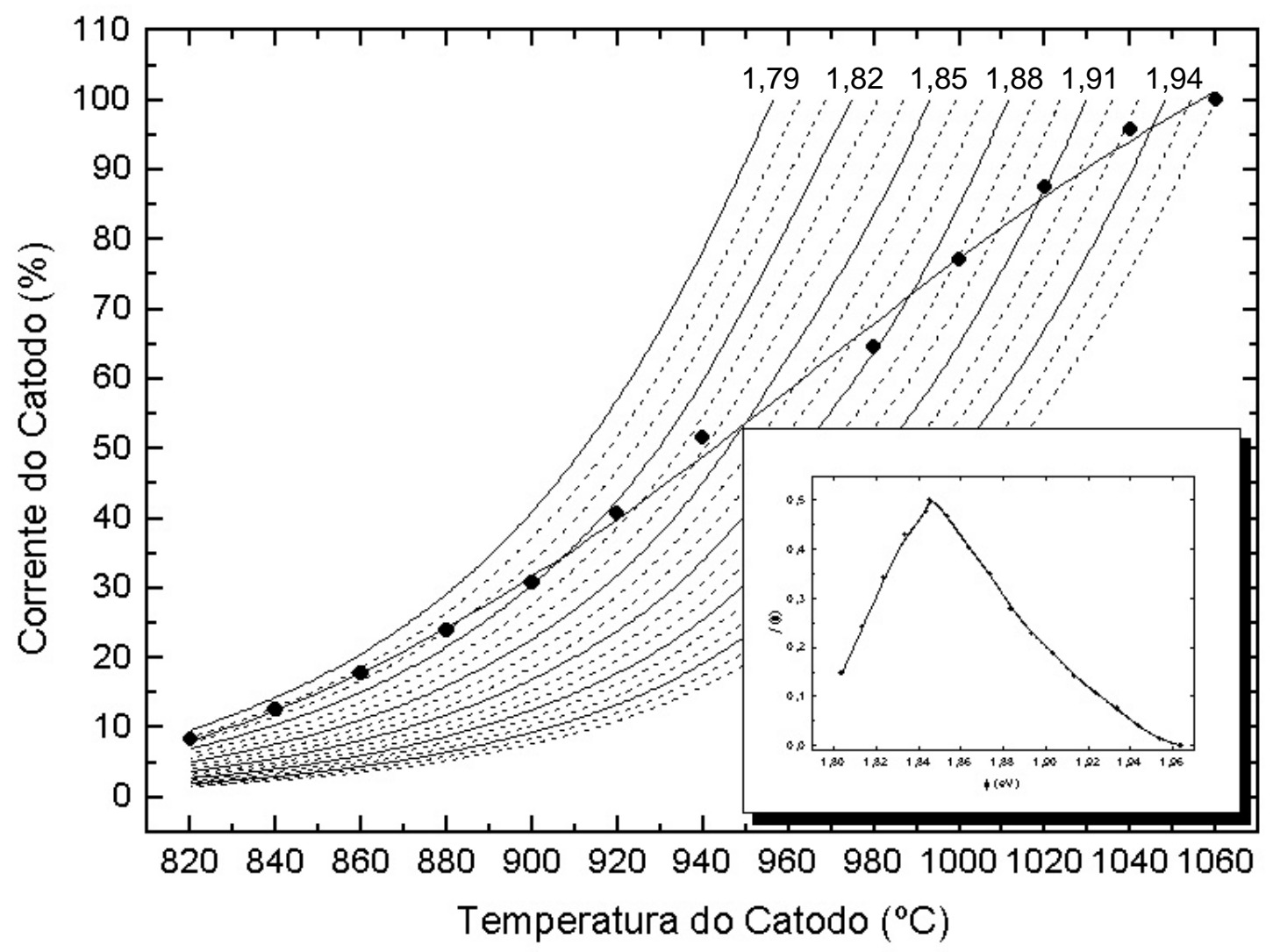

FIGURA 6.14- Gráfico PWFD para $J_{F S C}=8 \mathrm{Acm}^{-2}$.

Verifica-se por meio do gráfico da FIG. 6.14 que o intervalo da distribuição da função trabalho deste catodo situa-se entre 1,80 e 1,96 eV, e a função trabalho do catodo que corresponde à $50 \%$ de $f(\phi)$ está entre 1,83 e 1,84 eV.

b) Para as demais $J_{F S C L}$

O procedimento utilizado na obtenção das curvas PWFD para as densidades de corrente limitada pela carga espacial de 1,2 e $4 \mathrm{Acm}^{-2}$ é semelhante ao empregado no caso anterior $\left(J_{F S C L}=8 \mathrm{Acm}^{-2}\right)$. As FIG. 6.15 a FIG. 6.17 mostram as curvas PWFD para as outras densidades de corrente. A TAB. 6.8 apresenta as funções trabalho dos catodos para cada caso. 


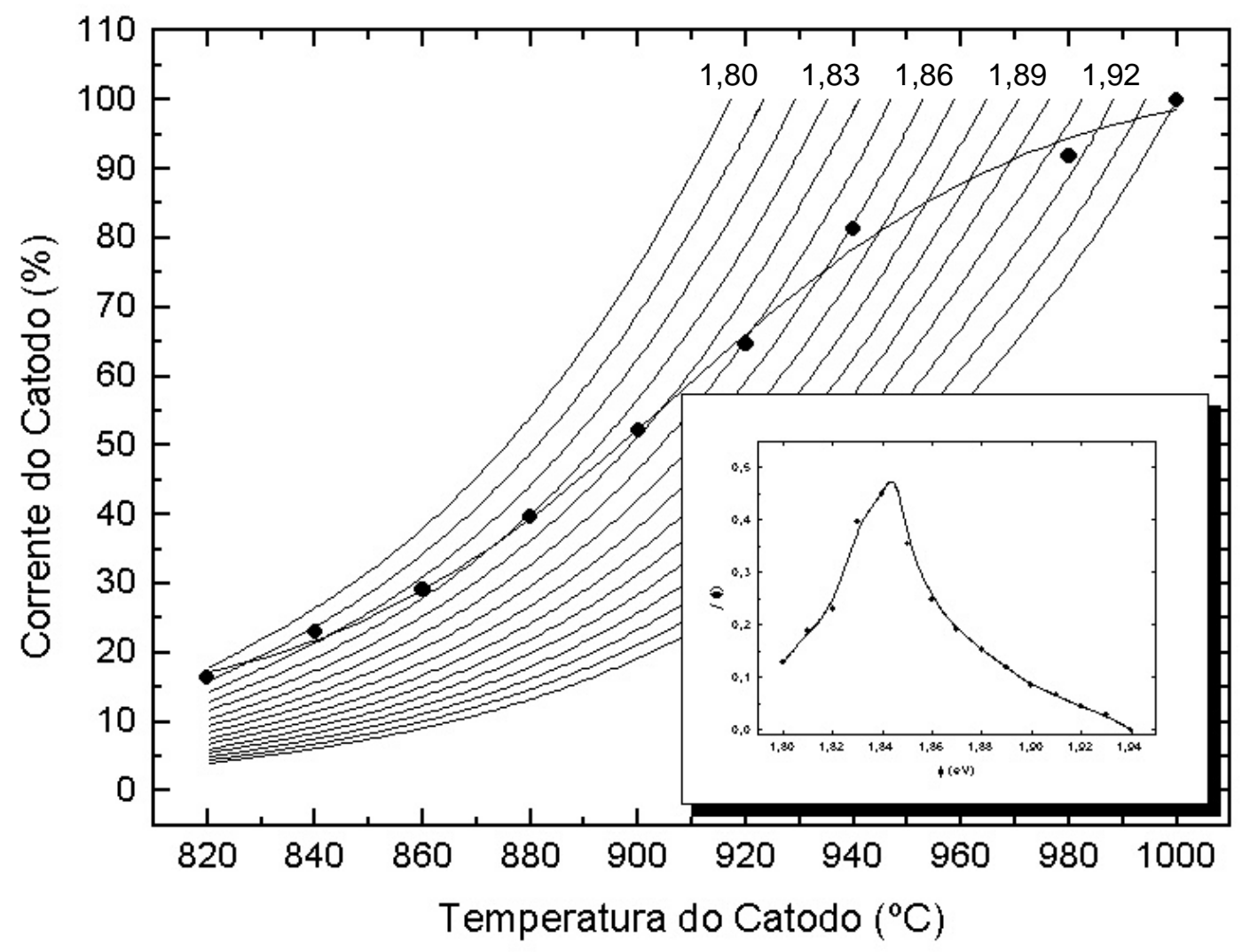

FIGURA 6.15 - Gráfico PWFD para $J_{F S C L}=4 \mathrm{Acm}^{-2}$.

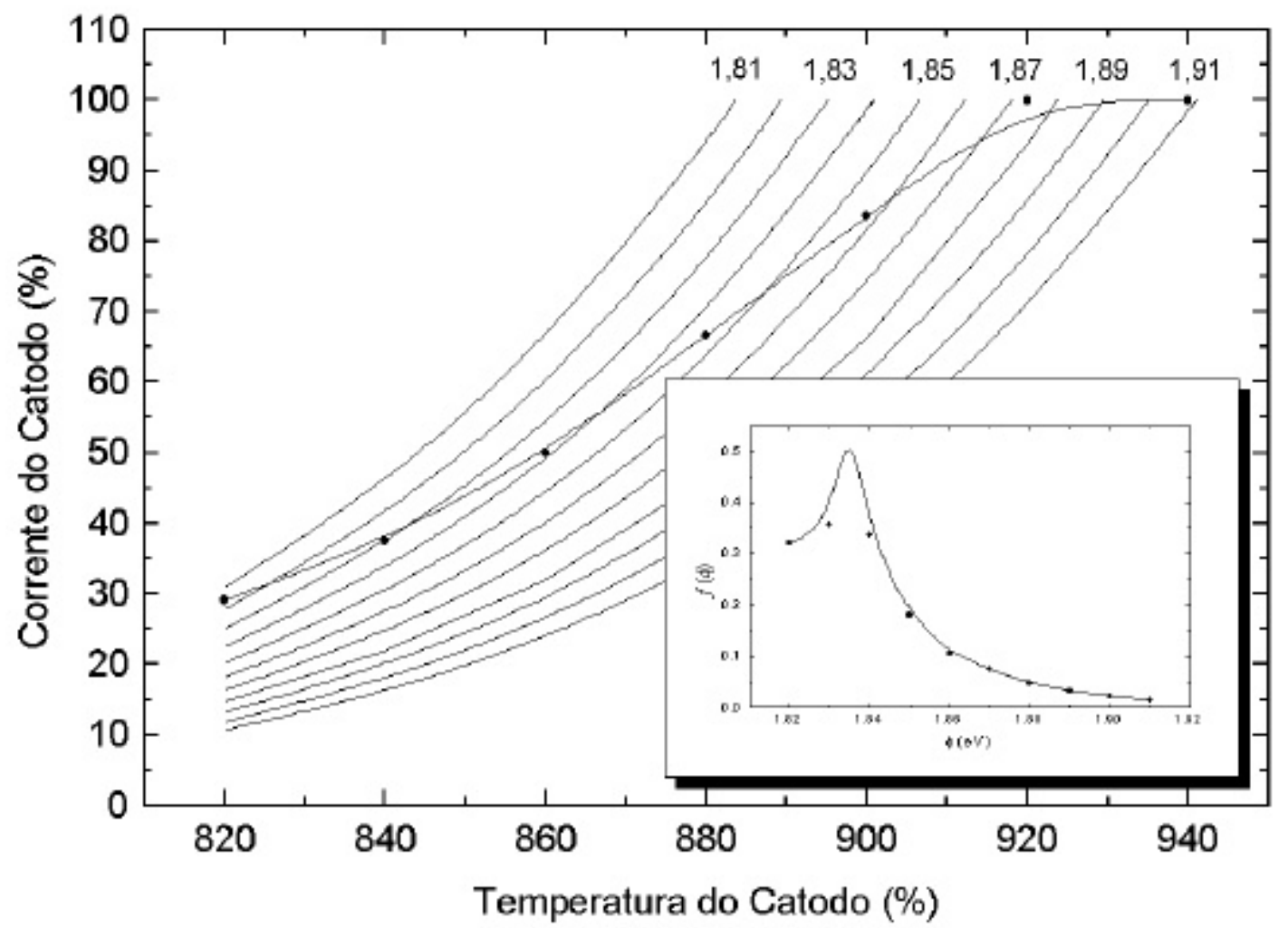

FIGURA 6.16-Gráfico PWFD para $J_{F S C L}=2 \mathrm{Acm}^{-2}$. 


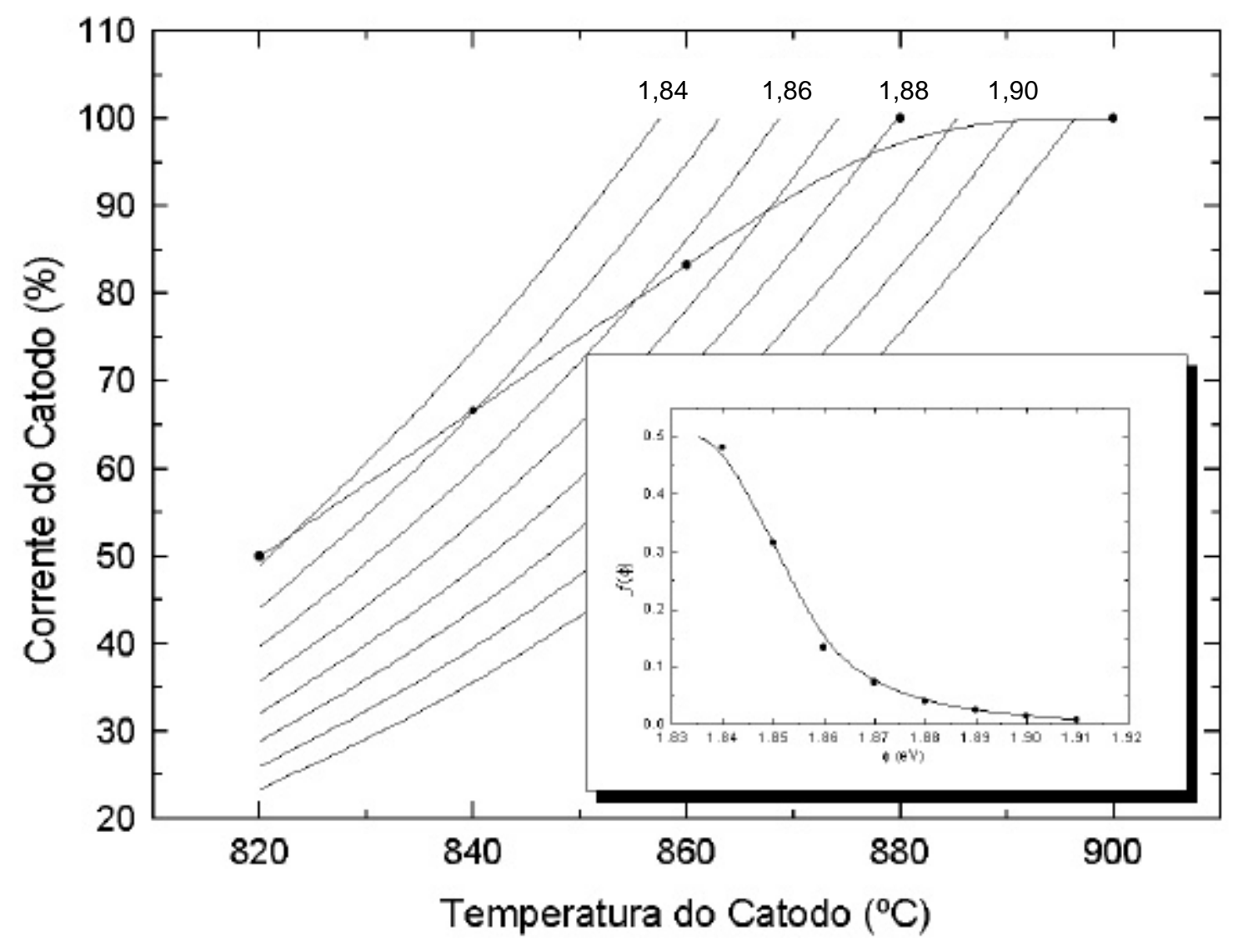

FIGURA 6.17 - Gráfico PWFD para $J_{F S C L}=1 \mathrm{Acm}^{-2}$.

TABELA 6.8 - Função trabalho média do catodo para diferentes densidades de corrente limitada pela carga espacial.

\begin{tabular}{|c|c|c|c|c|}
\hline & $J_{F S C L}=1 \mathrm{Acm}^{-2}$ & $J_{F S C L}=2 \mathrm{Acm}^{-2}$ & $J_{F S C L}=4 \mathrm{Acm}^{-2}$ & $J_{F S C L}=8 \mathrm{Acm}^{-2}$ \\
\hline $\begin{array}{c}\text { Função trabalho } \\
(\mathrm{eV})\end{array}$ & $1,83-1,84$ & $1,83-1,84$ & $1,83-1,84$ & 1,84 \\
\hline
\end{tabular}

A TAB. 6.8 mostra que para o mesmo canhão, a função trabalho permanece em, aproximadamente, 1,84 eV para diferentes condições de operação do canhão, sendo esta a função trabalho média do catodo termiônico avaliado.

Os gráficos apresentados nas FIG. 6.14 a FIG. 6.17 mostram que por meio da curva de Miram e do gráfico PWFD, pode-se determinar as condições de operação (a faixa de temperatura) de um canhão eletrônico para diferentes potenciais do anodo (densidade de corrente de emissão limitada pela carga espacial). 


\subsubsection{Construção da curva PWFD para alta tensão de aceleração}

Nesta Subseção descreve-se o procedimento de construção da curva PWFD para alta tensão de aceleração tomando como base os resultados experimentais em baixa tensão. Portanto, empregando-se a técnica de Miram, projetou-se a curva de Miram para

$J_{F S C L}=16$ $\mathrm{Acm}^{-2}$ utilizando os resultados de $J_{F S C L}=8 \mathrm{Acm}^{-2}$.

c) Para $J_{F S C L}=16 \mathrm{Acm}^{-2}$

Observa-se nos resultados anteriores que para uma densidade de corrente normalizada do catodo de $50 \%$, a função trabalho se mantém constante, em aproximadamente 1,83-1,84 eV. Verifica-se também, que as curvas de Miram de diferentes $J_{F S C L}$ apresentam comportamentos aproximadamente semelhantes. Partindo-se destes resultados, descreveu-se um procedimento para a construção da curva de desempenho. Considera-se, primeiramente, a incógnita do problema, dada pela faixa de temperatura de operação do catodo, $T_{2}=T_{1}+\Delta T$. Este procedimento está ilustrado na FIG. 6.18.

Dada a curva $J_{1}$ projeta-se $J_{2}$ :

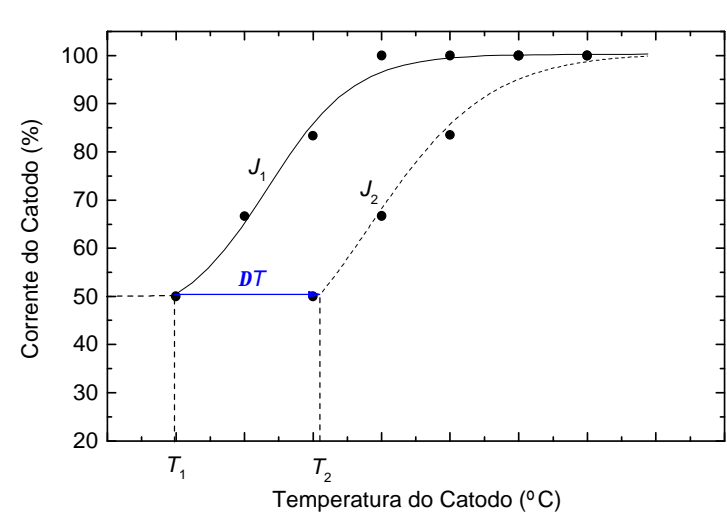

$$
\Rightarrow \quad \begin{aligned}
& \begin{array}{l}
\text { A função da curva de Miram } \\
\text { para } J_{1}:
\end{array} \\
& J_{1}(T)=\frac{A_{1}-A_{2}}{1+\exp \left(\frac{T-T_{1}}{d T}\right)}+A_{2} \\
& \text { sendo } A_{1}, A_{2} \text { e } d T \text { : constantes } \\
& \text { e } \Delta T=T_{2}-T_{1} .
\end{aligned}
$$

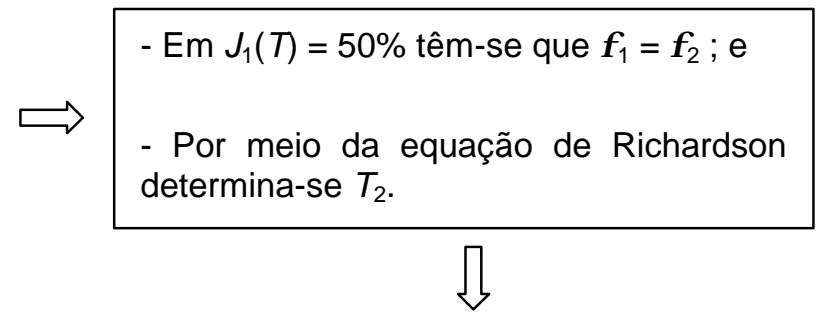

$$
\begin{aligned}
& \text { Resultando em: } \\
& J_{2}(T)=\frac{A_{1}-A_{2}}{1+\exp \left(\frac{T-T_{2}}{d T}\right)}+A_{2}
\end{aligned}
$$

FIGURA 6.18 - Determinação da faixa de temperatura do catodo para alta tensão de aceleração. 
Portanto, ao se determinar o ponto de intersecção das curvas de Richardson e de Miram, para uma densidade de corrente do catodo de 50\%, é possível obter a faixa de temperatura de operação para o catodo em regime de alta tensão de aceleração. A FIG. 6.19 mostra a curva para $J_{F S C L}=16 \mathrm{Acm}^{-2}$ projetada a partir da curva de $8 \mathrm{Acm}^{-2}$.

Traçando-se a curva da distribuição da função trabalho na curva de Miram de

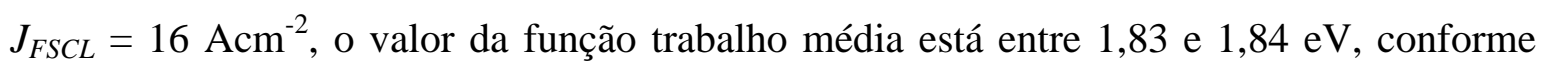
pode ser visualizado no gráfico apresentado na FIG. 6.20.

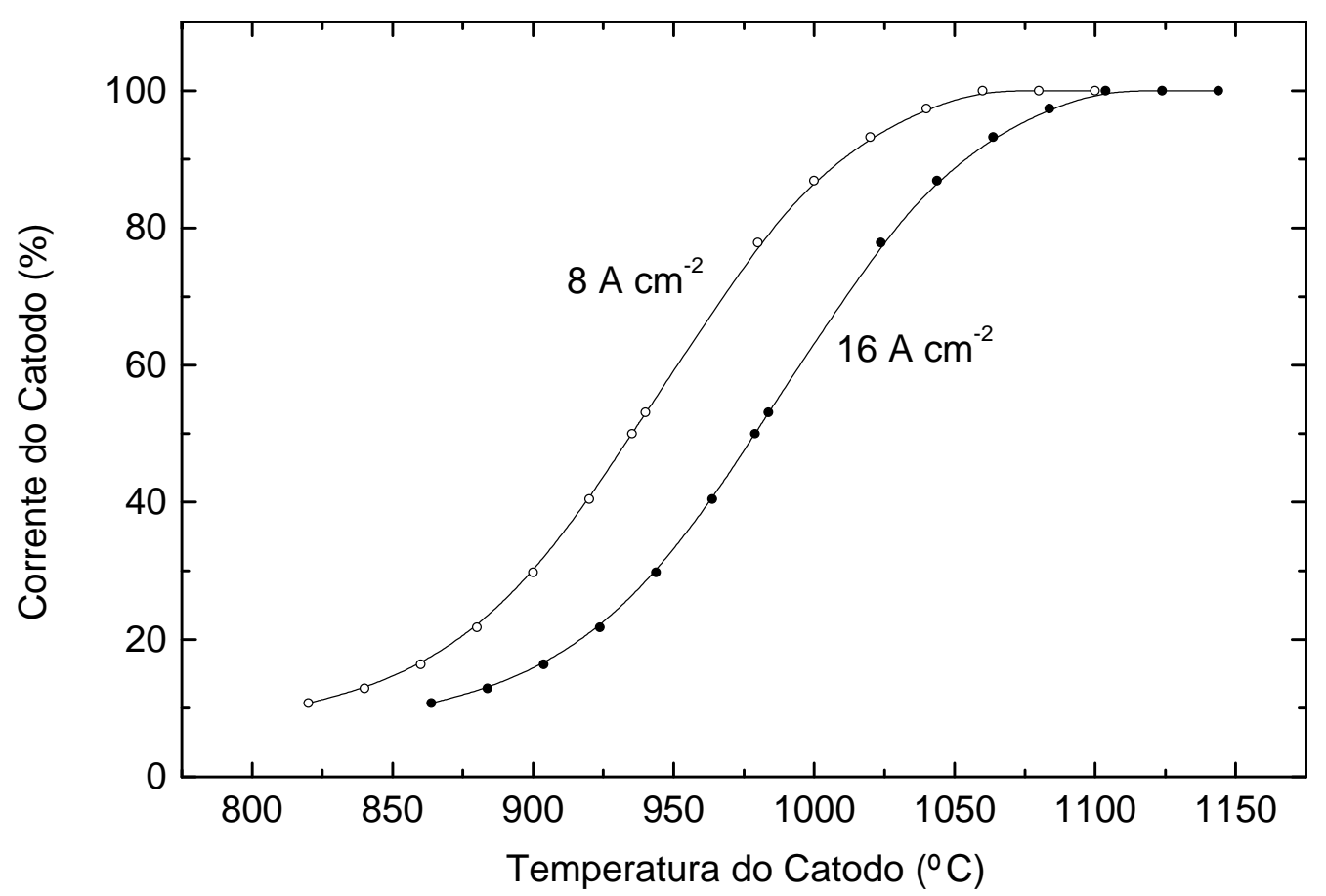

FIGURA 6.19-Curvas de Miram para $J_{F S C L}=8 \mathrm{Acm}^{-2}$ e para $J_{F S C L}=16 \mathrm{Acm}^{-2}$. 


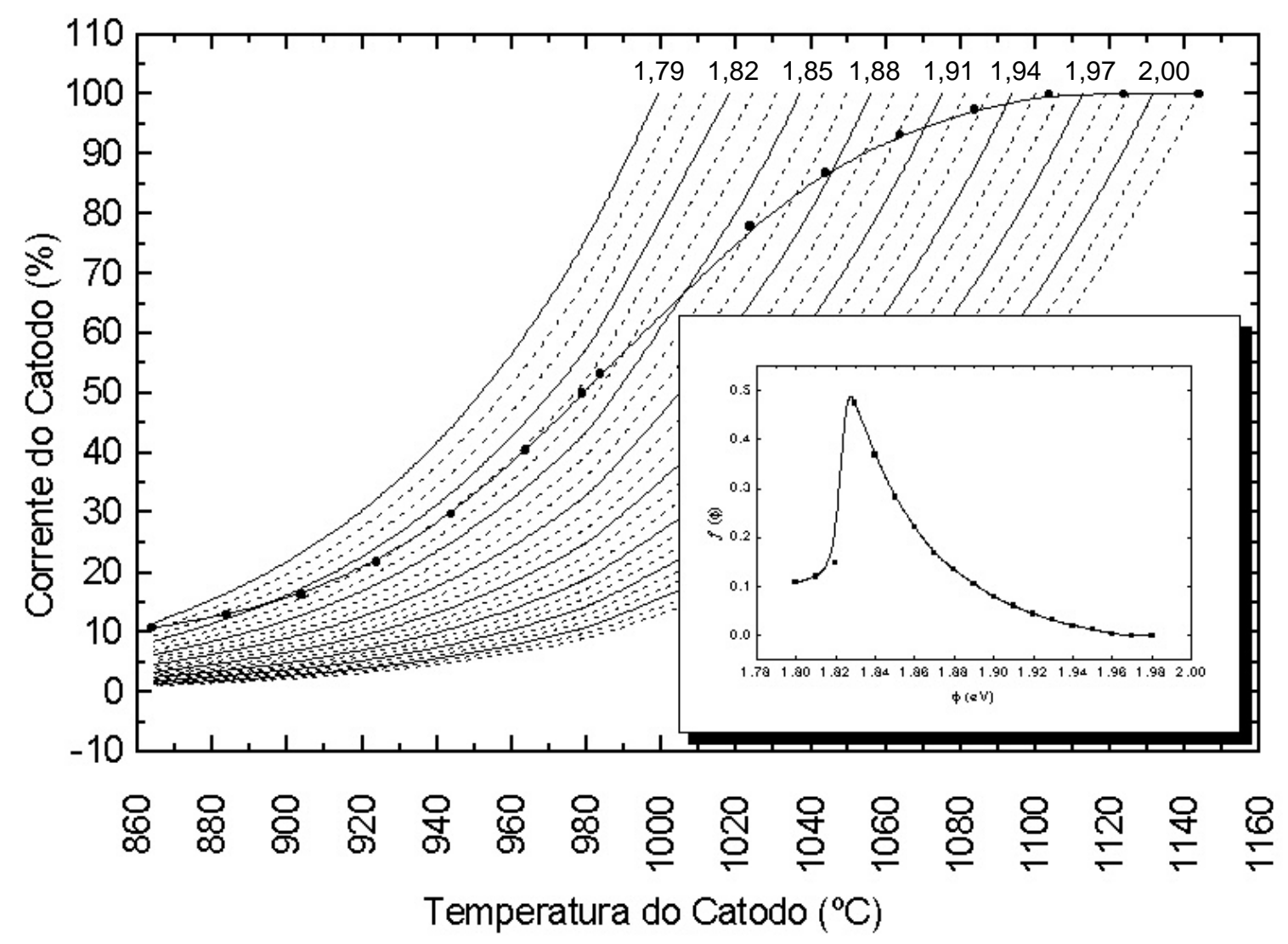

FIGURA 6.20 - Gráfico PWFD para $J_{F S C L}=16 \mathrm{Acm}^{-2}$.

Para se validar o procedimento desenvolvido até o presente momento realizouse um segundo experimento [53]. As TAB. 6.9 e 6.10 apresentam os parâmetros de operação do catodo que faz parte da "classe dos melhores catodos" de um experimento realizado por Miram. Desenvolveram o experimento nas seguintes condições: faixa de temperatura de 660 a $820^{\circ} \mathrm{C}$ com incremento de $10^{\circ} \mathrm{C}$ para $J_{F S C L}=0,09 \mathrm{Acm}^{-2}(7,3 \mathrm{kV}) \mathrm{e}$ faixa de temperatura de 680 a 820 com incremento de $10^{\circ} \mathrm{C}$ para $J_{F S C L}=0,18 \mathrm{Acm}^{-2}$ $(11,5 \mathrm{kV})$. 
TABELA 6.9 - Densidade de corrente normalizada utilizada na construção da curva de Miram para $J_{F S C L}=0,09 \mathrm{Acm}^{-2}$.

\begin{tabular}{cc}
\hline $\mathrm{T}\left({ }^{\circ} \mathrm{C}\right)$ & $\begin{array}{c}\text { Densidade de corrente } \\
\text { normalizada }\end{array}$ \\
& $J(\%)=\frac{J}{J_{F S C L}} \cdot 100$ \\
\hline 820 & 100 \\
810 & 100 \\
800 & 100 \\
790 & 100 \\
780 & 100 \\
770 & 100 \\
760 & 100 \\
750 & 99,58 \\
740 & 98,75 \\
730 & 95,83 \\
720 & 90 \\
710 & 80,83 \\
700 & 70 \\
690 & 58,33 \\
680 & 48,33 \\
670 & 39,16 \\
660 & 32,08 \\
\hline
\end{tabular}

TABELA 6.10 - Densidade de corrente normalizada utilizada na construção da curva de Miram para $J_{F S C L}=0,18 \mathrm{Acm}^{-2}$.

\begin{tabular}{cc}
\hline $\mathrm{T}\left({ }^{\circ} \mathrm{C}\right)$ & $\begin{array}{c}\text { Densidade de corrente } \\
\text { normalizada } \\
\end{array}$ \\
& $J(\%)=\frac{J}{J_{F S C L}} \cdot 100$ \\
\hline 820 & 100 \\
810 & 100 \\
800 & 100 \\
790 & 100 \\
780 & 99,20 \\
770 & 97,90 \\
760 & 95 \\
750 & 90 \\
740 & 80,40 \\
730 & 70,80 \\
720 & 61,25 \\
710 & 50 \\
700 & 42,90 \\
690 & 35,40 \\
680 & 29,20 \\
\hline
\end{tabular}


a) $J_{F S C L}=0,09 \mathrm{Acm}^{-2}$

Para se obter a faixa da função trabalho aplicada deste experimento, aplica-se a metodologia de obtenção da curva de Miram. O valor da máxima função trabalho do catodo encontrada foi de 2,00 eV. Para o intervalo de funções trabalho definido pela curva de Miram, obtiveram-se as curvas de $J$ versus $T$.

O gráfico da PWFD está apresentado na FIG.6.21, na qual se verifica o valor da função trabalho média de: 1,78-1,79 eV. Com o intuito de se projetar a curva de desempenho para alta tensão de operação, utiliza-se da metodologia apresentada na FIG. 6.18. Para este experimento definir a temperatura de operação do catodo para $J_{F S C L}=3 \mathrm{Acm}^{-2}$ e tensão de operação de $75,6 \mathrm{kV}$, mantendo-se a perveância constante $(0,144 \mu$ Perv $)$. Considerando a função trabalho como $1,78 \mathrm{eV}$, tem-se que para $J(T)=50 \%, T=847,48^{\circ} \mathrm{C}$. Assim, a curva de Miram para $J_{F S C L}=3 \mathrm{Acm}^{-2}$ pôde ser obtida e está apresentada na FIG. 6.22.

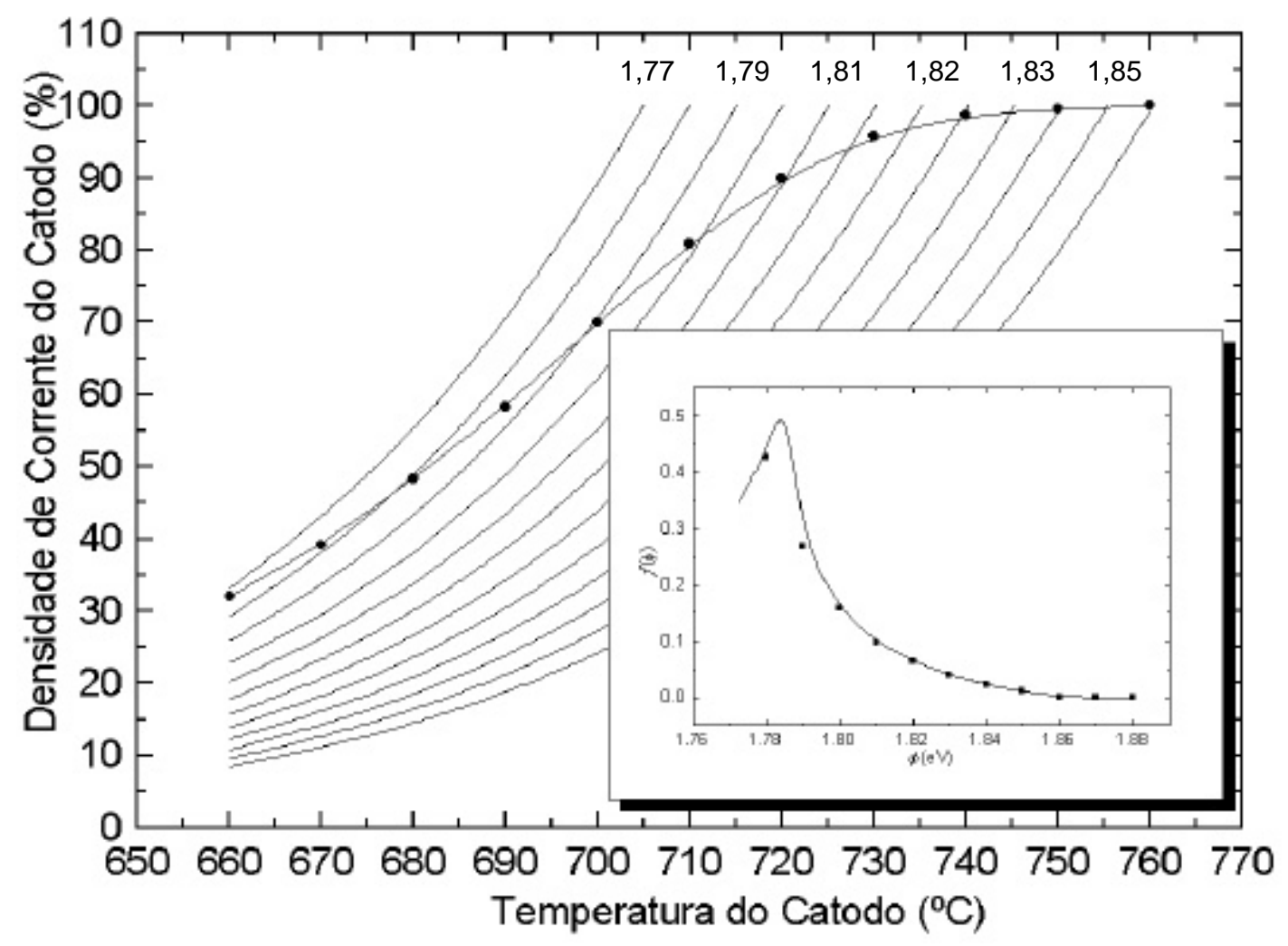

FIGURA 6.21 - Gráfico PWFD para $J_{F S C L}=0,09 \mathrm{Acm}^{-2}$. 


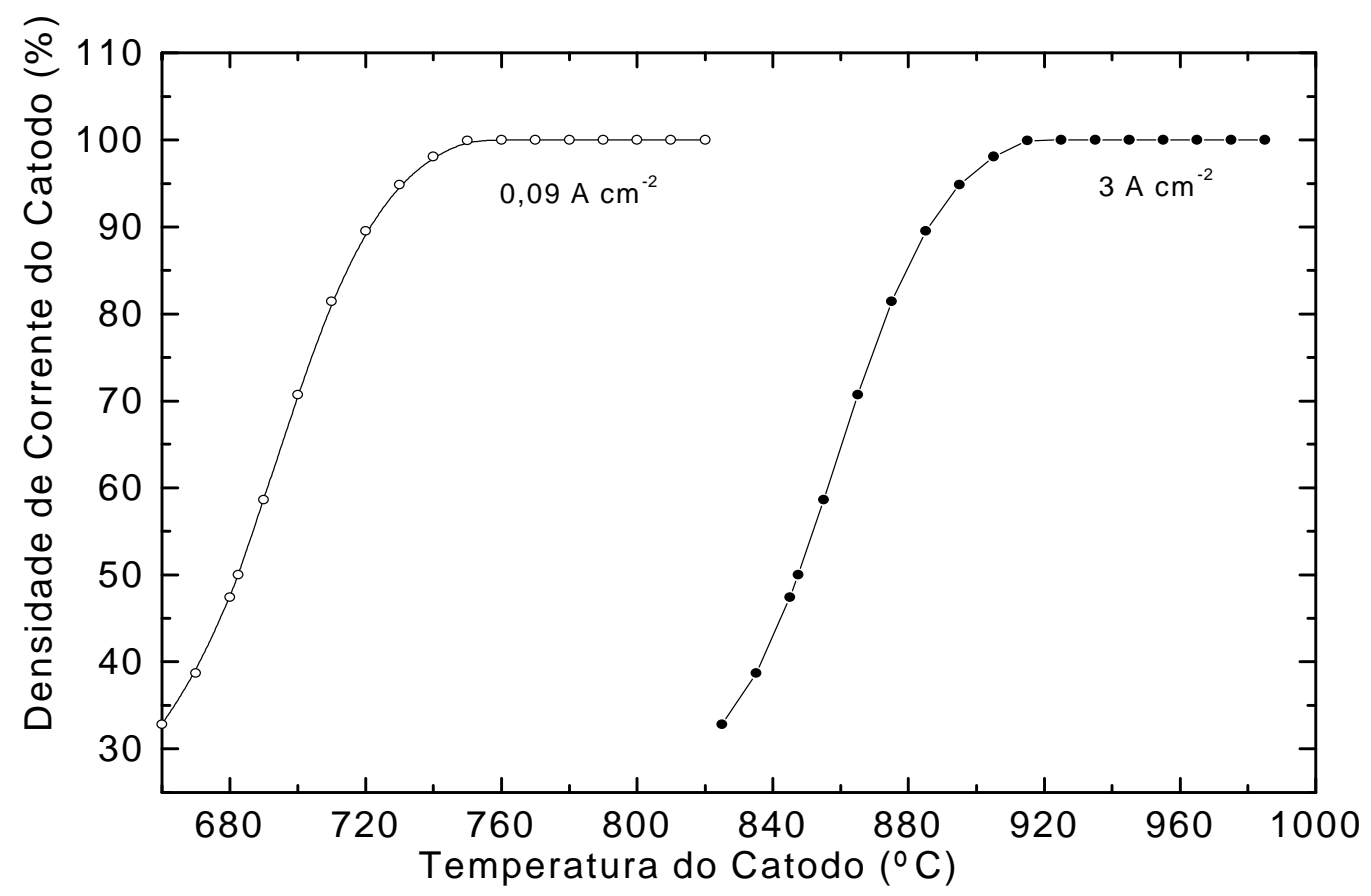

FIGURA 6.22 - Curvas de Miram para $J_{F S C L}=0,09 \mathrm{Acm}^{-2}$ e para $J_{F S C L}=3 \mathrm{Acm}^{-2}$.

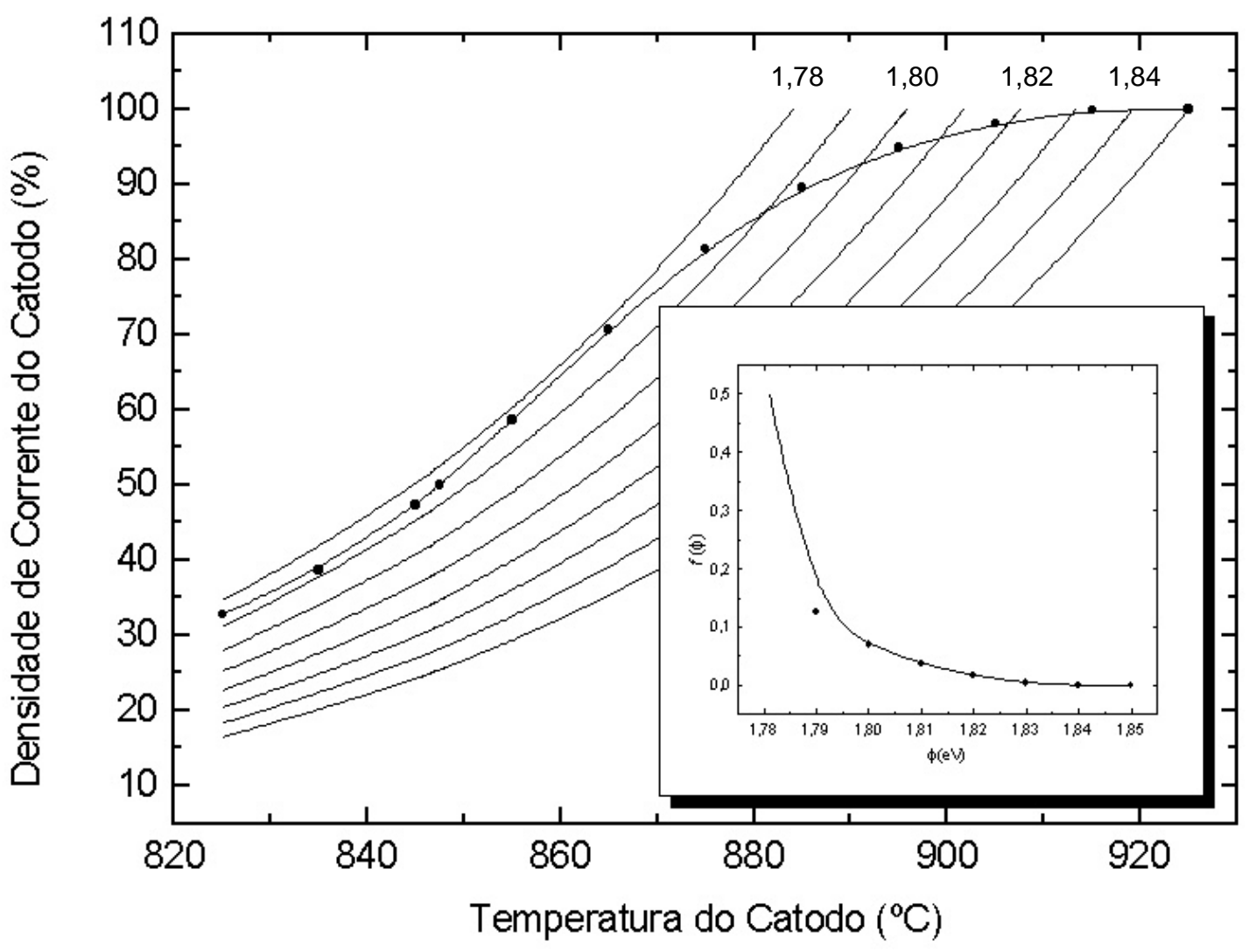

FIGURA 6.23- Gráfico PWFD para $J_{F S C L}=3 \mathrm{Acm}^{-2}$. 
A FIG. 6.23 apresenta a curva PWFD para $J_{F S C L}=3 \mathrm{Acm}^{-2}$, cuja função trabalho média está entre 1,78 e 1,79 eV.

b) $J_{F S C L}=0,18 \mathrm{Acm}^{-2}$

Semelhante ao experimento anterior, determinou-se a maior função trabalho para a faixa de temperatura apresentada anteriormente empregando o valor da densidade de corrente de emissão limitada pela carga espacial $\left(0,18 \mathrm{Acm}^{-2}\right)$ e o valor na maior temperatura de operação $\left(820^{\circ} \mathrm{C}\right)$ por meio da expressão (6.7). $\mathrm{O}$ valor da função trabalho encontrada foi de 1,93 eV. Empregando-se a metodologia desenvolvida para a construção da curva de Miram, obteve-se a curva apresentada na FIG. 6.24. Verifica-se na curva PWFD que a função trabalho média do catodo esta entre 1,77 e 1,78 eV.

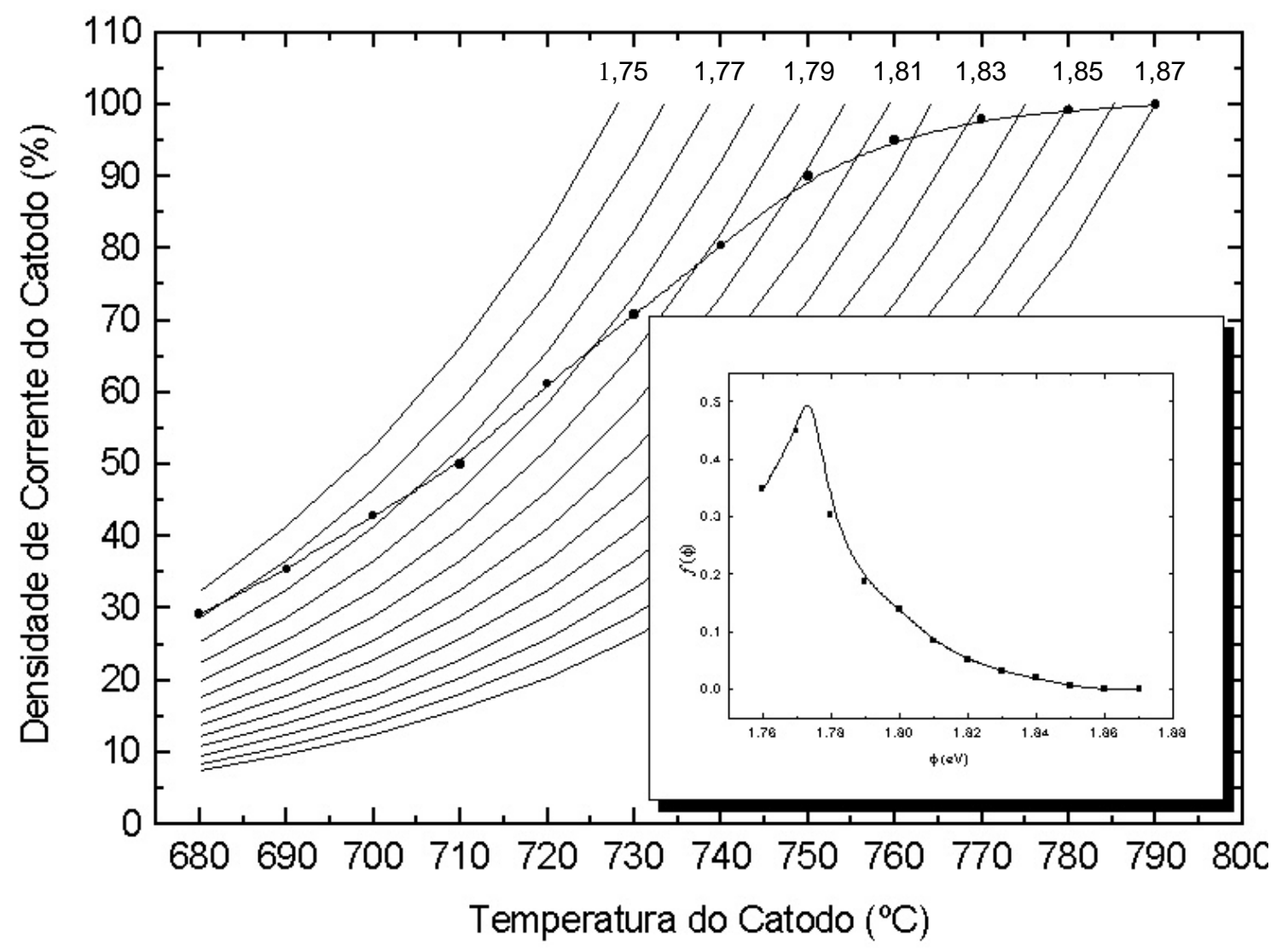

FIGURA 6.24-Gráfico PWFD para $J_{F S C L}=0,18 \mathrm{Acm}^{-2}$.

Para se obter a temperatura de operação do catodo para $J_{F S C L}=6 \mathrm{Acm}^{-2} \mathrm{e}$ tensão de operação de $120 \mathrm{kV}$ (dimensionamento do canhão eletrônico para alto potencial de aceleração), consideraram-se os seguintes dados:

a) Função trabalho média: $1,77 \mathrm{eV}$; 
b) Temperatura: $886,78^{\circ} \mathrm{C}$ em $J(\%)=50 \%$; e

c) Perveância: $0,144 \mu$ Perv.

Aplicando-se a metodologia apresentada anteriormente, a curva de Miram para $J_{F S C L}=6 \mathrm{Acm}^{-2}$ pôde ser obtida conforme ilustrada na FIG. 6.25. A FIG. 6.26 mostra a curva PWFD para $J_{F S C L}=6 \mathrm{Acm}$, que apresenta uma função trabalho média entre 1,77 e $1,78 \mathrm{eV}$.

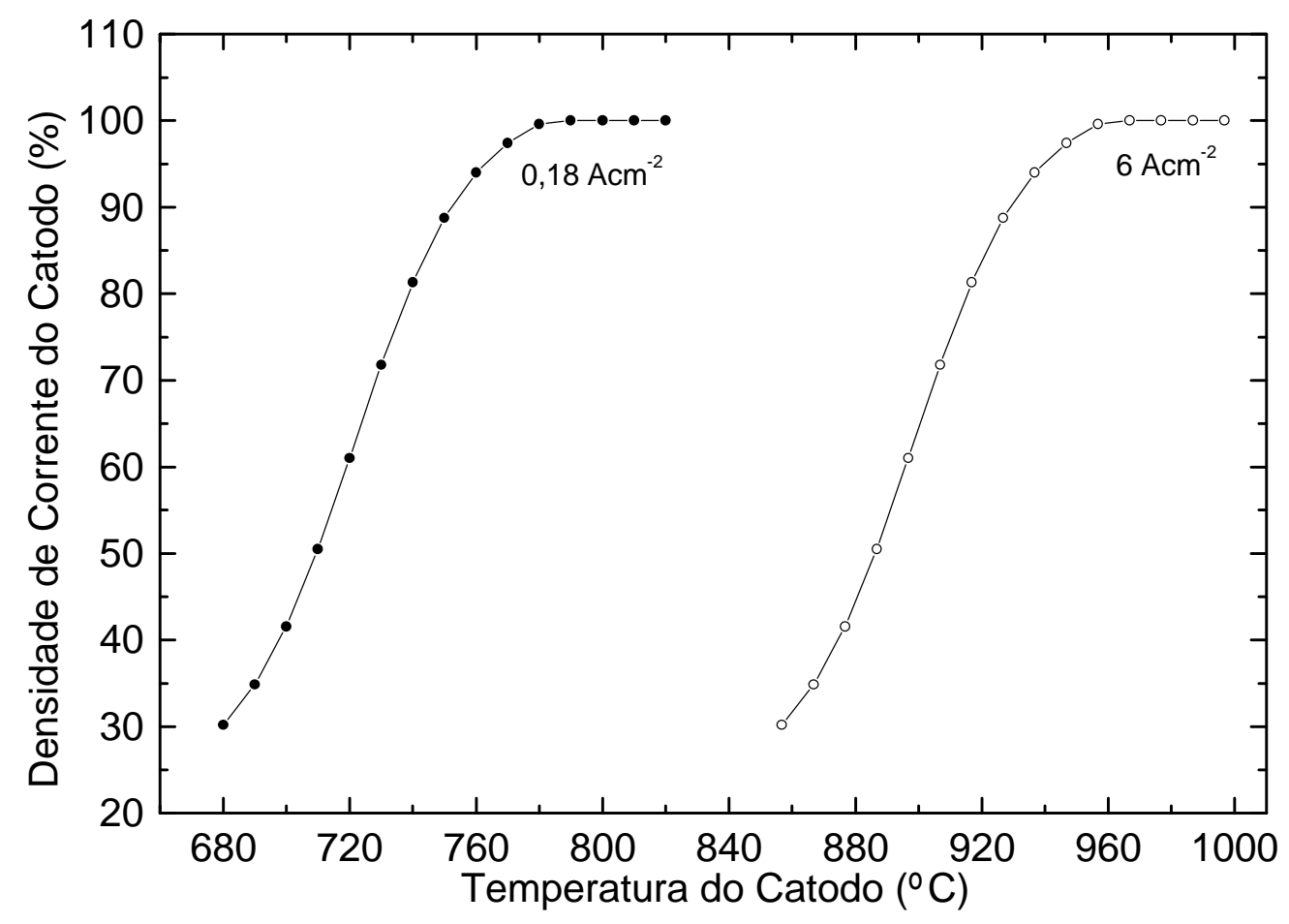

FIGURA 6.25-Gráfico PWFD para $J_{F S C L}=0,18 \mathrm{Acm}^{-2}$ e para $J_{F S C L}=6 \mathrm{Acm}^{-2}$. 


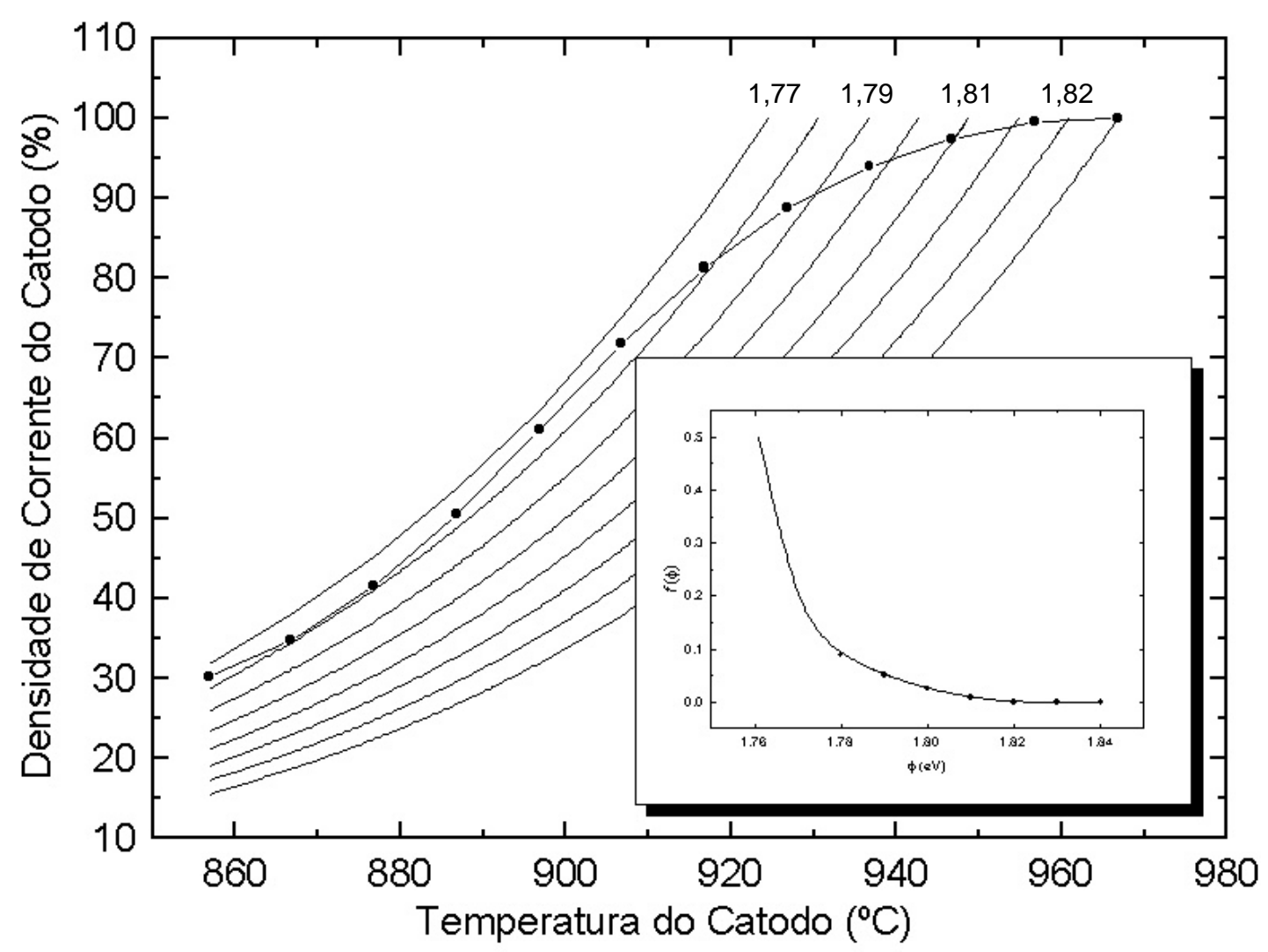

FIGURA 6.26-Gráfico PWFD para $J_{F S C L}=6 \mathrm{Acm}^{-2}$.

Observando os resultados obtidos nas FIG 6.21 a FIG. 6.26, percebe-se que há uma concordância entre as curvas do presente trabalho daqueles apresentados por Miram [55].

\subsection{Determinação da temperatura na superfície do catodo}

A temperatura é um importante fator na emissão termiônica e, portanto, esta propriedade do catodo quando em operação deve ser mensurada com elevada precisão. $\mathrm{O}$ medidor comumente empregado para obter esta temperatura é o pirômetro óptico. Este equipamento compara a brilhância de uma superfície desconhecida com a de um filamento padrão. A calibração da temperatura é realizada utilizando-se diversas correntes no filamento. A pirometria óptica é um método de grande precisão porque o aumento da brilhância de um corpo quente é 4 vezes maior do que a variação da temperatura. A brilhância, $T_{b}$, é sempre menor que a temperatura real, $T_{a}$. Por meio de (6.8) converte-se o valor da brilhância obtida no pirômetro óptico em temperatura verdadeira [1].

$$
\frac{1}{T_{a}}-\frac{1}{T_{b}}=\frac{\lambda}{1,4388} \ln \varepsilon_{\lambda}
$$




\subsection{Técnicas de análise dos aluminatos de bário e cálcio}

Nesta Seção serão apresentadas as condições de operação das análises físicoquímicas dos aluminatos de bário e cálcio obtidos pelas diferentes técnicas de síntese.

\subsubsection{Distribuição do tamanho de partículas}

A análise de distribuição de tamanho de partículas por espalhamento laser dos aluminatos de bário e cálcio foi feita com uma amostragem de aproximadamente $1 \mathrm{~g}$ à temperatura ambiente, sendo dispersa em água utilizando como dispersante pirofosfato de sódio. A dispersão foi realizada utilizando ultra-som (Vibracell Sonics \& Materials) durante 3 min. O equipamento utilizado foi o Granulômetro Cilas modelo 1064.

\subsubsection{Difração de raios $X$}

A caracterização quanto as fases dos aluminatos por difração de raios $\mathrm{X}$ dos produtos finais de síntese foi feita na faixa de $2 \theta=5^{\circ}$ a $90^{\circ}$, com radiação $\mathrm{CuK \alpha}$, em um difratômetro RIGAKU DMAX-2100.

\subsubsection{Microscopia eletrônica de varredura (MEV)}

Para se realizar as análises no MEV os aluminatos foram fixados sobre portaamostra com auxílio de uma fita colante e em seguida, recoberta com um filme de carbono pela técnica de espirramento ("sputtering").

\subsubsection{Espectrômetro de fluorescência de raios $X$ por dispersão de comprimento de onda}

As análises químicas dos aluminatos de bário e cálcio foram realizadas utilizando-se da técnica de espectroscopia de fluorescência de raios $\mathrm{X}$. O equipamento utilizado foi o espectrômetro da Rigaku Modelo RIX 3000.

\subsection{Conclusões do Capítulo}

Primeiramente, apresentou-se neste Capítulo, a seleção de materiais a serem empregados na preparação do aluminato de bário e cálcio, e na conformação da base do catodo termiônico. Em seguida, descreveram-se as metodologias desenvolvidas e empregadas na síntese dos aluminatos e, abordou-se a rota de impregnação do catodo com o material emissor (aluminato de bário e cálcio). Posteriormente, apresentaram-se os aparatos empregados na fabricação do catodo impregnado. 
Tomando-se como base as curvas de Miram e a equação de RichardsonDushman, apresentou-se um procedimento para a realização das medidas termiônicas empregando-se a distribuição da função trabalho prática. Empregando-se este procedimento houve possibilidade de se projetar um canhão eletrônico para ser operado em alta tensão de aceleração, tendo como base as características de emissão termiônicas realizadas em um experimento em baixa tensão. 


\section{CAPÍTULO 7 - RESULTADOS E DISCUSSÃO}

\subsection{Introdução do Capítulo}

Neste Capítulo apresentam-se os resultados das análises dos aluminatos de bário e cálcio obtidos pelas diferentes técnicas de síntese de material (reação em estado sólido, cristalização e precipitação). As curvas TG dos materiais precursores apontam algumas das características das técnicas de síntese de aluminato utilizados neste trabalho. Elas, também, são utilizadas na determinação das reações de desidratação, decomposição dos carbonatos e nitratos (liberação de gases, conseqüente perda de massa) e formação do aluminato de bário e cálcio. Por outro lado, as propriedades físico-químicas dos aluminatos foram obtidas empregando-se as seguintes técnicas de caracterização de materiais: difração de raios $X$, fluorescência de raios $X$, análise de tamanho de partícula, microscopia eletrônica de varredura e espectroscopia no infravermelho. A fim de se caracterizar termionicamente o aluminato de bário e cálcio (obtido pela técnica de reação de estado sólido), traçou-se a curva PWFD para se obter o valor da função trabalho média do catodo aluminato.

A Seção 7.2 relata os resultados das curvas TG dos reagentes de partida, produtos de cristalização e precipitação, para se definir os parâmetros de sintetização do aluminato de bário e cálcio: temperatura, atmosfera e tempo. Na Seção 7.3, por meio da técnica de difração de raios $\mathrm{X}$, são apresentadas as fases presentes nos aluminatos obtidos pelas diferentes técnicas de síntese. A Seção 7.4 reporta a análise química semiquantitativa das amostras do material emissor. As Seções 7.5 e 7.6 apresentam as características físicas dos aluminato de bário e cálcio. Na Seção 7.7, verifica-se a composição química/fases do aluminato de bário e cálcio obtida pela técnica de FTIR. As curvas de desempenho para caracterizar a emissão termiônica do catodo com aluminato de bário e cálcio estão apresentadas na Seção 7.8. Na Seção 7.9, realiza-se um experimento de fusão do aluminato com o intuito de se verificar a temperatura de impregnação. Por fim, na Seção 7.10, apresentam-se as conclusões parciais. 


\subsection{Termogravimetria}

Para se verificar perda de massa em função da temperatura, utilizou-se a termogravimetria (TG). Por meio desta técnica, estabeleceram-se as condições adequadas para a pirólise e/ou calcinação dos produtos da cristalização, precipitação e mistura dos carbonatos como dos reagentes de partida.

Realizaram-se os primeiros experimentos utilizando uma termobalança TGA 7 da PERKIN-ELMER, cadinho de platina, razão de aquecimento $(\beta) 10^{\circ} \mathrm{C} \min ^{-1}$, intervalo de temperatura de 50 a $900^{\circ} \mathrm{C}$ (temperatura máxima do equipamento) e massa de aproximadamente $7 \mathrm{mg}$. Nestas condições analisou-se cada reagente (carbonatos de bário, de cálcio e óxido de alumínio) e a mistura obtida no método de preparação do aluminato via reação em estado sólido.

As FIG. 7.1 e 7.2 apresentam as curvas TG dos reagentes empregados na obtenção do aluminato de bário e cálcio $\left(\mathrm{BaCO}_{3}, \mathrm{CaCO}_{3}, e \mathrm{Al}_{2} \mathrm{O}_{3}\right)$ e a da própria mistura resultante.

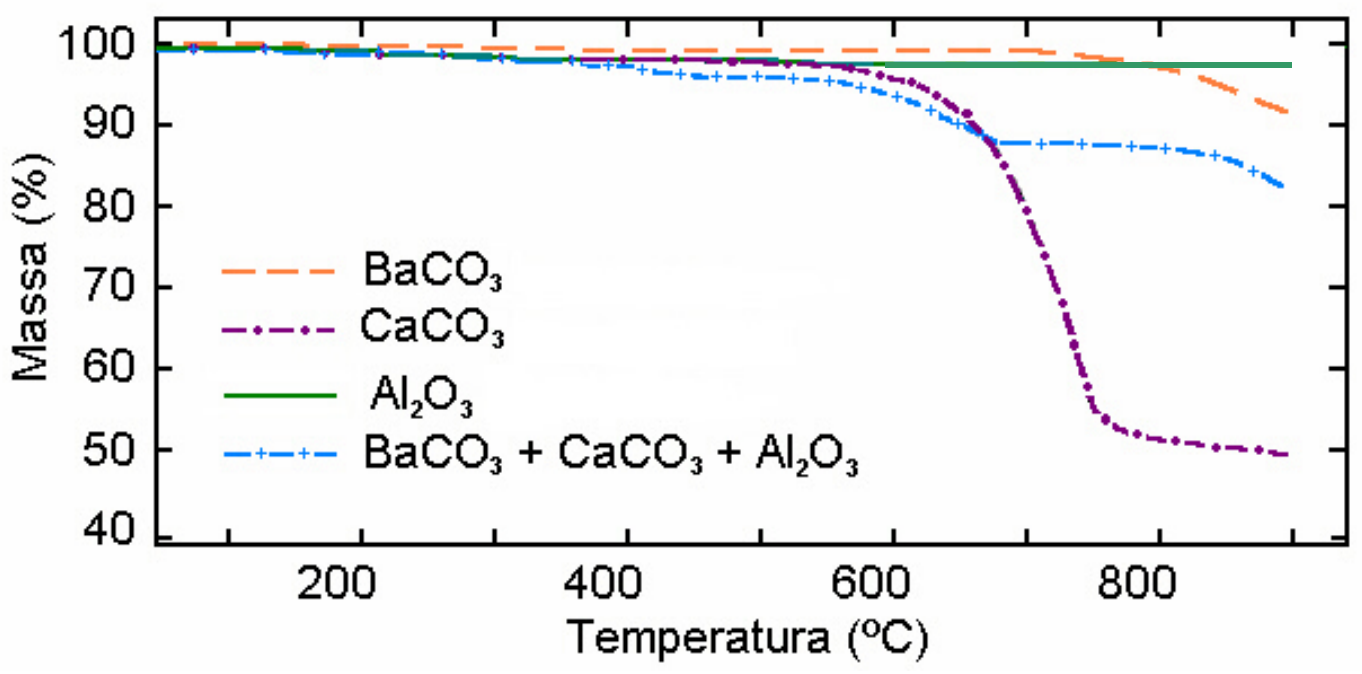

FIGURA 7.1 - Curvas TG dos carbonatos de bário e de cálcio, do óxido de alumínio e da mistura componentes (cadinho de platina) em atmosfera oxidante.

A FIG. 7.1 ilustra a curva TG da alumina em atmosfera oxidante, verificandose que o composto é termicamente estável até $900^{\circ} \mathrm{C}$. Entretanto, há perda de massa de aproximadamente $0,50 \%$ devido à água de umidade. As curvas dos outros reagentes também apresentam uma perda inicial de massa devido à água, além das perdas de massa referentes ao início da decomposição dos carbonatos. Na curva TG do carbonato de cálcio verifica-se uma perda de massa total de 50\% (teoricamente $44 \%$ ), que é devido à água de 
umidade $(\sim 2,5 \%)$, à decomposição do carbonato $(\sim 47,5 \%)$. Na curva TG do carbonato de bário verifica-se apenas a uma perda inicial de massa, que pode estar relacionada ao estágio inicial de decomposição do carbonato. Observa-se na curva TG da mistura $\left(\mathrm{BaCO}_{3}\right.$, $\mathrm{CaCO}_{3}$ e $\left.\mathrm{Al}_{2} \mathrm{O}_{3}\right)$ que há uma variação da temperatura inicial de decomposição dos carbonatos. Nesta curva há três etapas de perda de massa significativas, a primeira devido à água de umidade $(\sim 4 \%)$ e as duas últimas devido ao início da decomposição dos carbonatos.

Na FIG. 7.2 verifica-se a curva TG obtida em uma atmosfera inerte $\left(N_{2}\right)$, na qual se observam comportamentos semelhantes àqueles resultantes da atmosfera oxidante. Nestas condições é possível verificar que não se obtém produtos termicamente estáveis para a mistura e para o carbonato de bário. A curva TG da alumina apresentou uma estabilidade térmica com a presença de apenas um evento inicial devido à perda de massa referente àágua de umidade. Na curva do carbonato de bário verifica-se a perda inicial da água de umidade $(\sim 0,8 \%)$ para posterior perda de massa referente ao início da decomposição do carbonato. Para o carbonato de cálcio, há duas etapas de perda de massa, a primeira referente àágua de umidade $(\sim 2,0 \%)$ e a segunda a decomposição do carbonato de cálcio $(\sim 42 \%)$, para posterior estabilização da curva. Na curva TG da mistura, como na curva para a atmosfera oxidante, apresenta-se os mesmos três eventos.

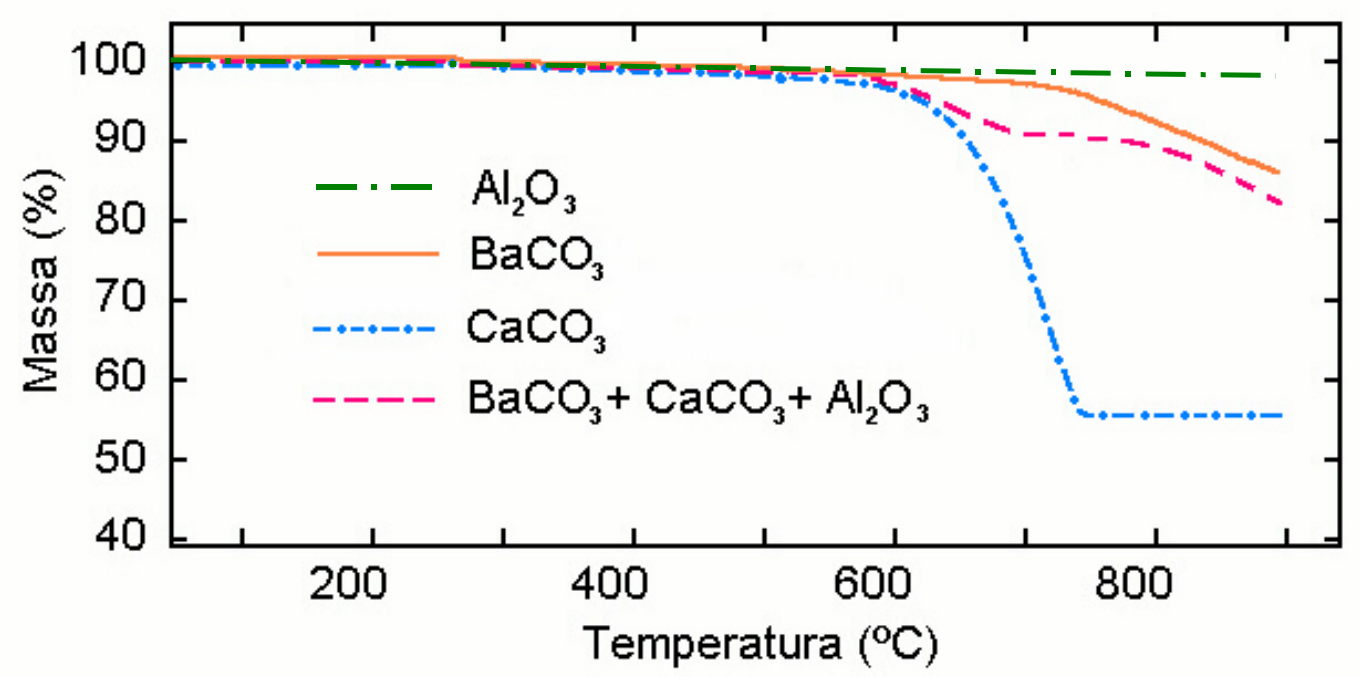

FIGURA 7.2 - Curvas TG dos carbonatos de bário e de cálcio, do óxido de alumínio e da mistura componentes (cadinho de platina) em atmosfera inerte.

Posteriormente, investigou-se o comportamento térmico do carbonato de bário em atmosfera inerte $\left(N_{2}\right)$ até a temperatura de $1300^{\circ} \mathrm{C}$, uma vez que nos experimentos 
anteriores (até $900^{\circ} \mathrm{C}$ ) não se atingiu a estabilidade térmica da mistura e do carbonato de bário. Neste caso utilizaram-se as seguintes condições: TGA 50 H SHIMADZU, cadinho de platina, $\beta=10^{\circ} \mathrm{C} \min ^{-1}$, intervalo de temperatura de 25 a $1300^{\circ} \mathrm{C}$, massa de aproximadamente $7 \mathrm{mg}$, fluxo de gás $50 \mathrm{~mL} \mathrm{~min}^{-1}$ e patamar de $30 \mathrm{~min}$ na temperatura de $1300^{\circ} \mathrm{C}$. As curvas TG/DTG da FIG. 7.3 mostram que o $\mathrm{BaCO}_{3}$ apresenta duas etapas de decomposição térmica em atmosfera inerte. A primeira está relacionada àperda de água de umidade (perda de massa de $0,7 \%$ ). A segunda etapa ocorre entre $700^{\circ} \mathrm{C}$ e $1300^{\circ} \mathrm{C}$ e corresponde ao estágio de decomposição do carbonato (perda de massa de 19,5\%). Considerando que, teoricamente, o carbonato de bário apresenta $22,3 \%$ de $\mathrm{CO}_{2}(\%$ em peso), verifica-se que a conversão do carbonato em óxido de bário não foi completa.

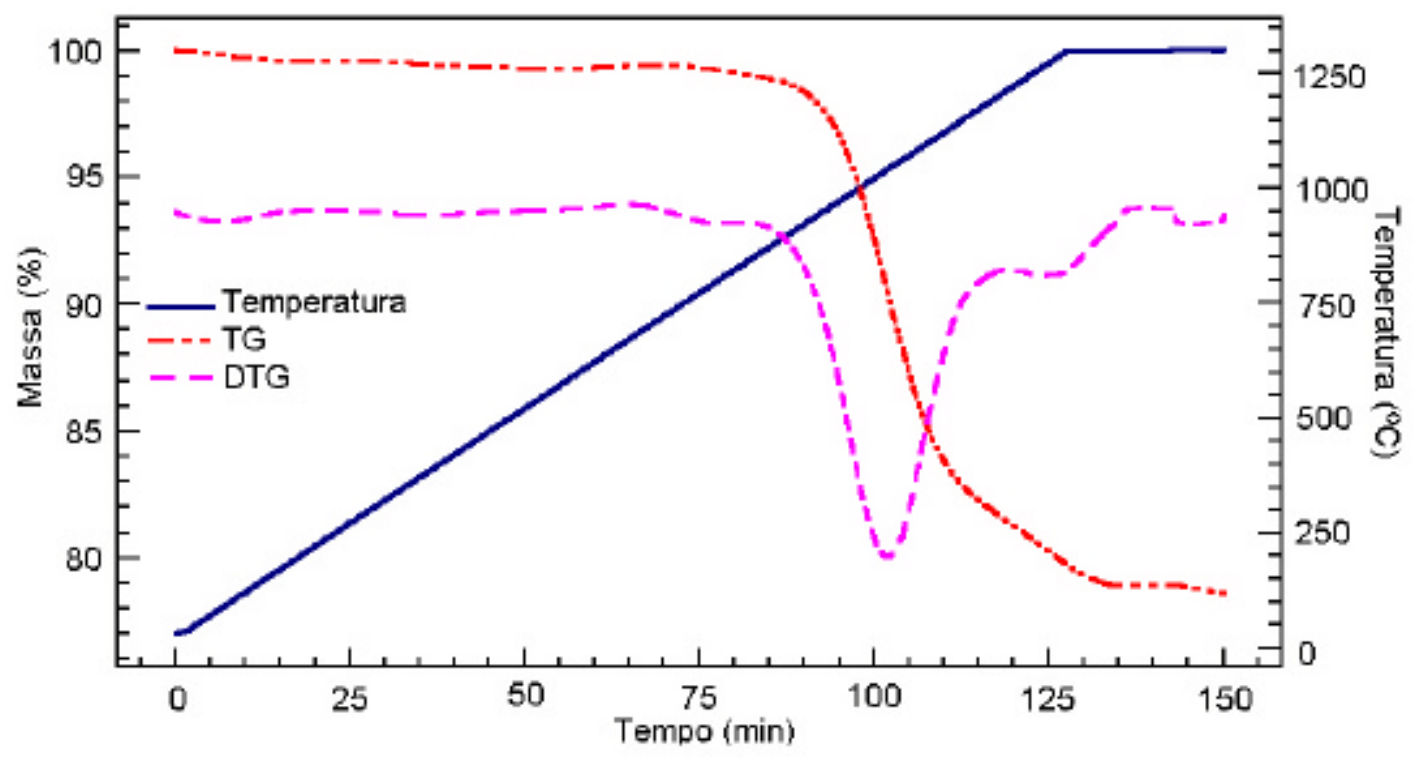

FIGURA 7.3 - Curvas TG/DTG do carbonato de bário em atmosfera inerte $\left(\mathrm{N}_{2}\right)$.

Nos experimentos seguintes, verificou-se o efeito de uma atmosfera redutora $\left(10 \% \mathrm{H}_{2}+90 \% \mathrm{Ar}\right)$. As condições experimentais foram as seguintes: termobalança SHIMADZU TGA $51 \mathrm{H}$, cadinho de alumina, $\beta$ igual a $10^{\circ} \mathrm{C} \mathrm{min}^{-1}$, intervalo de temperatura de 25 a $1300^{\circ} \mathrm{C}$, patamar de $30 \mathrm{~min}$ em $1300^{\circ} \mathrm{C}$, fluxo de gás de $100 \mathrm{~mL} \mathrm{~min}{ }^{-1}$ e massa de, aproximadamente, $50 \mathrm{mg}$.

Verifica-se por meio da FIG 7.4 que o óxido de alumínio apresenta apenas uma perda inicial de massa referente àágua de umidade (de aproximadamente 1,6\%), atingindo a estabilidade térmica a uma temperatura de $700^{\circ} \mathrm{C}$, sem qualquer outro tipo de perda de massa (estabilidade térmica até $1300^{\circ} \mathrm{C}$ ). A curva TG do carbonato de bário apresenta duas 
etapas de decomposição. A primeira devido àágua de umidade $(\sim 1,0 \%)$, e a segunda etapa, entre 870 e $1300^{\circ} \mathrm{C}$, devido àeliminação de $\mathrm{CO}_{2}$ (perda de massa de 20,3\%).

A curva TG do carbonato de cálcio mostra que o composto apresenta duas etapas de decomposição térmica. Semelhante a curva do carbonato de bário, a primeira etapa de decomposição está relacionada à eliminação de água de umidade $(\sim 2,0 \%)$ e a segunda àdecomposição do carbonato. Esta segunda etapa apresenta uma perda de massa de $42,2 \%$ e a estabilidade térmica é atingida na temperatura de, aproximadamente, $900^{\circ} \mathrm{C}$.

A curva TG da mistura (alumina, carbonatos de bário e de cálcio) apresenta três etapas de decomposição significativas. A primeira ocorre devido à perda da água de umidade (presente nos reagentes utilizados $\sim 0,8 \%$ ). A segunda e terceira etapa está relacionada ao processo de decomposição do carbonato de cálcio $(\sim 9,0 \%)$ e do carbonato de bário $(13,0 \%)$, respectivamente. A estabilização da mistura é obtida na temperatura de aproximadamente $1000^{\circ} \mathrm{C}$.

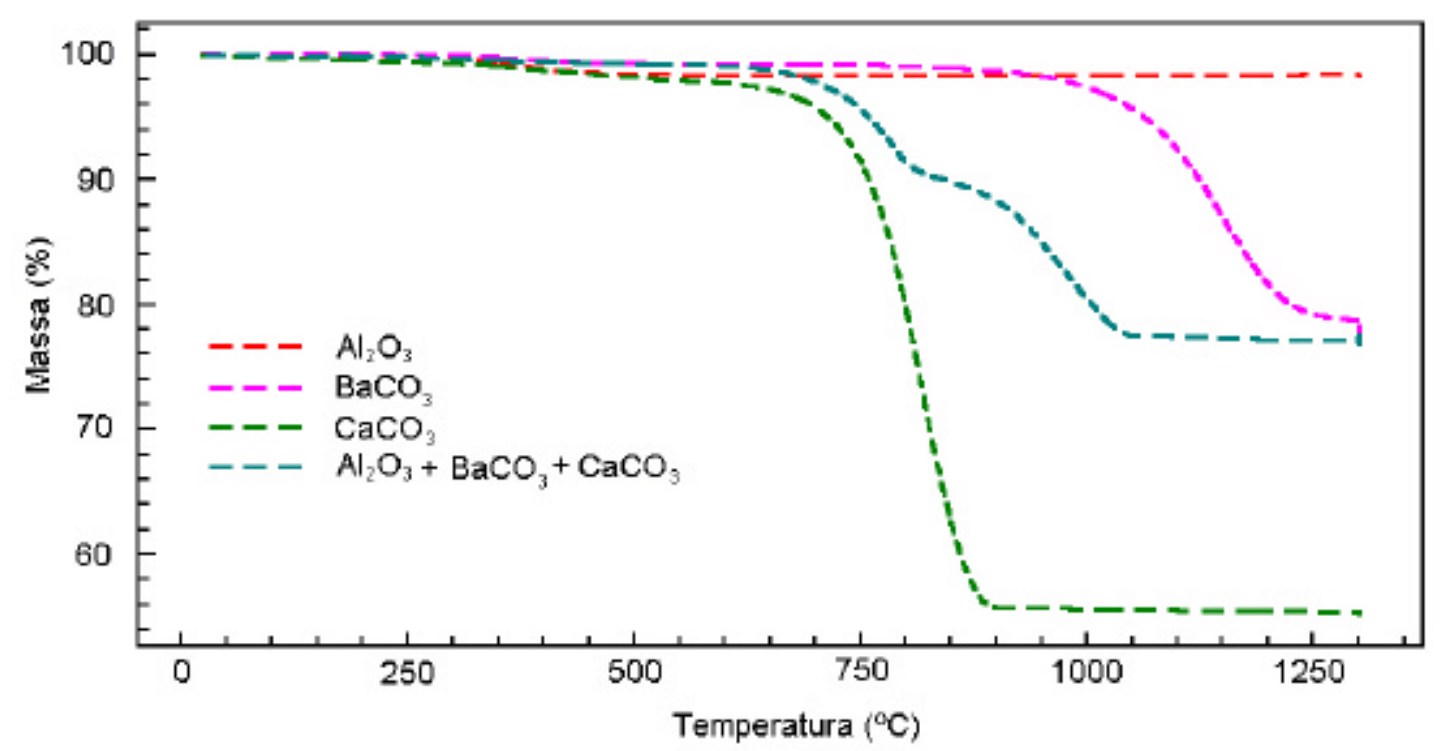

FIGURA 7.4 - Curvas TG dos carbonatos de bário e de cálcio, do óxido de alumínio e da mistura componentes (cadinho de alumina) em atmosfera redutora.

Por meio dos dados de análise térmica foi possível adequar a metodologia de obtenção dos aluminatos de bário e cálcio, determinando-se parâmetros como a proporção dos reagentes a ser utilizado e a temperatura de decomposição da mistura. Estabeleceramse estes parâmetros considerando-se a estabilização do material (a não variação da massa do produto final com a temperatura/tempo). Verificou-se nestas análises que há uma variação na faixa de temperatura da perda de massa devido a água de umidade e do processo de decomposição para diferentes atmosferas de decomposição. Isso ocorre devido 
a variação na pressão parcial de cada processo (pressão parcial: dióxido de carbono, oxigênio, nitrogênio e hidrogênio). Para uma análise mais aprofundada destes processos seria necessário realizar o estudo da cinética de reação para cada atmsfera (oxidante, redutor e inerte). No presente trabalho, investigou-se somente a faixa de temperatura e a análise químico-físca do material final.

Nos experimentos em fornos com atmosfera redutora (nas condições estabelecidas pela TG), observou-se que o produto final apresentava características diferentes das obtidas por termogravimetria, como mostra a FIG. 7.5.
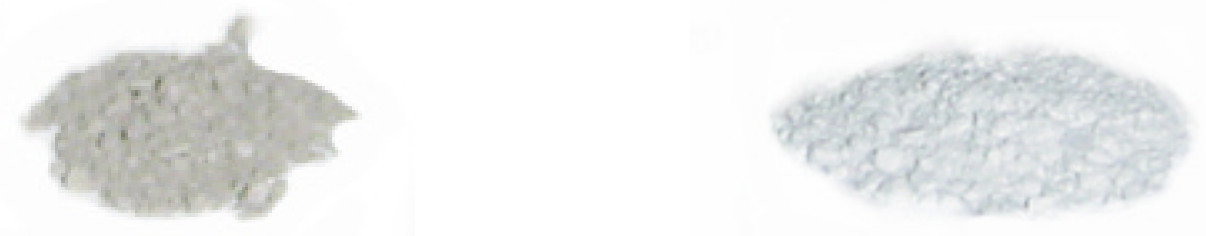

(a)

(b)

FIGURA 7.5 - (a) Aluminato de bário e cálcio obtido pelo método de reação em estado sólido (forno - atmosfera redutora $T=1000^{\circ} \mathrm{C}$ ). (b) Aluminato de bário e cálcio obtido por meio da $T G$ $\left(T=1300^{\circ} \mathrm{C}\right)$.

A amostra na FIG. 7.5 (a) apresenta uma coloração cinza, o que pode estar relacionado à presença de carbono elementar no material. Por outro lado, a amostra da FIG. 7.5 (b) apresenta uma coloração branca. Isto pode ser explicado pela alta taxa de aquecimento utilizado no processo convencional (forno), o que acarreta a não eliminação de todo $\mathrm{CO}_{2}$.

Realizou-se a termogravimetria da amostra de aluminato obtida por meio da reação em estado sólido (do forno). A curva TG referente a este experimento está apresentada na FIG 7.6. Na FIG. 7.6, observa-se que o aluminato apresenta diversas etapas de decomposição, as quais provavelmente correspondem à conversão do carbono elementar em dióxido de carbono. Devido à presença do carbono elementar no produto final da pirólise, adicionou-se àrota de obtenção do aluminato uma etapa de calcinação em atmosfera oxidante $\left(\mathrm{C}_{(\mathrm{s})}+\mathrm{O}_{2(\mathrm{~g})} \quad \mathrm{CO}_{2(\mathrm{~g})}\right)$. 


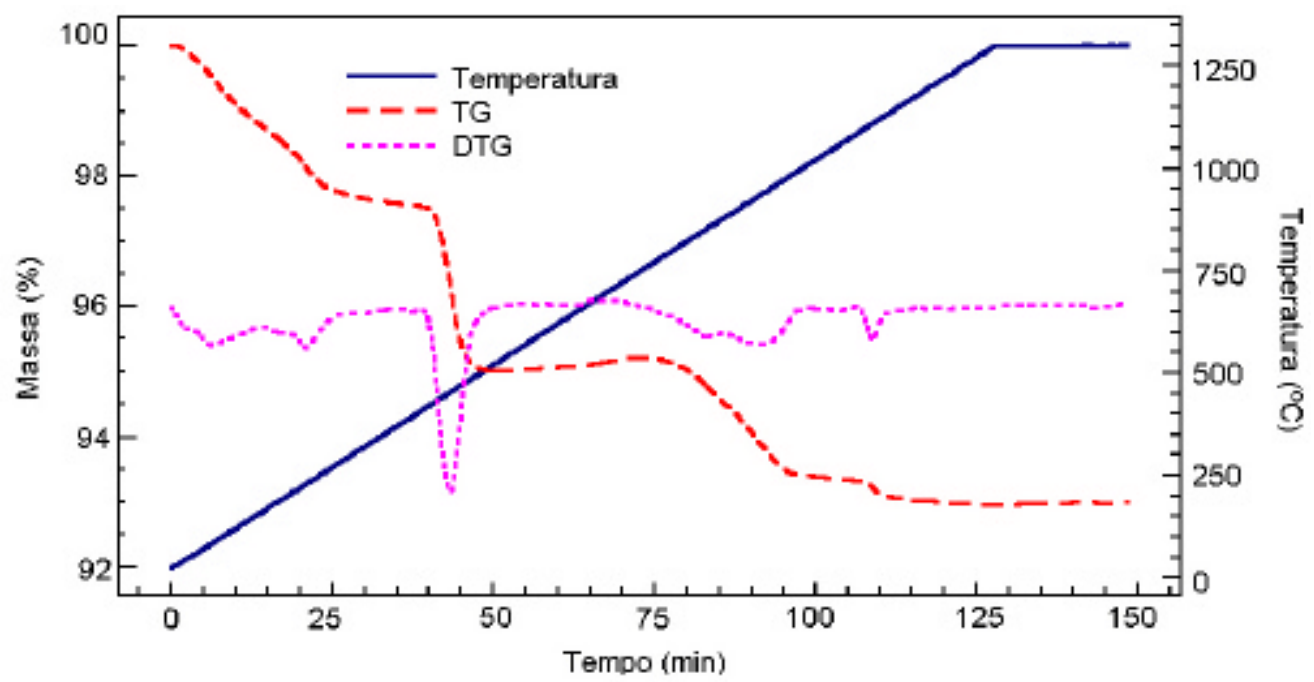

FIGURA 7.6 - Curvas TG/DTG para amostra de aluminato de bário e cálcio com presença de carbono elementar em atmosfera oxidante $\left(\mathrm{O}_{2}\right)$.

Posteriormente, avaliaram-se os comportamentos térmicos dos componentes utilizados na preparação do aluminato via método de cristalização, como apresenta a FIG. 7.7. Estes experimentos foram realizados utilizando-se: uma termobalança PERKINELMER TGA 7, cadinho de platina, razão de aquecimento $(\beta) 10^{\circ} \mathrm{C} \min ^{-1}$, intervalo de temperatura de 50 a $900^{\circ} \mathrm{C}$ e massa de aproximadamente $7 \mathrm{mg}$. A curva do nitrato de bário apresenta 4 etapas de decomposição, as quais provavelmente correspondem à "quebra" dos cristais do sal de bário, da perda de massa relativa a sua hidratação e posteriormente, uma perda de massa devido a decomposição do nitrato. A curva TG do nitrato de alumínio apresenta 3 etapas de decomposição (como a curva TG do nitrato de bário). Observam-se perdas de massa devido à presença das nove moléculas de água na estrutura do nitrato de alumínio, e à decomposição do nitrato (perda de massa de 82,8 \%), atingindo-se a estabilidade térmica acima dos $600^{\circ} \mathrm{C}$.

A curva TG do nitrato de cálcio evidencia a perda de massa, aproximadamente $29,2 \%$, entre 50 e $250^{\circ} \mathrm{C}$ devido ao processo de desidratação. O produto desta desidratação permanece estável até $550^{\circ} \mathrm{C}$. Acima de $600^{\circ} \mathrm{C}$, iniciase o processo de decomposição do nitrato, com perda de massa de 44,6\% e, conseguinte, estabilização do óxido. O processo de decomposição térmica do produto da cristalização corresponde aproximadamente ao processo térmico de cada nitrato. 


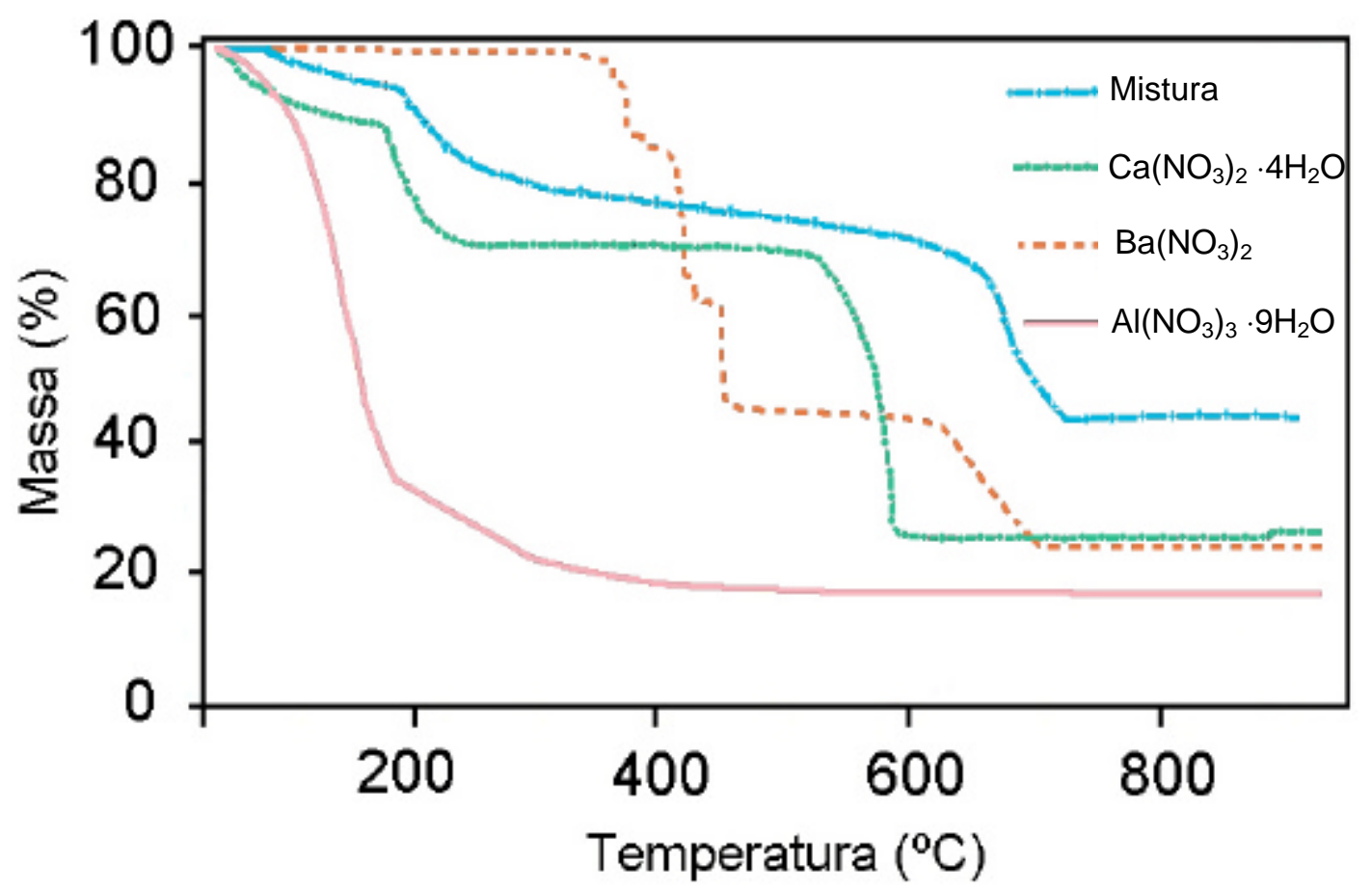

FIGURA 7.7 - Curvas TG dos nitratos de bário, de cálcio, de alumínio e do produto da cristalização em atmosfera oxidante.

A curva TG apresentada na FIG. 7.8 ilustra a perda de massa do produto obtido na preparação dos aluminatos via método de precipitação (TGA 51 H SHIMADZU, $\beta=10^{\circ} \mathrm{C} \mathrm{min}^{-1}$, cadinho de platina, massa de aproximadamente $50 \mathrm{mg}$, fluxo de gás de $100 \mathrm{~mL} \mathrm{~min}^{-1}\left(10 \% \mathrm{H}_{2}+90 \% A r\right)$ e $50 \mathrm{~mL} \mathrm{~min}^{-1}(\operatorname{ar})$, e patamar de $30 \mathrm{~min}$ na temperatura de $1300^{\circ} \mathrm{C}$ ). Observa-se que em atmosfera redutora, a estabilidade térmica é atingida em uma temperatura cerca de $200^{\circ} \mathrm{C}$ inferior àquela em atmosfera oxidante. As perdas de massa estão relacionadas à etapas de perda de massa devido a água de umidade (etapa inicial), de decomposição do hidróxido de alumínio, com provável liberação de água e, em seguida, a decomposição dos carbonatos de bário e cálcio com liberação de gases do tipo $\mathrm{CO}_{2}$. A perda de massa total foi de 53,7\% em atmosfera oxidante (ar) e de 54,9\% em atmosfera redutora. A variação da perda de massa pode estar relacionada com a quantidade de amostra empregada em cada análise. 


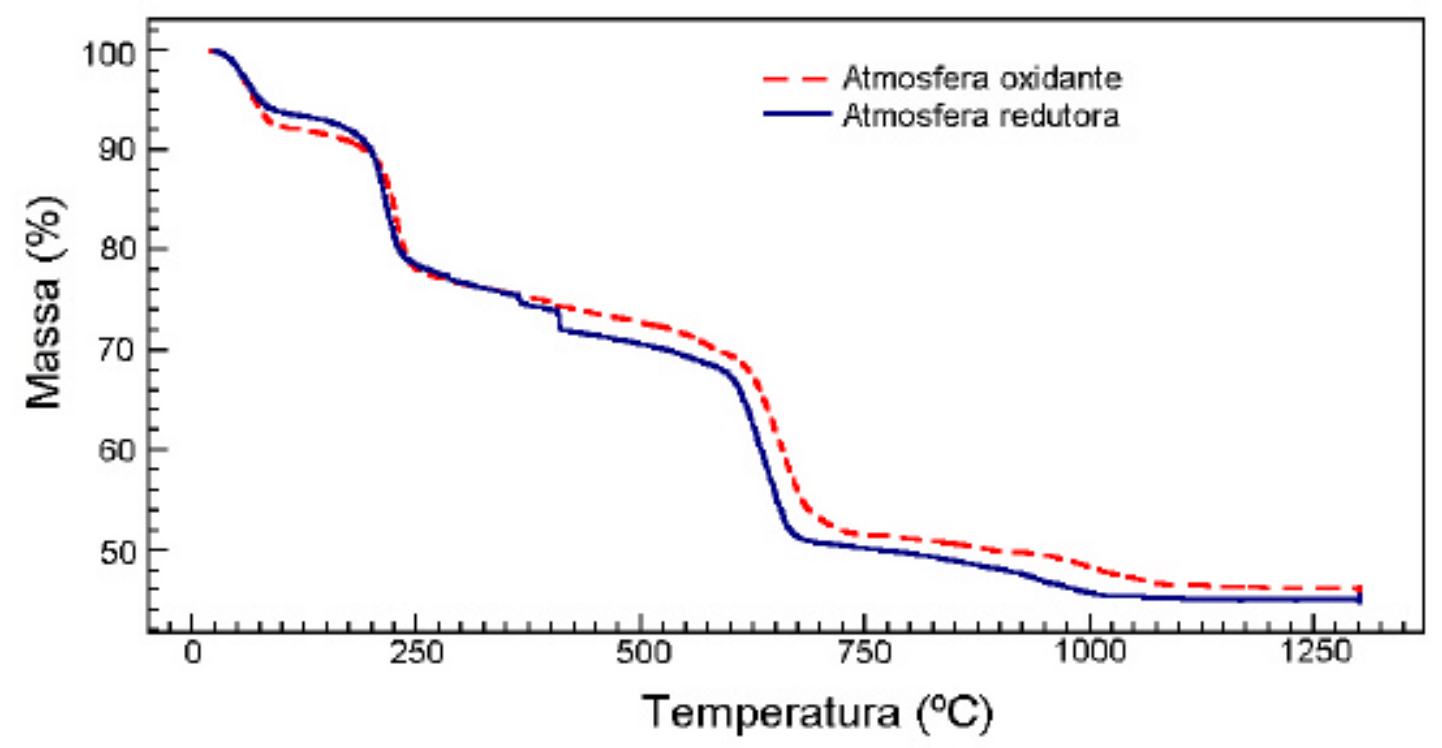

FIGURA 7.8 - Curvas TG do produto da precipitação em diferentes atmosferas (redutora e oxidante).

A FIG. 7.9 ilustra a sobreposição das curvas TG obtidas para os produtos obtidos em cada um dos métodos de síntese do material estudado (aluminato de bário e cálcio). Verifica-se que o método da cristalização gera um produto termicamente estável a uma temperatura mais baixa (aproximadamente $800^{\circ} \mathrm{C}$ ), comparado aos produtos obtidos nos outros dois métodos, termicamente estáveis em temperatura próxima a $1000^{\circ} \mathrm{C}$.

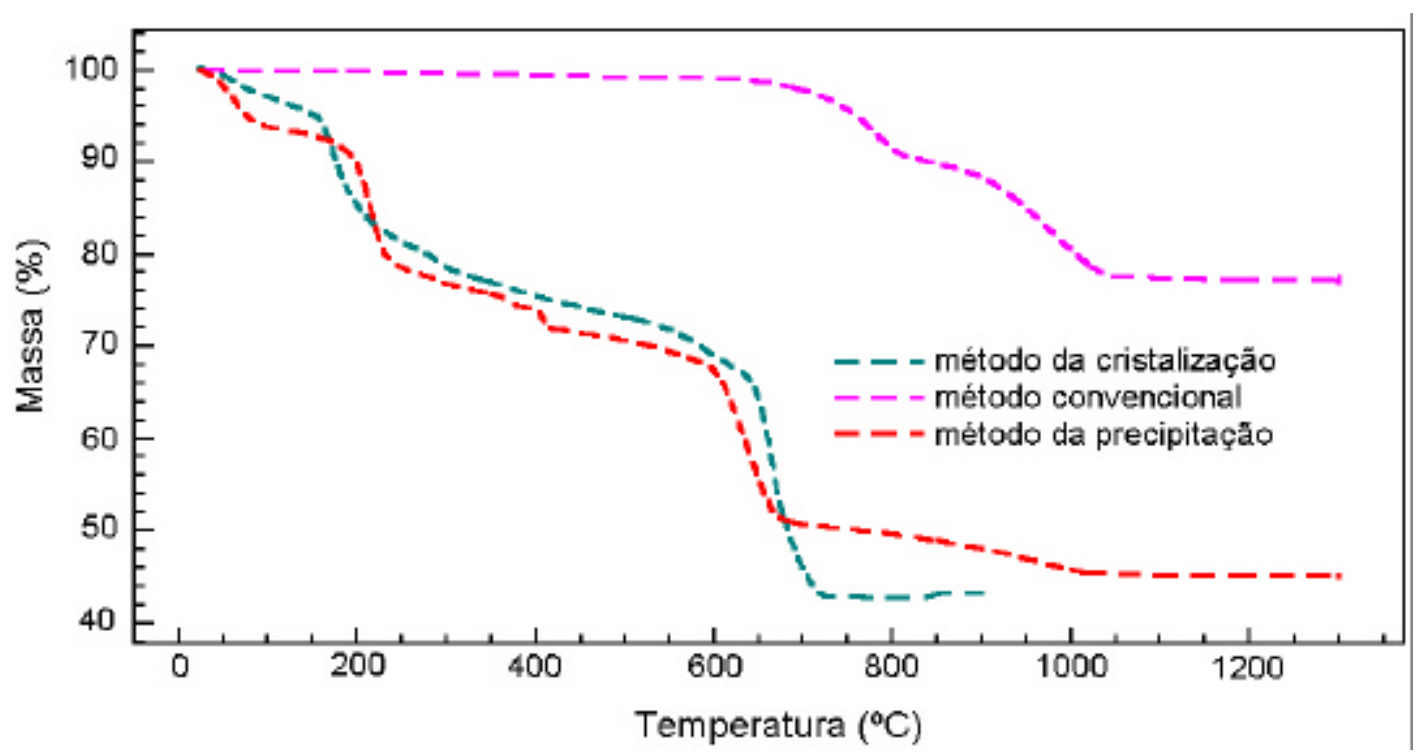

FIGURA 7.9 - Curvas TG dos aluminatos de bário e cálcio obtidos pelos diferentes métodos de síntese estudados. 


\subsection{Difração de raios $X$}

A investigação das condições de formação do aluminato e o estudo das fases formadas durante o processamento dos materiais foram realizados utilizando a técnica de difração de raios X.

A FIG. 7.10 ilustra o difratograma da mistura dos carbonatos $(B a$ e $C a)$ e óxido de alumínio (antes da etapa de pirólise).

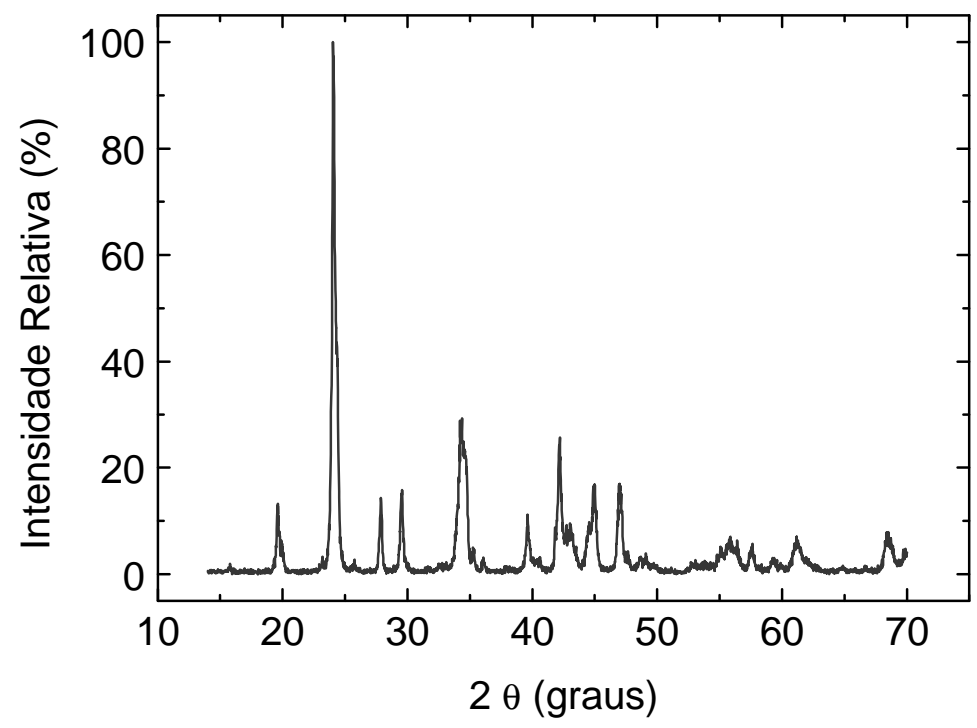

FIGURA 7.10 - Difratograma da mistura dos carbonatos de bário e de cálcio, e alumina.

Por meio da FIG. 7.11 verifica-se a formação do aluminato de bário e cálcio pelo deslocamento dos picos de difração (formação da fase $\mathrm{A}=\mathrm{Ba}_{5} \mathrm{CaAl} \mathrm{l}_{4} \mathrm{O}_{12}$ ). [52].

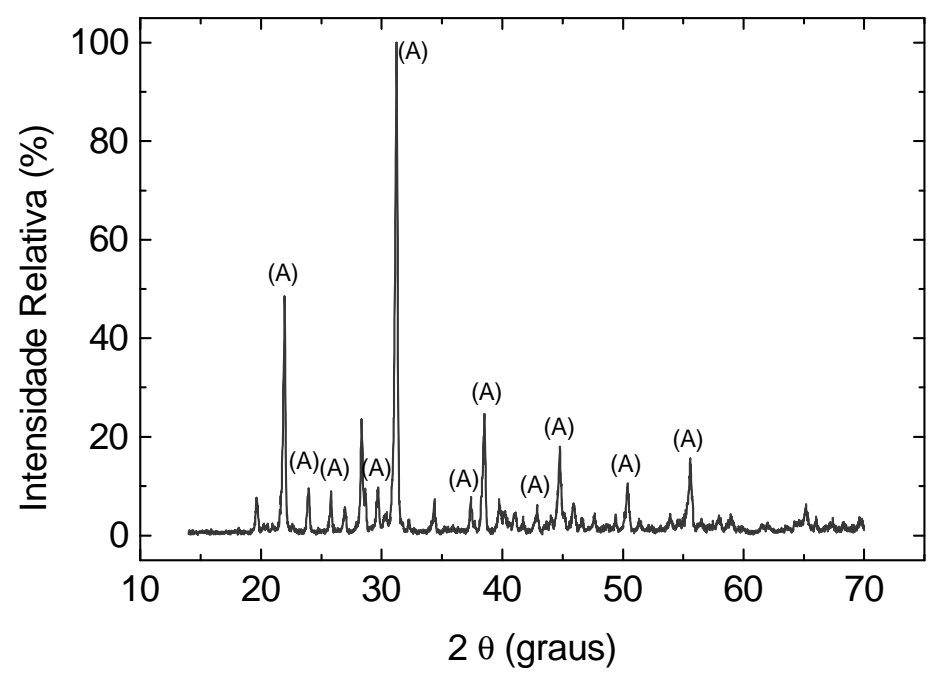

FIGURA 7.11 - Difratograma do aluminato de bário e cálcio obtido por meio do método de reação em estado sólido (convencional). 
A FIG. 7.12 ilustra o difratograma do produto obtido por meio do método de cristalização.

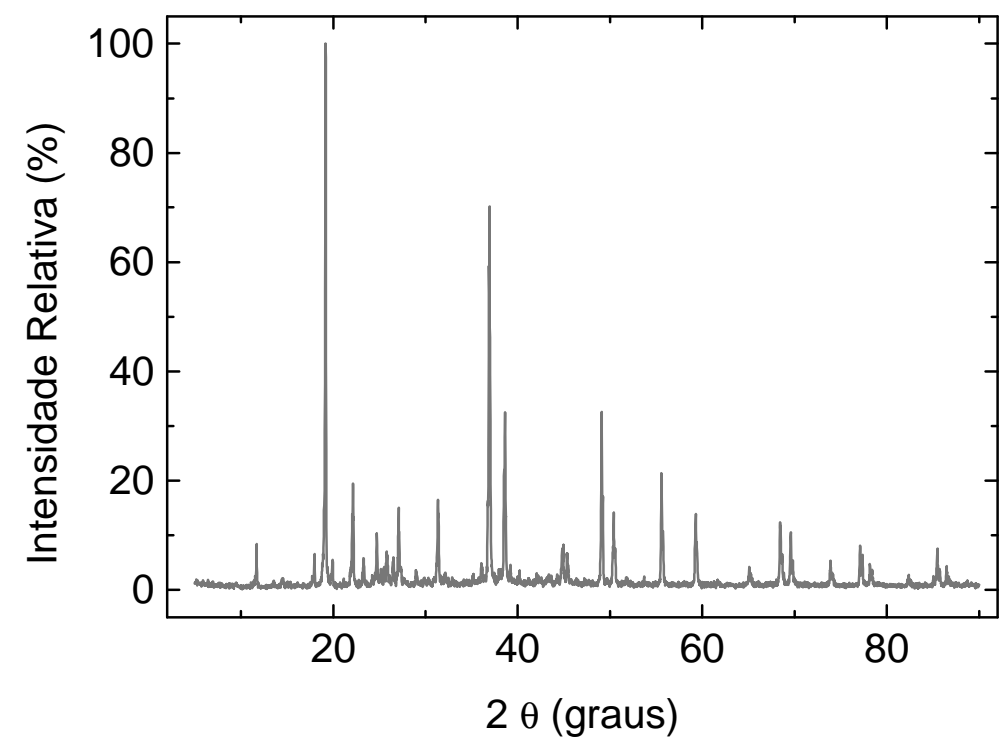

FIGURA 7.12 - Difratograma da mistura do produto da cristalização.

Por meio da FIG. 7.13, observa-se que após a etapa de calcinação do produto da cristalização, há formação da fase do aluminato de bário e cálcio (formação da fase $\left.\mathrm{A}=\mathrm{Ba}_{5} \mathrm{CaAl}_{4} \mathrm{O}_{12}\right)$. Este aluminato pode apresentar características de emissão adequadas aos experimentos iniciais, Maklakov [52] apresentou esta fase em seus experimentos de obtenção dos aluminatos de bário e cálcio que são empregados nos catodos termiônicos.

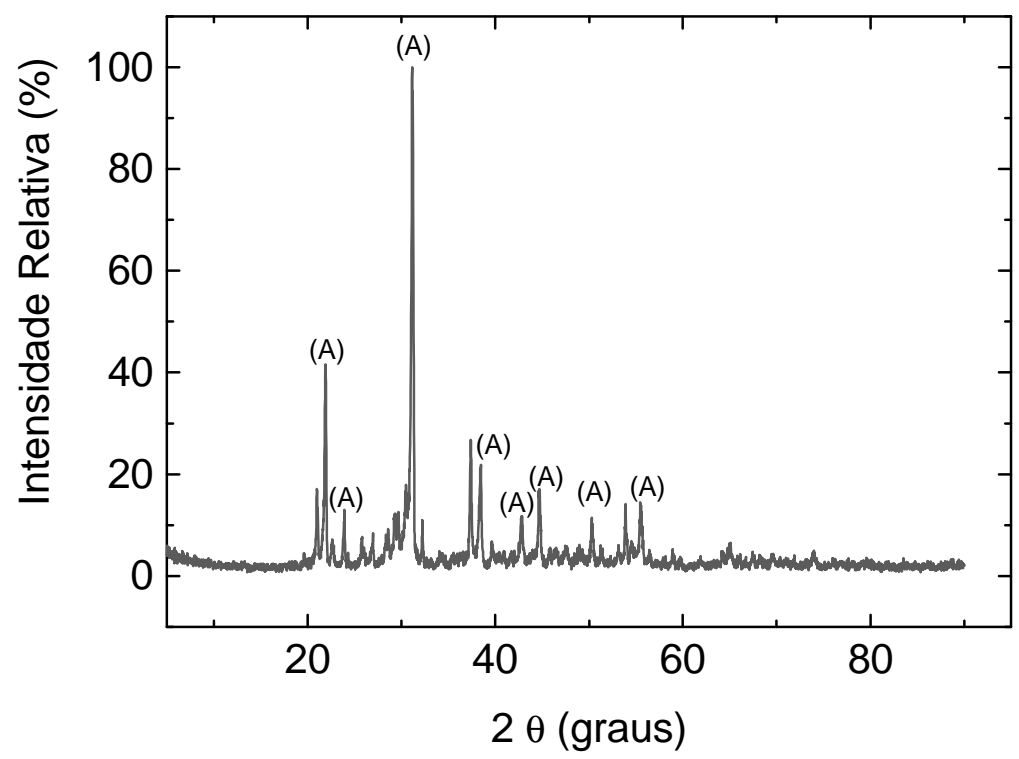

FIGURA 7.13 - Difratograma do aluminato de bário e cálcio obtido por meio do método de cristalização. 
Por meio da FIG. 7.14 verifica-se a formação da fase do aluminato de bário e cálcio no produto da síntese do material obtido pela técnica de precipitação. Entretanto, há presença de fases que podem estar relacionadas a outros compostos de bário, cálcio e alumínio.

Observando-se os dados obtidos, verifica-se que os produtos obtidos pelo método da reação em estado sólido, cristalização e precipitação apresentam fases semelhantes $\left(\mathrm{A}=\mathrm{Ba}_{5} \mathrm{CaAl}_{4} \mathrm{O}_{12}\right)$. Entretanto, no método da precipitação, o difratograma apresenta picos diferenciados, que podem estar relacionados a outras fases presentes na amostra (como os aluminatos, hidróxidos ou óxidos).

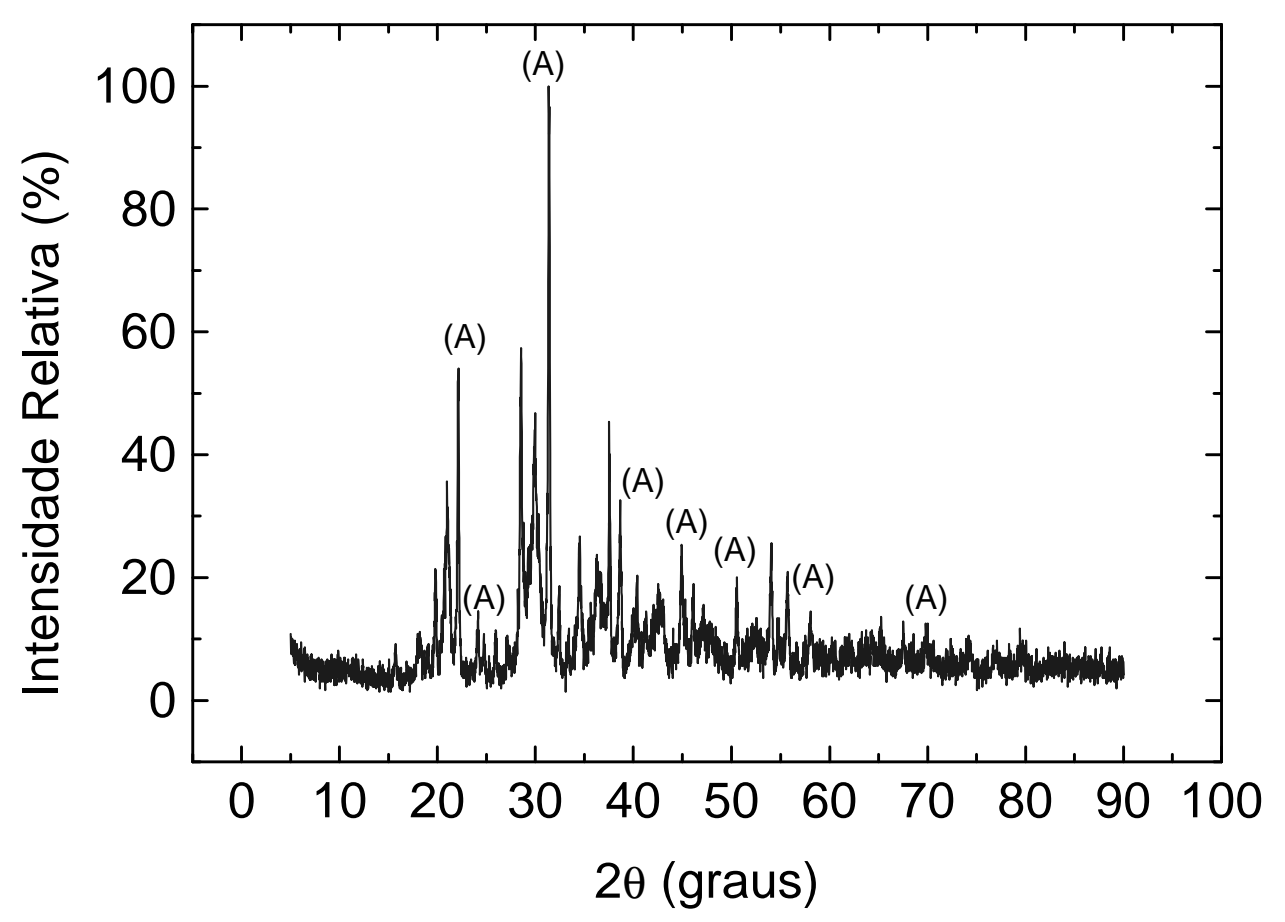

FIGURA 7.14 - Difratograma do aluminato de bário e cálcio obtido por meio da técnica de precipitação. 


\subsection{Fluorescência de raios $X$}

A análise de fluorescência de raios $\mathrm{X}$ foi realizada com o intuito de se verificar a proporção de $B a: C a: A l$ e suas possíveis impurezas. Na TAB. 7.1 apresentam-se os dados obtidos para as três metodologias.

TABELA 7.1 - Dados de fluorescência de raios X para a amostra obtida pelos diferentes métodos*.

\begin{tabular}{cccc} 
& Estado Sólido & Cristalização & Precipitação \\
\hline $\mathrm{Ba}(\%)$ & 46,3 & 44,3 & 38,8 \\
$\mathrm{Si}(\%)$ & 0,13 & 0,02 & 0,02 \\
$\mathrm{Sr}(\%)$ & 0,07 & 0,04 & 0,11 \\
$\mathrm{Cl}(\%)$ & - & - & 0,02 \\
$\mathrm{Mg}(\%)$ & 0,11 & - & - \\
$\mathrm{Ca}(\%)$ & 10,5 & 12,4 & 8,1 \\
$\mathrm{~S}(\%)$ & 0,17 & 0,02 & 0,02 \\
$\mathrm{Ni}(\%)$ & 0,01 & 0,02 & - \\
$\mathrm{Al}(\%)$ & 5,3 & 5,3 & 10,8 \\
$\mathrm{Na}(\%)$ & 0,28 & 0,38 & 0,30 \\
$\mathrm{Fe}(\%)$ & 0,05 & 0,07 & 0,03 \\
\hline
\end{tabular}

* Análise semiquantitativa - Método de Parâmetros Fundamentais - Erro relativo em termos de coeficiente de variação percentual inferior a $10 \%$.

Verifica-se, por meio da TAB. 7.1, a variação da proporção estequiométrica obtida pelos diferentes métodos. As discrepâncias existentes podem estar relacionadas com as metodologias de síntese dos aluminatos e, também, as condições das matérias-primas utilizadas (principalmente na técnica de precipitação, pois se utilizaram reagentes hidratados, como por exemplo: nitrato de cálcio tetrahidratado e nitrato de alumínio nonahidratado). Por meio dos valores da TAB. 7.1, verifica-se a reação em estado sólido e a cristalização apresentaram a proporção dos elementos próximos ao adequado $(5 \mathrm{BaO}$, $3 \mathrm{CaO}$ e $2 \mathrm{Al}_{2} \mathrm{O}_{3}$ ).

\subsection{Tamanho médio de partícula}

As FIG. 7.15 (a) e (b) apresentam as curvas da distribuição de tamanho de partículas para o aluminato obtido por meio da técnica de reação de estado sólido. $\mathrm{O}$ diâmetro médio de partículas determinado por meio da técnica de espalhamento laser foi de 2,21 $\mu \mathrm{m}$. Entretanto, verifica-se que na curva da freqüência acumulada que o tamanho médio a $50 \%$ é de $1,61 \mu \mathrm{m}$, tal fato é verificado devido à distribuição polimodal das partículas. 


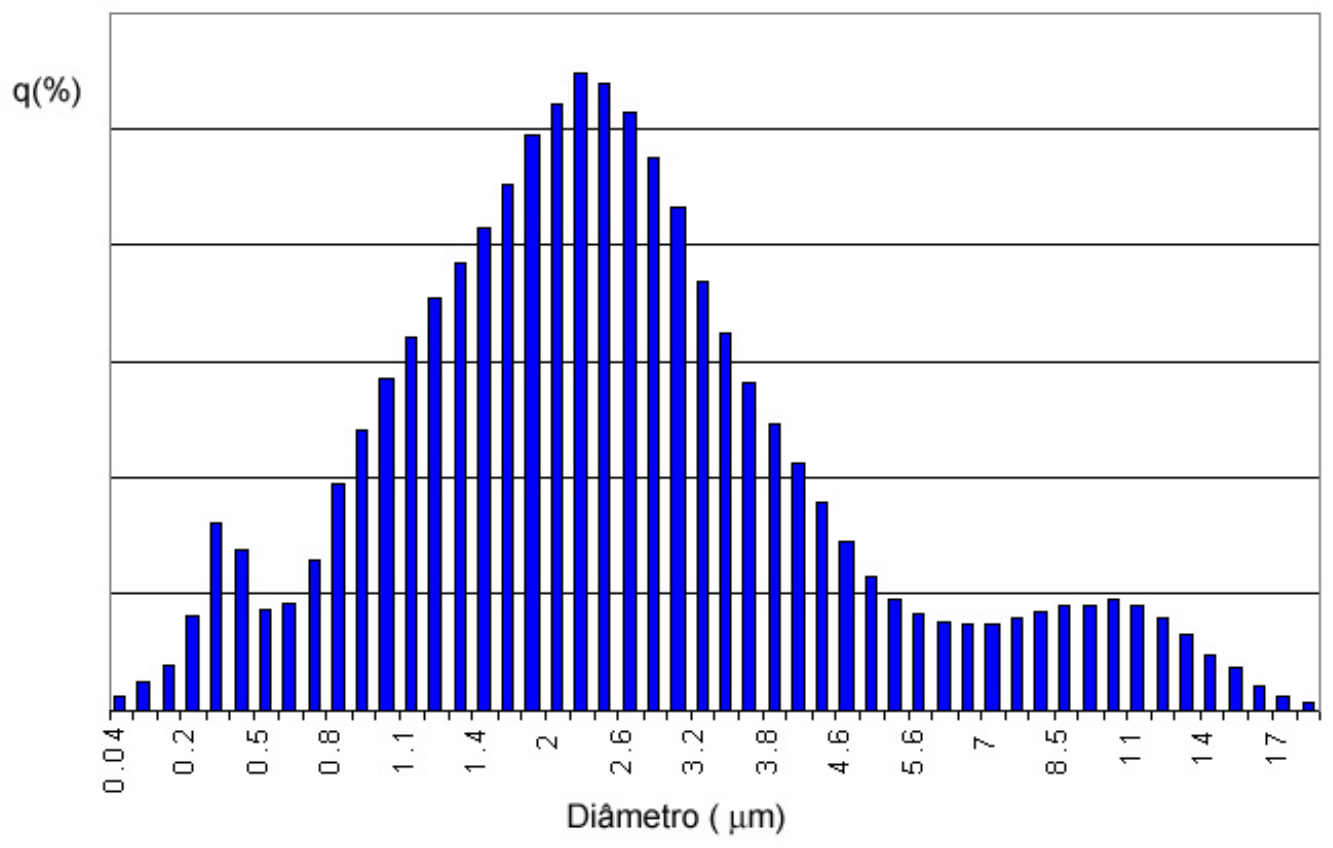

(a)

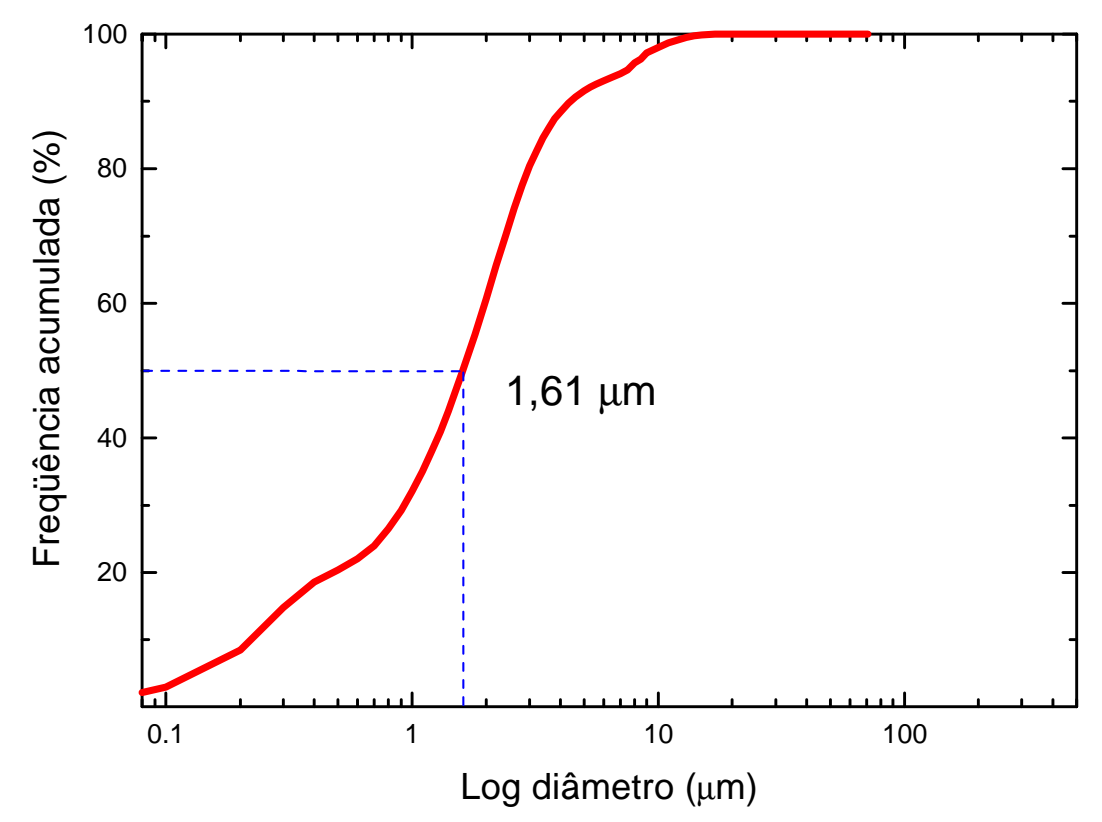

(b)

FIGURA 7.15 - Distribuição do tamanho de partícula para o aluminato de bário e cálcio obtido por meio da reação em estado sólido (a) Histograma. (b) Freqüência acumulada.

As FIG 7.16 (a) e (b) apresentam as curvas da distribuição de tamanho de partículas para o aluminato obtido por meio da técnica de reação de estado sólido após etapa de moagem (48 horas). O diâmetro médio de partículas determinado por meio da técnica de espalhamento laser foi $1,48 \mu \mathrm{m}$. Entretanto, verifica-se que na curva da 
freqüência acumulada que o tamanho médio a 50\% é de $1,08 \mu \mathrm{m}$. A variação nos valores do diâmetro médio das partículas é resultado da distribuição bimodal das partículas. Comparando-se as distribuições das partículas com e sem a etapa de moagem, verifica-se que a moagem auxilia na homogeneização da distribuição das partículas devido à uma possível desaglomeração das partículas.

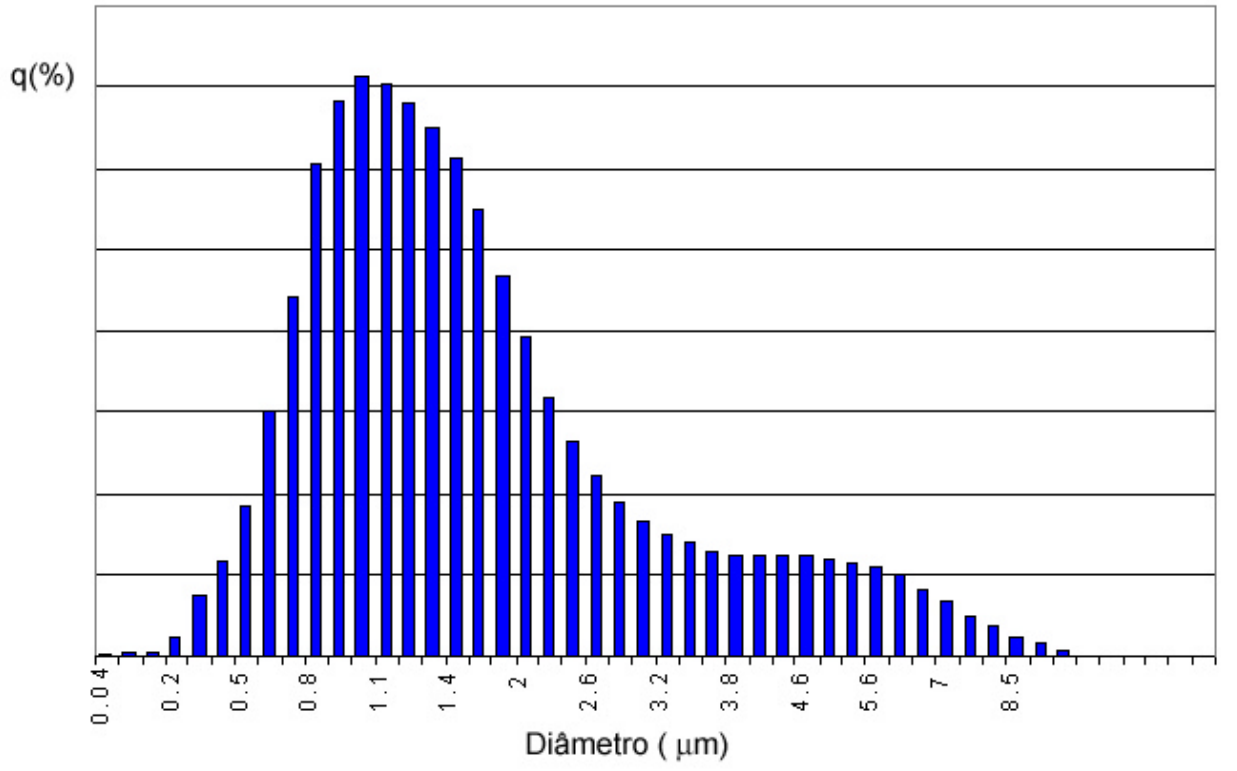

(a)

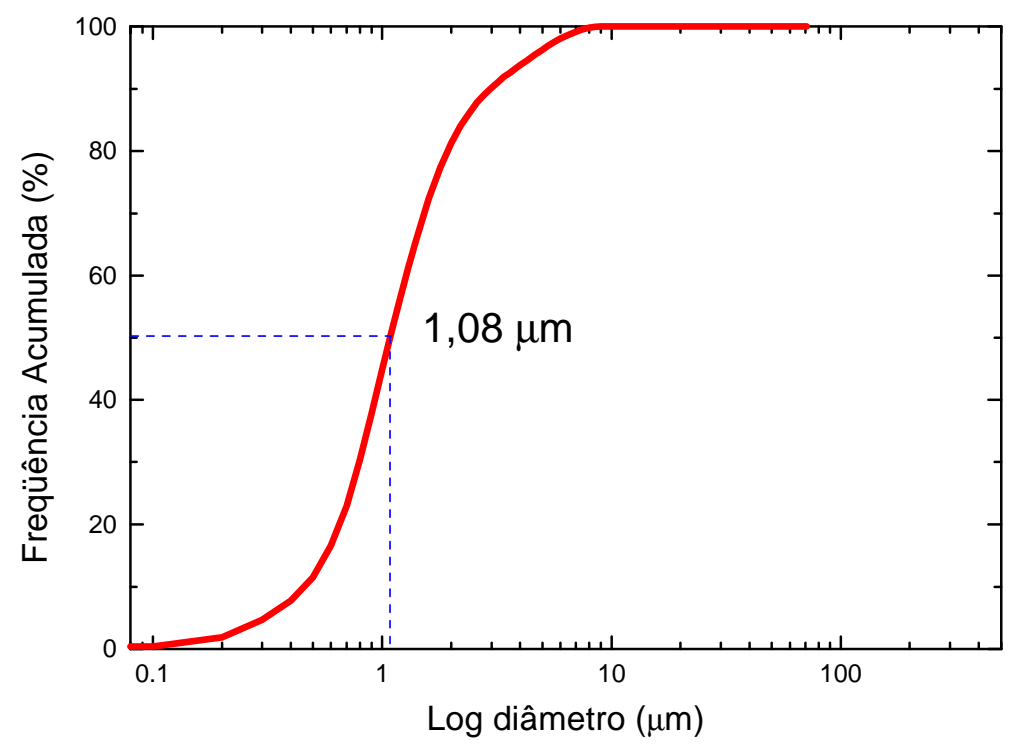

(b)

FIGURA 7.16 - Distribuição do tamanho de partícula para o aluminato de bário e cálcio obtido por meio da reação em estado sólido (48 h moagem) (a) Histograma. (b) Freqüência acumulada. 
As FIG. 7.17 (a) e (b) apresentam as curvas da distribuição de tamanho de partículas para o aluminato obtido por meio da técnica de cristalização. O diâmetro médio de partículas determinado por meio da técnica de espalhamento laser foi $2,48 \mu \mathrm{m}$. Entretanto, verifica-se que na curva da frequiência acumulada que o tamanho médio a $50 \%$ é de $1,37 \mu \mathrm{m}$. A variação nos valores do diâmetro médio das partículas é resultado da distribuição heterogênea das partículas.

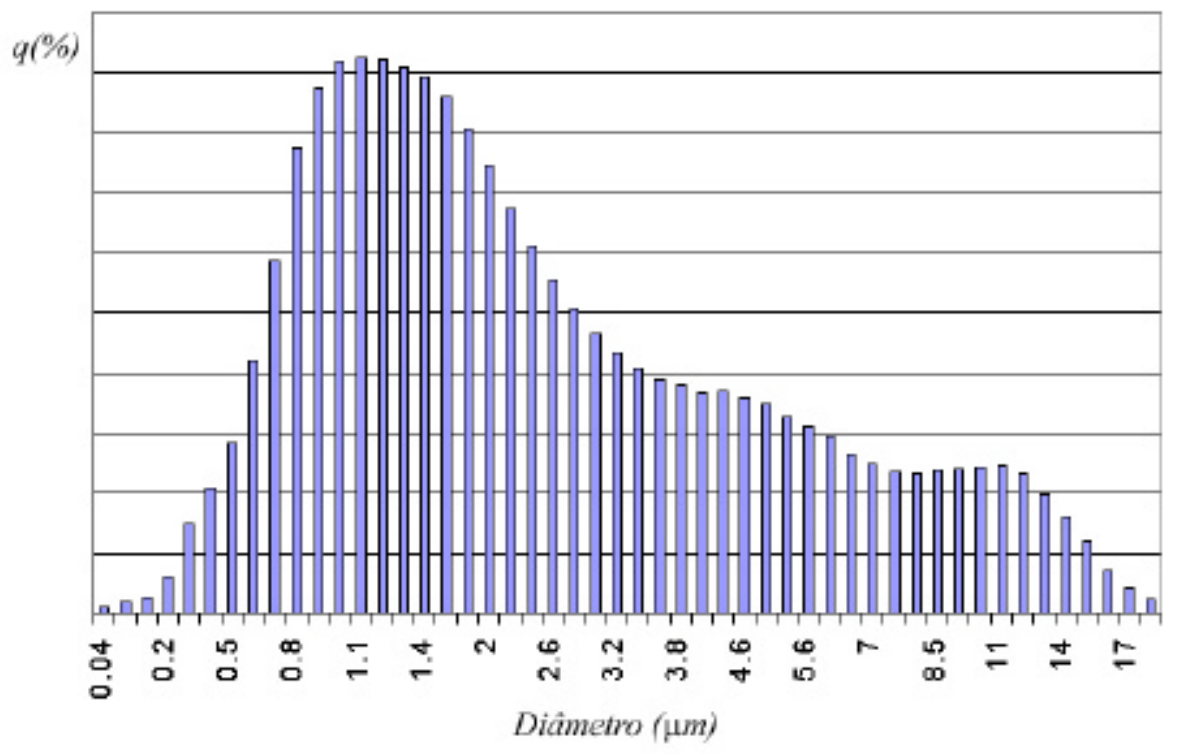

(a)

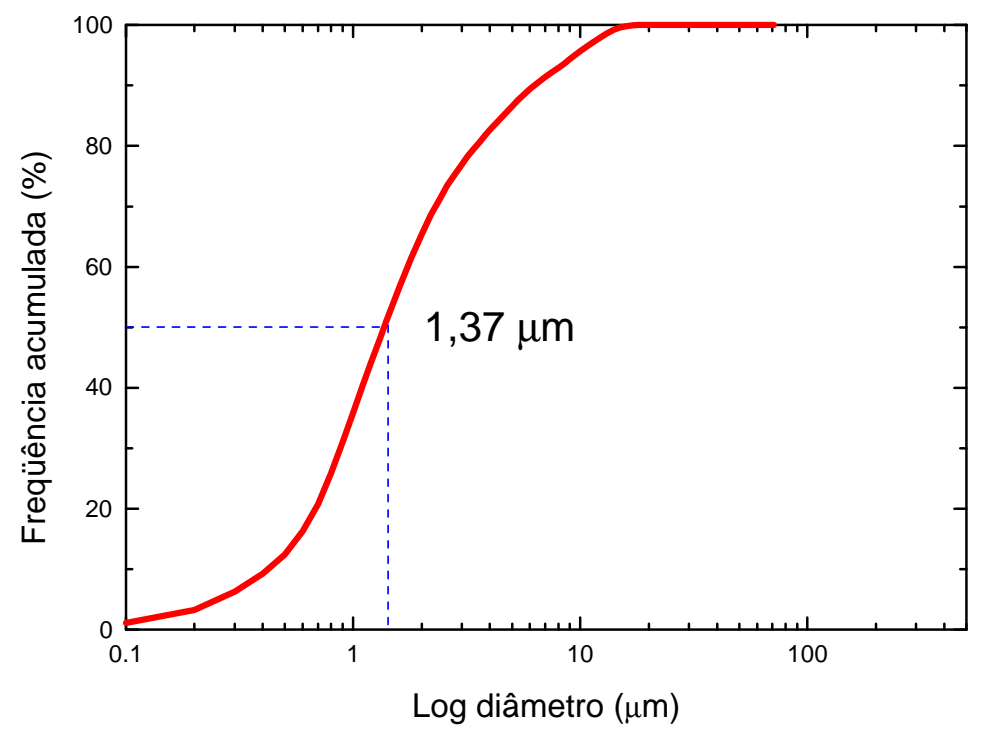

(b)

FIGURA 7.17 - Distribuição do tamanho de partícula para o aluminato obtido por meio da técnica de cristalização (a) Histograma. (b) Freqüência acumulada. 
As FIG. 7.18 (a) e (b) apresentam as curvas da distribuição de tamanho de partículas para o aluminato obtido por meio da técnica de precipitação. O diâmetro médio de partículas determinado por meio da técnica de espalhamento laser foi 9,57 $\mu \mathrm{m}$. Entretanto, verifica-se que na curva da frequiência acumulada que o tamanho médio a $50 \%$ é de $5,17 \mu \mathrm{m}$. A variação nos valores do diâmetro médio das partículas é resultado da distribuição polimodal das partículas.

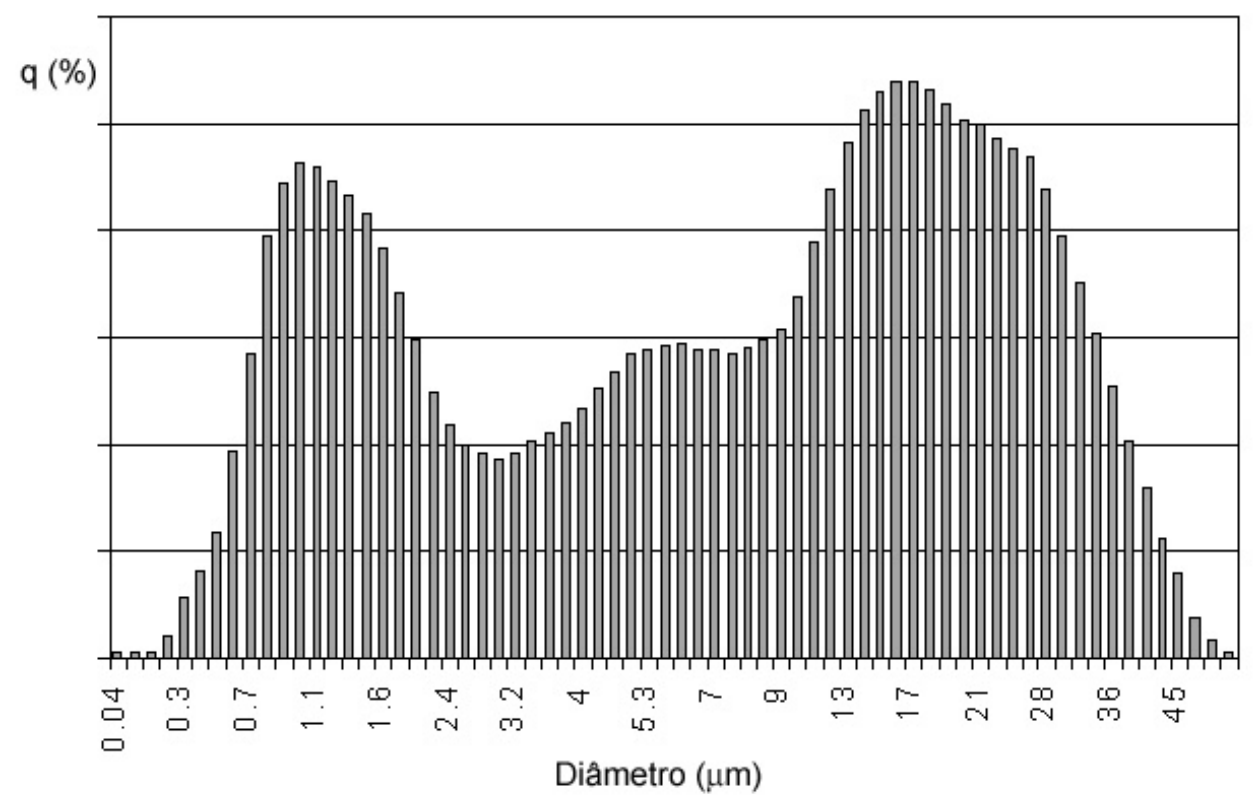

(a)

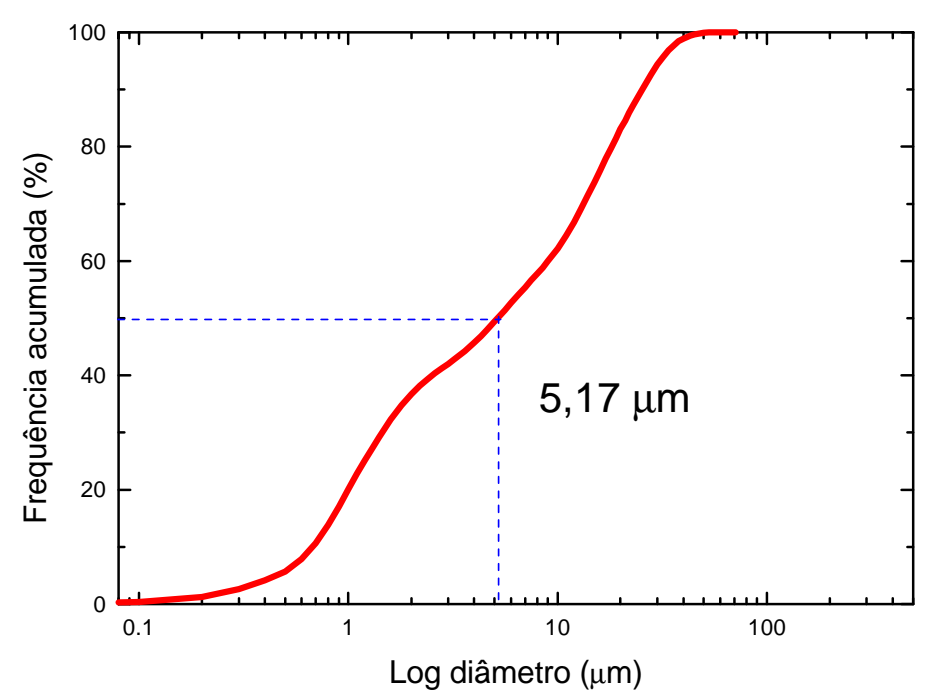

(b)

FIGURA 7.18 - Distribuição do tamanho de partícula para o aluminato de bário e cálcio obtido pela técnica de precipitação (a) Histograma. (b) Freqüência acumulada. 
Verifica-se por meio das FIG. 7.15 a 7.17 os tamanhos médios das partículas para os diferentes métodos. Os dados apresentados mostram que o menor diâmetro médio da partícula foi obtido por meio do método de reação em estado sólido com a etapa de homogeneização. Entretanto, a medida do tamanho médio das partículas depende da distribuição, forma, e estado de aglomeração das partículas. Desta forma, não se pode afirmar que a técnica de reação de estado sólido fornece um tamanho menor comparado à outras técnicas de síntese do aluminato estudadas. Uma observação importante é a variação do tamanho de partícula das amostras obtidos na reação em estado sólido em função do tempo de moagem. Há uma redução do tamanho de partícula de, aproximadamente, $33 \%$.

\subsection{Microscopia eletrônica de varredura}

Empregou-se a técnica de microscopia eletrônica de varredura (MEV) na caracterização da forma e estado de aglomeração das partículas dos aluminatos obtidos pelas diferentes técnicas de sintetização. Na FIG 7.19, verifica-se a forma da partícula obtida pela reação de estado sólido. Partículas alongadas e aglomeradas podem ser observadas.

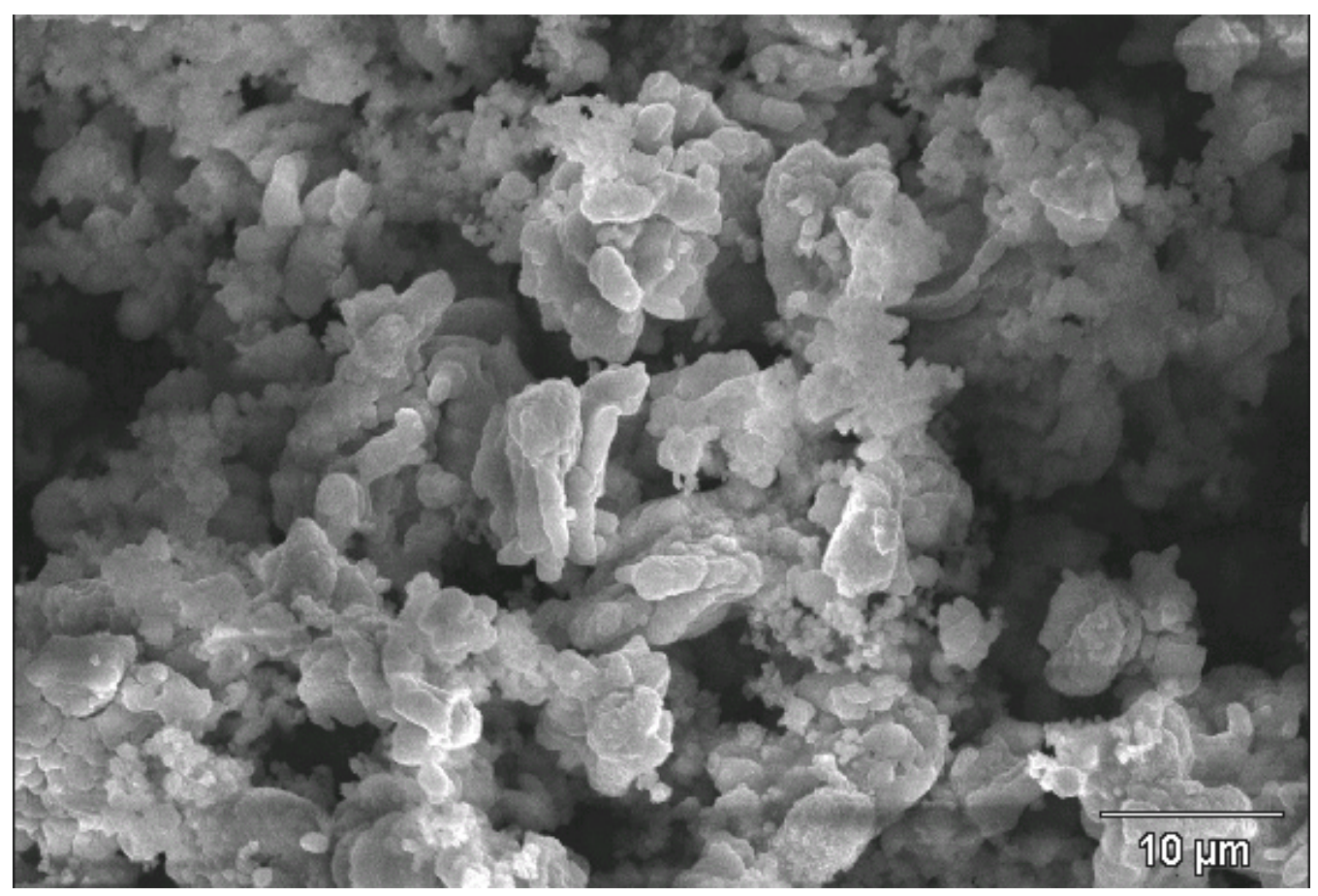

FIGURA 7.19-Forma das partículas do aluminato de bário e cálcio formado pela reação em estado sólido. 
A FIG. 7.20 apresenta a forma das partículas obtidas pela técnica de cristalização, as quais apresentam um maior estado de aglomeração quando comparadas com as partículas obtidas pela técnica de reação em estado sólido.

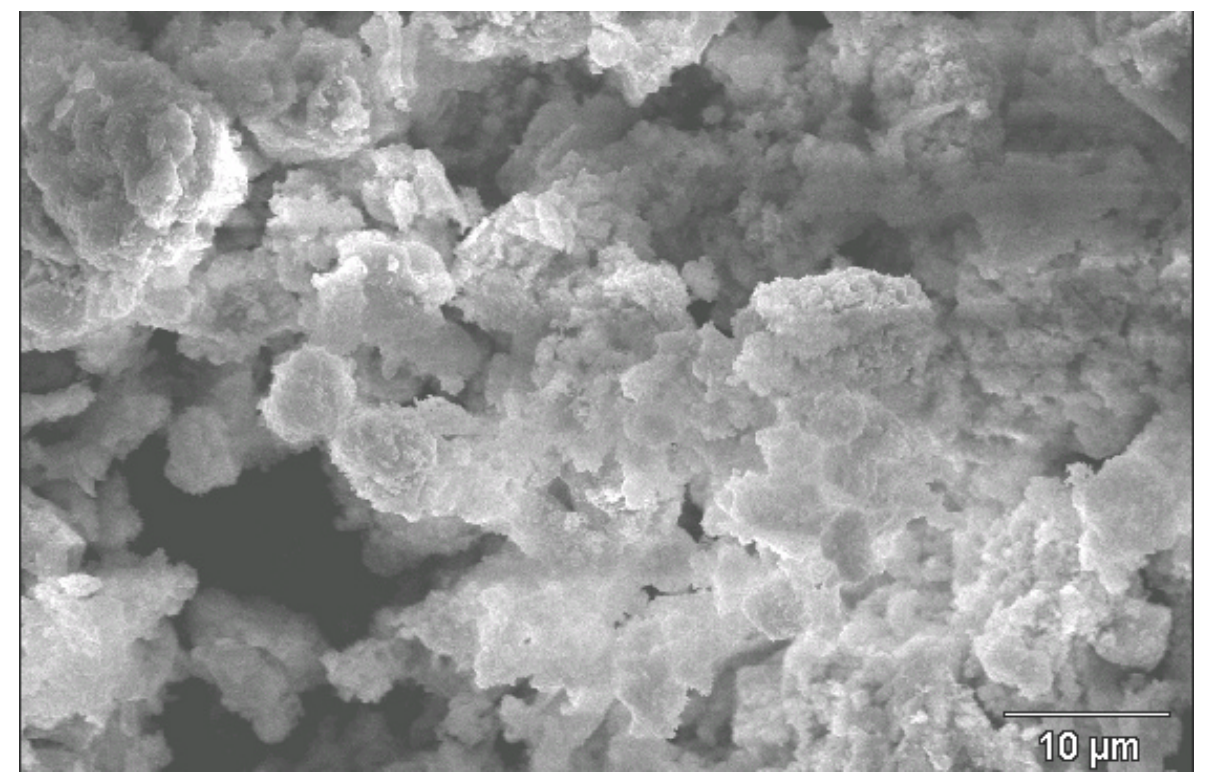

FIGURA 7.20 -Forma das partículas do aluminato de bário e cálcio formado pela técnica de cristalização.

Na FIG. 7.21 verifica-se uma irregularidade na forma das partículas do aluminato obtido pela técnica de precipitação, além do estado de aglomeração das mesmas.

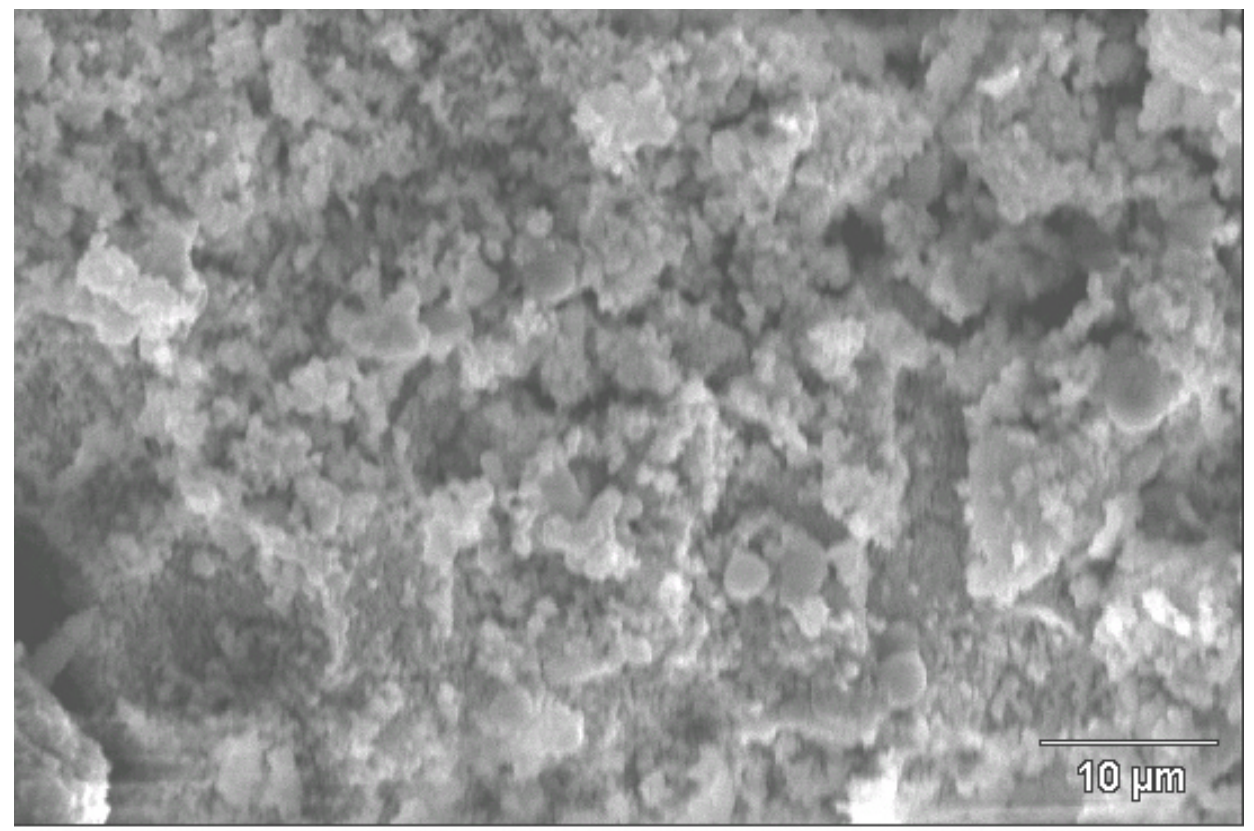

FIGURA 7.21 -Forma das partículas do aluminato de bário e cálcio formado pela técnica de precipitação. 
As análises realizadas pela técnica de microscopia eletrônica de varredura mostraram a influência da técnica de síntese do material na forma das partículas do aluminato de bário e cálcio, bem como no tamanho e no estado de aglomeração destas. A técnica de reação de estado apresentou partículas com forma regular e um menor estado de aglomeração.

A técnica de espectroscopia de energia dispersiva (EDS) auxilia na análise química e grau de homogeneidade dos aluminatos sintetizados. As FIG. 7.22 (a) e (b) apresentam as análises realizadas no aluminato obtido empregando-se a técnica de reação em estado sólido.

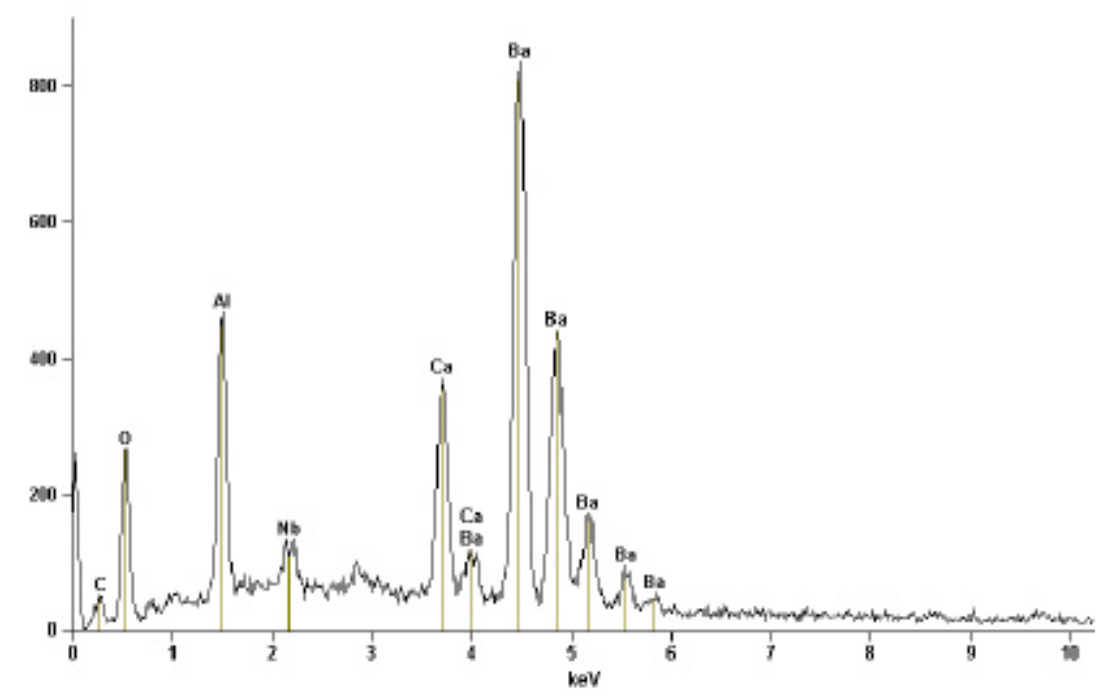

(a)

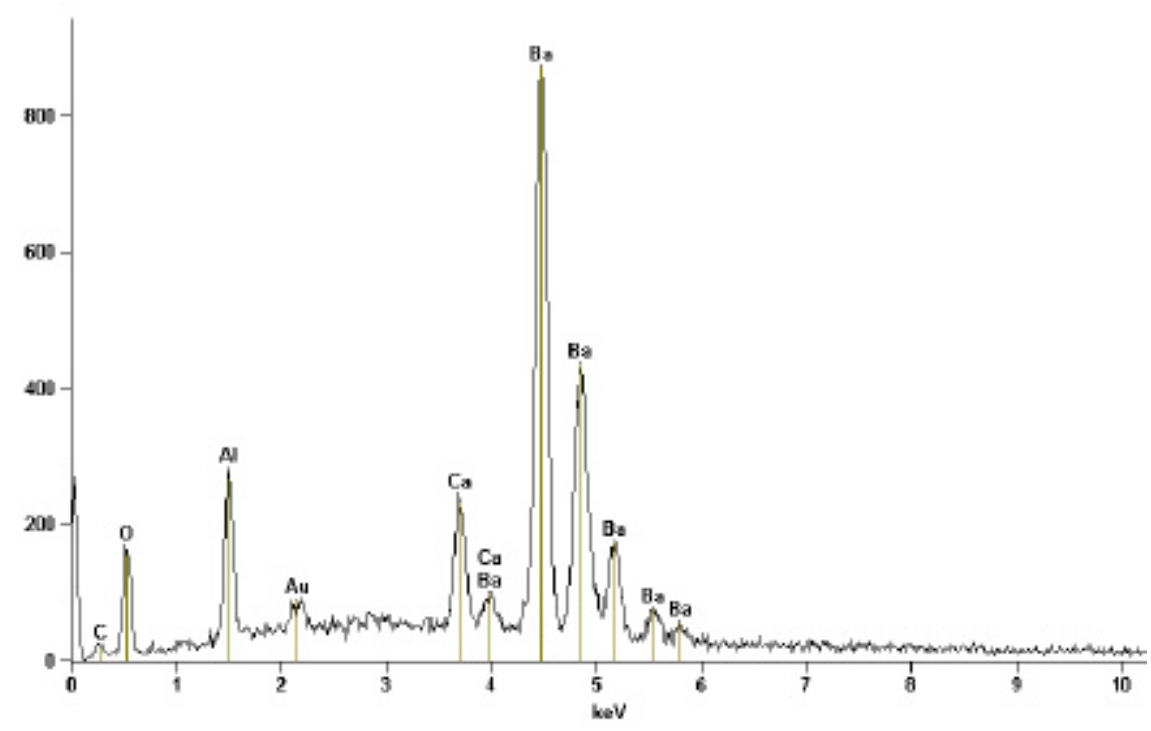

(b)

FIGURA 7.22 - Análises químicas do aluminato obtido por meio da técnica de reação de estado sólido em diferentes regiões. 
Verifica-se nas FIG. 7.22 (a) e (b) uma homogeneidade na proporção dos elementos que compõe o aluminato obtido pela reação de estado sólido.

As FIG. 7.23 (a) e (b) apresentam as análises realizadas no aluminato obtido empregando-se a técnica de cristalização.

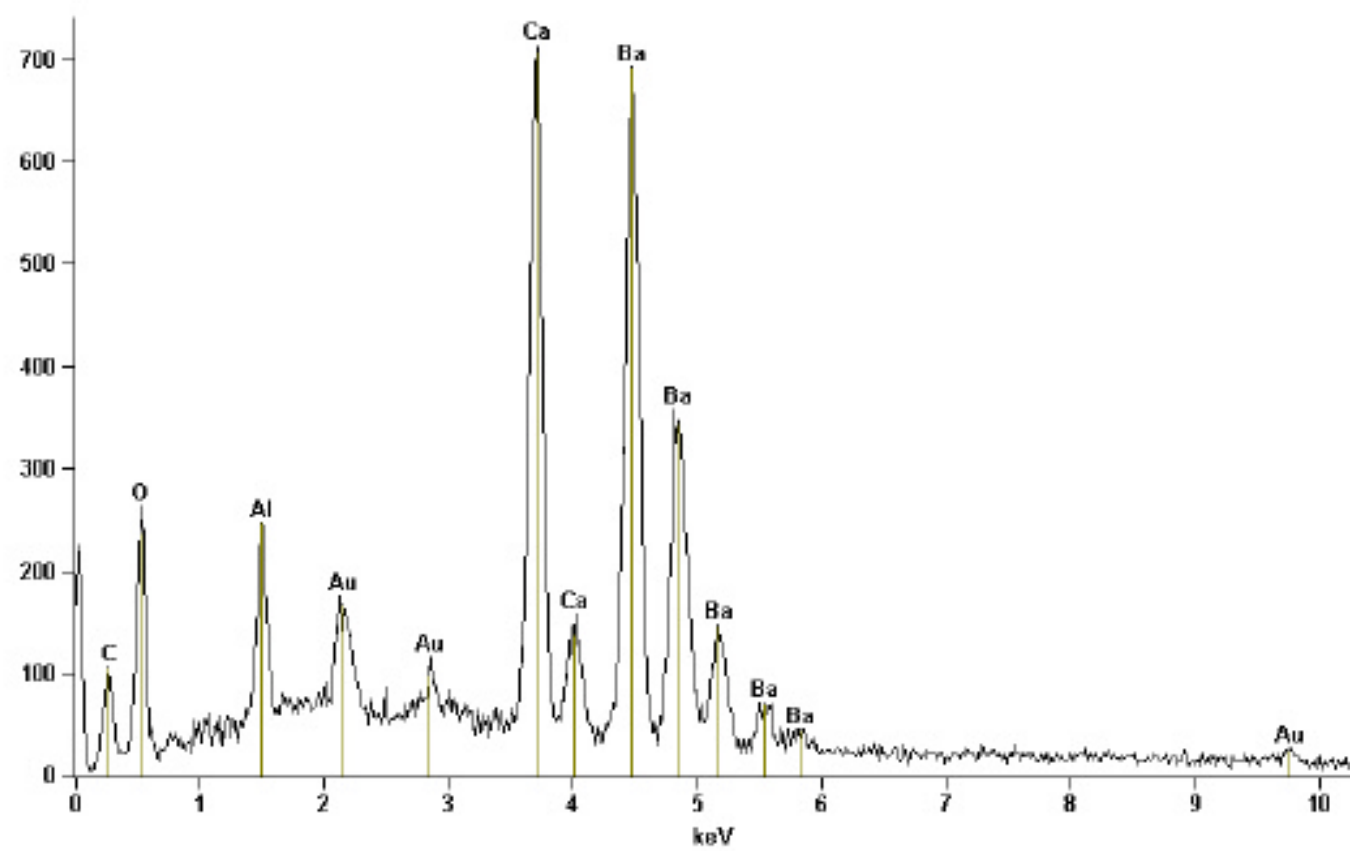

(a)

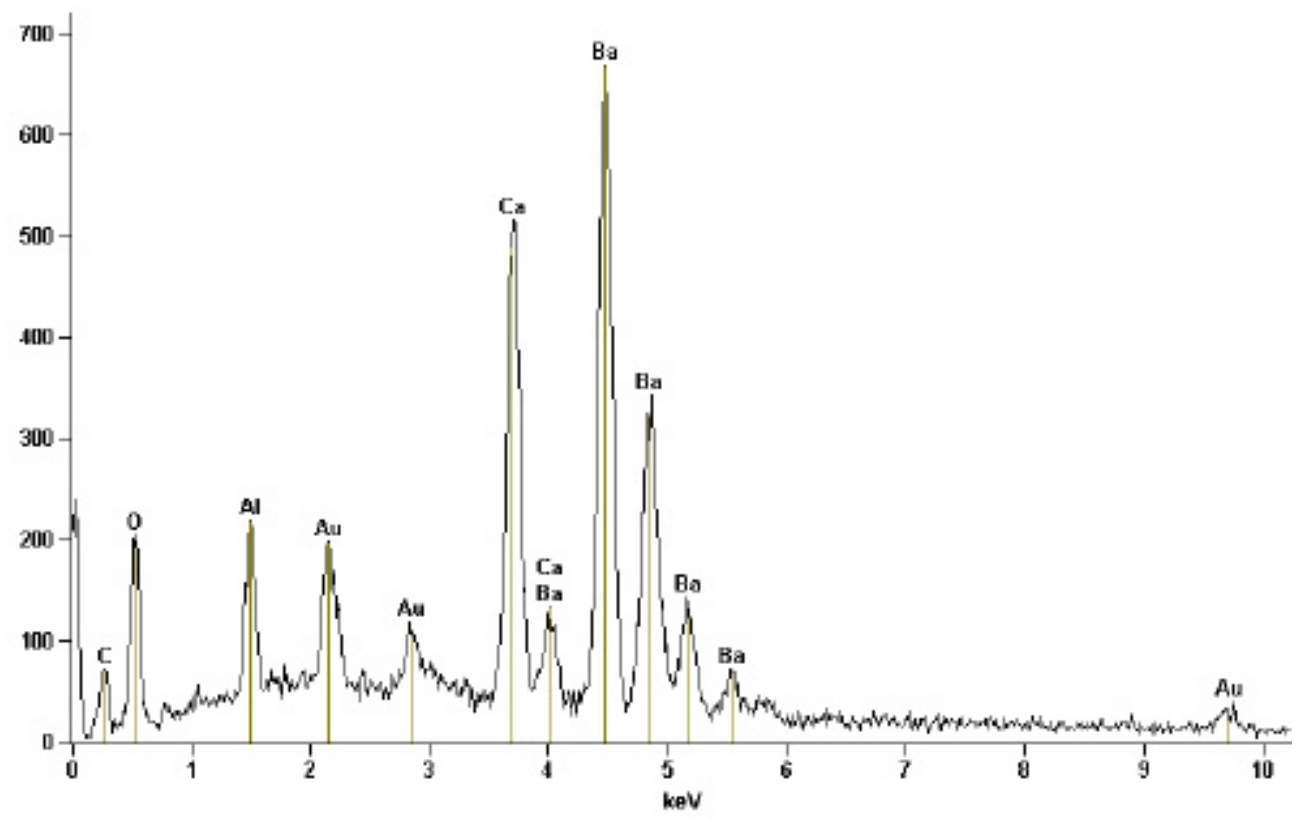

(b)

FIGURA 7.23 - Análises químicas do aluminato obtido por meio da técnica de cristalização em diferentes regiões. 
As FIG. 7.23 (a) e (b) mostram uma heterogeneidade na proporção dos elementos que compõem o aluminato obtido pela técnica de cristalização. Na região (a) há uma proporção significativa do elemento cálcio, diferente da região (b) que apresenta uma proporção maior de bário. As FIG. 7.24 (a) e (b) mostram as análises realizadas no aluminato obtido empregando-se a técnica de precipitação.

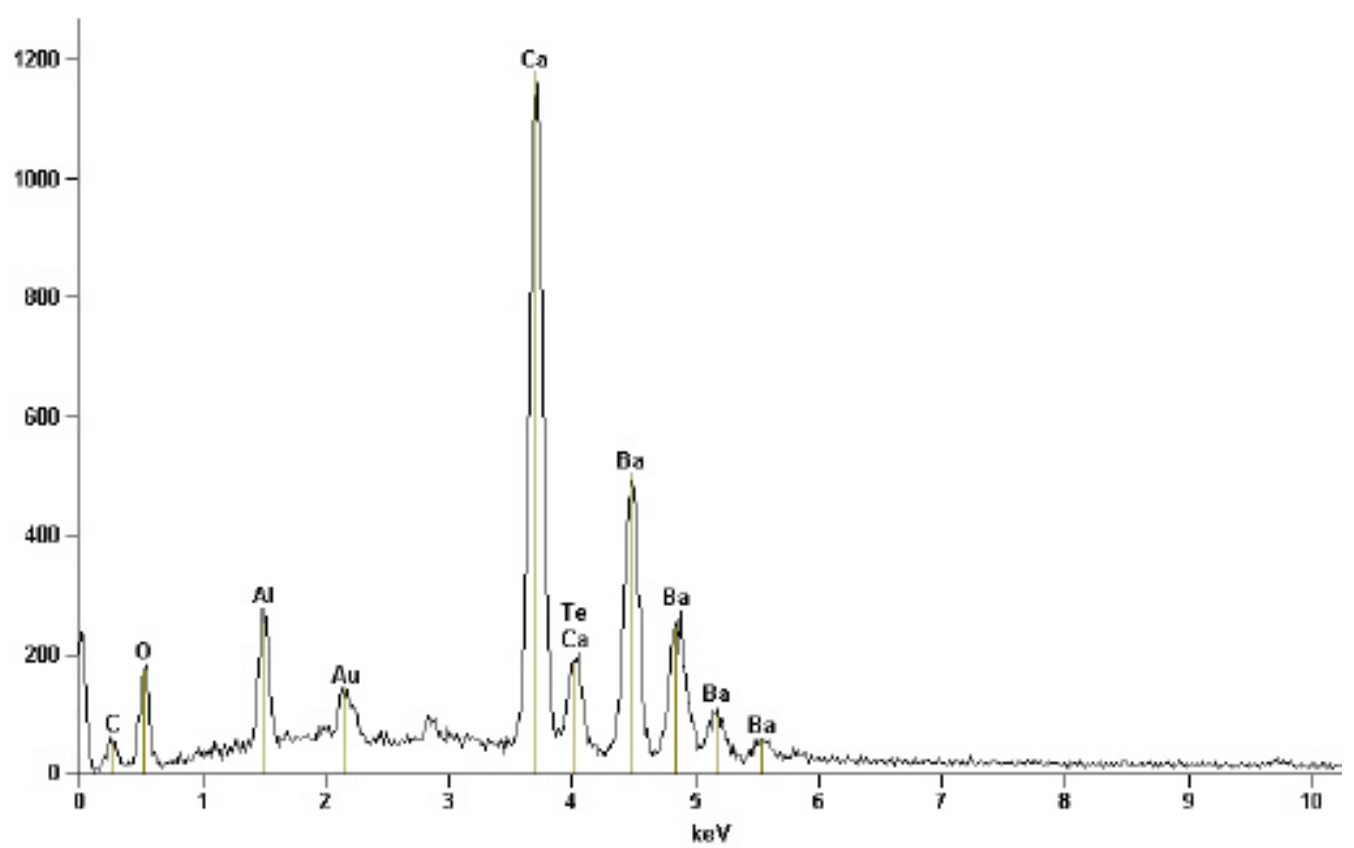

(a)

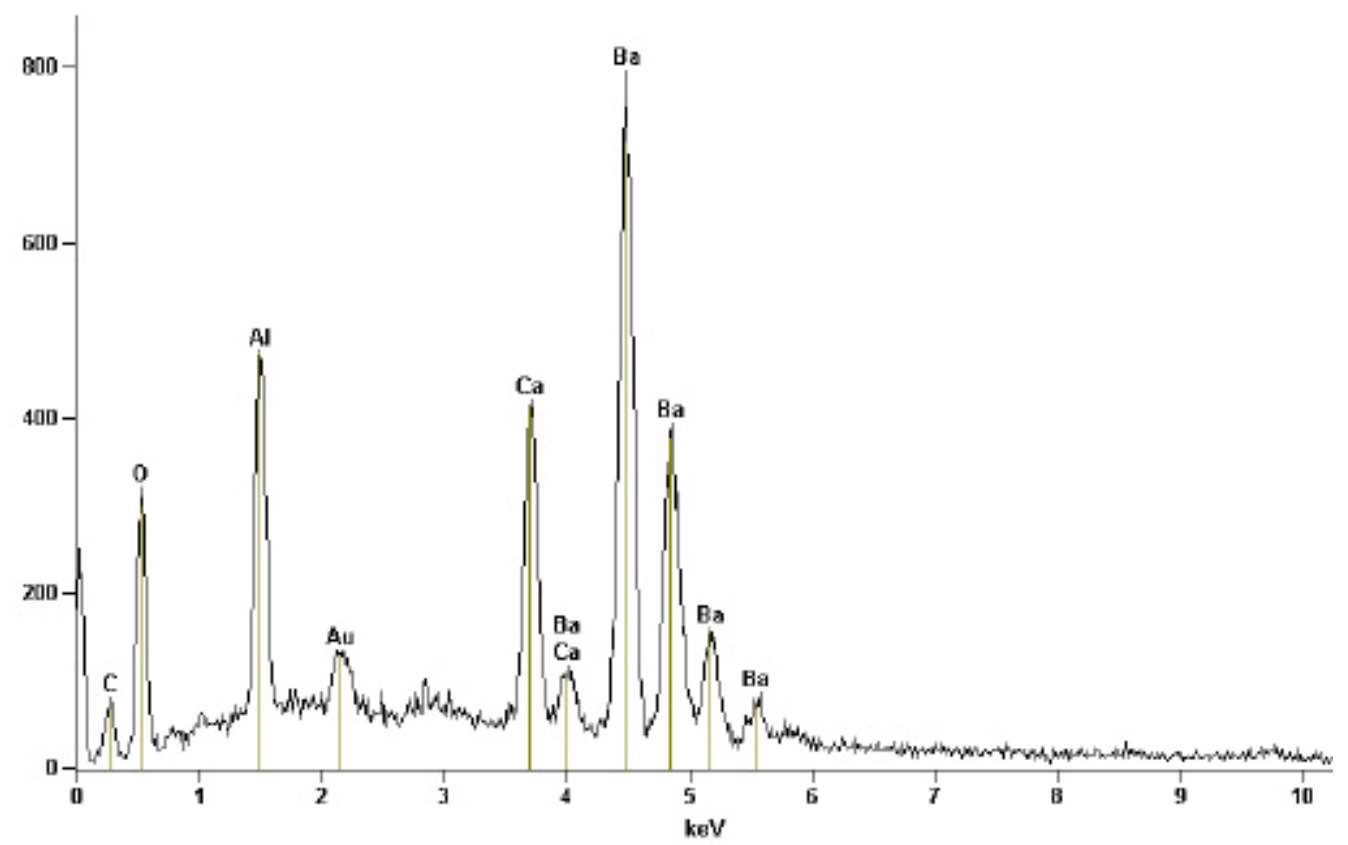

(b)

FIGURA 7.24 - Análises químicas do aluminato obtido por meio da técnica de precipitação em diferentes regiões. 
Semelhantemente à técnica de cristalização, para os aluminatos obtidos pela técnica de precipitação houve a presença de uma certa heterogeneidade na proporção do aluminato, como mostram as FIG. 7.24 (a) e (b). A diferença na proporção dos elementos que compõem o aluminato de bário e cálcio pode estar relacionada com as diferentes fases formadas em cada região.

\subsection{Espectroscopia no infravermelho}

A técnica de FTIR apresenta semelhanças na composição dos aluminatos obtidos pelos diferentes métodos, como mostra a FIG. 7.25. As variações existentes ocorrem devido à provável existência de fases diferentes e impurezas das amostras. No espectro de infravermelho para as curvas do método de reação em estado sólido e de precipitação, observam-se as mesmas vibrações no intervalo de 1000 e $500 \mathrm{~cm}^{-1}$. No método de cristalização, as vibrações neste intervalo não estão correlacionadas. As vibrações observadas para o intervalo de 1000 e $500 \mathrm{~cm}^{-1}$, no método de reação em estado sólido (convencional) e de precipitação, podem estar relacionadas à fase do aluminato $\mathrm{BaO} \cdot \mathrm{Al}_{2} \mathrm{O}_{3}$.

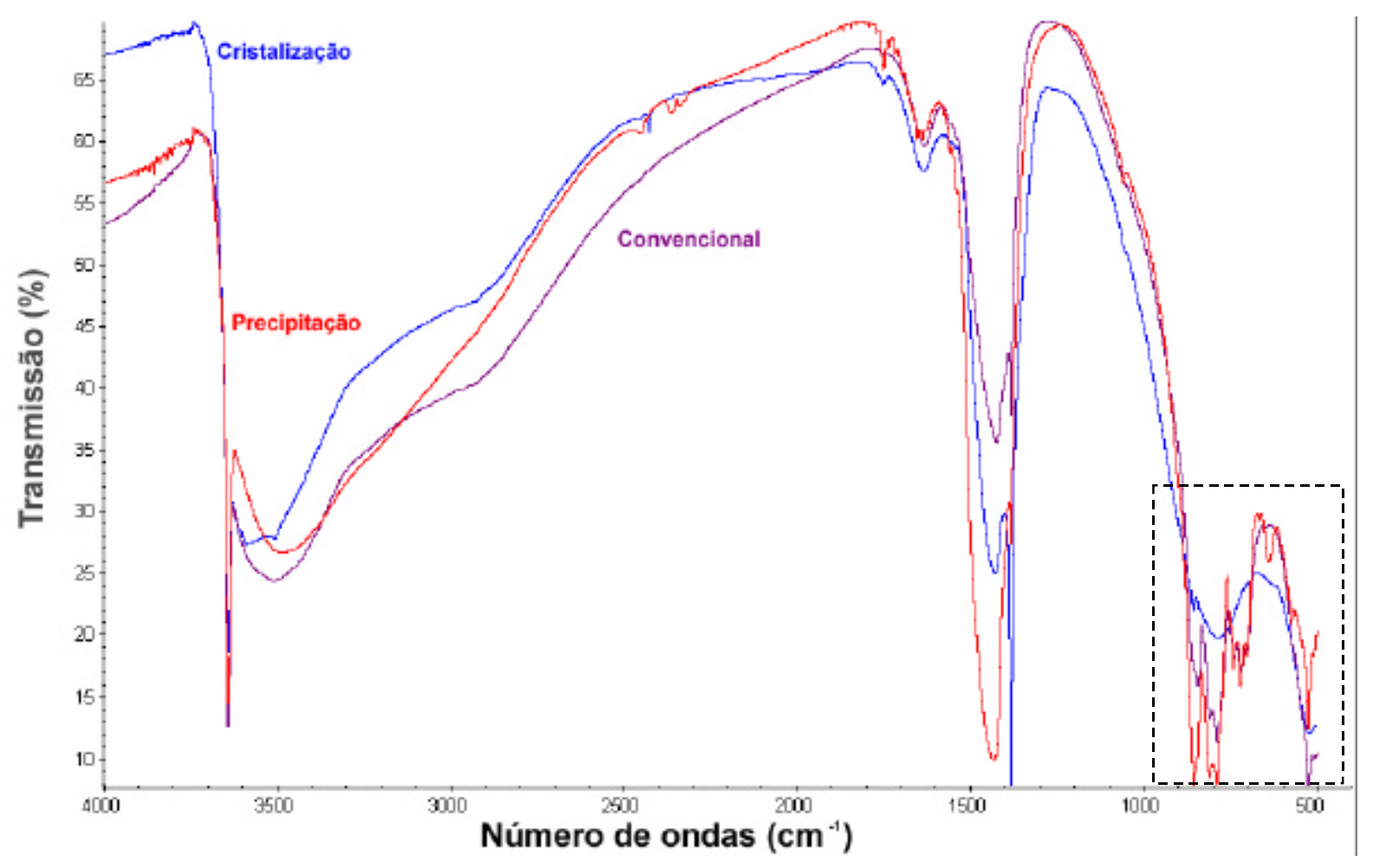

FIGURA 7.25 - Curvas FTIR dos alumiantos obtidos pelos diferentes métodos. 
As técnicas de síntese de material influenciam consideravelmente na obtenção das fases do aluminato de bário e cálcio e nas suas características físico-químicas. A técnica de solução apresenta vantagens nas etapas de síntese do material emissor, redução no tempo e/ou temperatura do processo. Por exemplo, a técnica de cristalização apresentou uma menor temperatura de operação em atmosfera oxidante. Entretanto, ao se considerar as propriedades físico-químicas do aluminato, a reação em estado sólido apresenta algumas vantagens, como a distribuição do tamanho de partícula e o estado de aglomeração.

\subsection{Caracterização termiônica}

Para realizar a caracterização termiônica do aluminato de bário e cálcio obtido pela técnica de reação em estado sólido utilizou-se como veículo de um catodo padrão (tipo Pierce). Na superfície do catodo (tungstênio poroso) foi depositada uma camada de uma tinta na qual continha o aluminato de bário (solvente e ligantes - acetato de amila, nitrocelulose, etanol e acetato). Realizou-se a aplicação utilizando-se um spray, pois esta fornece um filme homogêneo. A área de emissão do catodo utilizado é de $1,35 \mathrm{~cm}^{2}$.

A FIG. 7.26 apresenta a curva de densidade de corrente de emissão versus tensão para o catodo com aluminato de bário e cálcio. Verifica-se o aumento da densidade de corrente de emissão com o acréscimo na potência do filamento (mantendo-se constante a tensão).

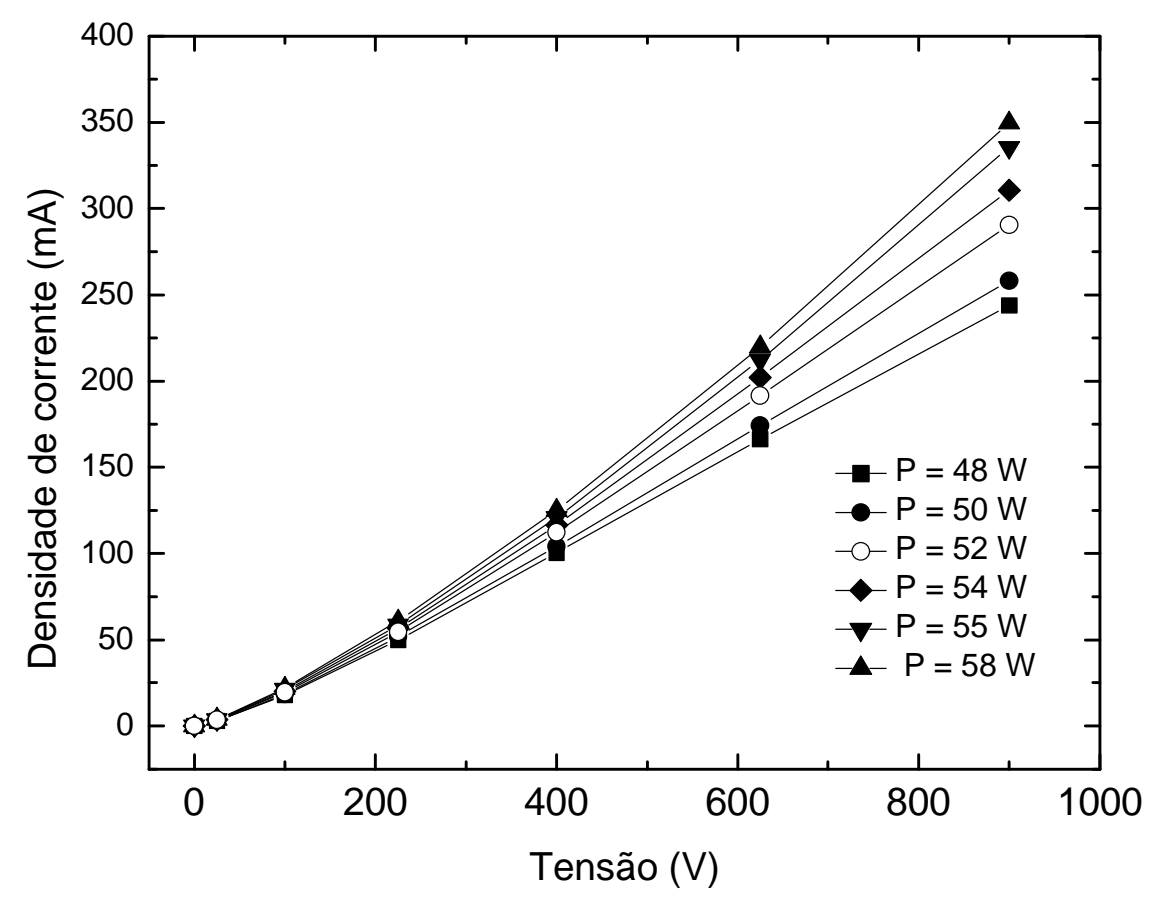

FIGURA 7.26 - Curva de emissão termiônica para um catodo aluminato obtido pela técnica de reação em estado sólido. 
A FIG. 7.27 mostra as curvas de densidade de corrente normalizada versus a potência do filamento para quatro densidades de corrente limitadas pela carga espacial, $J_{F S C L}\left(100,200,400\right.$ e $\left.800 \mathrm{mAcm}^{-2}\right)$. Traçaram-se estas curvas para obter a função trabalho média do catodo aluminato empregando a técnica de Miram (PWFD). As PWFD estão apresentadas nas FIG. 7.28 e FIG. 7.29.

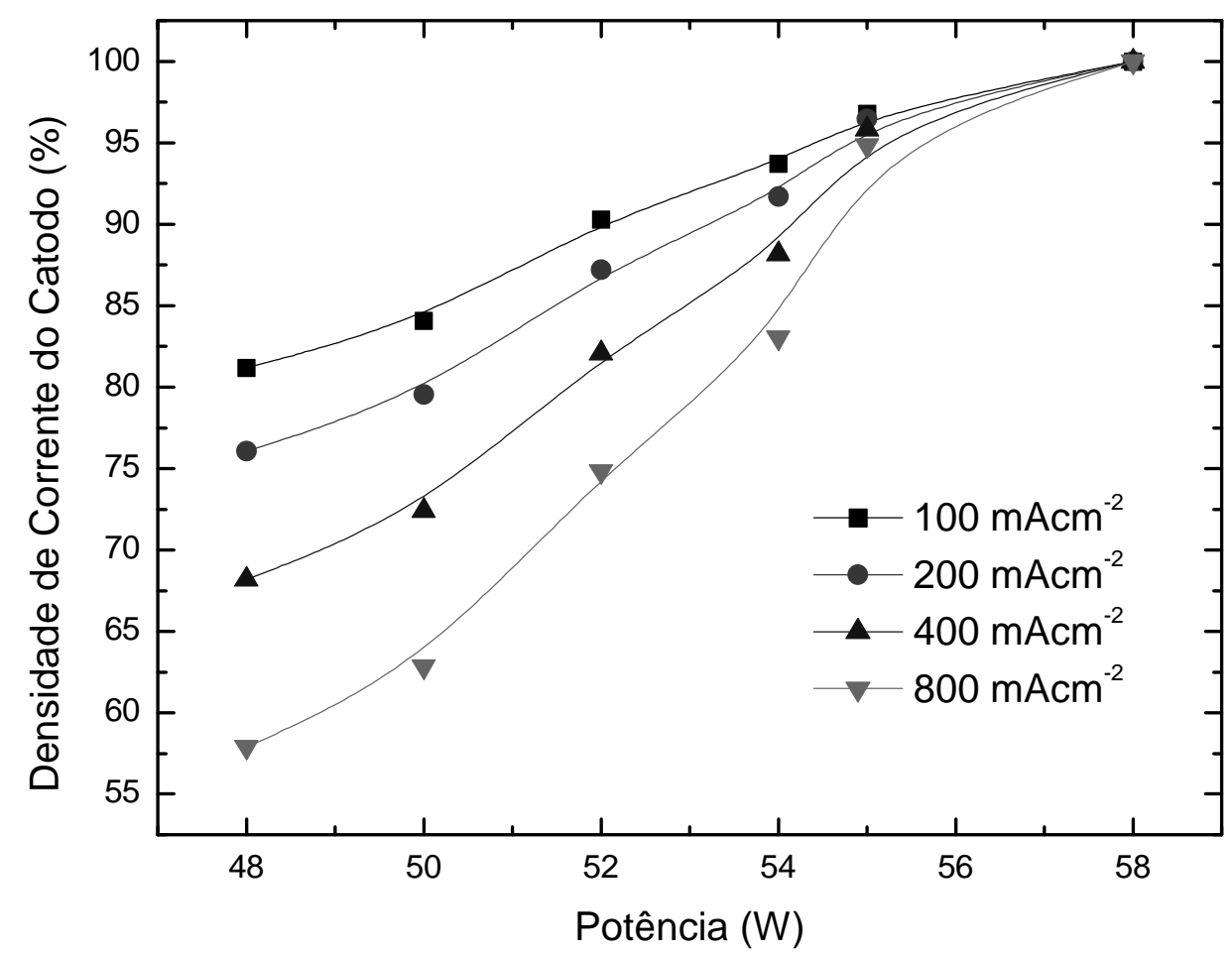

FIGURA 7.27 - Curva de densidade de corrente x potência para o catodo aluminato.

Verifica-se por meio do gráfico da FIG. 7.28, curva PWFD para $400 \mathrm{mAcm}^{-2}$ que o intervalo da distribuição da função trabalho deste catodo situa-se entre 1,95 e $2,20 \mathrm{eV}$, e a função trabalho do catodo que corresponde à $50 \%$ de $f(\phi)$ é de $2,00 \mathrm{eV}$.

Observa-se na FIG. 7.29, que a densidade de corrente normalizada do catodo de $50 \%$ corresponde a uma função trabalho de 2,00 eV. Considerando estes resultados, pode-se definir como a função trabalho média do catodo com aluminato de bário e cálcio é de aproximadamente 2,00 eV. 


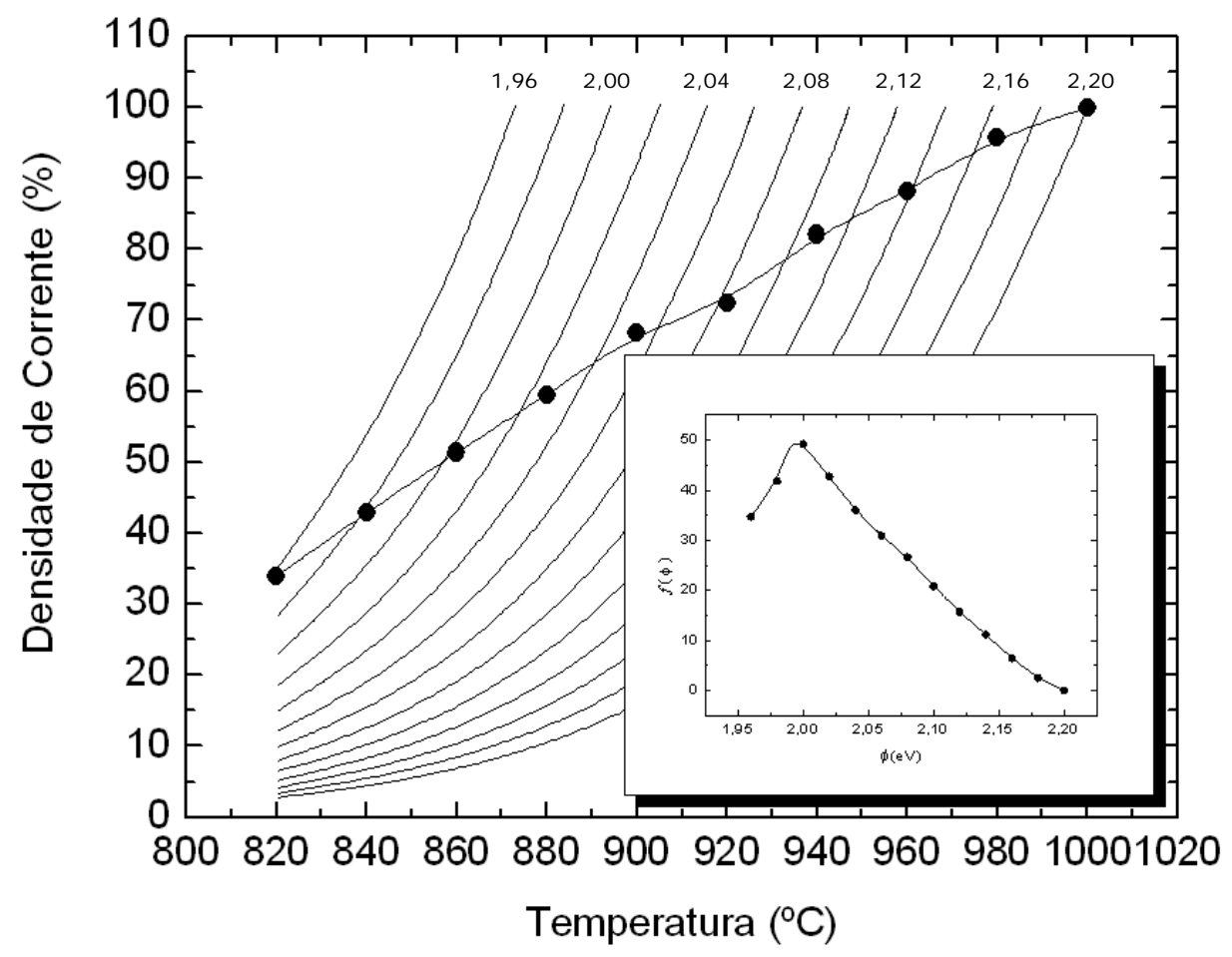

FIGURA 7.28 - Gráfico PWFD para $J_{F S C L}=400 \mathrm{mAcm}^{-2}$.

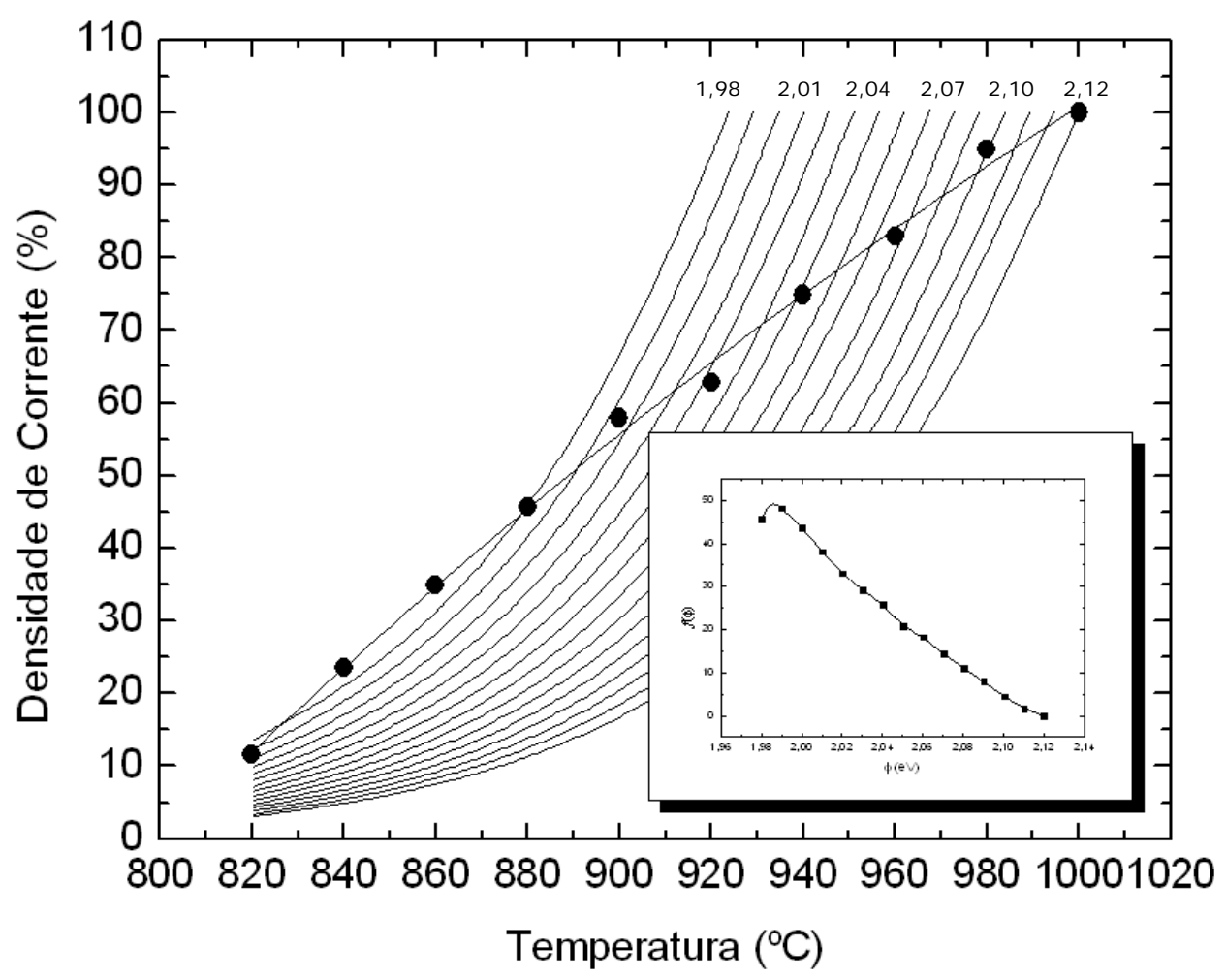

FIGURA 7.29 - Gráfico PWFD para $J_{F S C L}=800 \mathrm{mAcm}^{-2}$. 


\subsection{Fusão do aluminato de bário e cálcio}

Com o intuito de traçar o procedimento de impregnação do catodo, realizou-se experimento de fusão do aluminato de bário e cálcio. Para isso utilizou um cadinho de molibdênio, conforme ilustrado na FIG. 7.30, e o aluminato processado pela técnica de reação de estado sólido. O conjunto foi submetido a um aquecimento na temperatura que variou de $1600-1680^{\circ} \mathrm{C}$ (vácuo - p $10^{-4}$ torr). Após este processo, verificou-se que a perda de massa do aluminato não foi significativa e que houve a fusão do aluminato de bário e cálcio (formação do menisco no cadinho).

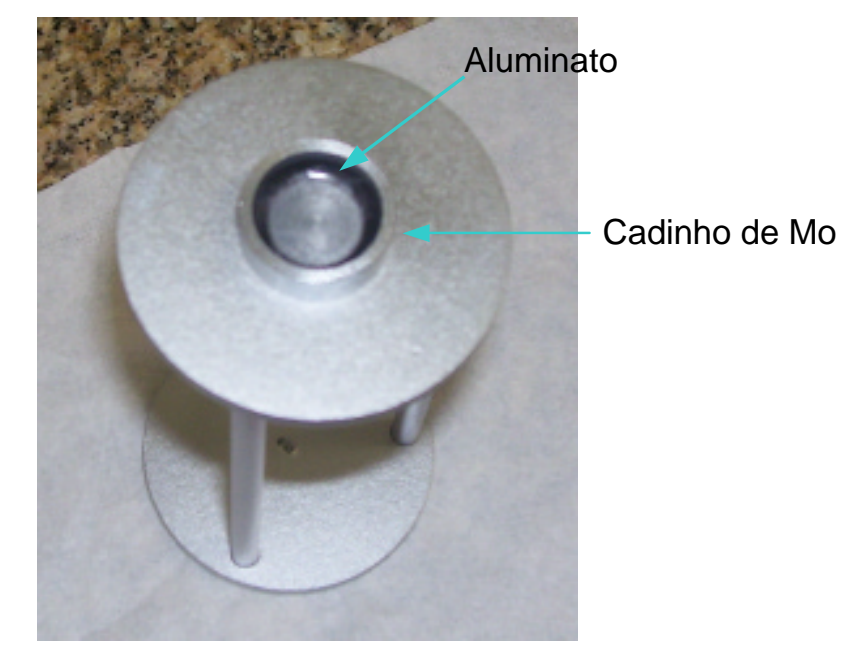

FIGURA 7.30 - Cadinho de molibdênio com aluminato de bário e cálcio.

\subsection{Conclusões do Capítulo}

Neste Capítulo apresentaram-se os resultados referentes ì metodologias empregadas na síntese do aluminato de bário e cálcio. Ademais, avaliaram-se as características físico-químicas dos materiais obtidos nos processos de sintetização. Por meio da termogravimetria avaliaram-se as reações de formação dos aluminatos, as perdas de massas dos reagentes determinaram as etapas de desidratação e decomposição dos reagentes. Empregando-se a termogravimetria, definiram-se atmosfera e o tempo de reação de cada técnica de síntese.

Com relação as fases presentes nos produtos da reação de cada técnica de síntese do aluminato de bário e cálcio, por meio da análise de difração de raios X, que há presença de uma fase emissora de elétrons, conforme apresentado na literatura por Maklakov [52]. Determinaram-se os elementos presentes nos aluminatos obtidos pelas diferentes técnicas de síntese. O aluminato de bário e cálcio obtida pela reação em estado 
sólido apresentou uma proporção próxima a teórica. Utilizando a técnica de precipitação verifica-se uma reduzida presença do elemento bário.

Avaliou-se posteriormente o tamanho médio da partícula dos aluminatos de bário e cálcio. Os resultados mostram que o menor diâmetro foi atingido quando se empregou o método da reação em estado sólido com uma etapa de homogeneização (moagem). Entretanto não se pode inferir que esta é a técnica que fornece o menor tamanho de partícula, pois esta depende da forma e estado de aglomeração das partículas. Por isso realizou-se a análise de microscopia eletrônica de varredura. Nestas análises verificaram-se as formas das partículas e seus estados de aglomeração, e foi confirmada que as técnicas de cristalização e de precipitação apresentaram partículas aglomeradas.

Por meio dos resultados da técnica de EDS, pode-se verificar a heterogeneidade das composições dos aluminatos de bário e cálcio. Posteriormente, apresentaram-se as curvas de FTIR para cada técnica de síntese do aluminato, obtiveram-se espectros semelhantes o que esta relacionada com as fases presentes nestes materiais.

$\mathrm{Na}$ curva característica de emissão termiônica para o catodo com aluminato de bário e cálcio observou-se o aumento da corrente de emissão com o acréscimo na potência do filamento (temperatura). Empregando-se o método de Miram, foi possível traçar o perfil termiônico do catodo com aluminato de bário e cálcio. As curvas PWFD resultaram em uma função trabalho média do catodo aluminato de, aproximadamente, 2,00 eV. O valor da função trabalho do catodo investigado é semelhante aos valores apresentados na literatura. O comportamento das curvas de Miram está próximo àqueles apresentados nos exemplos do Capítulo 6.

Pôde ser observada a fusão completa do aluminato de bário e cálcio (obtido por meio da reação em estado sólido) na temperatura de, aproximadamente, $1680^{\circ} \mathrm{C}$. 


\section{CAPÍTULO 8 - CONCLUSÕES}

Este trabalho apresentou os resultados obtidos durante o desenvolvimento de uma metodologia para a fabricação de catodos do tipo impregnado utilizando o aluminato de bário e cálcio (material fonte de bário) como material impregnante em uma pastilha de tungstênio porosa.

Discutiu-se o fenômeno de emissão termiônica empregando-se o formalismo da mecânica estatístico-quântica, obtendo-se a expressão para a densidade de corrente de emissão de Richardson-Dushman. Adicionalmente, quantificou-se o efeito de campos elétricos externos sobre a superfície metálica emissora (efeito Schottky). Este efeito reduz a altura da barreira de potencial em um material metálico e, conseqüentemente, aumenta a densidade de corrente de emissão para uma mesma temperatura.

Apresentou-se a solução do problema do fluxo de corrente elétrica limitada pela carga espacial empregando-se o modelo do diodo esférico. Por meio desta foi possível observar um efeito extremamente relevante, analisando a expressão para a solução do potencial. Uma vez fixados os raios do anodo e do catodo, além de uma dada diferença de potencial entre o catodo e o anodo, haverá uma corrente máxima que poderá ser drenada pelo diodo esférico de Langmuir. Verificou-se ainda que a razão entre a corrente máxima do feixe e o potencial de aceleração é igual a uma constante que depende apenas das características geométricas do diodo esférico, constante denominada perveância do canhão. Posteriormente, determinou-se densidade de corrente de emissão limitada pela carga espacial em um setor cônico do diodo esférico por meio do procedimento de Pierce. Aplicando-se a expressão da perveância do sistema, dependente das características geométricas, obteve-se os parâmetros necessários para a construção de um canhão eletrônico de fluxo convergente. Desta forma, foi possível estabelecer um procedimento analítico que pode ser empregado na construção do aparato experimental de caracterização termiônica. Seguindo este procedimento pode-se garantir que o fluxo eletrônico seja limitado pela carga espacial, o que reduz ou elimina o efeito Schottky. Realizou-se um estudo das variações do potencial e do campo elétrico na superfície do catodo. Por meio deste estudo, constatou-se que o efeito da carga espacial apresenta uma propriedade 
interessante sobre a distribuição do potencial na região entre os eletrodos: o campo elétrico na superfície do catodo, na situação onde o fluxo é complemente limitado pela carga especial, é nulo, diferentemente do que ocorre quando não há o efeito da carga espacial $(\mathrm{E} \neq 0)$.

Apresentou-se um procedimento de caracterização termiônica, para os catodos fabricados no presente trabalho, fundamentado no conceito da distribuição da função trabalho prática desenvolvido por Miram. O fato da curva PWFD ser uma distribuição e a função trabalho o valor mais provável desta distribuição, torna-se esta técnica adequada para caracterizar catodos que apresentam heterogeneidade tanto em temperatura superficial como na emissão. Tal situação é comumente observada na prática. O conceito da PWFD pode, também, ser empregado na síntese de um canhão eletrônico para alta tensão de aceleração, tendo como base as características de emissão obtidas de um experimento realizado com baixa tensão de aceleração.

Tendo em vista que a diversificação dos materiais empregados nos catodos termiônicos está relacionada à necessidade ao avanço tecnológico das válvulas de microondas, no que concerne à suas condições de operação (densidade de corrente de emissão, tempo de vida do catodo e temperatura de operação), neste trabalho utilizou-se diferentes técnicas de sintetização para se obter o aluminato de bário e cálcio emissor de elétrons com proporção molar 5:3:2.

Empregando-se a técnica de reação em estado sólido, verificou-se que os parâmetros de execução desta rota influenciam o produto final desejado. Temperatura, atmosfera e produtos de decomposição foram investigados por meio da termogravimetria. Por meio da TG, observou-se que em todos os reagentes empregados há quantidade suficiente de água que pode influenciar a estequiometria final do aluminato de bário e cálcio. Durante a investigação da atmosfera da pirólise do material, verificou-se que em uma atmosfera oxidante ou inerte, a temperatura e/ou tempo de processamento sofrem um acréscimo, quando comparada à atmosfera redutora. Por meio da difração de raios $\mathrm{X}$, identificaram-se as fases do aluminato de bário e cálcio nos produtos da pirólise.

$\mathrm{O}$ método da precipitação mostrou-se eficaz quanto à redução do tempo de pirólise. Entretanto, a temperatura manteve-se elevada, em torno de $1000^{\circ} \mathrm{C} \mathrm{em}$ atmosfera redutora. Houve também o problema da presença de carbono elementar após a etapa de pirólise, necessitando uma etapa adicional (calcinação). Suas vantagens sobre a reação em estado sólido são: não há necessidade da etapa de moagem, reduzindo a probabilidade de contaminação do material e redução do tempo de pirólise de 5 horas para 2 horas. 
A investigação do método de cristalização foi realizada por meio das técnicas de termogravimetria e difração de raios X. Por meio da TG, verificou-se a presença de água em todos os nitratos, e sua quantidade têm grande influência na composição molar do aluminato de bário e cálcio. Devido a este fato, os reagentes de partida utilizados neste processo foram os carbonatos de bário e de cálcio, e o alumínio metálico. Observou-se também que a temperatura de formação do aluminato de bário e cálcio $\left(800^{\circ} \mathrm{C}\right)$ é menor quando comparada aos dois métodos anteriores. Portanto, foi possível otimizar as condições de processamento do aluminato de bário e cálcio. Por meio da técnica de difração de raios X, verificou-se a presença das fases características do aluminato de bário e cálcio no produto final obtido pelo método de cristalização.

Os resultados apresentados pelo método de cristalização mostraram que a temperatura de calcinação reduziu de $1000^{\circ} \mathrm{C}$ para $800^{\circ} \mathrm{C}$ utilizando atmosfera oxidante, e uma mistura homogênea pode ser obtida sem a necessidade da etapa de moagem, reduzindo a contaminação. Não se verificou a presença de carbono elementar no produto final após calcinação. Estes fatores representam redução no tempo de processo e no consumo de energia e, ainda, garantem uma melhora nas características do aluminato.

Empregando-se o método PWFD de Miram, foi possível traçar o perfil termiônico do catodo com aluminato de bário e cálcio. As curvas PWFD apresentaram a função trabalho média do catodo aluminato de, aproximadamente, $2,00 \mathrm{eV}$. 


\subsection{SUGESTÕES PARA TRABALHOS FUTUROS}

A partir dos resultados obtidos neste trabalho, são sugeridos os seguintes trabalhos:

- investigar a cinética da reação de formação dos aluminatos de bário e cálcio para cada técnica de síntese do material;

- caracterizar termionicamente os catodos impregnados obtidos pelas outras técnicas de síntese do aluminato de bário e cálcio;

- construção de planta piloto para a realização do teste de vida do catodo impregnado;

- investigar a metodologia de síntese da pastilha de tungstênio poroso (análise físicoquímica do pó de tungstênio, definição dos parâmetros de conformação das pastilhas e determinação da temperatura e tempo de sinterização); e

- verificar a influência da porosidade das pastilhas de tungstênio no processo de impregnação e na emissão termiônica. 


\section{REFERÊNCIAS BIBLIOGRÁFICAS}

[1] SHROFF, A. M. Review of dispenser cathodes. Revue Technique Thomson-CSF, v. 23, p.958-965, 1991.

[2] CATtelinO, M. J.; MiRAM, G. V.; AYERS, W. R. A diagnostic technique for evaluation of cathode emission performance and defects in vehicle assembly. International Electron Devices Meeting Technical Digest, San Francisco, 1982, Proceedings ... San Francisco: IEEE, 1982. p. 36-39.

[3] BECK, A. H. W. Thermionic Valves. Cambridge: University Press, 1953.

[4] ASHCROFT, N. W. Solid State Physics. Philadelphia: CBS Publishing Asia, 1988.

[5] PATHRIA, R. K. Statistical Mechanics. New York, NY.: Pergamon Press, 1993.

[6] SALINAS, S. R. A. Introdução à Física Estatística . São Paulo, SP.: Editora da USP, 2005.

[7] LANGMUIR, I.; BLODGETT, K. B. Currents limited by space charge between concentric spheres. Physics Review, v. 24, p. 49-59, 1924.

[8] PIERCE, J. R. Theory and design of electron beams. New York, N.Y.: Van Nostrand, 1954.

[9] TIWARY, U.; BASU, B. N. Noniterative method for synthesis of convergent Pierce electron guns. IEEE Transactions on Electron Devices, v. 34, p. 1218-1222, 1987.

[10] CRONIN, J. L. Modern dispenser cathode. IEEE Proceedings, v. 128, p. 19-32, 1981.

[11] GILMOUR, A. S. Microwave Tubes. Norwood, M. A.: Artech House, 1986.

[12] GONÇALVES, J. A. N. Estudo e desenvolvimento de catodos óxidos (Ba, $\mathrm{Sr}, \mathrm{Ca}) \mathrm{O}$ 
em configuração cilíndrica. 1996. Dissertação (Mestrado) - Instituto Tecnológico de Aeronáutica, São José dos Campos.

[13] GEWARTOWSKI, J. W.; WATSON, H. A. Principles of electron tubes. Princeton, N. J.: Van Nostrand, 1965.

[14] SPANGENBERG, K. R. Vacuum tubes. Tokyo, Tokyo: Kogakusha Company, 1948.

[15] HEATWAVE LABS. TB-128 Notes on dispenser and oxide cathodes. Rev. Date 8/2/99. Disponível em: <http://www.cathode.com>. Acesso em 25 abr. 2005.

[16] ROBERTS, S. Sources of temperature variance in dispenser cathodes. In: Fifth International Vacuum Electronics Conference, April 27-29, 2004, Monterey, Proceedings ... Monterey: IEEE, 2004. p. 299-300.

[17] SASAKI, S.; YAGUCHI, T.; NONAKA, Y.; TAGUCHI, S.; SHIBATA, M. Surface coating influence on scandate cathode performance. Applied Surface Science, v. 195, p. 214-221, 2002.

[18] TMD TECHNOLOGIES LIMITED. Cathodes. Knowledge\&Innovation. Disponível em: <http:// www.tmdtechnologies.co.uk/ pdf/ innovation/ cathode_whitepaper.pdf>. Acesso em 11 nov. 2005.

[19] LI, J.; YU, Z.; SHAO, W.; ZHANG, K.; GAO, Y.; YUAN, H.; WANG, H.; HUANG, K.; CHEN, Q.; YAN, S.; CAI, S. High current density M-type cathodes for vacuum electron devices. Applied Surface Science, v. 251, p. 151-158, 2005.

[20] MITA, N. Degration factors of a coated impregnated cathode. IEEE Transaction on Electron Devices, v. 39, p. 2172-2175, 1992.

[21] DIEMEUGAR, D.; FONNERR, J. C.; BRION, D.; SHROFF, A. M. Life test performance of thermionic cathodes. Applied Surface Science, v. 111, p. 84-89, 1997. 
[22] GIBSON, J. W.; HAAS, G. A.; THOMAS, R. E. Investigation of scandate cathodes: emission, fabrication, and activation processes. IEEE Transactions on Electron Devices, v. 36, p. 209-214, 1989.

[23] RITTNER, E. S. On the mechanism of operation of the type B impregnated cathode. Journal of Applied Physics, v. 48, p. 4344-4346, 1977.

[24] HIGUCHI, T.; NAKAMURA, O.; MATSUMOTO, S.; UDA, E. Pore geometry of dispenser cathode surface vs. emission characteristics, and $\mathrm{Ba}$ recovery characteristics after ion bombardment. Applied Surface Science, v. 146, p. 51-61, 1999.

[25] ROMÃO, B. M. V.; MURATO JR, A.; TESSAROTTO, L. A. B.; TAKAHASHI, J.; Processos de preparação, deposição e análise de substâncias emissoras de elétrons. São Paulo: Instituto de Física, USP-SP, Set. 1992 (IEAv-006/92).

[26] PORET, F.; ROQUAIS, J. M. The base metal of the oxide-coated cathode. Applied Surface Science, v. 251, p. 31-41, 2005.

[27] HAAS, G. A.; THOMAS, R. E. Work-function distribution studies of pressed matrix cathodes, Journal of Applied Physics, v. 38, p. 3969-3981, 1967.

[28] SHUGUANG, W. Scandate cathode for TWT. Applied Surface Science, v. 251, p. 114-119, 2005.

[29] SEMICON ASSOCIATES. Dispenser cathodes: the current state of the technology. 2005. Technical papers. Disponível em:

http://www.semiconassociates.com/Uploads/dispenser_cathode_current_state_of_tec h_1.pdf>. Acesso em 10 nov. 2005.

[30] JONES, D.; McNEELY, D.; SWANSON, L. W. Surface and emission characterization of the impregnated dispenser cathode. Application of Surface Science, v.2, p. 232-257, 1979.

[31] SHROFF, A. M.; PALlUEL, P.; TONNERRE, J. C. Performance and life tests of 
various types of impregnated cathodes. Application of Surface Science, v. 8, p. 3649, 1981.

[32] LEVI, R. New dispenser type thermionic cathode. Journal of Applied Physics, v. 24, p. $233,1952$.

[33] BRODIE, I.; JENKINS, R. O. Impregnated barium dispenser cathodes containing strontium or calcium oxide. Journal of Applied Physics, v. 27, p. 417-418, 1956.

[34] MISHRA, D.; ANAND, S.; PANDA, R. K.; DAS, R. P. Characterization of products obtained during formation of barium monoaluminate through hydrothermal precipitation-calcination route. Journal of the American Ceramic Society, v. 85, p. 437-443, 2002.

[35] WANG, X.; LIAO, X.; LUO, J.; ZHAO, Q. An improved reservoir oxide cathode. Applied Surface Science, v. 251, p. 69-72, 2005.

[36] RITTNER, E. S.; AHLERT, R. H.; RUTLEDGE, W. C. Studies on the mechanism of operation of the L cathode. Journal of Applied Physics, v. 28, p. 156-166, 1957.

[37] TARTER, J. O; FARREL, J. J. Selection of dispenser cathode impregnant types. In: Fifth International Vacuum Electronics Conference, April 27-29, 2004, Monterey, Proceedings ... Monterey: IEEE, 2004. p. 301-302.

[38] KAN, H. K. A.; SEAVER, R. R. Impregnant composition in dispenser cathodes. Applied Surface Science, v. 25, p. 118-126, 1986.

[39] SCHOENBECK, L. Investigation of reactions between barium compounds and tungsten in a simulated reservoir hollow cathode environment. 2005. Master Thesis - Georgia Institute of Technology, Georgia.

[40] REED, J. S. Introduction to the principles of ceramic processing. New York, N. Y.: John Wiley \& Sons, 1988. 
[41] JOHNSON, D. W. Nonconventional powder preparation techniques. American Ceramic Society Bulletin, v. 60, p. 221-224, 1981.

[42] CAPRONI, E. Preparação de eletrólitos sólidos cerâmicos de zircônia estabilizada com cálcia. 2003. Dissertação (Mestrado) - Instituto de Pesquisas Energéticas e Nucleares, São Paulo.

[43] TADOKORO, S. K. Síntese de pós de zircônica estabilizada com tamanho nanométrico de partículas. 2000. Dissertação (Mestrado) - Instituto de Pesquisas Energéticas e Nucleares, São Paulo.

[44] SCHNEIDER, S. J. Engineered materials handbook - ceramic and glasses (v. 4). ASTM International the Materials Information Society, 1991.

[45] ONODA, G. Y.; HENCH, L. L. Ceramic processing before firing. New York, N. Y.: Wiley-Interscience, 1978.

[46] GERMAN, R. M. Powder metallurgy science. Princeton: Metal Powder Industries, 1994.

[47] CHIBA, R. Obtenção de manganito de lantânio dopado com estrôncio para aplicação em células a combustível de óxido sólido. 2005. Dissertação (Mestrado) Instituto de Pesquisas Energéticas e Nucleares, São Paulo.

[48] BROWN, M. E. Introduction to thermal analysis - techniques and applications. New York, N. Y.: Chapman and Hall, 1988.

[49] SCAPIN, M. A. Aplicação da difração e fluorescência de raios X (WDXRF) ensaios em argilominerais. 2003. Dissertação (Mestrado) - Instituto de Pesquisas Energéticas e Nucleares, São Paulo.

[50] HIGASHI, C.; LIMA, N. B.; MATOS, J. R.; GIOVEDI, C.; MOTTA, C. Investigation of electron emitting barium-calcium aluminate fabrication process for impregnated microwave tube cathodes. In: International Microwave and Optoelectronics Conference, July 25-28, 2005, Brasília, Proceedings ... Brasília: 
IEEE, 2005.

[51] HIGASHI, C.; LIMA, N. B.; MATOS, J. R.; GIOVEDI, C.; MOTTA, C. Electron emitting barium-calcium aluminate obtained from chemical solution techniques. In: International Microwave and Optoelectronics Conference, July 25-28, 2005, Brasília, Proceedings ... Brasília: IEEE, 2005.

[52] MAKLAKOV, A. A.; OSTAPCHENKO, E. P. An x-ray diffraction study of the kinetics of formation of barium-calcium aluminates and tungstates. Journal of Structural Chemistry, v. 1, n. 2, p. 163-167, 1961.

[53] CATTElinO, M.; MIRAM, G. Predicting cathode life expectancy and emission quality from PWFD measurements. Applied Surface Science, v. 111, p. 90-95, 1997. 